\author{
UNIVERSIDADE DE SÃO PAULO \\ FACULDADE DE MEDICINA DE RIBEIRÃO PRETO \\ DEPARTAMENTO DE FARMACOLOGIA
}

GABRIEL GRIPP FERNANDES

Avaliação do nicho neurogênico hipocampal adulto em camundongos machos geneticamente modificados para a não expressão de fatores próinflamatórios (iNOS) ou anti-inflamatórios (IL-10) submetidos a um protocolo de estresse crônico.

Ribeirão Preto 
Avaliação do nicho neurogênico hipocampal adulto em camundongos machos geneticamente modificados para a não expressão de fatores próinflamatórios (iNOS) ou anti-inflamatórios (IL-10) submetidos a um protocolo de estresse crônico.

Tese apresentada à Faculdade de Medicina de Ribeirão Preto da Universidade de São Paulo para obtenção de título de Doutor em Ciências. Área de concentração: Farmacologia Orientadora: Prof $^{\mathrm{a}} \mathrm{Dr}^{\mathrm{a}}$ Alline Cristina de Campos

Ribeirão Preto 
AUTORIZO A REPRODUÇÃO TOTAL OU PARCIAL DESTE TRABALHO, POR MEIO DE QUALQUER MEIO CONVENCIONAL OU ELETRÔNICO, PARA FINS DE ESTUDO E PESQUISA, DESDE DE CITADA A FONTE.

Ficha Catalográfica

Fernandes, Gabriel Gripp
Avaliação do nicho neurogênico hipocampal adulto em camundongos
machos geneticamente modificados para a não expressão de fatores pró-
inflamatórios (iNOS) ou anti-inflamatórios (IL-10) submetidos a um protocolo de
estresse crônico/ Gabriel Gripp Fernandes; orientadora: Prof-a. Drâ. Alline Cristina de
Campos. Ribeirão Preto, 2021.176f.
Tese (Doutorado em Ciências - Área de Concentração: Farmacologia) -
- Faculdade de Medicina de Ribeirão Preto, Universidade de São Paulo,
Ribeirão Preto, SP, 2021.
1. iNOS, 2. IL-10, 3. Neurogênese hipocampal adulta, 4. Estresse crônico
5. Micróglia, 6. Comportamento




\section{FOLHA DE APROVAÇÃO}

\section{Gabriel Gripp Fernandes}

Avaliação do nicho neurogênico hipocampal adulto em camundongos machos geneticamente modificados para a não expressão de fatores próinflamatórios (iNOS) ou anti-inflamatórios (IL-10) submetidos a um protocolo de estresse crônico.

Tese apresentada à Faculdade Medicina de Ribeirão Preto da Universidade de São Paulo para obtenção de título de Doutor em Ciências.

Área de concentração: Farmacologia

Aprovado em: $/ 2021$

Banca Examinadora

Presidente(a):

Assinatura:

Instituição:

Julgamento:

Examinador(a):

Assinatura:

Instituição:

Julgamento:

Examinador(a):

Assinatura:

Instituição:

Julgamento:

Examinador(a):

Assinatura:

Instituição:

Julgamento: 
Dedico este trabalho a Eni, Adeclides, Lourdes, Inês, Eloir e lgor. 


\section{Agradecimentos}

Inicialmente gostaria de agradecer as entidades superiores que regem nosso universo por me proteger e proteger as pessoas que eu amo durante todo esse período em que morei em Ribeirão Preto.

A minha mãe e ao meu pai por sempre terem colocado meu bem psíquico e minha estabilidade emocional acima de tudo, e por sempre estarem dispostos a tudo por mim. Eu amo muito vocês. Obrigado por me auxiliarem a tornar o meu sonho, essa tese real.

A minha família, minha avó Lourdes e meus tios Inês e Eloir. Obrigado por tudo, e por todos os ensinamentos.

Ao Igor, que mesmo diante de tantas dificuldades e da distância geográfica, nunca hesitou em estar presente no meu dia-a-dia e me ajudar quando eu precisava. Muito obrigado por todos esses anos e pelo seu apoio e amor. Você tornou essa tese possível.

A minha orientadora prof $^{-}$Dr $^{\text {a }}$ Alline Cristina de Campos, por ter me aceitado como seu aluno em um momento muito difícil na minha vida acadêmica e por ter me ensinado muito durante esses últimos quatro anos.

Aos meus amigos atuais do laboratório, Mel, Fran, Zezé, Dri, Rafa, Isa e Tamíres. Mesmo durante a pandemia, ir ao laboratório e encontrar vocês, nem que por alguns minutos, tornava tudo mais fácil.

Aos meus parceiros de bancada Pacu e Karla. Vocês não imaginam o quanto serei eternamente grato a vocês. Vocês me fizeram rir, me abraçaram (quando podia) quando eu chorei e principalmente me auxiliaram em praticamente todos os momentos da tese. Muito obrigado.

A Juliana Bueno, a melhor aluna de iniciação científica que alguém pode ter. Obrigado pela ajuda nos experimentos e por ter me feito tentar ser o melhor supervisor possível.

Aos meus amigos de departamento, em especial a Anna Barbara, Nai, Jeimison e Alana. Muito obrigado pelas conversas no corredor durante 0 intervalo dos experimentos.

As minhas amigas fora de Ribeirão, Peixoto, Isadora e Nathy. Obrigado por todas as conversas pelo telefone. 
A minha grande amiga Thaís. Por sempre se preocupar comigo e sempre me aturar nos nossos bares online. Muito obrigado.

Ao profo $^{0}$ Dro $^{0}$ Francisco Silveira Guimarães por disponibilizar seu laboratório para a realização da parte comportamental dos experimentos.

Ao apoio técnico e ensinamentos da Eleni e do Tadeuzinho. Aprendi a ser muito independente graças a vocês. A técnica $\mathrm{Gi}$, por todo companheirismo e amizade no laboratório.

Aos funcionários do departamento de Farmacologia, Ramon e Gi, pel trabalho burocrático e eficiente, e por sempre estarem dispostos a esclarecer minhas dúvidas.

A coordenação de Aperfeiçoamento de Pessoal do Nível Superior (CAPES), Conselho Nacional de Desenvolvimento Científico e Tecnológico (CNPq) e a Fundação de Amparo a Pesquisa do Estado de São Paulo (FAPESP), pelo apoio financeiro. 
Resumo 


\section{Resumo}

Fernandes, G.G. Avaliação do nicho neurogênico hipocampal adulto em camundongos machos geneticamente modificados para a não expressão de fatores pro-inflamatórios (iNOS) ou anti-inflamatórios (IL-10) submetidos a um protocolo de estresse crônico. Tese (Doutorado)Faculdade de Medicina de Ribeirão Preto, Universidade de São Paulo, Ribeirão Preto, 2021.

As consequências comportamentais após exposição estresse crônico imprevisível (CUS) tem sido associado a um desbalanço neuroimune, a qual em última instância parece interferir no processo de neurogênese hipocampal adulta (AHN). Diante disso, avaliamos as consequências comportamentais e neurogênicas após exposição ao protocolo de 21 dias de CUS de animais com ablação genética total de importantes mediadores de respostas pró ou antiinflamatórias, a enzima óxido nítrico sintase induzível (iNOS) ou a interleucina10 (IL-10), respectivamente. Em direção oposta à nossa hipótese inicial, animais iNOS knockout (KO) apresentavam alterações comportamentais as quais não eram afetadas após exposição ao CUS. Curiosamente, o fenótipo comportamental observado não era decorrente de alterações nas micróglias presente no nicho neurogênico, e embora o processo de AHN mostra-se reduzido nos animais iNOS KO, esse não era alterado após exposição ao CUS. Diante disso, posteriormente investigamos se um estímulo pró-neurogênico, a administração repetida de escitalopram, recuperaria a capacidade neurogênica de animais iNOS KO. Curiosamente, este protocolo não foi capaz de promover alterações comportamentais e neurogênicas em animais iNOS KO. Por fim, decidimos investigar se outros mecanismos poderiam explicar o fenótipo observado em animais iNOS KO. Para isso, avaliamos os níveis de FOSB (um marcador de atividade neuronal) e de interneurônios parvalbumina-positivos (PV) no córtex pré-frontal medial (mPFC). Embora não tenhamos observados alterações na densidade de PV ou alterações em seu recrutamento, observamos que a porção pré-límbica (PrL), mas não infra-límbica (IL), do mPFC era mais recrutada em animais iNOS KO. Nossos resultados sugerem que a enzima iNOS parece ser essencial para a sobrevivência de novos neurônios. Ademais, a ausência desta enzima resulta em maior recrutamento do PrL. Paralelamente, observamos que animais IL-10 KO apresentavam alterações comportamentais paralelas as observadas em animais WT. Ademais, observamos que a densidade de neuroblastos nestes animais encontrava-se reduzida, sendo este fenômeno não exacerbado após exposição ao CUS. Esses resultados fazem paralelo e auxiliam na compreensão do fenótipo comportamental observado, sendo associado ao comportamento tipo-ansioso a redução na $\mathrm{AHN}$ observada e a maior atividade do PrL a resposta de enfrentamento ativo.

Palavras-chave: iNOS, IL-10, Neurogênese hipocampal adulta, estresse crônico, micróglia, comportamento 
Abstract 


\begin{abstract}
Fernandes, GG. Evaluation of hippocampal neurogenic niche of male mice genetically modified to not express either a pro-inflammatory (iNOS) or antiinflammatory (IL-10) mediator under chronic stress conditions. Thesis (Doctorate) - Faculty of Medicine of Ribeirão Preto, University of São Paulo, Ribeirão Preto, 2021.

The behavioral effects promoted by chronic unpredictable stress (CUS) has been associated with a neuroimmune imbalance, that may disturb the adult hippocampal neurogenesis $(A H N)$. In this sense, we evaluated the behavioral and neurogenic consequences of 21 days CUS exposure on mice lacking either an important pro- or anti-inflammatory mediator, inducible nitric oxide synthase (iNOS) or interleukin-10 (IL-10), respectively. Contrary to our initial hypothesis, iNOS KO mice presented behavioral alterations that were not altered by CUS, and this phenotype was not associated with microglial alterations. Although the AHN was basally reduced on iNOS KO mice, CUS had no further effect. Next, we evaluated whether a proneurogenic stimulus, escitalopram chronic treatment, would rescues the impaired AHN observed on iNOS KO mice. Curiously, this protocol was ineffective to induce any behavioral or neurogenic changes on iNOS $\mathrm{KO}$ mice. Finally, in order to further address the possible mechanism responsible for the iNOS KO mice phenotype, we evaluated the FOSB (neuronal activity marker) and parvalbumine-positive (PV) interneurons on the medial prefrontal cortex (mPFC). Although we did not observed alterations on PV cell density or their recruitment, we found that the prelimbic (PrL) mPFC, but not infralimbic (IL) mPFC, was more activated on iNOS KO mice. Our results suggests that iNOS seems to be essential for the maturation and survival of adult newborn neurons. Also, the absence of iNOS seem to facilitate PrL recruitment. In parallel, we observed that IL-10 $\mathrm{KO}$ mice had behavioral alteration that paralleled those observed on WT mice. Besides, we observed a reduced density of neuroblast that was not further decreased by CUS. These results parallel the behavioral phenotype observed, for instance while the reduced AHN may contribute to the anxiogenic-like phenotype observed on iNOS KO mice, the PrL may be responsible for their active coping response.
\end{abstract}

Keywords: iNOS, IL-10, adult hippocampal neurogenesis, chronic stress, microglia, behavior. 


\section{Sumário}

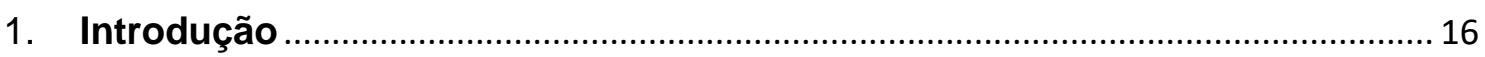

1.1. Estresse, depressão e ansiedade: aspectos gerais .................................... 16

1.2. Neurobiologia da resposta ao estresse: relevância para ansiedade e

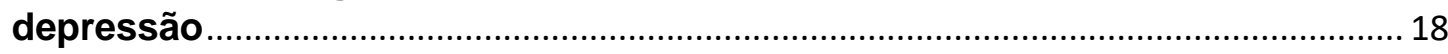

1.3. Neurogênese hipocampal adulta: papel nos transtornos depressivos e ansiedade.

1.5. Micróglia e suas facetas: possível elo entre hipótese neuro-imune e

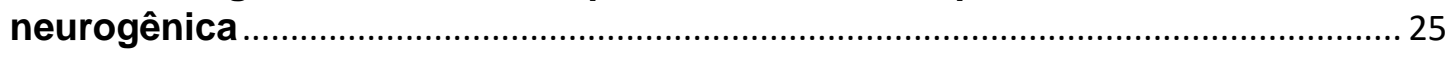

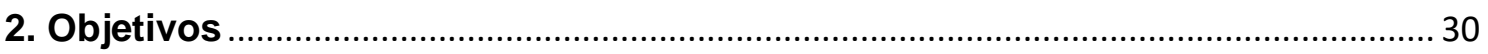

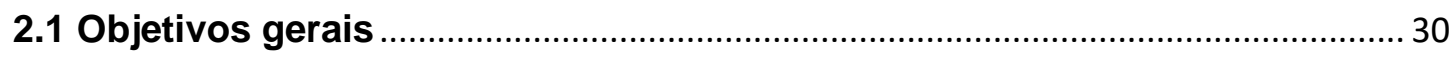

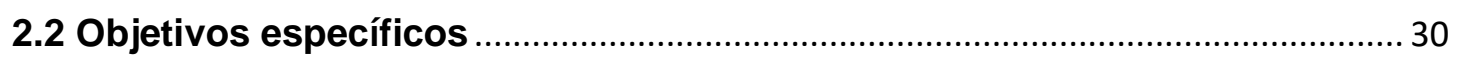

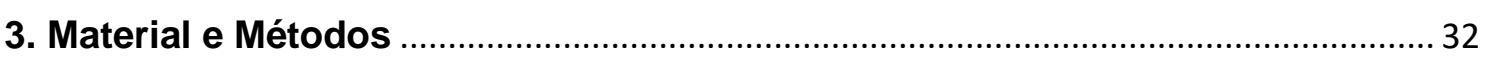

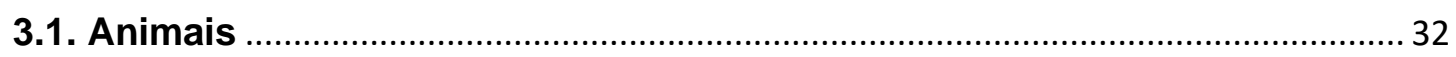

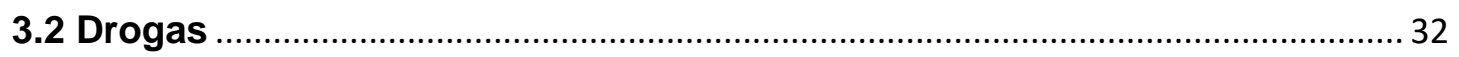

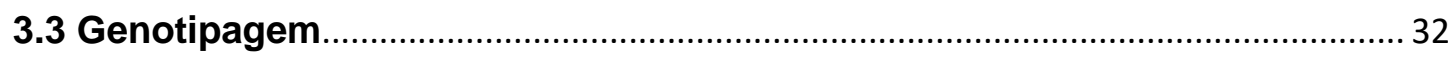

3.3 Estresse Crônico Imprevisível (“Chronic Umpredictable Stress”- CUS) ..... 34

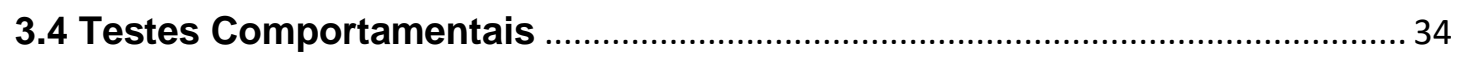

3.4.1 Teste do campo aberto ("Open Field Test” -OFT) ...................................... 34

3.4.2 Teste de suspensão pela cauda ("Tail suspension test" - TST) .............. 35

3.4.3 Teste da supressão da alimentação pela novidade ("Novelty supressed

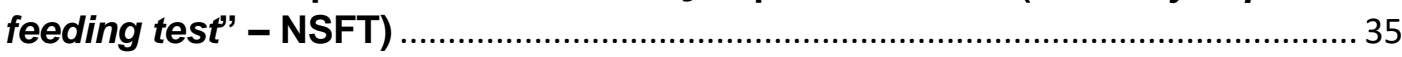

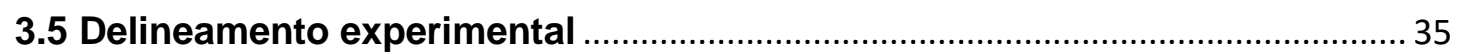

3.5.1 Experimento 1: efeito do CUS em animais iNOS KO .................................. 35

3.5.2 Experimento 2: efeito do escitalopram em animais iNOS KO

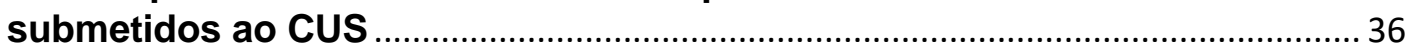

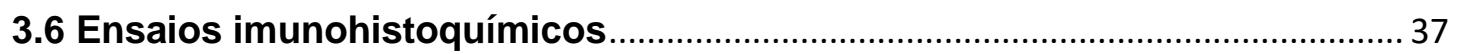

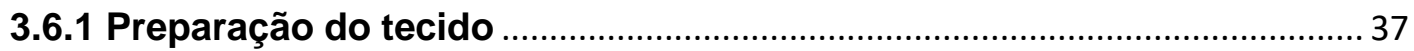

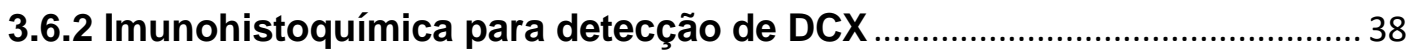

3.6.3 Imunofluorescência para detecção de BrdU, DCX e NeuN ........................ 38

3.6.4 Imunofluorescência para detecção de IBA-1, GFAP, SOX2, FOSB e PV39

3.6.5 Aquisição e quantificação das imagens ..................................................... 39

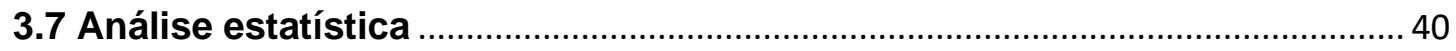

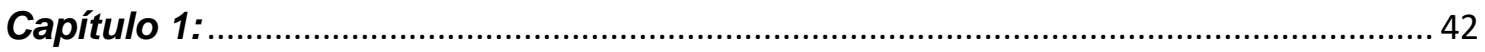

Consequências da ausência genética da iNOS em contextos anti e próneurogênicos. 
Efeito comportamental do CUS em animais iNOS não-consanguíneos............... 43

Efeito comportamental do CUS em animais iNOS consanguíneos ..................... 45

Efeito do CUS sobre as micróglias presentes na camada granular .................... 47

Efeito do CUS sobre densidade de neuroblastos de animais iNOS KO.............. 49

Efeito do CUS sobre a sobrevivência de novos neurônios de animais iNOS KO.

Efeito do tratamento repetido com escitalopram em animais iNOS KO submetidos ao CUS.

Efeito do tratamento repetido com escitalopram na densidade de neuroblastos de animais iNOS KO submetidos ao CUS

Efeito do tratamento repetido com escitalopram na sobrevivência de novos neurônios de animais iNOS KO submetidos ao CUS

Efeito do tratamento repetido com escitalopram sobre as células tronco neurais de animais iNOS KO submetidos ao CUS.

Efeito do tratamento repetido com escitalopram sobre recrutamento de células parvalbuminas/FOSB positivas no córtex pré-límbico de animais iNOS KO submetidos ao CUS

Efeito do tratamento repetido com escitalopram sobre recrutamento de células parvalbuminas/FOSB positivas no córtex infralímbico de animais iNOS KO submetidos ao CUS

Discussão- Capítulo 1

Capítulo 2:

Consequências comportamentais da ausência genética da IL-10 em animais submetidos ao CUS: impacto sobre a densidade de micróglias e neuroblastos residentes da camada granular do giro denteado.

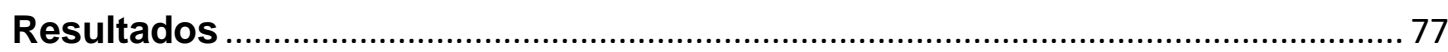

Efeito comportamental de animais IL-10 KO submetidos ao CUS........................ 77

Efeito do CUS na densidade de micróglias presente na camada granular de animais IL-10 KO

Efeito do CUS na densidade e na migração de neuroblastos animais IL-10 KO

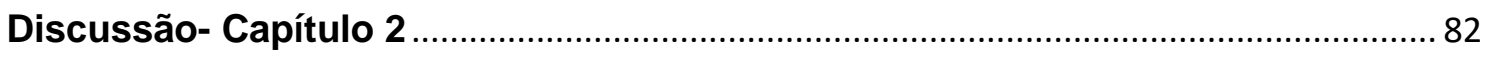

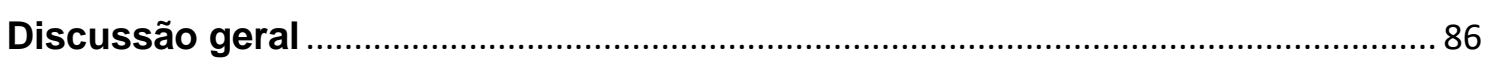

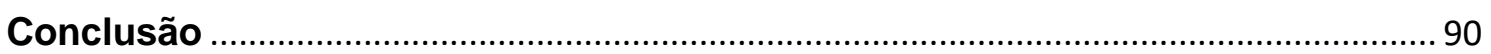

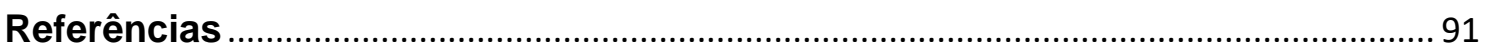


Introdução 


\section{Introdução}

\subsection{Estresse, depressão e ansiedade: aspectos gerais}

Todos seres vivos irão, em algum momento de suas vidas, vivenciar situações que colocarão em risco sua integridade física e mental. Dessa forma, como postulado por Charles Darwin no livro "A origem das espécies" apenas os seres capazes de se adaptar irão sobreviver e, como consequência, propagar a sua espécie (apud ROM e REZNIK, 2015).

Corroborando essa premissa, distintas respostas adaptativas estão conservadas evolutivamente em todos os seres vivos. Por exemplo, algumas espécies de procariotos ao serem expostas a situações extremas de variações de pH ou a situações na qual a disponibilidade de água é insuficiente para manter suas funções metabólicas ativas, esporulam até que sejam carreadas para um ambiente favorável (HIGGINS e DWORKIN, 2011). Seres mais complexos, como os pluricelulares, também apresentam mecanismos adaptativos, entretanto estes são mais intricados e, muitas vezes, orquestrados por diversos tipos celulares distintos.

No que diz respeito aos mamíferos, a elucidação e caracterização dessas respostas adaptativas a mudanças ambientais e suas consequências foi inicialmente estudada por Hans Selye. Em uma carta escrita ao editor da Nature em julho de 1936, Selye aponta que ratos expostos a diferentes agentes nocivos apresentavam uma série de respostas as quais eram temporalmente semelhantes, independente do estímulo utilizado (SELYE, 1936). Embora na carta não seja mencionado o termo estresse, posteriormente Selye passa a adotá-lo em seu livro "The phisyology and pathology of stress exposure" (1950 apud KOOLHAAS et al., 2011). Ele utiliza o termo para descrever a "síndrome de adaptação geral" a qual refere-se a resposta aguda e crônica a agentes estressores (SELYE, 1976).

Diante disso, o conceito de estresse passou por diversas reformulações, as quais continuam sendo discutidas rotineiramente no meio acadêmico através de congressos, simpósios e afins (KOOLHAAS et al., 2011). Nesse sentido, 
atualmente tem-se acordado que a resposta ao estresse não é necessariamente prejudicial, na verdade, trata-se de um mecanismo adaptativo que visa aprimorar a sobrevivência de um organismo (MCEWEN e AKIL, 2020). Essa redefinição trouxe consigo novos conceitos e parâmetros como, p.e., alostasia (do grego allos que significa variável e stasis que significa estabilidade), o qual está associado a um processo dinâmico cuja finalidade é manter a estabilidade do organismo através da adaptação, e carga alostática, o qual refere-se ao custo despendido pelo organismo no intuito de se adaptar a uma situação adversa (MCEWEN, 1998; MCEWEN e AKIL, 2020).

Nesse sentido, a exposição prolongada a agentes estressores pode ter efeitos maléficos ao organismo como um todo. Indivíduos sedentários que realizam uma sessão intensa de atividade física provavelmente apresentaram posteriormente dores musculares intensas com possíveis câimbras locais. $O$ mesmo ocorre aos indivíduos expostos a outros tipos de estressores, como os psicossociais (problemas matrimoniais, no trabalho, insegurança financeira, entre outras), sendo estes muitas vezes encontram-se associados a precipitação de sintomas relacionados a transtornos depressivos e de ansiedade (CRASKE et al., 2018).

Segundo dados emitidos pela Organização Mundial da Saúde (OMS, 2017) os transtornos depressivos e de ansiedade aumentaram sua prevalência em aproximadamente 50\% na população mundial, passando de 416 milhões para 615 milhões de indivíduos afetados, no decorrer dos anos de 1990 a 2013. Esses transtornos psiquiátricos, além de promoverem um prejuízo substancial ao paciente, também acarretam em custos de trilhões de dólares para os sistemas de saúde do mundo (OMS, 2017). Ademais, o tratamento farmacológico utilizado para tratar estes transtornos, principalmente antidepressivos de diferentes classes, apresentam limitações que dificultam a adesão do paciente, p.e., a necessidade de várias semanas para que o paciente apresente uma melhora significativa na clínica, bem como a não responsividade de aproximadamente $33 \%$ dos pacientes ao tratamento (para revisão sobre esses transtornos ver OTTE et al., 2016; CRASKE et al., 2018). Diante disso, é de extrema importância elucidar os mecanismos pelos quais a exposição ao estresse pode precipitar o desenvolvimento destes transtornos psiquiátricos, 
para que assim novas abordagens terapêuticas, mais eficazes, possam ser desenvolvidas.

\subsection{Neurobiologia da resposta ao estresse: relevância para ansiedade e depressão}

A capacidade que os mamíferos apresentam de observar, avaliar e integrar informações presentes no meio externo e dessa forma responder ao mesmo está associado ao sistema nervoso central (SNC), mais especificamente ao encéfalo (MCEWEN, 2007). Dessa forma, é concebível a suposição de que o encéfalo seja um dos principais órgãos responsáveis pela manutenção da homeostasia e um importante maestro para uma resposta apropriada a distintos agentes estressores.

Corroborando a premissa proposta por Selye (1936), diversos estudos demonstraram que diferentes agentes estressores, como a exposição de roedores ao odor de um predador (PERROT-SINAL, et al., 1999), estresse crônico (SNYDER, et al., 2011), simulação de discurso em público (GRAEFF e ZANGROSSI, 2010), teste de estresse social de Trier (KUDIELKA, et al., 2004), são capazes de mobilizar distintas vias em comum, sendo uma delas denominada hipotálamo-hipófise-adrenal (HHA) (MCEWEN e AKIL, 2020).

Resumidamente, essa via inicia-se com a percepção de um evento que leva ao recrutamento de células presentes no núcleo paraventricular do hipotálamo (PVN) as quais secretam o fator de liberação de corticotrofina (CRF) e arginina-vasopressina. Por sua vez, esses fatores são liberados em vasos que conectam o PVN à hipófise anterior, onde estes a estimulam a produzir e a secretar o hormônio adrenocorticotrófico (ACTH) na circulação sistêmica. Uma vez na circulação, o ACTH pode atingir as glândulas adrenais e estimular a produção e secreção de glicocorticoides na porção cortical da glândula (MCEWEN e AKIL, 2020; STEPHENS e WAND, 2012). Os glicocorticoides, sendo o cortisol o mais abundante em humanos e corticosterona o mais abundante em roedores, podem então atuar em dois tipos distintos de 
receptores, os receptores mineralocorticoides (MR) e os receptores de glicocorticoides (GR), porém seu papel no SNC passou a ser reconhecido recentemente.

Nesse sentido, a participação do encéfalo nas ações dos corticoides, bem como a recíproca, passou a ser devidamente explorada após as observações realizadas por Bruce McEwen e colaboradores no final da década de 1960 (MCEWEN et al., 1968; 1969). Mais especificamente, os pesquisadores estavam interessados em determinar se o encéfalo de ratos era capaz de captar a corticosterona presente no sangue e se aconteceria retenção da mesma em estruturas encefálicas específicas. Como resultado, eles observaram que a administração de $\left[1,2-{ }^{3} \mathrm{H}\right]$ corticosterona em ratos adrenalectomizados promovia um aumento no sinal radioativo (averiguado em um cintilógrafo) proporcional aos níveis plasmáticos em todos as regiões encefálicas analisadas (MEWEN et al., 1969). Curiosamente, nesse mesmo estudo, também foi observado que o material radioativo apresentava tempo de retenção maior no hipocampo e no septo, sendo esse fenômeno parcialmente atribuído a um "fator(es) de ligação". Posteriormente, os fatores de ligação foram identificados e denominados como receptores de glicocorticoides (GR) ou de mineralocorticoides (MR), e sua localização no SNC mapeada, sendo assim, identificado sua presença em estruturas límbicas, inclusive no hipocampo (apud KLOET et al., 1998; REUL e KLOET, 1985VAN EEKELEN et a., 1988).

Tendo como base a capacidade dos corticoides modular certos aspectos comportamentais, como p.e. o aprendizado em comportamentos de esquiva (para revisão ver MCEWEN et al., 1986), e a ciência da relevância do hipocampo para esses efeitos, diversos trabalhos foram realizados no intuito de dissecar a ação dos corticoides no hipocampo. Dessa forma, atualmente sabe-se que tanto a administração de corticoides como a exposição a estressores de forma crônica induz alterações morfológicas em neurônios hipocampais, p.e. atrofia dos dendritos apicais de neurônios piramidais localizados na região Corno Amonis (CA) 3 (MARGARINO e MCEWEN, 1995).

Além de promover alterações estruturais no hipocampo, a exposição prolongada ao estresse também altera a morfologia de neurônios presentes no córtex pré-frontal e na amígdala (para revisão ver MCEWEN et al., 2015). 
Curiosamente, as observações descritas acima fazem um paralelo àquelas realizadas em pacientes acometidos por transtornos psiquiátricos. Nesse sentido, observa-se que pacientes com depressão ou ansiedade apresentam alterações morfológicas no hipocampo, bem como no córtex, por outro lado, é creditado a uma maior atividade do complexo amigdaloide a ansiedade observada em pacientes acometidos por esse transtorno (HÖLZEL et al., 2010; MADONNA et al., 20211; Ll et al., 2021).

Concomitante às observações realizadas sobre a influência dos corticoides no hipocampo, estudos começam a demonstrar a possível geração de novos neurônios no hipocampo de roedores (ver seção 1.3). Interessantemente, ambas as linhas de pesquisas acabam convergindo, porém tal feito ocorre apenas no final do século XX, com experimentos realizados por Elizabeth Gould e colaboradores (GOULD et al., 1992, 1995 e 1998).

\subsection{Neurogênese hipocampal adulta: papel nos transtornos depressivos e ansiedade.}

Embora alguns trabalhos já apontassem uma possível capacidade do encéfalo de vertebrados de gerar novos neurônios na fase adulta (GLOBUS e KUHLENBECK, 1944), está premissa permaneceu obscura e pouco explorada até meados da década de 1960. As evidências relatadas pelos trabalhos seminais realizados por Joseph Altman e Gopal Das (1962, 1963 e 1965) foram um importante passo para a caracterização da neurogênese adulta. Os autores descreveram que células presentes no giro denteado de ratos eram capazes de captar e reter em seu núcleo $\left[{ }^{3} \mathrm{H}\right]$ timidina (ALTMAN e DAS, 1968), sugerindo assim, que as células presentes nessa região apresentavam ciclo-celular ativo, visto que a timidina é captada e incorporada no ácido desoxirribonucleico (DNA) cromossomal durante a fase $S$ do ciclo celular (DENOTH-LIPPUNER e JESSBERGER, 2021).

Posteriormente, Kaplan e colaboradores (1977) observaram através de microscopia óptica e eletrônica a retenção de $\left[{ }^{3} \mathrm{H}\right]$ timidina trinta dias após sua administração em neurônios presentes no giro denteado e no bulbo olfatório de 
ratos. Outro estudo realizado por Paton e Nottebohm (1984) demonstrou que canarios também apresentavam incorporação e retenção de [ $\left.{ }^{3} \mathrm{H}\right]$ timidina em uma região associada com o controle do canto. De forma elegante, os autores observaram, utilizando técnicas de eletrofisiologia e imunohistoquímica, que células registradas e que apresentavam a $\left[{ }^{3} \mathrm{H}\right]$ timidina em seu núcleo, respondiam de forma semelhante aos neurônios registrados, sugerindo que as novas células geradas eram neurônios e esses eram funcionais (PATON e NOTTEBOHM, 1984). Posteriormente, foi demonstrado por imunohistoquímica que a incorporação de $\left[{ }^{3} \mathrm{H}\right]$ timidina nas células do giro denteado de roedores eram neurônios (CAMERON et al., 1993).

Entretanto, mesmo diante dessas evidências a aceitação deste fenômeno permaneceu por muitas décadas uma polêmica no meio acadêmico (KAPLAN, 2001). Aparentemente, a neurogênese adulta passou a apresentar relevância no meio científico, após a publicação do trabalho pioneiro de Erickson e col. (1998). Valendo-se de técnicas de imunofluorescência e microscopia confocal, os autores demonstram que encéfalos humanos eram capazes de incorporar o composto 5-bromo-2'-deoxiuridina (BrdU- um análogo de timidina) este estava localizado no giro denteado e colocalizado com marcador de neurônios (NSEenolase específica de neurônios).

A posterior identificação e descrição de proteínas expressas em tipo células específicas do processo neurogênico, o isolamento de células tronco neurais (NSC- do inglês "neural stem cells") provenientes de encéfalos de roedores, bem como o advento de animais transgênicos para uso em técnicas de "fate-mapping", permitiu um estudo pormenorizado deste evento, bem como uma melhor compreensão de sua regulação (KEMPERMANN, 2015; DENOTHLIPPUNER e JESSBERGER, 2021). Atualmente, é reconhecido que o encéfalo de mamíferos apresenta ao menos dois nichos neurogênicos, a região subventricular dos ventrículos laterais (SVZ- do inglês "subventricular zone") e, de particular interesse para o presente trabalho, a região subgranular do giro denteado (SGZ - do inglês "subgranular zone").

Um dos primeiros moduladores do processo da neurogênese hipocampal adulta (AHN- do inglês "adult hippocampal neurogenesis") a ser reconhecido foi a exposição ao estresse e os corticoides associados a essa exposição (GOULD 
et al., 1992, 1995, 1998). Curiosamente, também foi posteriormente demonstrado que o processo de AHN é um importante modulador do eixo HHA, visto que sua ausência exacerba respostas endócrinas e comportamentais a estressores agudos e a estressores crônicos (SCHLOESSER et al., 2009; SNYDER et al., 2011). Além dessa interação recíproca, estudos também sugerem que a ação de diferentes drogas com propriedades antidepressivas depende da AHN (SANTARELLI et al., 2003; SURGET et al., 2011; CAMPOS et al., 2013). Mais especificamente, o trabalho realizado por Luca Santarelli e col. (2003) elegantemente demonstrou que a ablação por radiação de progenitores neurais localizados no hipocampo bloqueava 0 efeito tipoantidepressivo/ansiolítico da fluoxetina (inibidor seletivo da recaptação de serotonina) e da imipramina (antidepressivo tricíclico).

Além dessas observações, também foi demonstrado que a deleção condicional do gene Bax (gene codificador da proteína Bax que apresenta atividade pró-apoptótica) em NSC aumentava a sobrevivência de novos neurônios, evidenciado por aumento no número de células doublecortina (DCX), marcador utilizado para identificar neuroblastos, no giro denteado de camundongos e promovia um fenótipo resiliente no modelo de subjugação social (SDS- do inglês "social defeat stress"- ANACKER et al., 2018).

Diante disso, alguns pesquisadores sugerem que alterações no processo da AHN podem estar envolvidos na precipitação de sintomas e instauração de transtornos depressivos e de ansiedade (SURGET e BELZUNG, 2021). Reforçando esta hipótese, um estudo realizado por Boldrini e colaboradores (2009) demonstrou que pacientes acometidos com depressão maior tratados com antidepressivos apresentavam aumento no número de NSC no giro denteado.

Entretanto os mecanismos que conectam a exposição ao estresse crônico e redução da $A H N$ ainda permanecem obscuros. Nesse sentido, tem sido proposto que a mobilização e aumento de glicocorticoides seria um dos possíveis mediadores dos efeitos deletérios do estresse sobre as NSC (ODAKA et al., 2017). Outra hipótese complementar a mobilização de glicocorticoides tem sido proposta e sugere que um desbalanço inflamatório promovido pelo estresse 
poderia subjazer os efeitos comportamentais e neurogênicos observados (HODES et al., 2015).

\subsection{Mediadores inflamatórios, AHN e transtornos psiquiátricos}

Uma das primeiras evidências que apontaram para a existência de um componente inflamatório no desencadeamento de transtornos psiquiátricos advém de um estudo realizado no final da década de 1980. Nesse estudo foi observado que a administração crônica de interferon- $\alpha$ (IFNa - agente citostático utilizado para tratamento de hepatites) em pacientes acometidos por hepatite era capaz de promover alterações similares a alguns sintomas de transtornos mentais, tais como a Depressão Maior, em uma coorte de pacientes (17\%) o qual era revertido após interrupção do tratamento (RENAULT et al., 1987). Posteriormente foi demonstrado que antidepressivos eram capazes de prevenir o aparecimento de episódios depressivos em pacientes tratados com INFa (SCHAEFFER et al., 2005; SARKAR e SCHAEFFER, 2014). Corroborando essas observações, outro estudo demonstrou que a administração de INFa em pacientes acometidos por câncer de pulmão de pequenas células, porém mentalmente saudáveis, apresentavam alterações comportamentais, como ansiedade e humor deprimido, os quais cessavam 2 semanas após o término do tratamento (NIIRANEN et al., 1988). Diante dessas, e outras evidências, foi proposto a teoria macrofágica da depressão (SMITH, 1991) a qual fomentou a hipótese de um desbalanço neuroimune nos transtornos psiquiátricos, incluindo depressão e ansiedade (HODES et al., 2015; FELGER, 2018).

Na mesma direção das observações realizadas em humanos, modelos animais demonstraram que administração de intermitente de baixas doses lipopolissacarídeo (LPS), substância com propriedades pró-inflamatórias, era capaz de promover alterações comportamentais tipo-anedônica no teste de preferência pela sacarose (SPT- do inglês "sucrose preference test" (KUBERA et al., 2013; RODRIGUES et al., 2018), sendo esta revertida com administração crônica de fluoxetina (RODRIGUES et al., 2018). Ademais, também foi demonstrado que a administração crônica de INFa em camundongos resulta em 
respostas comportamentais similares àquelas observadas em humanos, sendo este fenômeno associado a uma redução na AHN (ZHENG et al., 2014).

Embora a capacidade de eventos inflamatórios em reduzir a AHN seja reconhecida desde trabalhos que demonstraram que administração intraperitoneal de LPS reduz a retenção de BrdU por células DCX positivas (DCX+) (MONJE et al., 2003) e em neurônios maduros, imunomarcados pela proteína nuclear neuronal (NeuN- do inglês "neuronal nuclear") (EKDAHL et al., 2003), os estudos mencionados previamente fomentam a hipótese que alterações comportamentais induzidas por agentes pró-inflamatórios seriam decorrentes de uma redução na $\mathrm{AHN}$ e, que em humanos, poderiam estar associados com o surgimento de transtornos psiquiátricos, como depressão e ansiedade.

No intuito de melhor compreender essa complexa interação, Koo e col. (2008), utilizando ratos e camundongos, demonstraram a administração de antagonistas de receptores para interleucina-1 $\beta$ (IL-1 / / IL-1Ra) bloqueava os efeitos tipo-anedônicos e antineurogênicos promovidos pela exposição ao modelo de estresse crônico imprevisível (CUS- do inglês "chronic unpredictable stress"), sendo este efeito similar em animais "knockout" (KO) para o receptor de IL-1. Além desse, estudos utilizando modelos de estresse distintos reportaram observações semelhantes. Especificamente, foi observado que a exposição de ratos ao SDS aumenta a imunorreatividade de IL-1 $\beta, I L-6$, fator de necrose tumoral a (TNFa- do inglês "tumor necrosis fator alpha"), mediadores próinflamatórios, no giro denteado, bem como em outras estruturas límbicas (YANG et al., 2015), sendo creditado ao aumento rápido e sustentado de IL-6 um fenótipo suscetível de roedores ao SDS e ao modelo de desamparo aprendido (LH- do inglês "learned helplessness") (HODES et al., 2014; YANG et al., 2015). Corroborando as evidências obtidas com modelos animais, estudos clínicos demonstraram que indivíduos acometidos por depressão e/ou ansiedade apresentam níveis elevados de citocinas inflamatórias plasmático (para revisão detalhada ver MÉNARD et al., 2017; FELGER, 2018).

$O$ mecanismo pelo qual citocinas presentes na periferia interagem com 0 SNC ainda permanecem sob debate. Acredita-se que diferentes vias podem ser responsáveis por essa comunicação neuroimune, dentre elas pode-se citar: i) via 
os ramos simpático e parassimpático do sistema nervoso periférico; ii) através da ocupação do parênquima encefálico por monócitos periféricos; iii) através da interação mediado por receptor de citocinas periféricas com astrócitos que compõe a barreira hematoencefálica; iv) através da captação de citocinas periféricas pelo SNC; entre outros (para revisão ver HODES et al., 2015; KENNEDY e SILVER, 2015; DANTZER et al., 2017; CHU et al., 2020; KOO e WOHLEB, 2021). De forma interessante, as vias citadas previamente parecem ser capazes de recrutar e modular a atividade de um tipo de célula especifico encontrado no SNC, as micróglias.

\subsection{Micróglia e suas facetas: possível elo entre hipótese neuro-imune e neurogênica}

Em 2019 foi celebrado o centenário da caracterização da micróglia pelo cientista Río-Hortega (para revisão ver SIERRA et al., 2019). Além de descrever suas propriedades morfológicas utilizando técnicas de impregnação semelhantes àquelas empregadas por Ramon y Cajal, Río-Hortega propôs uma série de características para estas células como: i) origem embrionária mesodermica, diferentemente das demais células que compões o SNC, cuja origem é ectodérmica; ii) capacidade fagocítica tanto para "debris" (destroços) quanto de espinhos dendríticos durante a embriogênese; iii) a capacidade das micróglias de alterarem sua morfologia diante de injúrias do parênquima nervoso; iv) sua aparente capacidade proliferativa perante dano do SNC (apud SIERRA et al., 2019).

Atualmente, diversos estudos corroboram as observações iniciais feitas por Río-Hortega, expandem seus achados iniciais e demonstram que o papel da micróglia na homeostasia do SNC é muito mais amplo do que o inicialmente proposto (para revisão ver KETTENMANN et al., 2011).

Nesse sentido, técnicas avançadas, como o "fate-mapping", permitiram a identificação de uma população de células mielóides primitivas na parede do saco-vitelínico capazes de migrar para o SNC ainda em desenvolvimento e gerar 
as micróglias (PRINZ e PRILLER, 2014). Ademais, o uso de animais heterozigotos para o gene codificante do receptor de fractalquina (CX3CR1GFP) permitiu visualizar a dinâmica dos processos da micróglia em tempo real no parênquima nervoso, bem como a rápida mobilização dessas células em sítios lesados (DAVALOS et al., 2005; NIMMERJAHN et al., 2005). Diante dessas evidências, surge o conceito de que as micróglias não estariam em um estado de repouso, mas sim em um estado constante de vigilância, respondendo de forma dinâmica a micro eventos que acontecem ao seu redor no SNC.

A evolução do conceito e da função da micróglia presente no SGZ seguiu de forma paralela aos estudos acerca de suas funções nas demais localidades do SNC. Nesse sentido, um dos primeiros relatos da regulação da AHN pela micróglia advém das observações acerca da administração de LPS, onde foi reportado que a redução na AHN era acompanho de um aumento linear da densidade de micróglias in vivo e, elegantemente, demonstrado in vitro que o meio condicionado de uma linhagem de micróglia imortalizadas (BV-2) estimuladas com LPS apresentava fatores solúveis que reduziam a diferenciação de NSC em neuroblastos (EKDAHL et al., 2003; MONJE et al., 2003). Por outro lado, Ziv e col. (2006) demonstraram que os efeitos próneurogênicos promovidos pela exposição ao ambiente enriquecido eram modulados por células $\mathrm{T}$ periféricas, e em última instância as micróglias, reforçando o conceito de seu papel dual no nicho neurogênico. Posteriormente, foi demonstrado que em condições basais, NSC que morrem por vias apoptóticas são eliminados através de fagocitose pelas micróglias (SIERRA et al., 2010).

Curiosamente, estudos demonstraram que a exposição a estresse é capaz de recrutar e modular o fenótipo dessas células em regiões encefálicas implicadas em transtornos psiquiátricos, inclusive no hipocampo (para revisão ver TYNAN et al., 2013). Mais especificamente, Kreisel e colaboradores (2014) demonstraram que a exposição ao CUS, além de promover um efeito tipoanedônico, alterava a densidade e produzia retração dos processos das micróglias, sendo essa associada a um fenótipo inflamatório, no giro denteado. Curiosamente, os autores observaram que o tratamento com imipramina era capaz de bloquear as alterações produzidas pelo CUS. No mesmo sentido, 
Hellwig e colaboradores (2016) observaram que o estresse por natação forçado era capaz de induzir um comportamento tipo-depressivo e alterar a ramificação das micróglias no giro denteado, sendo este revertido pelo tratamento crônico com venlafaxina (um inibidor seletivo da recaptação de serotonina e noradrenalina).

Por outro lado, um estudo recente elegantemente demonstrou a versatilidade das micróglias no contexto do estresse e sua atuação sobre a AHN (ZHANG et al., 2021). Inicialmente, os autores observaram que animais suscetíveis ao estresse apresentavam um aumento e uma redução nos genes com propriedades pró-inflamatórias e anti-inflamatórias, respectivamente, no hipocampo. Mobilizados pela redução da IL-4, citocina anti-inflamatória, em animais suscetíveis, os autores induziram por manipulação genética a supraexpressão de IL-4 no hipocampo de camundongos e estes após serem submetidos ao CUS por um período de 4 semanas não apresentaram redução na $\mathrm{AHN}$, nem alterações comportamentais. Curiosamente, esse protocolo também induziu um aumento na AHN nos animais não submetidos ao estresse, sugerindo que a IL-4 tem capacidade pró-neurogênica. Entretanto, quando Zhang e colaboradores suprimiram a expressão do receptor de IL-4 especificamente das micróglias estes efeitos não eram observados. Estas evidências reforçam a premissa que a relação da micróglia com o nichoneurogênico e seu impacto sobre o processo de AHN depende do contexto ao qual ela encontra-se exposta.

Além de manipulações genéticas para ganho de função, estudos in vitro sugerem que diferentes classes de antidepressivos são capazes de prevenir a capacidade do LPS em induzir um fenótipo pró-inflamatório pelas micróglias (LIU et al., 2011; DU et al., 2014; SU et al., 2015) e estes também seriam capazes de induzir um fenótipo anti-inflamatório/neuroprotetor/pró-neurogênico (EKDAHL et al., 2009; SATO, 2015). Em consonância com essas observações, Ramirez e colaboradores (2015) observaram que micróglias, oriundas de animais submetidos ao SDS 24 dias antes de seu isolamento, respondiam ao estimulo com LPS com uma expressão gênica exacerbada de IL-1ß, IL-6 e TNFa (fenômeno descrito como "priming") sendo esta revertido em animais que foram tratados com imipramina após o término do protocolo de SDS. 
Como exposto, diversos mediadores inflamatórios são recrutados e mobilizados durante a exposição a diferentes protocolos de estresse, e apresentam um papel como moduladores negativos da AHN. Entretanto, muitos dos mediadores supracitados convergem durante sua via de sinalização intracelular e são capazes de induzir a expressão de uma enzima em comum denominada, óxido nítrico sintase induzível (iNOS) (ZAKI et al., 2007). Nesse sentido, um estudo clínico sugeriu que indivíduos com polimorfismo genético desta enzima apresentam maior predisposição para desenvolvimento de depressão maior recorrente (GALECKI et al., 2010). Ademais, outro estudo detectou maiores níveis plasmáticos de iNOS em pacientes acometidos por depressão (GALECKI et al., 2012). Curiosamente, evidencias pré-clínicas vão no mesmo sentido e sugerem que a inibição ou a ablação genética da iNOS promove efeito tipo-antidepressivo (MONTEZUMA et al., 2012; PENG et al., 2012).

Em contrapartida, foi demonstrado que pacientes depressivos apresentam níveis reduzidos da interleucina-10 (IL-10), um importante mediador anti-inflamatório, sendo que a administração de antidepressivos mostrou-se capaz de aumentar os níveis dessa citocina (STRLE et al., 2001; DHABHAR et al., 2009; KOHLER et al., 2018). No mesmo sentido, Kubera e colaboradores (2001) demonstraram que animais estressados tratados com desipramina apresentava níveis séricos de IL-10 maiores quando comparados aos animais estressados tratados com veículo.

Diante do exposto, o presente trabalho investigou em duas etapas paralelas o efeito comportamental e neurogênico da deleção gênica da iNOS ou da IL-10 em animais submetidos ao CUS. Nossa hipótese inicial foi que enquanto a ausência da iNOS preveniria as alterações neurogênicas e comportamentais induzidas pelo CUS por impedir que as micróglias adotassem um fenótipo próinflamatório. Em contrapartida, a ausência da IL-10 induziria um fenótipo suscetível ao CUS por redução da neurogênese via adoção de um perfil inflamatório pelas micróglias do giro denteado. 
Objetivos 


\section{Objetivos}

\subsection{Objetivos gerais}

- Avaliar as consequências da exposição de animais iNOS KO e IL-10 $\mathrm{KO}$ ao CUS.

- Avaliar as consequências do tratamento repetido com escitalopram em animais iNOS KO submetidos ao CUS.

\subsection{Objetivos específicos}

Avaliar:

- a resposta comportamental de animais iNOS KO submetidos ao CUS em testes comportamentais relacionados a depressão e ansiedade.

- se o CUS é capaz de induzir alterações nas micróglias presente na camada granular do giro denteado

- o impacto do CUS sob parâmetros neurogênicos de animais iNOS KO.

- se o tratamento repetido com escitalopram é capaz de induzir alterações comportamentais em animais iNOS KO.

- a resposta de parâmetros neurogênicos em animais iNOS KO após tratamento repetido com escitalopram.

- o recrutamento de células parvalbumina no córtex pré-frontal de animais iNOS KO após tratamento repetido com escitalopram.

- a resposta comportamental de animais IL-10 KO submetidos ao CUS em testes relacionados a depressão e ansiedade

- se o CUS é capaz de induzir alterações nas micróglias presente no giro denteado

- o impacto do CUS sob o número de neuroblastos nos animais IL-10 KO. 


\section{Material e métodos}




\section{Material e Métodos}

\subsection{Animais}

Foram utilizados camundongos iNOS knock-out (iNOS KO), Interleucina10 KO (IL-10 KO) e C57BI6 ("wild-type"- WT) oriundos do Centro de Criação de Camundongos Especiais de Ribeirão Preto e do Biotério Central da Universidade de São Paulo, Campus Ribeirão Preto, respectivamente. Totalizando 45 animais WT, 26 animais iNOS KO e 16 IL-10 KO nos experimentos não-consanguíneos. $\mathrm{O}$ acasalamento para obtenção de linhagens consanguíneas foi feito a partir da obtenção de fêmeas 4 iNOS KO do CCE e de 4 machos WT obtidos do biotério da Clínica Médica. O acasalamento destes permitiu a obtenção de uma prole heterozigoto (F1). Posteriormente, estes animais foram acasalados afim de se obter os animais experimentais (F2), totalizando 15 animais WT, 14 animais iNOS e Heterozigoto (Het) e 20 animais iNOS KO. Os animais foram mantidos em condições de temperatura $\left(23 \pm 2^{\circ} \mathrm{C}\right)$ e umidade controlados. Ciclo-claro escuro de 12h/12h (luzes acesas 6h) e alimentação ad libitum, a menos que seja especificado de forma diferente. Todos protocolos foram previamente aprovados pelo Comitê de Ética no Uso de Animais da FMRP (CEUA- no protocolo 187/2017).

\subsection{Drogas}

A droga 5-bromodeoxuridina (BrdU- Sigma Aldrich, Missouri, Estados Unidos da América) foi dissolvido e administrado via intraperitoneal (i.p.) na dose de $200 \mathrm{mg} / \mathrm{kg}$. O escitalopram (ESC- Prati Donaduzzi®) foi dissolvido e administrado via i.p. na dose de $10 \mathrm{mg} / \mathrm{kg}$. A mistura de cetamina e xilazina foi administrada via i.p. nas doses de $375 \mathrm{mg} / \mathrm{kg}$ e $25 \mathrm{mg} / \mathrm{kg}$, respectivamente, com intuito de anestesiar os animais. Todas as drogas empregas foram dissolvidas em salina estéril $0,9 \%$ e administradas em volume de $10 \mathrm{~mL} / \mathrm{kg}$.

\subsection{Genotipagem}


Para determinar o genótipo dos animais utilizados para o experimento com animais consanguíneos, logo após ser realizado o desmame (dia pós-natal 21 a 24) um pequeno fragmento distal da cauda foi coletado em um tubo de 1,5 $\mathrm{mL}$. Esse material foi digerido em $200 \mu \mathrm{L}$ de tampão de lise (NaCL 5M, EDTA $500 \mathrm{mM} \mathrm{pH}=8,10 \%$ de SDS, Tris Base $1 \mathrm{M} \mathrm{e} 500 \mu \mathrm{L}$ de proteinase $\mathrm{K}$ armazenada em alíquotas de $20 \mathrm{mg} / \mathrm{mL}$ ) e incubado a $55^{\circ} \mathrm{C}$ overnight sob banho seco (Thoth, modelo 2120, São Paulo, Brasil). Após, o DNA genômico foi precipitado com a adição de isopropanol na proporção 1:1 em relação ao volume do tampão de lise, com subsequente centrifugação (13.000 rpm por $5 \mathrm{~min}$ a $4^{\circ} \mathrm{C}$ ). Posterior à centrifugação, o sobrenadante foi descartado e o "pellet" formado foi ressuspenso em $50 \mu \mathrm{L}$ de água miliQ e armazenado a $4^{\circ} \mathrm{C}$ até a realização da técnica de reação em cadeia da polimerase (PCR- do inglês "polymerase chain reaction").

Para reação, $1 \mu \mathrm{L}$ da amostra armazenada foi adicionado a uma solução contendo $8,4 \mu \mathrm{L}$ de água miliQ, 2,5 $\mu \mathrm{L}$ de buffer para PCR (Invitrogen, Califórnia, EUA), 0,25 $\mu \mathrm{L}$ de dNTPs (Invitrogen, Califórnia, EUA), 0,06 $\mu \mathrm{L}$ da enzima Taq polimerase (GoTaq $\AA$, Promega, Wisconsin, EUA) e 0,125 $\mu \mathrm{L}$ de primer (Tabela 1).

Tabela 1: Sequência de primer utilizados para genotipagem.

Tipo de primer Sequência

Comum 5' - TCA CCA CCA GCA GTA GTT GC - 3'

WT forward $\quad$ 5' - TCC GAT TTA GAG TCT TGG TGA - 3'

Mutante forward $\quad 5$ ' - CCT TCT ATC GCC TTC TTG ACG - 3'

Após adição da amostra ao mix, estas foram colocadas em um termociclador (9902 Veriti PCR Thermal cycler, Applied Byosystems scientific, Massachussetts, EUA) programado para: i) estágio 1 (1x): 95ํㅡ por 3 minutos; ii) estágio 2 : $95^{\circ} \mathrm{C}$ por $30 \mathrm{~s}, 60^{\circ} \mathrm{C}$ por $45 \mathrm{~s}, 72^{\circ} \mathrm{C}$ por $1 \mathrm{~min}$, estes ciclos repitiram 35 vezes; iii) estágio 3: $72^{\circ} \mathrm{C}$ por $7 \mathrm{~min}$; iv) estágio 4: $4^{\circ} \mathrm{C}$ até retirada da amostra. 
Ao final da reação, as amostras foram pipetadas em um gel de agarose 1,5\% diluída em tampão (Tris $\mathrm{HCl} 2 \mathrm{M}$, ácido acético 20mM, EDTA 0.5M, pH=7,8) contendo $10 \mu \mathrm{L}$ de SYBR Safe (Invitrogen, ThermoFischer, Massachusetts, EUA). Este foi colocado em um cuba de eletroforese a qual foi realizada por 30 minutos a uma voltagem fixada em 100V. Passado este tempo, o gel foi revelado em um aparelho ChemiDoc XRS+ (BioRad, Califórnia, EUA).

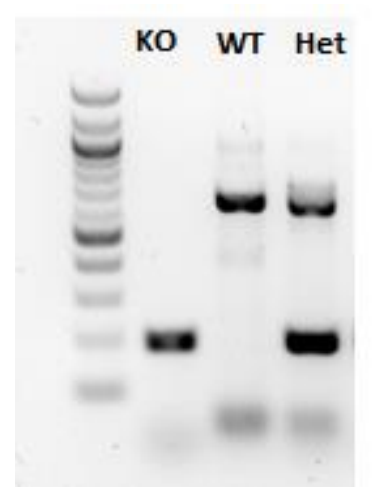

Figura 1: Foto representativa das genotipagens realizadas. Observar banda com a aproximadamente peso de 200 pares de base (bp) indicando replicação das fitas mutantes e em aproximadamente 640 bp as fitas "wild-type". Apreciar também a presença de duas bandas nos pesos mencionados para os animais hetetozigotos.

\subsection{Estresse Crônico Imprevisível ("Chronic Umpredictable Stress"- CUS)}

O protocolo empregado no presente trabalho consistiu em modificações realizados no trabalho pioneiro de Willner e colaboradores (1982) e em outros trabalhos (CAMPOS et al., 2013 e FOGAÇA et al., 2018). Nosso protocolo consistiu na exposição randomizado de sete agentes estressores distintos: inversão do ciclo claro-escuro (24h), ciclo intermitente (24h), estresse por restrição (2h), nado forçado (15min), caixa-inclinada (durante a noite), privação de alimentação (24h) e ausência de maravalha (24h).

\subsection{Testes Comportamentais}

\subsubsection{Teste do campo aberto (“Open Field Test” -OFT)}


Para avaliar a atividade locomotora dos animais, foi utilizado uma arena circular com $40 \mathrm{~cm}$ de diâmetro onde os animais foram colocados no dia teste. Foi avaliado com o auxílio do software Anymaze (Stoeling Co, IL, EUA) a distância total percorrida pelos animais durante 5 minutos.

\subsubsection{Teste de suspensão pela cauda (“Tail suspension test" - TST)}

No intuito de avaliar a resposta de enfrentamento perante a um estressor agudo, os animais foram suspensos a uma altura de $60 \mathrm{~cm}$ pela cauda por 6 minutos. Foram mensurados a latência para o primeiro episódio de imobilidade e o tempo de imobilidade total. Animais que escalaram ou caíram durante o experimento foram removidos das análises (CAN et al., 2012).

\subsubsection{Teste da supressão da alimentação pela novidade ("Novelty supressed feeding test" - NSFT)}

Para acessar o comportamento tipo-ansioso, animais previamente privados de acesso a comida foram colocados em uma caixa de acrílico triangular $(50 \times 50 \times 40 \mathrm{~cm}) \mathrm{com}$ o assoalho coberto de maravalha. No centro da arena foi colocado um único "pellet" de ração no topo de uma plataforma iluminada. Cada animal foi colocado no canto da arena e a latência para começar a se alimentar foi mensurada com tempo máximo de "cutoff' de $10 \mathrm{~min}$. Após o teste, todos os animais retornaram para sua caixa-moradia e a quantidade de alimento consumido em 5 min foi quantificado (CAMPOS et al., 2013; FOGAÇA et al. 2018).

\subsection{Delineamento experimental}

\subsubsection{Experimento 1: efeito do CUS em animais iNOS KO}

Foram submetidos de forma independente a este experimento animais não-consanguíneos e posteriormente animais consanguíneos. Todos os animais receberam $1 \mathrm{~h}$ antes do início do protocolo $200 \mathrm{mg} / \mathrm{kg}$ de BrdU por via intraperitoneal. Randomicamente, uma coorte de camundongos de todos os 
genótipos foi designada para ser submetido ao protocolo de CUS, os demais permaneceram na caixa-moradia durante o protocolo. No $20^{\circ}$ dia do protocolo, todos os animas foram submetidos ao OFT durante período da manhã (iniciando as $8 \mathrm{~h}$ ), e no período vespertino foram submetidos ao TST (iniciando as 13h). No $21^{\circ}$ dia, todos os animais foram privados de comida e após $24 \mathrm{~h}$ foram submetidos ao NSFT. No dia posterior ao NSFT todos os animais foram perfundidos e seus encéfalos coletados para posterior ensaios imunohistoquímicos (Fig 1A).

\subsubsection{Experimento 2: efeito do escitalopram em animais iNOS KO submetidos ao CUS}

Apenas animais não-consanguíneos foram utilizados neste experimento. Conforme ilustrado na figura $1 \mathrm{~B}$, todos os animais receberam uma injeção de $200 \mathrm{mg} / \mathrm{kg}$ de BrdU $1 \mathrm{~h}$ antes do início do protocolo do CUS. Animais selecionados randomicamente, foram submetidos ao CUS ou permaneceram na caixamoradia durante o protocolo. Ademais, os animais foram divididos e designados para receber injeções diária entre as 16-17h de veículo ou de escitalopram na dose de $10 \mathrm{mg} / \mathrm{kg}$ (i.p.). No $20^{\circ}$ dia do protocolo, todos os animas foram submetidos ao OFT durante período da manhã (iniciando as 8h), e no período vespertino foram submetidos ao TST (iniciando as $13 \mathrm{~h}$ ). No $21^{\circ}$ dia, todos os animais foram privados de comida e após $24 \mathrm{~h}$ foram submetidos ao NSFT. No dia posterior ao NSFT todos os animais foram perfundidos e seus encéfalos coletados para posterior ensaios imunohistoquímicos (Fig 1B).

\subsubsection{Experimento 3: efeito do CUS em animais IL-10 KO}

Todos os procedimentos utilizados neste experimento foram idênticos àqueles descritos na seção 3.5.1, porém foram utilizados animais IL-10 KO e WT não consanguíneos apenas (Fig 1A). 


\section{$\mathbf{A}$}
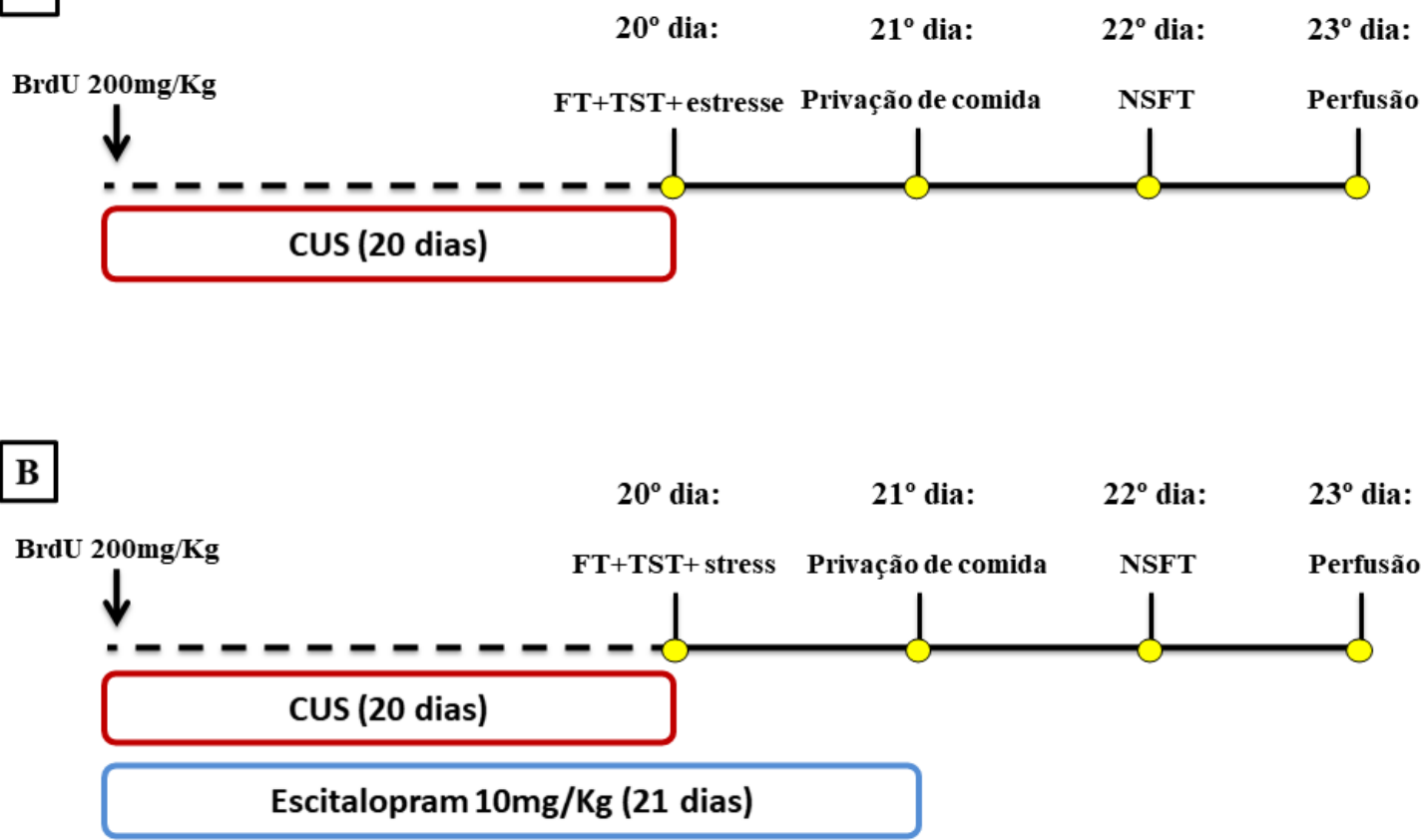

Figura 2: Esquema representativo mostrando uma linha temporal denotando os tratamentos, o protocolo de estresse empregado e a avaliação comportamentais. Grupos independentes foram submetidos ao CUS apenas (A), ou receberam injeções diárias de escitalopram $10 \mathrm{mg} / \mathrm{kg}$ (B).

\subsection{Ensaios imunohistoquímicos}

\subsubsection{Preparação do tecido}

Após serem anestesiados profundamente com uma mistura de cetamina e xilazina, todos os animais foram perfundidos por infusão transcardíaca de 25 $\mathrm{mL}$ PBS 0.01M ( $\mathrm{pH}=7.4)$ seguido de $20 \mathrm{~mL}$ de PFA 4\% diluído em PB 0.2M $(\mathrm{pH}=7.4)$. Após serem removidos, os encéfalos foram fixados PFA $4 \%$ por $24 \mathrm{~h}$. Passado este período, os encéfalos transferidos para uma solução de $30 \%$ de sacarose, onde permaneceram uma semana, seguido de imersão em isopentano a $-30^{\circ} \mathrm{C}$ por 30 s para crioproteção. Oito a dez secções coronais com $30 \mu \mathrm{m}$ de espessura foram obtidas do córtex pré-frontal (Bregma -2.1 a $-1.5 \mathrm{~mm}$ ) e hipocampo (Bregma 1.46 a $3.08 \mathrm{~mm}$ ) com o auxílio de um criostato a $-20^{\circ} \mathrm{C}$. Os cortes foram armazenados em solução anticongelante (30\% de etileno glicol e $20 \%$ de glicerol) até que fosse realizado os ensaios. 


\subsubsection{Imunohistoquímica para detecção de DCX}

Secções contendo o hipocampo, foram lavadas em "free-floating" três vezes em TBS (Tampão Tris Salina, $50 \mathrm{mM}, \mathrm{pH}=7.6,15 \mathrm{~min}$ ) seguido de $30 \mathrm{~min}$ de incubação em tampão citrato $10 \mathrm{mM}(\mathrm{pH}=6)$ a $70^{\circ} \mathrm{C}$ para recuperação antigênica. Após três lavagens em TBS (15min/lavagem), as secções foram incubadas com solução de bloqueio (TBS + Triton X 0.025\% + BSA 1\%) por quatro horas, seguido de incubação "overnight" a $18^{\circ} \mathrm{C}$ sob agitação com o anticorpo primário anti-DCX (goat; 1:200; Santa Cruz Biotechnology, Texas, EUA). No dia seguinte, os cortes foram lavados três vezes e incubados com anticorpo secundário (Vectastain anti-goat biotinilado, 1:1000) por 1,5h. Após, as seç̧ões foram incubadas com o complexo $A+B$ por 1h (1:500; $A B C$ EliteVectastain kit, Vector Labs, Burlingame, CA, USA) seguido de incubação com 3,3'-diaminobenzidina ( $0.2 \mathrm{mg} / \mathrm{mL}$ por $10 \mathrm{~min}$; Sigma-Aldrich, Montana, EUA). Após, as lâminas passaram pelo processo de diafanização e foram montadas utilizando meio Permount (Sigma-Aldrich).

\subsubsection{Imunofluorescência para detecção de BrdU, DCX e NeuN}

Após três lavagens com TBS, as secções em "free-floal" foram incubadas por trinta minutos com solução de $\mathrm{HCl} 2 \mathrm{~N}$ a $37^{\circ} \mathrm{C}$, para desnaturação das fitas de DNA, seguido de duas lavagens de 10 min com ácido bórico $(0.1 \mathrm{M}, \mathrm{pH}=8.9)$. Então as secções foram incubadas com solução de bloqueio por quatro horas, $\mathrm{e}$ em seguida, foram incubadas overnight a $18^{\circ} \mathrm{C}$ sob agitação com anticorpos primários anti-BrdU (rabbit, 1:100; Abcam, Cambridge, UK ), anti-DCX (rat, 1:500, Cell-Signaling) e anti-NeuN ( mouse, 1:500; Millipore, Massachusetts, EUA). No dia seguinte, após três lavagens em TBS os anticorpos secundários foram incubados por 1,5h (anti-rabitt AlexaFluor 488, anti-rat AlexaFluor $594 \mathrm{e}$ anti-mouse AlexaFluor 647; Invitrogen, Massachusetts, EUA). Finalizado o ensaio, as lâminas foram montadas em Fluormount G (Invitrogen, Massachusetts, EUA). 


\subsubsection{Imunofluorescência para detecção de IBA-1, GFAP, SOX2, FOSB e PV}

Similar ao descrito na seção 3.6.2, após bloqueio, os cortes foram incubados com os anticorpos primários anti-IBA (rabbit, 1:1000; Wako, Virginia, EUA), anti-GFAP (1:500, mouse, Cell-Signaling, Massachusetts, EUA) mais antiSOX2 (rabbit, 1:500, Millipore, Massachusetts, EUA) ou com anti-parvalbumina (1:500, mouse, Sigma-Aldrich, Montana, EUA) mais anti-FOSB (1:500, rabbit, Cell-Signaling, Massachusetts, EUA), "overnight" a $18^{\circ} \mathrm{C}$ sob agitação. Posteriormente, as secções foram lavadas três vezes comTBS e incubadas com anticorpo secundário por 1,5h (anti-rabbit AlexaFluor 488 e anti-mouse AlexaFluor 594; Invitrogen, Massachusetts, EUA). Para visualização do hipocampo e do córtex, os tecidos foram expostos por 10 min a uma solução 1:100000 de Hoechst (solução estoque a $2 \mu \mathrm{g} / \mathrm{mL}$ ).

\subsubsection{Aquisição e quantificação das imagens}

\subsubsection{Quantificação de BrdU/DCX/NeuN, GFAP/SOX2 e PV/FOSB}

As células BrdU positivas localizadas na camada granular/subgranular do giro denteado foram visualizadas e manualmente quantificadas com o aucílio de um microscópio Leica TSE-SPE (Leica, Wetzlar, Alemanha) na objetiva de 40x. A microscopia confocal (Leica TSE-SPE) foi utilizada para análise de marcações duplas e triplas com as seguintes configurações: BrdU/DCX/NeuN, "smart-gain": 840V; GFAP/SOX2, "smart-gain": 890V; PV/FOSB, "smart gain": 950V. Em todas as analises, o "smart-offset" utilizado era de $-100 \%$, e as células eram traçadas através de " $z$-stacks" (6 planos confocais) e visualizadas em 3D com o auxílio do software Leica X Software (Leica Microsystem, Wetzlar, Alemanha). Para o hipocampo, um mínimo de seis secções contendo ambos hemisférios foram analisadas. O número absoluto de células positivas foi calculado multiplicando o número total de células pela área total analisada e pela distância entre os cortes (CAMPOS et al., 2013). Para as marcações no córtex, um mínimo de oito cortes foi analisado, e a densidade de células foi calculada dividindo o número de total de células positivas pela área analisada. 


\subsubsection{Quantificação de IBA-1 e análise de Sholl}

Células IBA-1 positivas presentes na camada granular do giro denteado foram quantificadas manualmente usando um microscópio de epifluorescência (Olympus, Tóquio, Japão; objetiva de 40x). A densidade de células foi calculada através da divisão do número total de células quantificadas pela área analisada (mensurada na objetiva de 10x). Para a análise de Sholl, células IBA-1 positivas na camada granular foram reconstruídas com auxílio de um microscópio confocal (Leica TSE-SPE, objetiva de 63x, "smart-gain":940V), sendo posteriormente analisadas com o software Imaris ( $v$ 9.3.1) através da função Filament Tracer. Apenas células com corpo celular marcado e com processos visíveis na projeção 3D foram analisadas para avaliação do tamanho total de seus processos e para análise de Sholl, o software foi previamente configurado para que esferas concêntricas de $5 \mu \mathrm{m}$ de raio irradiassem do centro da célula analisada. Quinze células por animal foram analisadas, totalizando setenta e cinco por grupo experimental (HELLWIG, et al., 2016).

\subsubsection{Quantificação de células PV+ FOSB+}

Para quantificação de células $\mathrm{PV}+\mathrm{FOSB}+$, imagens foram obtidas através de microscopia confocal (Leica TSE-SPE) com objetivas de 20x. Células positivas foram manualmente quantificadas com o auxílio do software Leica $\mathrm{X}$ (Leica Microsystem, Wetzlar, Alemanha). Valores foram normalizadas pela área analisada utilizando o mesmo software.

\subsection{Análise estatística}

Todos os dados obtidos foram analisados para avaliar se há distribuição normal através do teste Kolmogorov-Smirnov e homoscedasticidade através do teste de Levene. Resultados obtidos no experimento com animais consanguíneos no NSFT (Fig 4D) e análise SOX2/GFAP (Fig Y) não seguiram tais pré-requisitos e foram analisados pelo teste não-paramétrico de Kruskall- 
Wallis e Mann-Whitney, e seus dados foram representados graficamente como mediana e intervalos interquartil. Caso contrário, os resultados obtidos no experimento 1 e 3 foram analisados pela ANOVA de duas-vias (fator 1: estresse, fator 2: genótipo) e dados coletados no experimento 2 foram analisados pela ANOVA de três-vias (fator 1:estresse, fator 2:genótipo e fator 3:tratamento). Quando apropriado, o post hoc de Duncan foi utilizado. Valores de $\mathrm{p}$ iguais ou menores que 0.05 foram considerados significativos. Dados desses experimentos encontram-se expressos como média \pm erro padrão da média (EPM). 


\section{Capítulo 1:}

Consequências da ausência genética da iNOS em contextos anti e próneurogênicos 


\section{$\underline{\text { Resultados }}$}

\section{Efeito comportamental do CUS em animais iNOS não-consanguíneos}

Foi observado que animais iNOS KO apresentavam uma latência maior para o primeiro episódio de imobilidade no TST sendo este parâmetro não afetado pela exposição ao CUS (ANOVA de duas-vias df=1,16; genótipo: $F=6.52, \quad p<0.05$; estresse: $F=0.64$; interação: $F=0.95$; Fig 2B). Diferente dos animais WT, o tempo total de imobilidade dos animais iNOS KO não foi alterado pela exposição ao CUS (ANOVA de duas-vias $d f=1,16$; genótipo: $F=14.07$, $p<0.05$; estresse: $F=4.27$; interação: $F=8.58, p<0.05$; Fig $3 C$ ).

No que tange respostas comportamentais associadas à ansiedade, 0 NSFT revelou que os animais iNOS KO apresentavam um fenótipo tipo-ansioso o qual não era afetado pelo CUS. Entretanto, a exposição de animais WT ao CUS foi capaz de aumentar a latência para se alimentar no ambiente novo (ANOVA de duas-vias $d f=1,19$; genótipo: $F=7.81, p<0.05$; estresse: $F=1.45$; interação: $F=4.52, p<0.05$; Fig 3D), porém este protocolo não foi capaz de alterar o consumo de ração na caixa-moradia (ANOVA de duas-vias df=1,19; genótipo: $F=2.57$; estresse: $F=0.38$; interação: $F=0.23$; Fig $3 E$ ). Ao avaliar a atividade locomotora no OFT, a qual pode interferir no TST, foi revelado que os animais iNOS KO apresentavam uma hipolocomoção quando comparados aos animais WT (ANOVA de duas-vias $d f=1,19$; genótipo: $F=9.71, p<0.05$; estresse: $F=0.49$; interação: $F=1.29$; Fig 3A). 

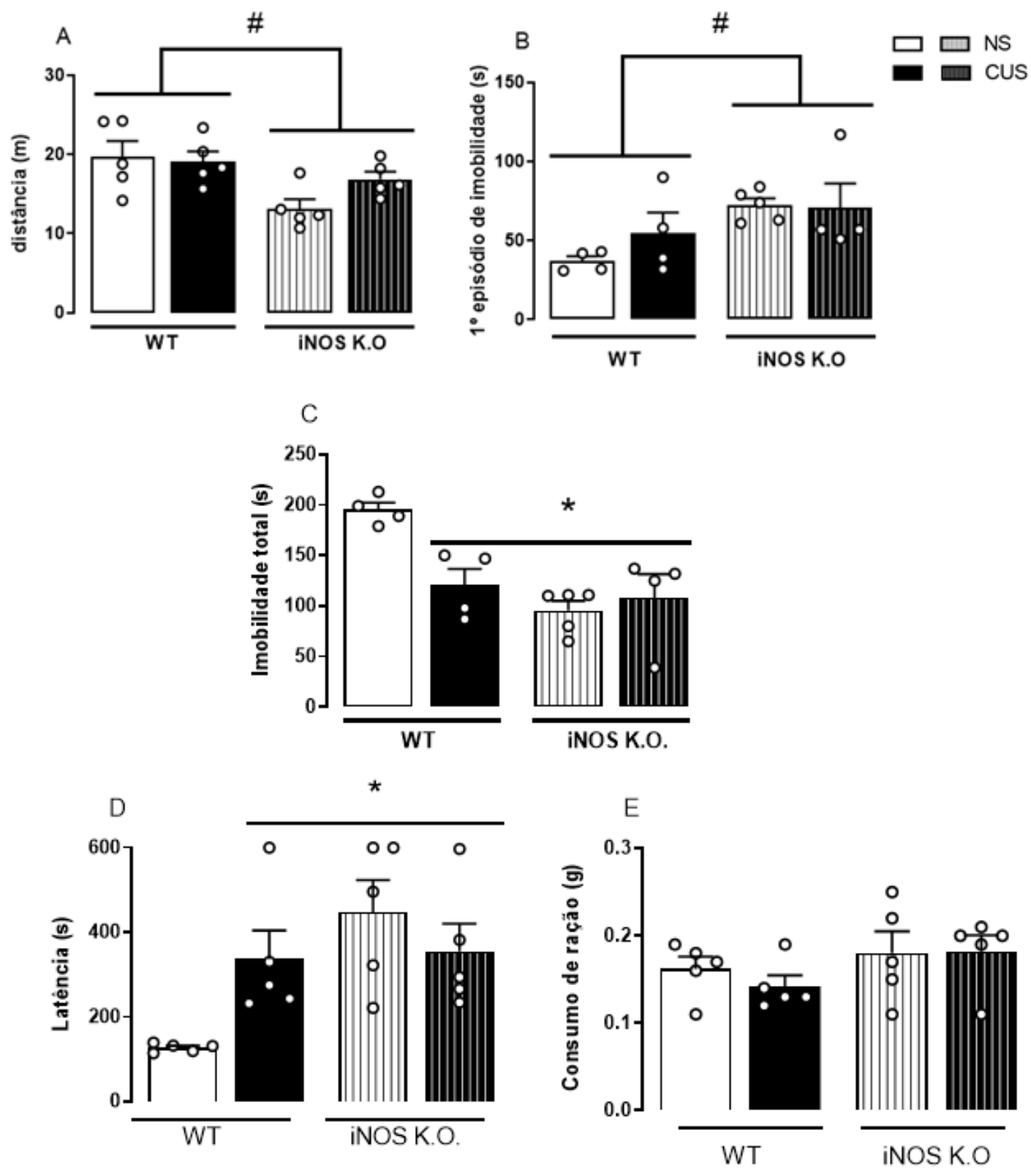

Figura 3: Diferente responsividade ao CUS de animais WT e iNOS K.O. nãoconsanguíneos. (A) Distância total percorrida no campo aberto ( $n=5 / g r u p o)$; latência para primeiro episódio de imobilidade (B) e imobilidade total (C) no TST ( $n=4,4,5$ e 4, respectivamente); (D) latência para se alimentar em um ambiente novo e (E) consumo na caixa-residência durante 5 minutos ( $n=5 / g r u p o$ ). Gráficos mostram média \pm EPM. * $p<0,05$ comparado ao WT NS; \# indica $p<0,05$ no fator genótipo. 


\section{Efeito comportamental do CUS em animais iNOS consanguíneos}

No TST não foi observado alteração na latência para o primeiro episódio de imobilidade nos grupos analisados (ANOVA de duas-vias $\mathrm{df}=1,46$; genótipo: $F=0.70$; estresse: $F=0.01$; interação: $F=1.32$; Fig $3 B$ ), porém observamos um efeito significativo do estresse em animais WT e iNOS KO mice (ANOVA de duas-vias df=1,46; genótipo: $F=0.29$; estresse: $F=7.16$; interação: $F=0.32$; Fig 4C). No NSFT, o teste de Kruskall-Wallis demonstrou a existência de uma diferença significativa entres os grupos $\left(X^{2}=11.63, p<0.05\right)$. Foi observado que os animais iNOS KO NS apresentavam uma tendência no comportamento tipoansioso, porém este não era alterado pelo CUS (Mann-Whitney WT NS x iNOS $N S=20, p=0.07$; WT NS $\times$ iNOS CUS=10, $p<0.05$; iNOS NS $\times$ iNOS CUS= 38). Entretanto, os animais WT apresentaram uma tendência em aumentar a latência para se alimentar no novo ambiente após exposição ao CUS (Mann-Whitney WT NS $x$ WT CUS $=11.5, p=0.051$; Fig 4D). Nenhuma de nossas intervenções foi capaz de alterar o consumo de ração na caixa-residência (ANOVA de duas-vias

$\mathrm{df}=1.48$; genótipo: $F=2.22$; estresse: $F=1.14$; interação: $F=0.64$; Fig $4 \mathrm{E})$ nem a atividade locomotora, avaliado no OFT (ANOVA de duas-vias df=1,48; genótipo: $F=0.14$; estresse: $F=2.66$; interação: $F=1.89$; Fig 4A). 

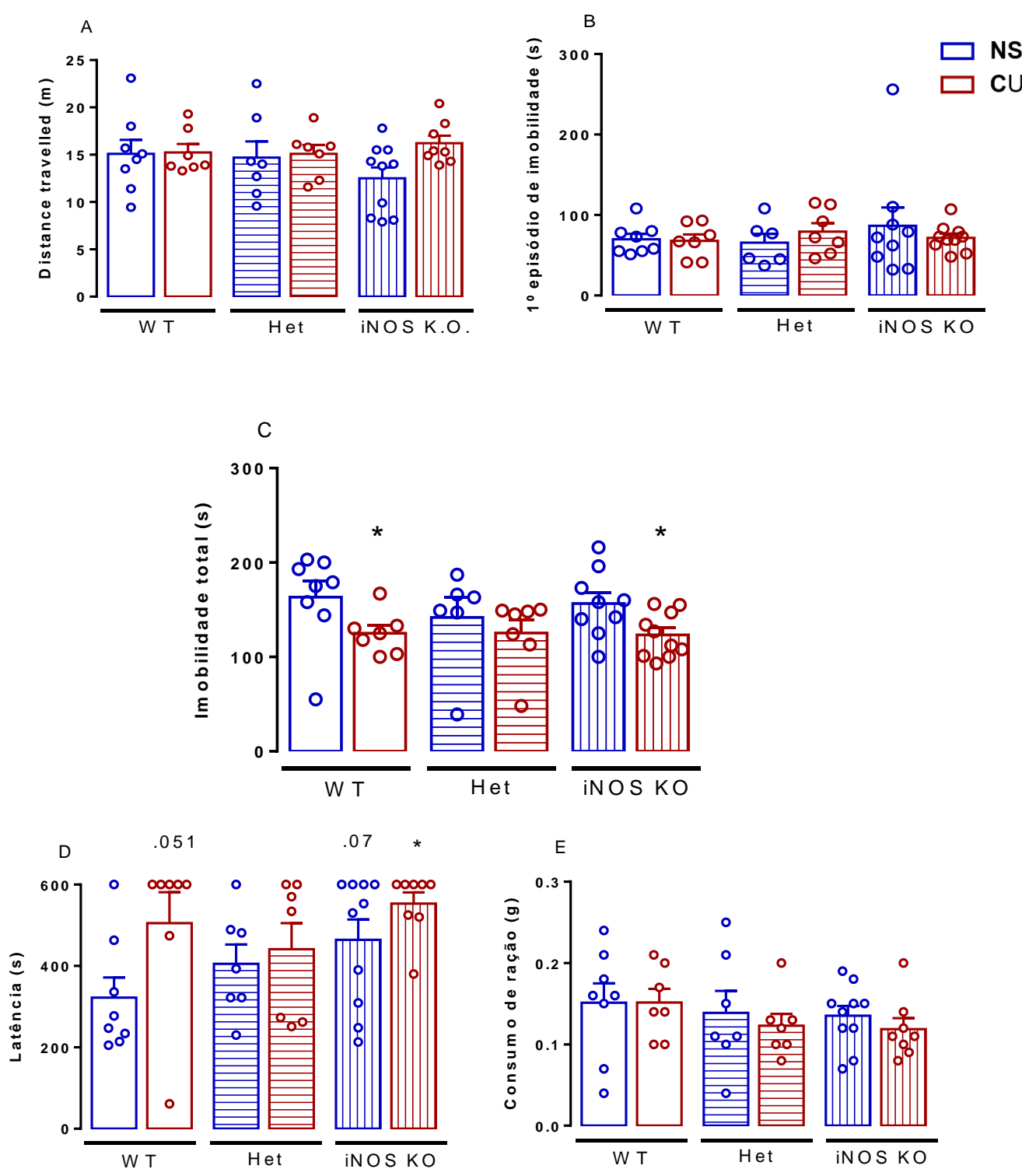

Figura 4: Diferente responsividade ao CUS de animais WT, Het e iNOS K.O. consanguíneos. (A) Distância total percorrida no campo aberto $(n=8,7,7,7,10$ e 10, respectivamente); latência para primeiro episódio de imobilidade (B) e imobilidade total (C) no TST ( $\mathrm{n}=8,7,6,7,9$ e 10, respectivamente); (D) latência para se alimentar em um ambiente novo e (E) consumo na caixa-residência durante 5 minutos ( $n=8,7,7,7,10$ e 10 , respectivamente). Gráficos mostram média \pm EPM. * $p<0,05$ comparado ao WT NS; \# indica $p<0,05$ no fator genótipo. 


\section{Efeito do CUS sobre as micróglias presentes na camada granular}

A exposição ao CUS não foi eficaz em alterar a densidade de células da micróglia presentes na camada granular do giro denteado em nenhum dos grupos analisados (ANOVA de duas-vias $\mathrm{df}=1,19$; genótipo: $\mathrm{F}=0.32$; estresse: $F=2.16$; interação: $F=1.80$; Fig $5 \mathrm{~A}$ ). Ao avaliar a morfologia dessas células, também não foi observado alterações significativas no tamanho total de seus processos (ANOVA de duas-vias df=1,19; genótipo: $F=3.66$; estresse: $F=0.03$; interação: $F=0.47$; Fig $5 B$ ). A análise pormenorizada de Sholl também não revelou alterações significativas no número de intersecções em esferas concêntricas de $5 \mu \mathrm{m}$ nem no número total de intersecções (ANOVA de duasvias $d f=1,19$; genótipo: $F=3.45$; estresse: $F=0.25$; interação: $F=0.01$; Fig $5 E$ ). 
A
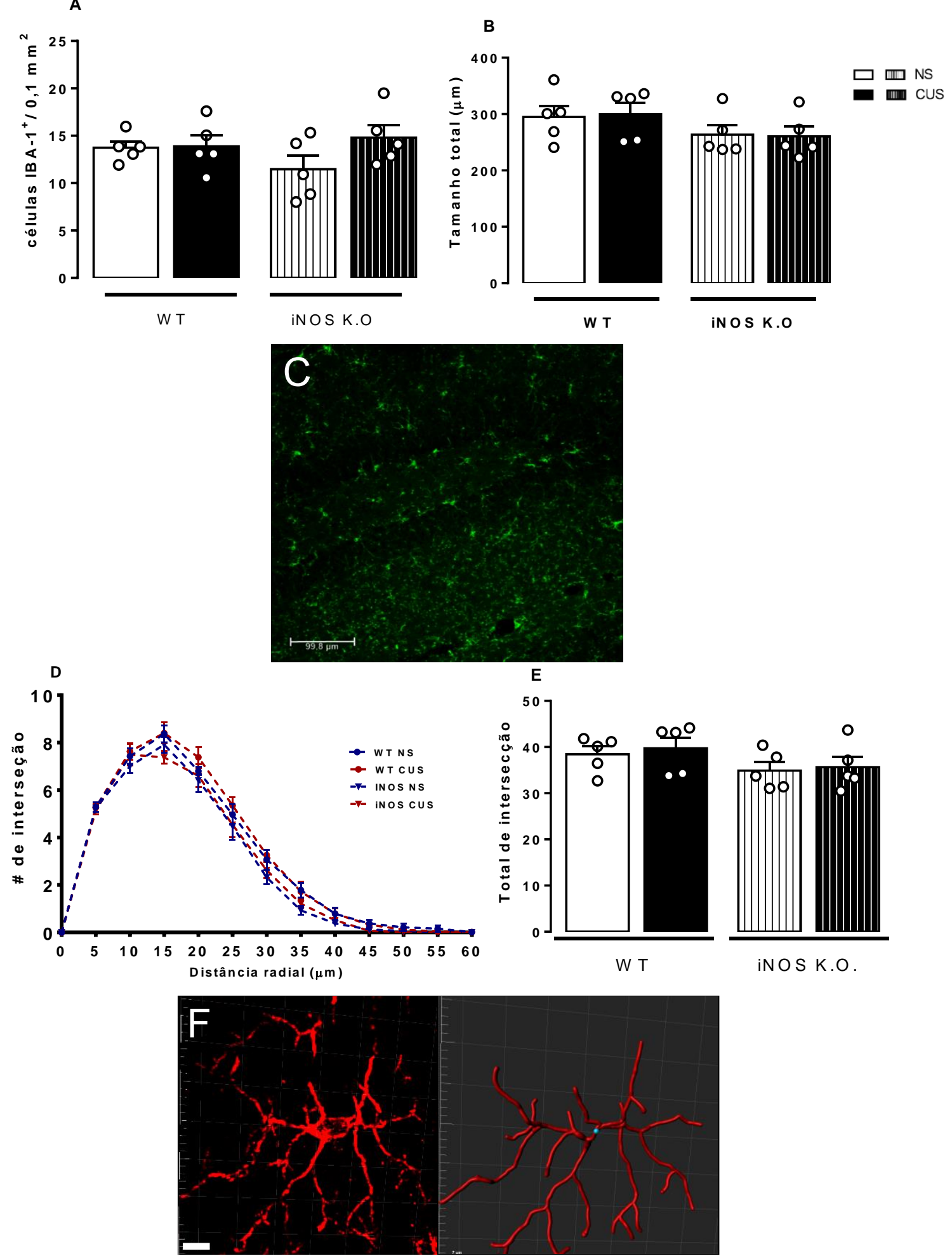

Figura 5: CUS não altera a densidade de micróglias (A) na camada granular ou sua complexidade morfológica (B,D e E) em animais WT ou iNOS KO. Fotomicrografia representativa do giro denteado de animal WT NS (barra $=98,98$ $\mu \mathrm{m})$ e da reconstrução 3D dos filamentos realizados no Imaris $(F$, barra $=7 \mu \mathrm{m})$. Gráficos expressos em média \pm EPM ( $n=5 / g r u p o)$. 
Efeito do CUS sobre densidade de neuroblastos de animais iNOS KO.

Ao avaliar a o número de células que expressam DCX, também denominadas neuroblastos, foi constatado que animais iNOS KO apresentavam um número reduzidos destas células e, que diferente dos animais WT, não eram alteradas pela exposição ao estresse (ANOVA de duas-vias $\mathrm{df}=1,19$; genótipo: $F=35.94, p<0.05$; estresse: $F=5.87, p<0.05$; interação: $F=3.20$; Fig $6 A$ ). No mesmo sentido, o número de células $\mathrm{DCX}+$ presentes na camada granular era menor nos animais iNOS KO quando comparados ao WT, sendo este não alterado pelo protocolo de CUS empregado (ANOVA de duas-via $\mathrm{df}=1,19$; genótipo: $F=36.84, p<0.05$; estresse: $F=1.36$; interação: $F=3.06$; Fig $6 B-C$ ). 

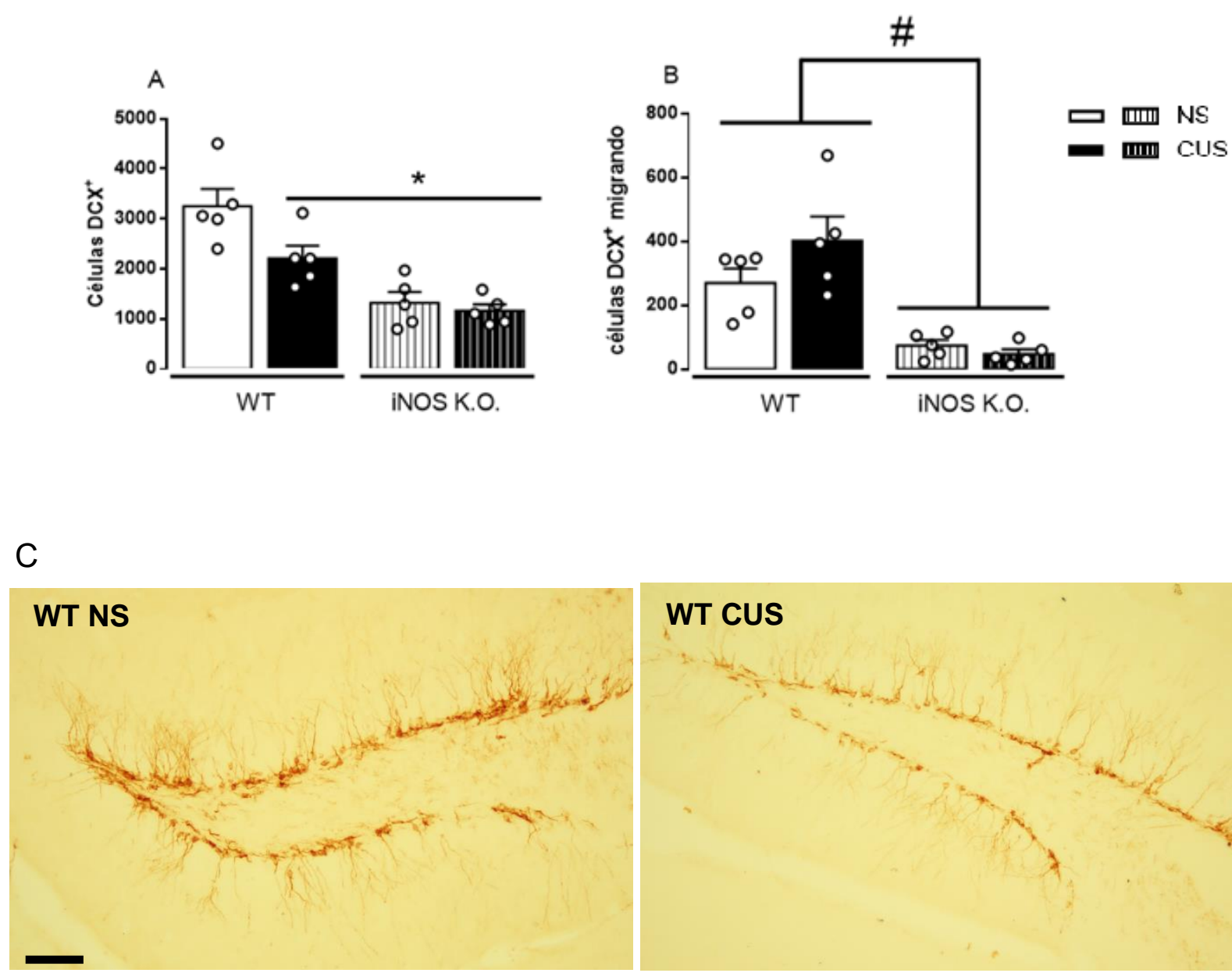

iNOS KO NS

WT CUS
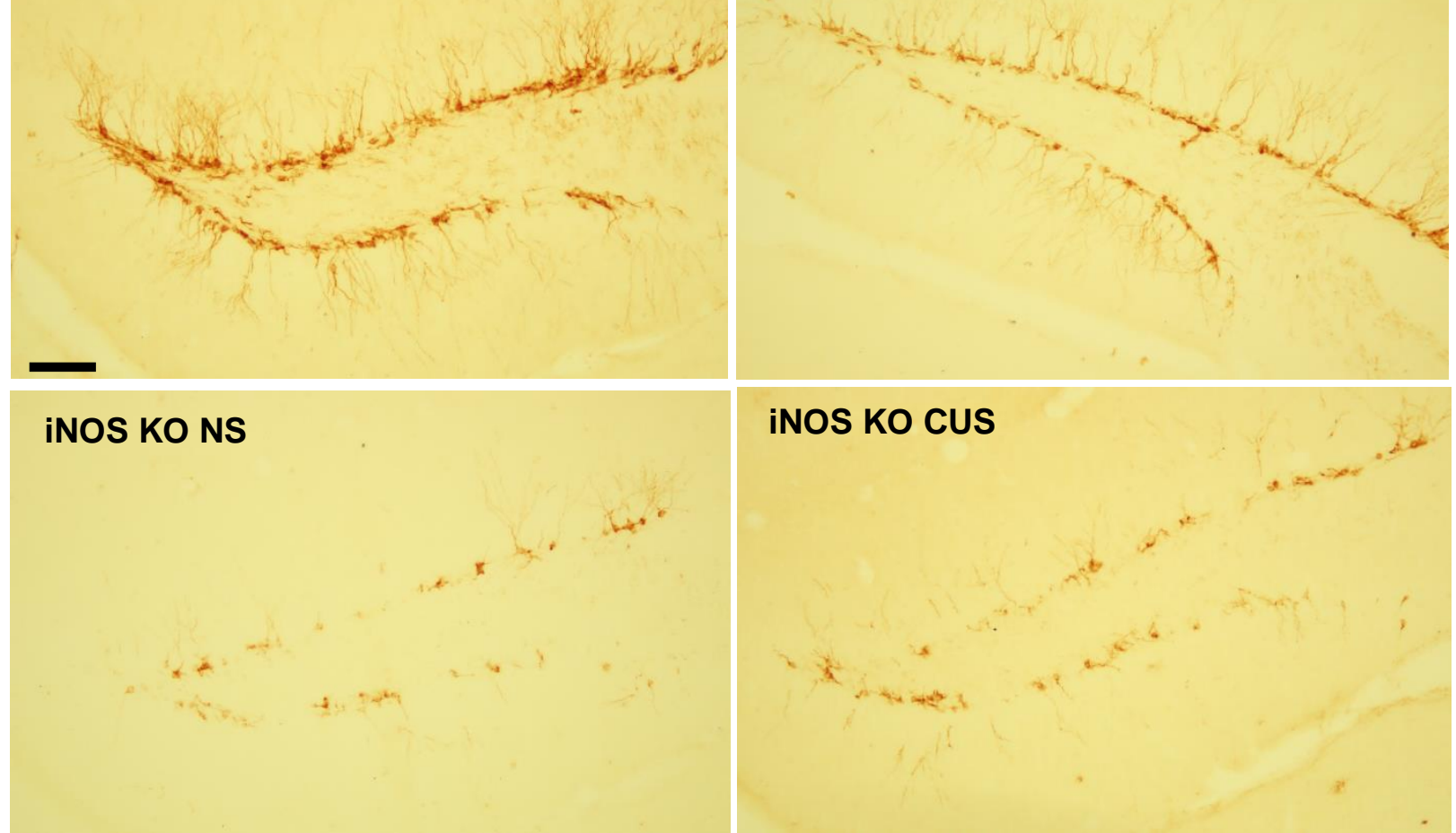

iNOS KO CUS

Figura 6: Quantificação do número de neuroblastos ( $D C X+)$ demonstrou redução basal em animais iNOS KO não afetadas pelo CUS, diferente de WT (A). Migração para camada granular também está reduzida em animais iNOS KO (B). Fotomicrografica $(C)$ representativa de todos os grupos $(n=5 /$ grupo; escala $=100$ $\mu \mathrm{m})$. Gráficos expressos em média \pm EPM. 
Efeito do CUS sobre a sobrevivência de novos neurônios de animais iNOS KO.

Como representado nas figuras 7 e 8 , a avaliação do número de células $\mathrm{BrdU}+23$ dias após sua administração revelou que animais iNOS KO apresentavam uma redução significativa no número destas células no giro denteado, sendo este fenômeno não alterado pela exposição ao CUS (ANOVA de duas-vias $d f=1,17$; genótipeo: $F=21.97, p<0.05$; estresse: $F=2.61$; interação: $\mathrm{F}=3.15$; Fig 7A). A análise fenotípica das células BrdU+ através da tripla marcação com DCX e NeuN revelou que células classificadas como tipo Ilb/ll $(\mathrm{BdrU}+\mathrm{DCX}+\mathrm{NeuN}+$ ) estavam reduzidas em animais iNOS KO (ANOVA de duas-vias $d f=1,17$; genótipo: $F=21.99, p<0.05$; estresse: $F=2.65$; interação: F=3.16; Fig 7B). No mesmo sentido, foi observado uma redução no número de neurônios maduros (NeuN) colocalizados com BrdU. Curiosamente, o CUS foi capaz de reduzir a sobrevivência de novos neurônios até a fase madura (ANOVA de duas-vias $d f=1,17$; genótipo: $F=20.87, p<0.05$; estresse: $F=4.40, p=0.054$; interação: $F=4.63, p<0.05$; Fig 7C). 

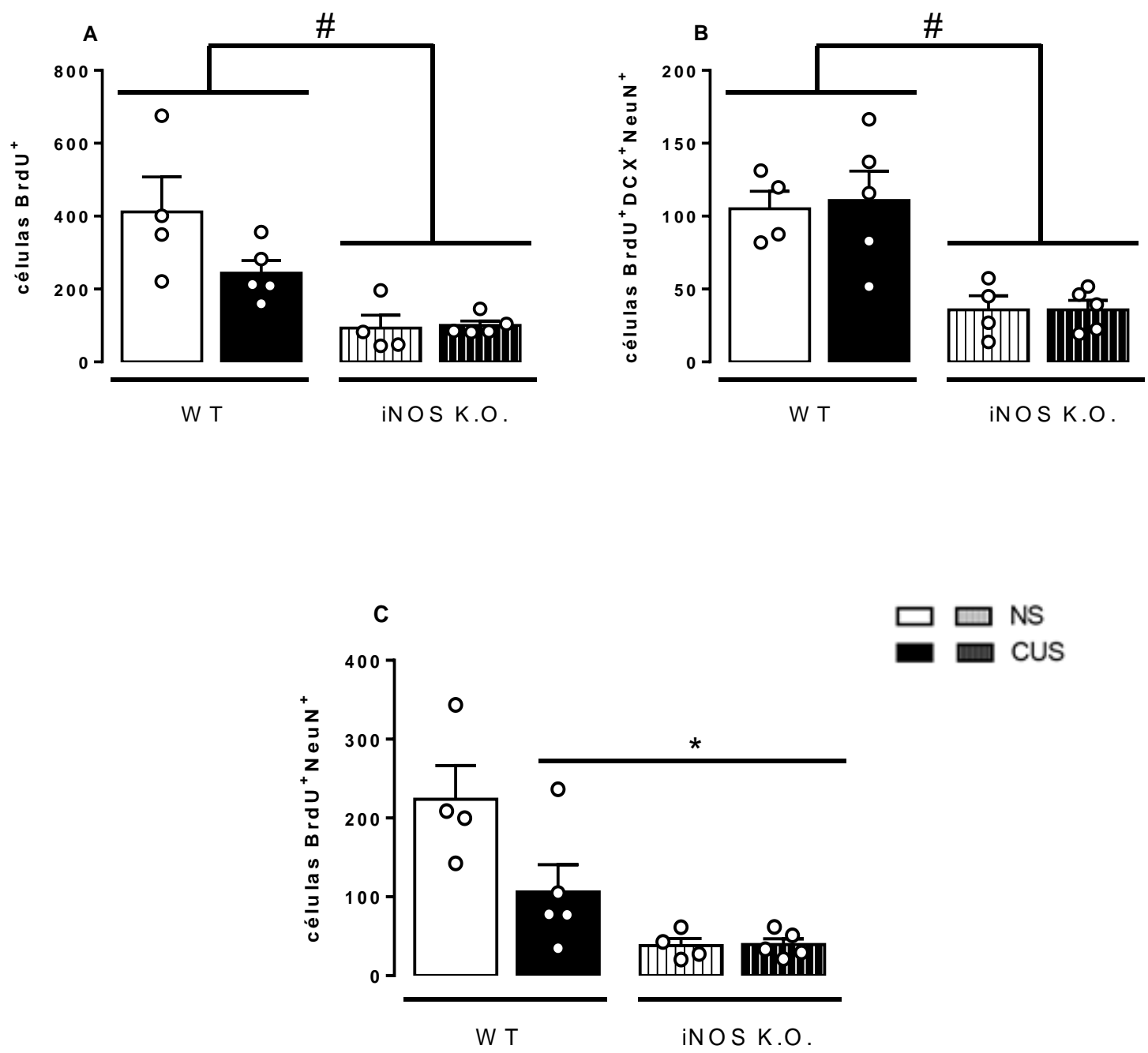


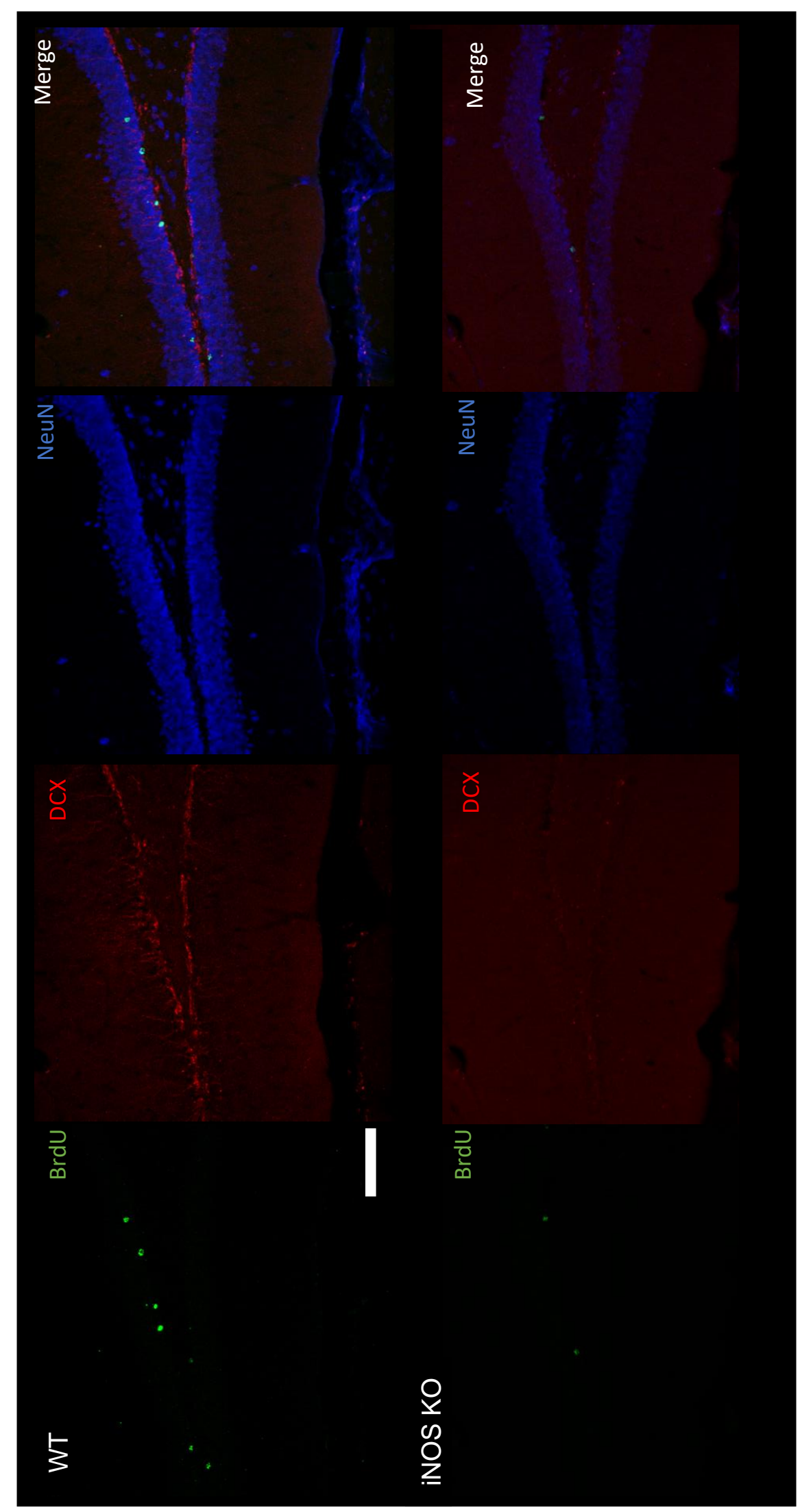

Figura 7: Análise da incorporação de BrdU demonstrou que a redução basal na sobrevivência de novos neurônios gerados durante fase adulta de animais iNOS KO não é alterada pela exposição ao CUS ( $n=4,5,4,5$, respectivamente). * indica $p<0,05$ comparado aos animais WT NS; \# indica diferença significativa no fator genótipo. Gráficos expressos em média \pm EPM. Escala $=100 \mu \mathrm{m}$ 


\section{Efeito do tratamento repetido com escitalopram em animais iNOS KO submetidos ao CUS}

Foi observado que o tratamento com escitalopram não alterou a latência para o primeiro episódio de imobilidade (ANOVA de três-vias df=1,32; genótipo: $F=13.01, p<0.05$; estresse: $F=1.87$; tratamento: $F=0.54$; genótipo $x$ estresse: $F=$ 2.87; genótipo $x$ tratamento: $F=0.18$; estresse $x$ tratamento: $F=0.30$; estresse $x$ tratamento $\times$ genótipo: $F=0.25 .11$, Fig $8 B$ ) nem o tempo total de imobilidade no TST (ANOVA de três-vias $d f=1,32$; genótipo: $F=20.83$, $p<0.05$; estresse: $F=0.54$; tratamento: $F=0.08$; genótipo $x$ estresse: $F=0.62$; genótipo $x$ tratamento: $F=0.88$; stress $x$ tratamento: $F=2.46$; estresse $x$ tratamento $x$ genótipo: $F=1.48$, Fig $8 \mathrm{C}$ ). No NSFT foi observado que o fenótipo tipo-ansioso dos animais iNOS KO não eram alterado pelo tratamento repetido com escitalopram. Por outro lado, os animais WT responderam ao CUS através de um aumento na latência para se alimentar e o escitalopram foi capaz de bloquear este efeito (ANOVA de três-vias $\mathrm{df}=1,33$; genótipo: $\mathrm{F}=42.97, \mathrm{p}<0.05$; estresse: $\mathrm{F}=0.99$; tratamento: $\mathrm{F}=3.68$; genótipo $\mathrm{x}$ estresse: $\mathrm{F}=0.12$; genótipo $X$ tratamento: $F=0.47$; estress $X$ tratamento: $F=2.08$; estresse $x$ tratamento $\times$ genótipo: $F=4.40, p<0.05$, Fig $8 D$ ). Esse efeito não foi acompanhado por uma alteração no consumo de ração como evidenciado pela análise do consumo de ração na caixa-residência (ANOVA de três-vias $d f=1,33$; genótipo: $F=1.08$; estresse: $F=0.94$; tratamento: $F=0.71$; genótipo $x$ estresse: $F=0.17$; genótipo $x$ tratamento: $F=0.35$; estresse $X$ tratamento: $F=1.08$; estresse $X$ tratamento $X$ genótipo: $F=0.03$, Fig $9 E$ ). O OFT revelou que animais iNOS KO apresentaram uma hipolocomoção em comparação aos animais WT, sendo este fenômeno não alterado por nenhuma das intervenções empregadas ANOVA de três-vias $d f=1,33$; genótipo: $F=29.45$ $p<0.05$; estresse: $F=3.05$; tratamento: $F=0.18$; genótipo $x$ estresse: $F=0.53$; genótipo $x$ tratamento: $F=0.32$; estresse $X$ tratamento: $F=0.03$; estresse $X$ tratamento $\mathrm{X}$ genótipo: $\mathrm{F}=0.01$, Fig $8 \mathrm{~A}$ ). 

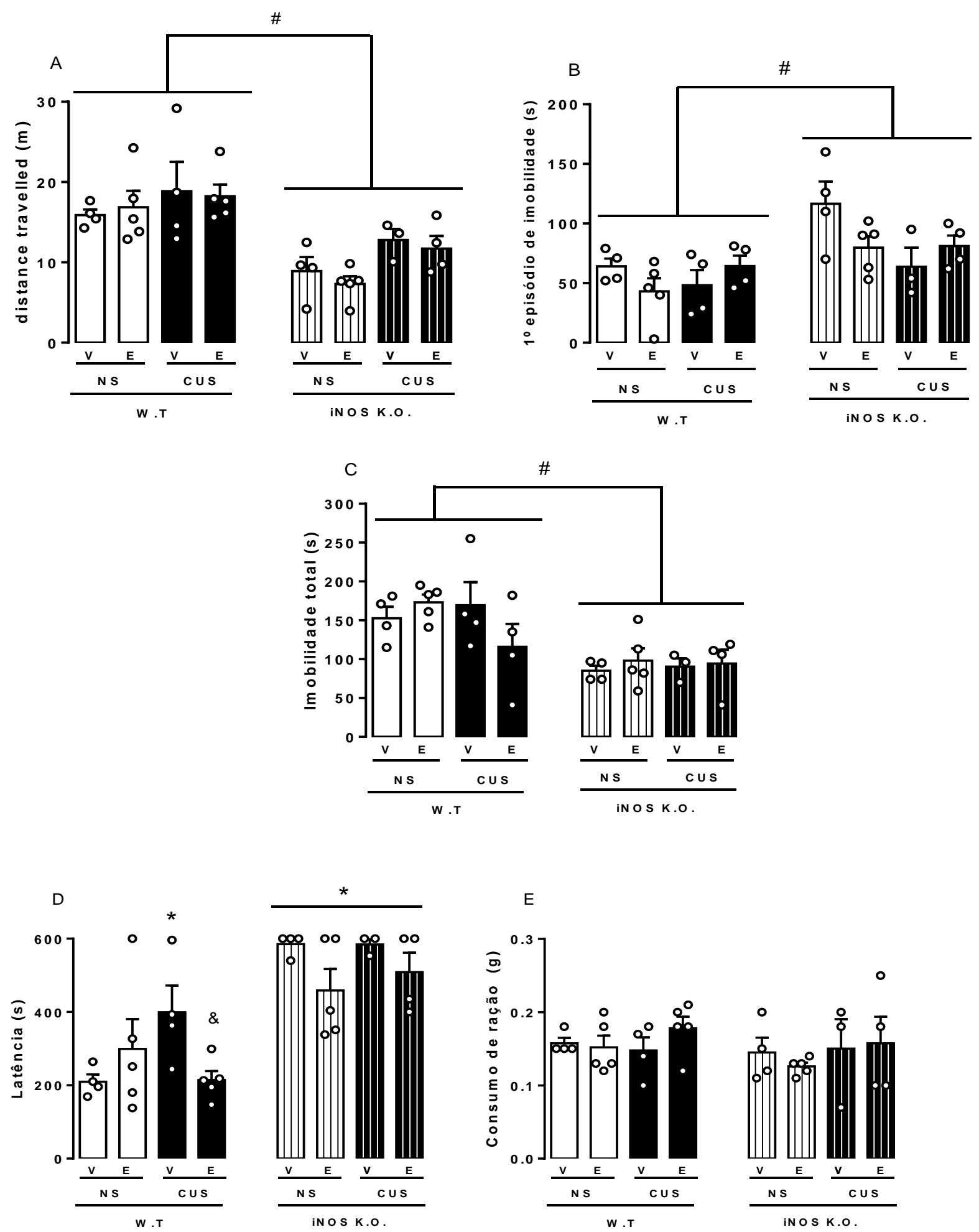

Figura 8: Escitalopram não altera os comportamentos observados em animais iNOS KO. (A): distância total percorrida $(n=4,5,4,5,4,5,3$ e 4, respectivamente; (B) latência para imobilidade e (C) imobilidade total no TST ( $n=4,5,4,4,4,4,3$ e 4 respectivamente; (D): latência para se alimentar no $\mathrm{NSFT}(\mathrm{E})$ : total ração consumida na caixa-moradia ( $n=4,5,4,5,4,5,3$ e 4 respectivamente). ${ }^{*} p<0,05$ comparado a WT NS veículo; \# indica $p<0.05$ no fator genótipo; \& $p<0.05$ comparado com WT CUS veículo. Gráficos expressos em média \pm EPM. 


\section{Efeito do tratamento repetido com escitalopram na densidade de neuroblastos de animais iNOS KO submetidos ao CUS}

A tratamento com escitalopram não foi eficaz em alterar a densidade de neuroblastos no giro denteado de animais iNOS KO. Entretanto, foi observado que este fármaco foi capaz de aumentar de aumentar a densidade dos mesmo em animais WT. Curiosamente, foi observado que a exposição ao CUS aumentou a densidade dessas células no giro denteado de animais WT, porém a combinação do tratamento com o estresse não foi capaz de produzir alterações no número de neuroblastos em animais WT (ANOVA de três-vias $\mathrm{df}=1,33$; genótipo: $F=128.56, p<0.05$; estresse: $F=1.98$; tratamento: $F=0.05$; genótipo $x$ estresse: $F=2.18$; genótipo $x$ tratamento: $F=0.70$; estresse $x$ tratamento: $F=$ 20.93, $p<0,05$; estresse $x$ tratamento $x$ genótipo: $F=16.87, p<0,05$ Fig $9 A) . A$ avaliação da migração de neuroblastos para camada granular revelou que animais INOS KO apresentavam uma redução nessa taxa que não era alterada pelas intervenções utilizadas (ANOVA de três-vias df=1,33; genótipo: $F=108.78$, $p<0.05$; estresse: $F=0.45$; tratamento: $F=2.34$; genótipo $x$ estresse: $F=0.68$; genótipo $\mathrm{x}$ tratamento: $\mathrm{F}=2.15$; estresse $\mathrm{x}$ tratamento: $\mathrm{F}=1.89$; stress $\mathrm{x}$ tratamento $\times$ genótipo: $F=1.05$, Fig 9B). 

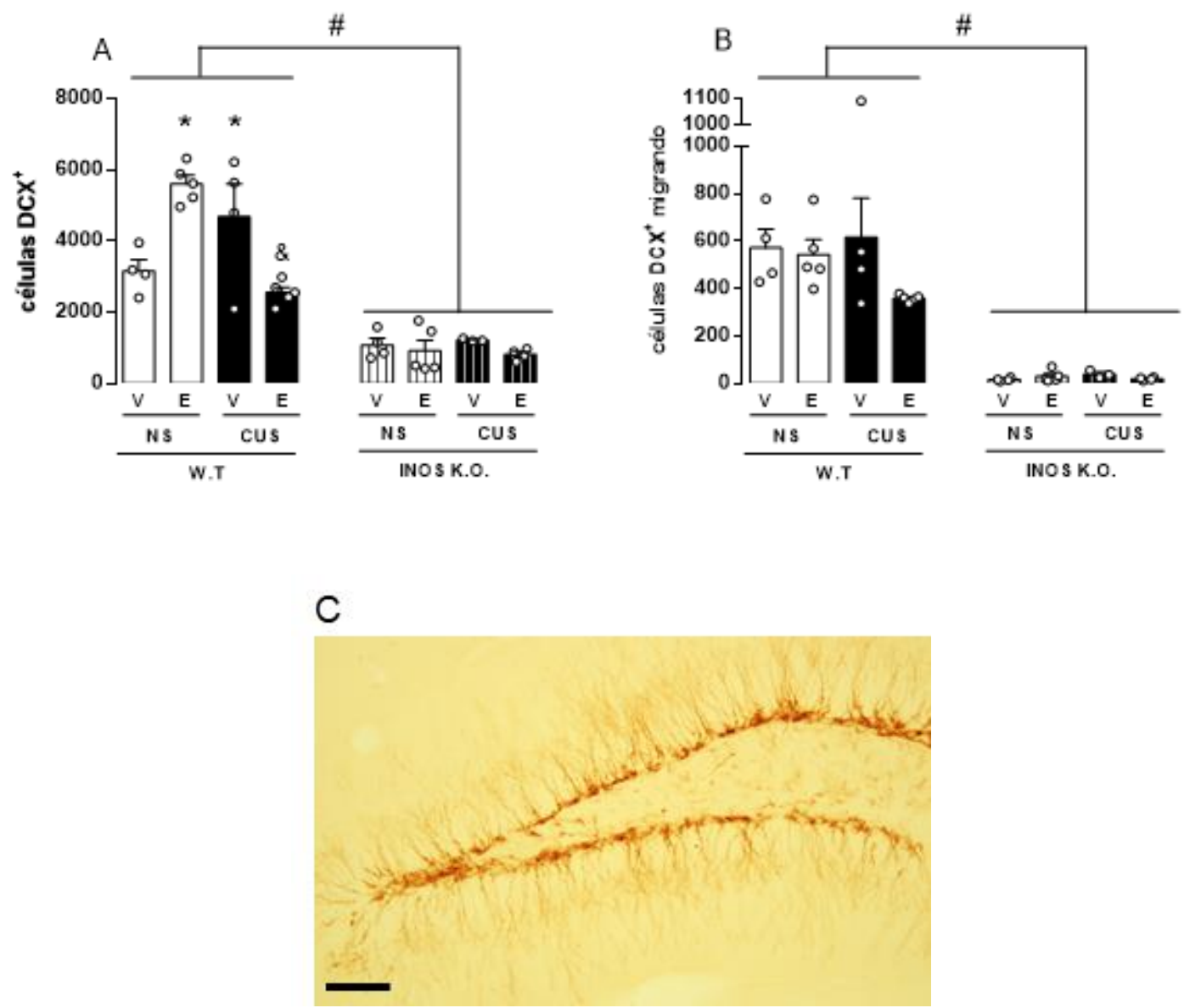

Figura 9: Tratamento com escitalopram não alterou o número de neuroblastos presentes no giro denteado $(A)$ nem o número de neuroblastos migrando para camada granular (B) de animais iNOS ( $n=4,5,4,5,4,5,3$ and 4 , respectivamente). Fotomicrografia representativa de um animal WT NS veículo. * $p<0,05$ em comparação ao animal WT NS veículo; \# indica $p<0,05$ para fator genótipo; \& indica $p<0,05$ em comparação ao animal WT CUS veículo. Gráficos expressos em média \pm EPM. 


\section{Efeito do tratamento repetido com escitalopram na sobrevivência de novos neurônios de animais iNOS KO submetidos ao CUS}

Os animais iNOS KO apresentaram uma sobrevivência menor de células que incorporaram BrdU 23 dias antes da análise imunohistológica. Entretanto, nenhuma de nossas manipulações foi capaz de alterar esses níveis. Curiosamente, na mesma direção dos resultados com DCX (seção 4.7), os animais injetados com escitalopram ou que passaram pelo protocolo do CUS, tiveram um aumento significativo no número de células BrdU+ (ANOVA de trêsvias $d f=1,33$; genótipo: $F=18.15, p<0.05$; estresse: $F=0.40$; tratamento: $F=0.14$; genótipo $x$ estresse: $F=0.48$; genótipo $x$ tratamento: $F=0.02$; estresse $x$ tratamento: $F=5.17, p<0.05$; estresse $x$ tratamento $x$ genótipo: $F=5.58, p<0.05$ Fig 10A). A análise fenotípica das células BrdU+ revelou que nenhuma de nossas intervenções foram capazes de alterar os valores basais das células tipo $\mathrm{Ilb} / \mathrm{lll}$ em animais iNOS KO ou WT (ANOVA de três-vias $\mathrm{df}=1,33$; genótipo: $F=15.85, p<0.05$; estresse: $F=0.27$; tratamento: $F=0.44$; genótipo $x$ estresse: $F=$ 0.12; genótipo $x$ tratamento: $F=0.01$; estresse $x$ tratamento: $F=3.41$; estresse $x$ tratamento $\times$ genótipo: $F=3.58$ Fig 10B). No mesmo sentido, nenhuma de nossas manipulações alterou a sobrevivência de novos neurônios maduros em animais iNOS KO e WT (ANOVA três-vias df=1,33; genótipo: $F=8.64, p<0.05$; stress: $F=0.01$; tratamento: $F=0.35$; genótipo $x$ estresse: $F=0.22$; genótipo $x$ tratamento: $F=0.06$; estresse $\times$ tratamento: $F=0.55$; estresse $\times$ tratamento $\times$ genótipo: $F=$ 1.11, Fig 10C). 

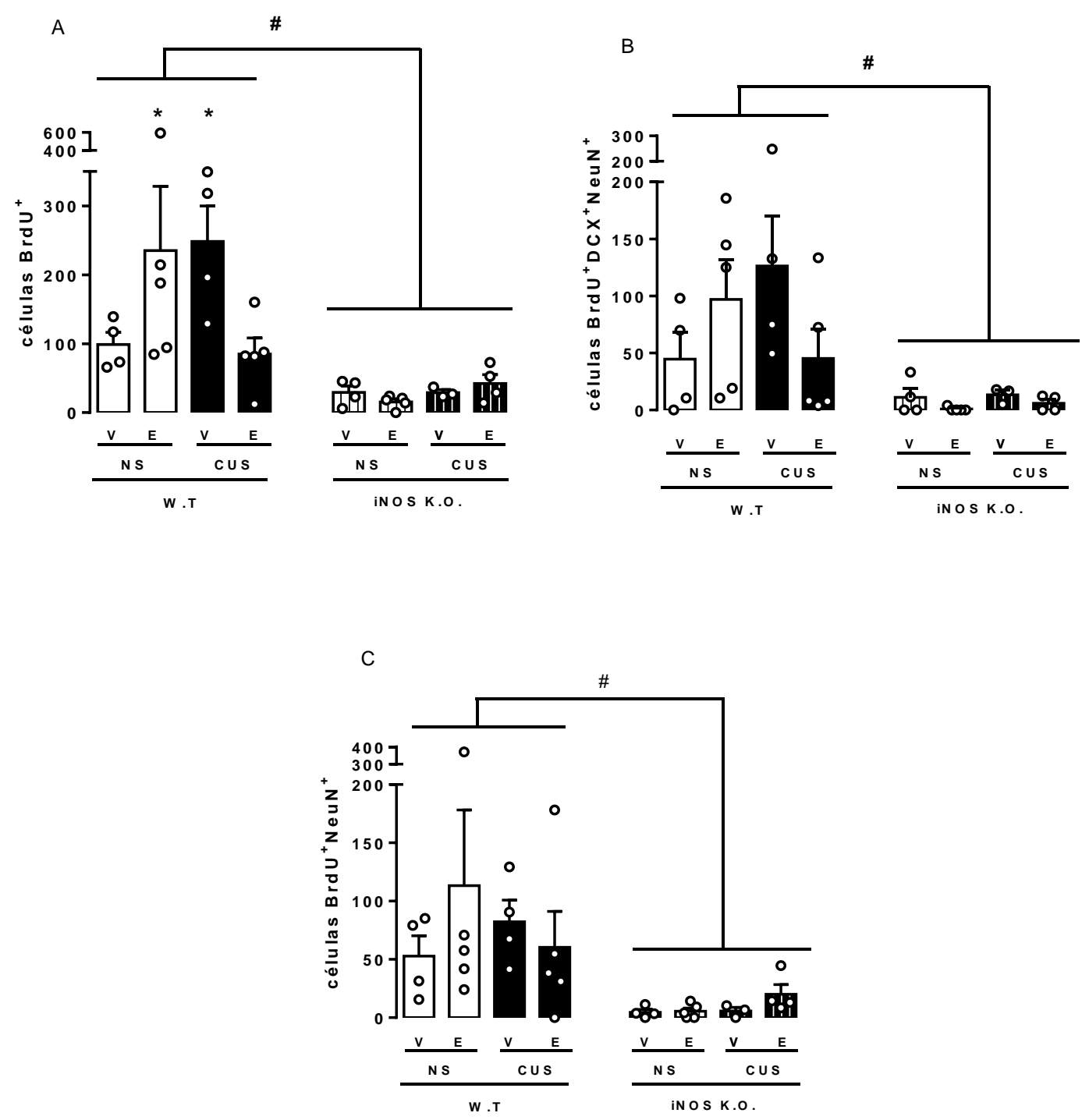


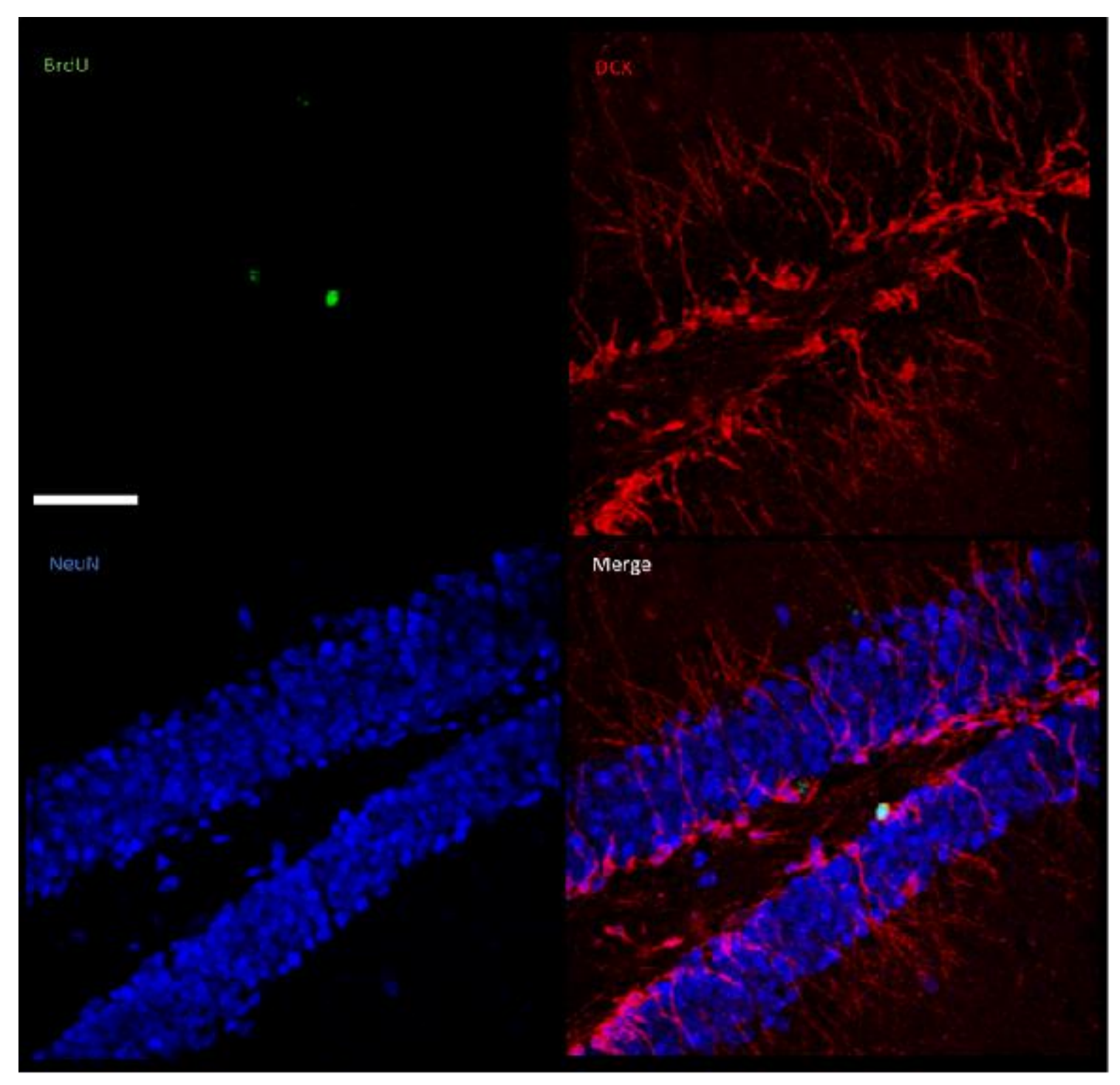

Figura 10: A análise de sobrevivência por incorporação e retenção de BrdU demonstrou que animais iNOS KO não são responsivos ao CUS ou ao tratamento repetido com escitalopram no número total de células $\mathrm{BrdU}^{+}(\mathrm{A})$, no número de células $\mathrm{BrdU}^{+} \mathrm{DCX}+\mathrm{NeuN}^{+}(\mathrm{B})$, nem no número de células $\mathrm{BrdU}+\mathrm{DCX}^{-}$ $\mathrm{NeuN}^{+}\left(\mathrm{n}=4,5,4,5,4,5,3\right.$ e 4, respectivamente). ${ }^{*} \mathrm{p}<0,05$ comparado a animais WT NS veículo; \# indica diferença no fator genótipo. Gráficos expressos em média \pm EPM. Escala $=50 \mu \mathrm{m}$. 
Efeito do tratamento repetido com escitalopram sobre as células tronco neurais de animais iNOS KO submetidos ao CUS

A análise de células tipo I $\left(\mathrm{GFAP}^{+} \mathrm{SOX} 2^{+}\right)$revelou que não diferença significativa entre o número de NSCs presente no nicho neurogênico de animais WT e iNOS KO ( $X^{2}=4,59$, Fig 11A). Curiosamente, o número de células GFAPSOX2+ era significativamente maior nos animais iNOS KO, sendo este efeito não alterado por nenhumas das intervenções utilizadas (ANOVA de três-vias $d f=1,33$; genótipo: $F=6.44, p<0.05$; estresse: $F=0.52$; tratamento: $F=0.02$; genótipo $x$ estresse: $F=0.62$; genótipo $x$ tratamento: $F=0.46$; estresse $x$ tratamento: $F=$ 0.83; estresse $x$ tratamento $x$ genótipo: $F=0.75$, Fig 11B). 

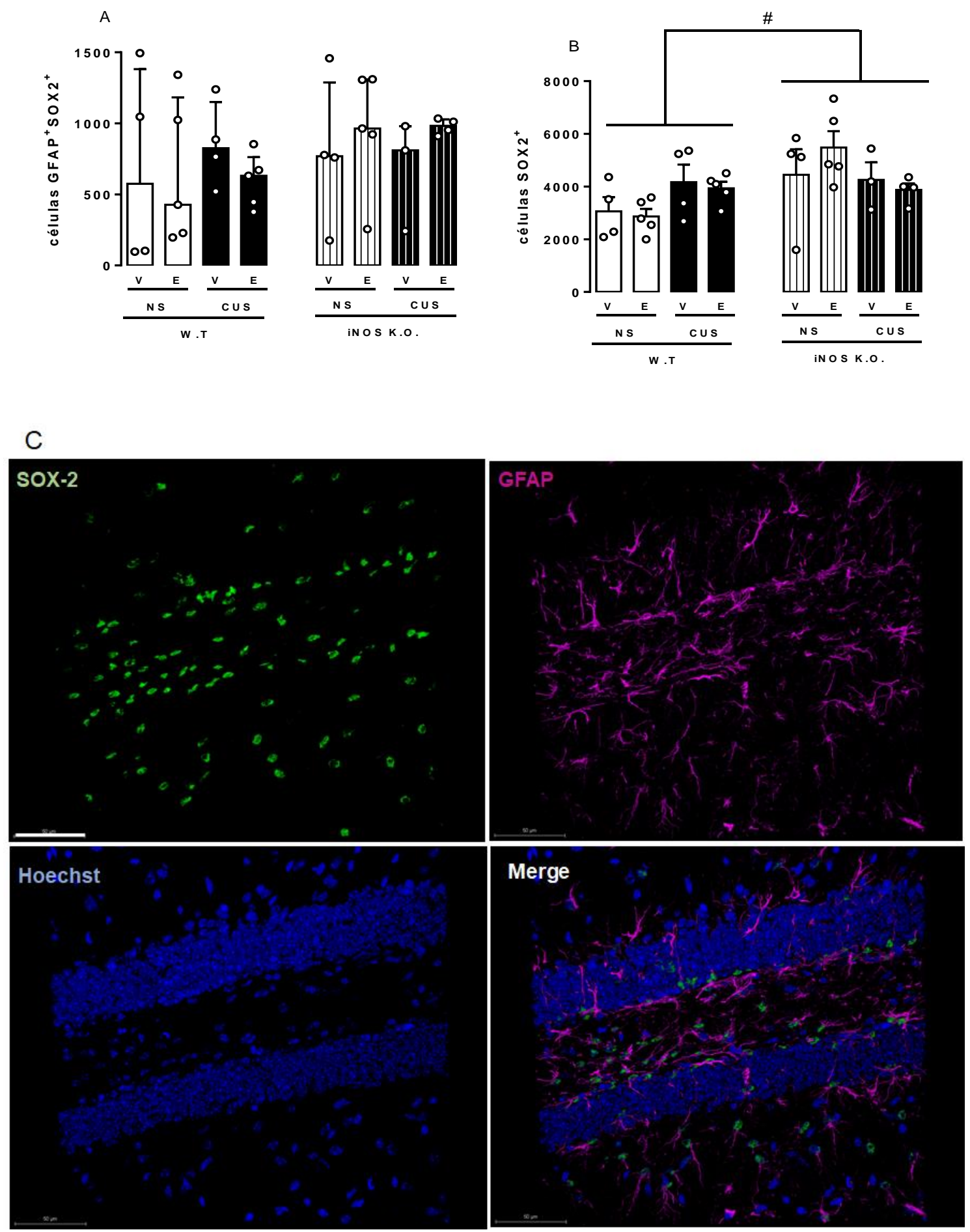

Figura 11: Nicho neurogênico de animais iNOS KO não difere dos animais WT (A). Células tipo lla mostram-se elevadas em animais iNOS KO, mas não são afetadas pelo tratamento com escitalopram ou após o CUS (B). Fotomicrografia representativa de um animal WT NS veículo (C; escala $=50 \mu \mathrm{m}) .(\mathrm{n}=4,5,4,5,4,5,3$ e 4, respectivamente). \# $p<0,05$ no fator genótipo. Gráficos expressos em mediana e intervalo interquartil $(A)$ e média \pm EPM (B). 


\section{Efeito do tratamento repetido com escitalopram sobre recrutamento de células parvalbuminas/FOSB positivas no córtex pré-límbico de animais iNOS KO submetidos ao CUS}

Foi observado que animais iNOS KO apresentavam um maior recrutamento da região do PrL em comparação com animais WT. Ademais, a exposição ao CUS aumentou de forma significativa o número de células FOSB+ no PrL de animais WT tratados com veículo (ANOVA de três-vias $d f=1,31$; genótipo: $F=5.55, p<0,05$; estresse: $F=0.57$; tratamento: $F=6.43, p<0.05$; genótipo $x$ estresse: $F=6.07, p<0.05$; genótipo $x$ tratamento: $F=3.95$; estresse $x$ tratamento: $F=0.01$; estresse $x$ tratamento $\times$ genótipo: $F=2.99$, Fig 12A). Entretanto, não foi encontrado diferenças significativas na densidade de células $\mathrm{PV}^{+}$no $\mathrm{PrL}$ entre os grupos analisados (ANOVA de três-vias $\mathrm{df}=1,31$; genótipo: $F=0.38$; estresse: $F=3.81$; tratamento: $F=0.01$; genótipo $x$ estresse: $F=0,23$; genótipo $x$ tratamento: $F=1,71$; estresse $x$ tratamento: $F=0.45$; estresse $x$ tratamento $\times$ genótipo: $F=0.02$, Fig $12 \mathrm{~B}$ ), nem no número de células $\mathrm{PV}^{+} \mathrm{FOSB}^{+}$ (ANOVA de três-vias $d f=1,31$; genótipo: $F=0.02$; estresse: $F=0.32$; tratamento: $F=0.31$; genótipo $x$ estresse: $F=4.03$; genótipo $x$ tratamento: $F=3.53$; estresse $x$ tratamento: $F=2.06$; estresse $x$ tratamento $\times$ genótipo: $F=0.79$, Fig $12 \mathrm{C}$ ). 

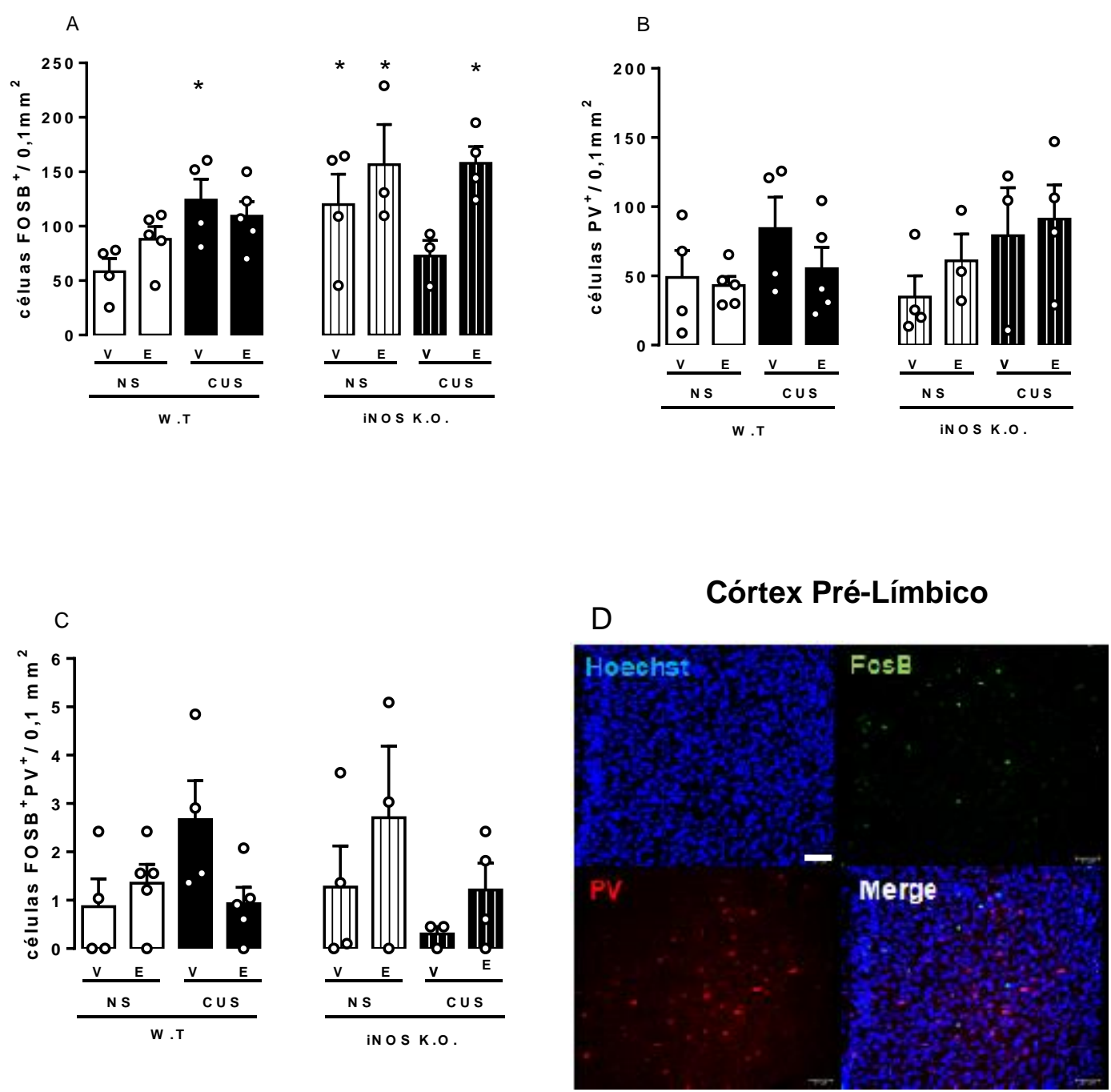

Figura 12: Animais iNOS KO apresentam um maior recrutamento da porção PrL do córtex de células que não expressam PV (A), porém não apresentam alterações na população de interneurônios que positivos para parvalbumina (B). Não foi observado alterações no recrutamento de células PV nas manipulações utilizadas (C; escala $=100 \mu \mathrm{m})$. ( $n=4,5,4,5,4,3,3$ e 4, respectivamente). ${ }^{*} p<0,05$ comparados a animais WT NS veículo. Gráficos expressos como média \pm EPM. 
Efeito do tratamento repetido com escitalopram sobre recrutamento de células parvalbuminas/FOSB positivas no córtex infralímbico de animais iNOS KO submetidos ao CUS

A avaliação do número de células $\mathrm{FOSB}^{+}$no córtex IL revelou que nenhuma de nossas intervenções promoveram alterações significativas (ANOVA de três-vias $d f=1,31$; genótipo: $F=0.26$; estresse: $F=0.07$; tratamento: $F=2.71$; genótipo $x$ estresse: $F=1,65$; genótipo $x$ tratamento: $F=1.31$; estresse $x$ tratamento: $F=2.87$; estresse $x$ tratamento $x$ genótipo: $F=0.15$, Fig $13 \mathrm{~A}$ ). Também não foi observado alterações significativas na densidade de células $\mathrm{PV}^{+}$ (ANOVA de três-vias $d f=1,31$; genótipo: $F=0.14$; estresse: $F=2,90$; tratamento: $F=0.35$; genótipo $x$ estresse: $F=0.10$; genótipo $x$ tratamento: $F=3.29$; estresse $x$ tratamento: $F=0.37$; estresse $x$ tratamento $x$ genótipo: $F=0.06$, Fig 13B) nem no número de células $\mathrm{PV}^{+} \mathrm{FOS}^{+}$(ANOVA de três-vias df=1,31; genótipo: $\mathrm{F}=1.55$; estresse: $F=1.16$; tratamento: $F=0.14$; genótipo $x$ estresse: $F=0.04$; genótipo $x$ tratamento: $F=1.11$; estresse $x$ tratamento: $F=0.11$; estresse $x$ tratamento $x$ genótipo: $F=0.01$, Fig 13C). 

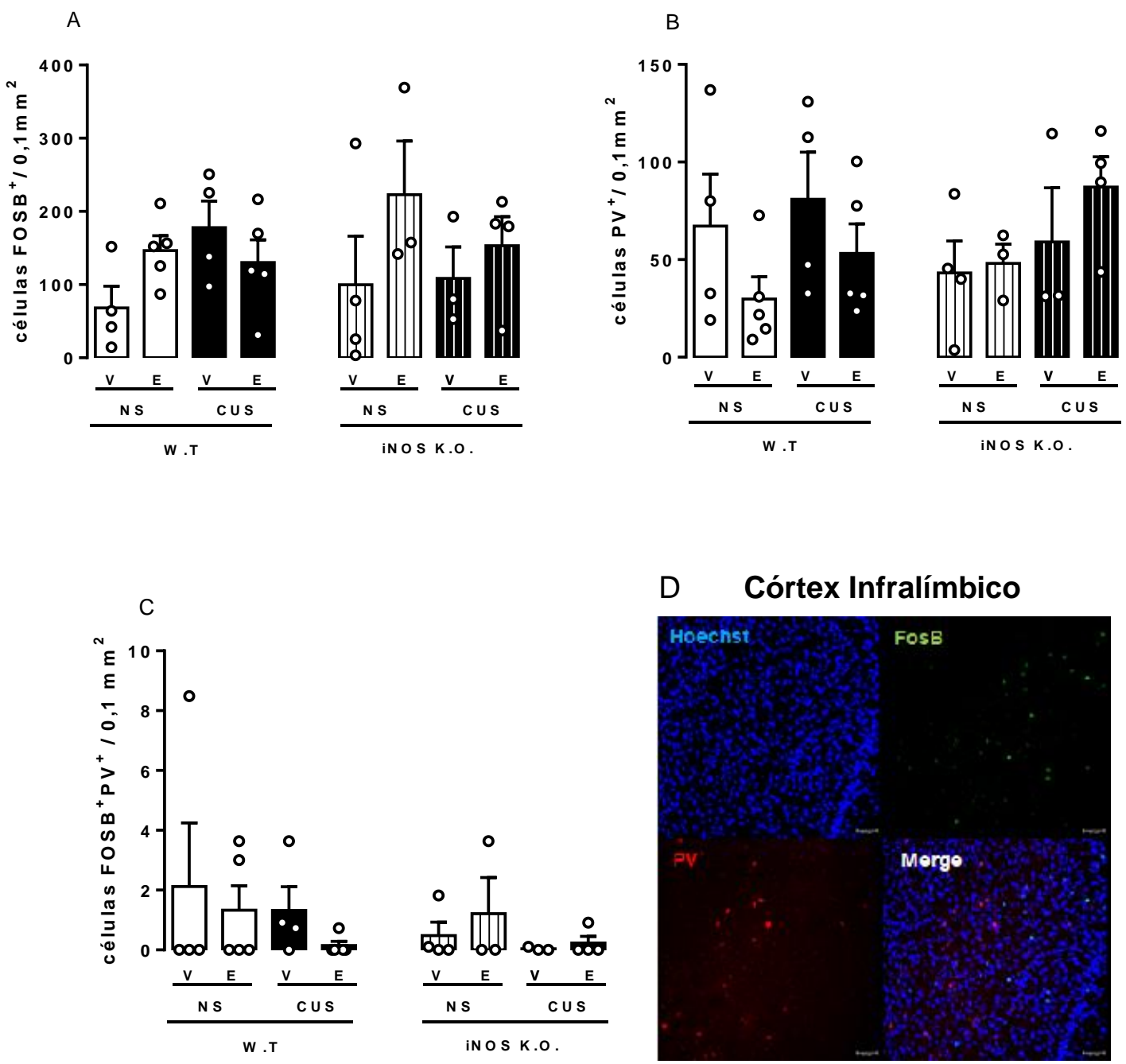

Figura 13: Animais iNOS KO ou o CUS não promove alterações no recrutamento da porção IL do córtex $(A)$, não altera a densidade de células $P V$ nessa região (B) e não modifica o recrutamento de células PV (C; escala $=100 \mu \mathrm{m})$. ( $n=4,5,4,5,4,3,3$ e 4, respectivamente). Gráficos expressos como média \pm EPM. 


\section{Discussão- Capítulo 1}

Os resultados obtidos no presente capítulo da tese não corroboraram a hipótese inicial de que a enzima iNOS seria essencial para a diminuição do processo de AHN após exposição ao estresse. Curiosamente, os resultados demonstraram que esta enzima parece ser de extrema importância para manutenção de fases tardias do processo neurogênico adulto, a qual envolve a expressão da proteína associada a microtúbulo, DCX, a migração dos neuroblastos da camada SGZ para camada granular e sua maturação.

Inicialmente, nossos resultados comportamentais vão de encontro a dados presentes na literatura em animais não estressado cronicamente. Nesse sentido, trabalhos já demonstraram que animais iNOS KO apresentam um fenótipo tipo-antidepressivo, descrito como uma resposta de enfrentamento ativa nos testes de TST e no FST (MONTEZUMA et al., 2012), e um fenótipo tipoansioso, como evidenciado pelos trabalhos de Buskila e colaboradores (2007) que utilizaram o teste de labirinto em cruz-elevado, e o trabalho de Lisboa e col. (2015) que utilizaram o modelo do medo condicionado ao contexto. Entretanto, nenhum resultado na literatura, até o presente momento, descreveu o resultado da exposição de animais iNOS KO a protocolos de estresse crônico.

De forma inesperada, nossos animais WT estressados apresentaram respostas de enfrentamento ativa no TST. Esse resultado fomenta a discussão acerca da validade deste teste para respostas tipo-depressivas. Corroborando nossas observações, um estudo prospectivo com o intuito de identificar as alterações comportamentais induzidas pelo CUS em distintas cepas de camundongos evidenciou que animais C57BI6 estressados apresentavam resposta de enfretamento ativa no TST, mas não no FST (MINEUR et al., 2006). Além disso, outros trabalhos na literatura não reportaram alteração de animais estressados neste teste (MONTEIRO et al., 2015; ELIWA et al., 2021; TROUBAT et al., 2021). Devido a essas inconsistências, atualmente alguns pesquisadores propõem que este teste não reflita de forma propriamente dita um fenótipo que possa ser associado à depressão, mas estaria associado a capacidade adaptativa a um estressor agudo (COMMONS et al., 2017). 
De forma menos controversa, nossos resultados obtidos com o NSFT evidenciaram que o CUS aplicado nos animais WT foi capaz de evocar respostas tipo-ansiosa e corroboraram o fenótipo tipo-ansioso dos animais iNOS KO, sendo este não exacerbado pelo CUS. Esse resultado encontra-se em consonância com resultados obtidos em nosso grupo (CAMPOS et al., 2013; em processo de publicação SCARANTE et al., 2021; AGUIAR et al., 2021) e àqueles presentes na literatura (JUNG et al., 2014; FOGAÇA et al., 2018; ELIWA et al., 2021). Embora não tenhamos nos aprofundado no estudo dos animais heterozigotos, futuros estudos devem ser realizados para melhor compreender seu fenótipo comportamental, visto que eles não apresentaram responsividade comportamental após exposição CUS, sugerindo que a heterozigose para a iNOS parece promover um fenótipo resiliente as alterações comportamentais induzidas pelo estresse. Ademais, embora tenha sido descrito na literatura uma enzima iNOS sem atividade devido ao seu truncamento induzido por uma mutação genética, esse fenômeno é muito raro e possivelmente letal (DRUTMAN et al., 2020).

Posteriormente, avaliamos como estaria a densidade e reatividade das células da micróglia no giro denteado destes animais, uma vez que dados na literatura sugerem que essas células sejam mediadores importantes na plasticidade do SNC e altamente responsivas ao estresse (TYNAN et al., 2010; KETTENMANN et al., 2011). Curiosamente, não observamos quaisquer alterações, seja na densidade ou na morfologia das micróglias presentes na camada granular do giro denteado. Embora dados na literatura vão na direção oposta, é importante ressaltar as diferenças metodológicas entre os esses estudos e os empregados no presente trabalho. Por exemplo, Kreisel e colaboradores (2014) observaram que a exposição ao estresse reduz a densidade de micróglias no DG e reduz o tamanho de seus processos. Entretanto, esses autores reportaram que a quantificação foi realizada todo 0 giro denteado, incluindo hílus, camada granular e camada molecular, diferente da nossa a qual se ateve à camada granular. Ademais, os autores não especificam os critérios utilizados para a análise morfológica, nem o número total de células analisadas por grupo. Em direção oposta, Hellwig e colaboradores (2016) demonstraram que a exposição ao estresse homotípico de natação 
forçada por 5 dias produzia um aumento na densidade de micróglias no giro denteado e um aumento na sua complexidade morfológica, evidenciado pela análise de Sholl. Nesse trabalho, os autores restringiram a análise de densidade à camada molecular superior e inferior do giro denteado, e a análise de Sholl a micróglias presentes na camada molecular inferior. Porém, é importante destacar que outros parâmetros morfológicos, como por exemplo, cálices fagocíticos (os quais estão associados a fagocitose de NSC), e outros marcadores associados a fenótipo inflamatório como MHC-II e CD-68 não foram analisados (SIERRA et al a., 2010). Todavia, nossos resultados somados aos supracitados vão de encontro a hipótese que sugere que as micróglias são células da glia altamente plásticas e fenotipicamente distintas de acordo com a região encefálica ao qual encontram-se inseridas (TAN et al., 2020).

Embora nossos resultados tenham demonstrado que nenhuma de nossas intervenções alteraram as micróglias presentes no giro denteado, observamos que animais iNOS e animais WT estressados apresentavam redução no processo de AHN. Acerca dos animais WT, nossos resultados encontram-se em consonância com dados obtidos por diferentes grupos, os quais demonstram que diferentes protocolos de estresse crônico são capazes de reduzir o número de neuroblastos e a sobrevivência de novos neurônios (GOULD et al., 1998; CAMPOS et al., 2013; FOGAÇA et al., 2018; ELIWA et al., 2021; TROUBAT et al., 2021). No que tange os animais iNOS KO, observamos que a redução basal no processo de AHN não era alterado após exposição ao CUS.

Diante desses resultados, nos perguntamos se um estímulo farmacológico pró-neurogênico seria capaz de recuperar o fenótipo alterado dos animais iNOS KO por aumentar a AHN. Para isso, nós utilizamos um protocolo de tratamento crônico com escitalopram inibidor seletivo da recaptação de serotonina, visto que resultados na literatura sugerem que esta classe de fármacos aumenta a $\mathrm{AHN}$ e seus efeitos comportamentais estão associados a uma AHN intacta (MALBERG et al., 2000; SANTARELLI et al., 2003).

Nesse contexto, observamos que animais iNOS KO não eram responsivos ao tratamento com escitalopram na dose de $10 \mathrm{mg} / \mathrm{kg}$ no TST nem no NSFT, e também não apresentavam alterações no processo de AHN. Curiosamente, os 
animais WT apresentaram alterações no NSFT e no AHN após o mesmo tratamento.

No que tange o efeito no TST, dados de nosso grupo de pesquisa vão na direção oposta àquelas obtidas no presente projeto. Mais especificamente, Aguiar e colaboradores (em publicação) demonstraram que a exposição ao CUS aumenta o tempo de imobilidade no TST sendo este revertido pelo tratamento repetido com mesma dose de escitolopram. Curiosamente, no NSFT os resultados foram na mesma direção. Essa discrepância pode estar associada a ausência de efeito nos animais WT CUS, visto que não observamos alterações significativas no TST de animais WT CUS tratados com veículo.

Nossos resultados comportamentais e a análise da AHN vão parcialmente ao encontro com o proposto por Santarelli e colaboradores (2003), visto que o tratamento repetido com escitolopram não altera a latência no NSFT nem o número de neuroblastos ou a sobrevivência de novos neurônios em animais iNOS KO. Um possível mecanismo que justifica esse fenômeno pode residir no fato que a ausência genética da enzima iNOS desde as primeiras etapas da organogênese pode promover um efeito compensatório das outras isoformas da NOS (EL-BROLOSY e STAINIER, 2017).

Nesse sentido, foi demonstrado que a ausência da isoforma neuronal da NOS (nNOS) promove um aumento na expressão da iNOS no hipocampo contralateral a uma lesão isquêmica, sendo esse efeito não observado em animais WT (LUO et al., 2007). Acerca da ausência genética da iNOS, Lisboa e colaboradores (2015) observaram que animais iNOS KO apresentavam redução nos níveis de RNAm da enzima eNOS no hipocampo, porém não da nNOS. Entretanto, os autores não avaliaram o nível proteico dessa enzima, nem de sua forma fosforilada, a qual tem sido creditado como um importante modulador da atividade catalítica das enzimas NOS (LADURNER et al., 2012).

Diversos estudos demonstraram que os eventos neurogênicos e angiogênicos não ocorrem de forma paralela e independente (PALMER et al., 2000; SUN et al., 2015; SHEN et al., 2019). Diante disso, a alteração da do RNAm da eNOS no hipocampo de animais iNOS KO pode, em última instância, influenciar processos neurogênicos diretamente, pela interação do NO com NSC, ou indiretamente por modular processos angiogênicos (DUDA et al., 2004). 
Mais especificamente, Ha e colaboradores (2016) reportaram que a isoforma eNOS é importante para o processo angiogênico que ocorre na retina durante $o$ desenvolvimento de camundongos. Além disso, a capacidade da isquemia cerebral em aumentar processos neurogênicos não é observada em animais iNOS KO (ZHENG et al., 2003). Esses estudos suportam a hipótese de que animais iNOS KO podem apresentar um déficit angiogênico em todo seu SNC ou, como de interesse para esse trabalho, na SGZ.

Outro mecanismo associado a essa possível compensação genética pode estar associada a uma maior produção de NO e que, devido a sua natureza química altamente reativa, pode inativar importantes neuromodulares do processo neurogênico. Nesta direção, foi demonstrado que o NO pode reagir com a serotonina presente na fenda sináptica, formando dímeros de serotonina os quais não apresentam capacidade de ativar seus receptores e executar seu papel em diferentes processos inclusive na AHN (FOSSIER et al., 1998). Especificamente, foi demonstrado que os efeitos suprarreguladores do exercício físico sobre a $A H N$ são dependentes da sinalização mediada por serotonina (KEMPLIN et al., 2013; KONDO et al., 2015). Como é postulado que o principal mecanismo de ação dos antidepressivos envolve o sistema monoaminérgico, no caso do escitalopram o serotoninérgico, é concebível a suposição de que a ausência de efeito do escitalopram em animais iNOS KO possa ser resultado da inativação da serotonina na fenda sináptica.

Curiosamente observamos que células do tipo Ila, mas não células tipo I, estão aumentadas nos animais iNOS KO. Essas células também são denominadas células progenitores amplificadores transientes (TAPCs- do inglês "transiente amplifying progenitor cells"), e uma característica marcante delas é a sua alta taxa mitótica (KEMPERMANN, 2015). O aumento das células tipo lla em animais iNOS KO pode estar associado a um mecanismo compensatório, uma vez que a taxa de diferenciação e maturação dos novos neurônios encontra-se comprometida. O estudo in vitro realizado por Carreira e colaboradores (2010) vai na mesma direção de nossas observações e da premissa discutida acima, acerca de aumento de NO mediado por outras isoformas. Nesse trabalho, os autores demonstraram que a exposição de NSCs, oriundas da SVZ, expostas ao NOC-9 (doador de NO) induz uma maior proliferação com concomitante aumento 
na expressão de Ki67 (antígeno expresso em TAPCs cuja função ainda permanece obscura). Além da influência direta do NO sobre os TAPCs, esse mediador pode modular a atividade de neurônios GABAérgicos no SNC de forma bifásica (GETTING et al., 1996).

Embora o ácido gama-aminobutírico (GABA, do inglês "gammaaminobutyric acid") no encéfalo maduro atua como o principal neurotransmissor inibitório (NGO e VO, 2019), no encéfalo em desenvolvimento, mais especificamente nas NSCs ele apresenta caráter excitatório. Essa peculiaridade advém de uma maior concentração plasmática do íon cloreto devido a expressão predominante do transportador de íon NKCC1, o qual promove influxo de $\mathrm{Na}^{+} / \mathrm{K}^{+} / \mathrm{Cl}^{-}$na razão estequiométrica de 1:1:2, e a ausência do transportador de efluxo $\mathrm{KCC}^{2}$, o qual promove efluxo de $\mathrm{K}^{-} \mathrm{e} \mathrm{Cl}^{-}$na razão de 1:1 (para revisão ver PONTES et al., 2013). Elegantemente, Song e colaboradores (2012) demonstraram que a ativação ou inativação de interneurônios PV localizados na camada granular, principal fonte GABAérgica para as NSCs localizadas na SGZ, pela técnica de optogenética alterava a taxa de proliferação de células tipo I, sendo a inibição destes interneurônios responsável pela ativação e diferenciação dessas células, observado através de um aumento na expressão de MCM2 (fator envolvido na replicação de células eucarióticas presente majoritariamente em TPACs). Dessa forma, a possível compensação genética devida ausência da iNOS, via aumento da nNOS e/ou eNOS, poderia produzir concentrações basais de NO maiores, o qual poderia modular o sistema GABAérgico presente no nicho neurogênico culminando nos efeitos observados no presente trabalho.

É proposto que a AHN seja responsável pela regulação minuciosa das funções realizadas pelo hipocampo, modulando tanto eventos mnemônicos quanto respostas adaptativas ao estresse (para revisão ver SURGET e BELZUNG, 2021). Nesse sentido, Hill e col. (2015) demonstraram que o aumento da AHN por manipulações genéticas previne o comportamento tipo-depressivo e -ansioso induzido pela administração crônica de corticosterona. Em contrapartida, manipulações genéticas semelhantes falharam em reproduzir esse fenótipo comportamental (CULLIG et al., 2017; ELIWA et al., 2021), sugerindo que os efeitos comportamentais induzidos pela AHN dependem do desafio utilizado. 
Curiosamente, nossos resultados sugerem que o estresse aumentou a neurogênese em animais WT, como revelado por um aumento em neuroblastos no giro denteado. Porém um trabalho recente sugere que a presença de um elevado número DCX positivas, não necessariamente reflete um aumento proporcional na AHN (preprint MENDEZ-DAVID et al., 2020). Essa premissa vai de encontro aos nossos resultados obtidos acerca do destino das células que incorporaram BrdU.

Resultados prévios obtidos em nosso laboratório (DETONI, 2018; preprint SCARANTE et al., 2021) demonstraram que o tratamento repetido por 7 dias com escitalopram produz efeito comportamental no NSFT sem alterar a AHN. Essa observação encontra-se em consonância com os resultados obtidos no presente trabalho, uma vez que o efeito tipo-ansiolítico promovido pelo escitalopram não foi acompanhado por um aumento na AHN nos animais WT.

Por fim, decidimos investigar se o fenótipo observado no TST estaria associado a outra estrutura, o córtex pré-frontal medial (mPFC). Diversos estudos demonstraram que a ativação, por diferentes formas, desta estrutura é capaz de induzir respostas tipo-antidepressivas (MOSHCE et al., 2016; HARE et al., 2019; FUKUMOTO et al., 2020), sendo esta região de extrema importância para os efeitos antidepressivos rápidos (WOHLEB et al., 2016; para revisão ver HARE e DUMAN, 2020) Nesse sentido investigamos o recrutamento de interneurônios, mais especificamente interneurônios GABAérgicos que expressam PV, em duas sub-regiões do mPFC, o PrL e IL. Dados na literatura sugerem que esses interneurônios são essências para elaboração de comportamentos associados a depressão e ansiedade. Mais especificamente, Fogaça e col. (2020) demonstraram que a inibição quimiogenética não seletiva de população de interneurônios GABAérgicos no mPFC ou a inibição seletiva de interneurônios PV produzia efeitos tipo-ansiolíticos no NSFT e respostas de enfrentamento ativo no FST. Ademais, esse mesmo estudo demonstrou que o efeito tipo-antidepressivo rápido observado pela escopolamina era abolido após ativação quimiogenética de interneurônios GABAérgicos PV (FOGAÇA et al., 2020).

Diante disso, inicialmente avaliamos a densidade de células positivas para o fator transcricional FOSB. Esse fator transcricional apresenta uma forma 
truncada, denominada $\triangle F O S B$, a qual apresenta tempo de meia-vida e estabilidade distinto (NESTLER, 1999; 2008). Devido a essa propriedade, o fator $\triangle$ FOSB é capaz de se acumular nas células por períodos maiores e revelar estruturas que são recrutadas diante de estímulos crônicos.

Nossos resultados revelaram que apenas o PrL era mais recrutado após o estresse em animais WT, sendo este mais ativo nos animais iNOS KO mesmo em condições onde não houve exposição ao CUS. Corroborando nossas observações, diferentes estudos demonstraram que a exposição a diferentes protocolos de estresse crônico mostra-se capazes de recrutar o córtex mPFC (PERROTTI et al., 2004; NIKULINA et al., 2008). Curiosamente, a ativação farmacológica do PrL é associada a evocação de comportamentos tipo-ansiosos (SAITOH et al., 2014), e maior comportamento de congelamento durante processo de extinção teste do medo-condicionado (SIERRA-MERCADO et al., 2011). Além disso, também foi demonstrado que a estimulação elétrica subconvulsivante do PrL evoca respostas de enfrentamento ativo no FST em uma linhagem de ratos depressivos (DRL- do inglês "depressive rat line"). Dessa forma, o fenótipo basal observado em animais iNOS KO parece ter seu mecanismo parcialmente revelado.

Ao analisarmos a densidade de células PV não observamos alterações significativas em nenhum dos nossos grupos. Esses dados vão ao encontro dos dados presentes na literatura, uma vez que, ainda são observadas certas inconstâncias acerca da densidade de células PV tanto em pacientes com depressão maior quanto em modelos animais baseados na exposição ao estresse (para revisão detalhada ver FOGAÇA e DUMAN, 2019).

Entretanto, no presente trabalho não avaliamos a integridade das células $P V$. Mais especificamente, alguns trabalhos sugerem que para o funcionamento adequado dos interneurônios PV é necessário a presença de uma rede perineuronal a qual garante estabilização das conexões sinápticas, proteção físico-química a possíveis agentes tóxicos, ancoramento de moléculas que podem favorecer ou não a formação de sinapses e refinamento do processamento de sinal de forma temporal e espacial (REICHELT et al., 2019). Nesse sentido, Yu e col. (2020) demonstraram que a exposição de ratos ao CUS reduz o número de células NeuN colocalizadas com Wisteria floribunda 
aglutinina (WFA, lectina que interage com componentes da PNN e utilizado como marcador) no PrL apenas de animais suscetíveis ao estresse.

Contudo, no presente trabalho demonstramos que a resposta ao estresse e o fenótipo de animais iNOS KO parece não advir do recrutamento de interneurônios PV presentes no mPFC. O estudo realizado por Page e col. (2019) vai parcialmente na direção oposta as nossas observações. Mais especificamente, Page e col. demonstraram que a exposição ao CUS é capaz de recrutar de maneira aguda interneurônios PV no mPFC, e a ativação quimiogenética dessa população produz efeitos comportamentais semelhantes ao CUS em fêmeas. É importante ressaltar que algumas diferenças metodológicas podem explicar essa disparidade. Primeiramente, nosso estudo investigou o recrutamento do PV de forma crônica, não aguda como feito por Page e colaboradores. Além disso, eles demonstraram que apenas a estimulação crônica, e não aguda desses interneurônios é capaz de promover alterações comportamentais. Outra diferença importante, é que os autores deste trabalho não dissecaram o mPFC como realizado nessa tese, sendo essa dissecção importante, visto que diversos trabalhos sugerem que a porção PrL modula comportamentos de forma distinta a IL (SCOPINHO et al., 2010; SIERRA-MERCADO et al., 2011; NAWREEN et al., 2020).

Coletivamente, nossos resultados sugerem que a AHN parece modular respostas tipo-ansiosas após exposição ao estresse, enquanto o PrL poderia estar envolvido na resposta de enfrentamento ativa observadas nos animais iNOS KO e WT expostos ao CUS (MOSHE et al., 2016; HARE e DUMAN et al., 2020). 
Consequências comportamentais da ausência genética da IL-10 em animais submetidos ao CUS: impacto sobre a densidade de micróglias e neuroblastos residentes da camada granular do giro denteado. 


\section{$\underline{\text { Resultados }}$}

\section{Efeito comportamental de animais IL-10 KO submetidos ao CUS}

No TST não foi observado alteração na latência para o primeiro episódio de imobilidade nos grupos analisados (ANOVA de duas-vias df=1,30; genótipo: $F=2.26$; estresse: $F=1.90$; interação: $F=2.17$; Fig 14B), porém houve um efeito significativo do estresse no tempo total de imobilidade (ANOVA de duas-vias $\mathrm{df}=1,30$; genótipo: $F=0.30$; estresse: $F=7.44, p<0,05$; interação: $F=0.19$; Fig 14C). No NSFT, nenhuma das manipulações realizadas apresentou efeitos estaticamente significativos (ANOVA de duas-vias $\mathrm{df}=1,32$; genótipo: $\mathrm{F}=2.98$; estresse: $F=3.33, p=0.07$; interação: $F=0.89$; Fig 14D). Curiosamente, foi observado que animais IL-10 KO consumiam mais ração na caixa residência em comparação aos animais WT (ANOVA de duas-vias $d f=1,32$; genótipo: $F=8.39$, $p<0.05$; estresse: $F=0.38$; interação: $F=0.54$; Fig $14 \mathrm{E}$ ). No que tange o $\mathrm{OFT}$, observamos que animais IL10 KO apresentam uma hipolocomoção quando comparados aos animais WT sendo este efeito revertido após exposição ao CUS (ANOVA de duas-vias $d f=1,32$; genótipo: $F=25.43, p<0.05$; estresse: $F=28.71$, $p<0.05$; interação: $F=3.91, p=0.055$; Fig 14A). 

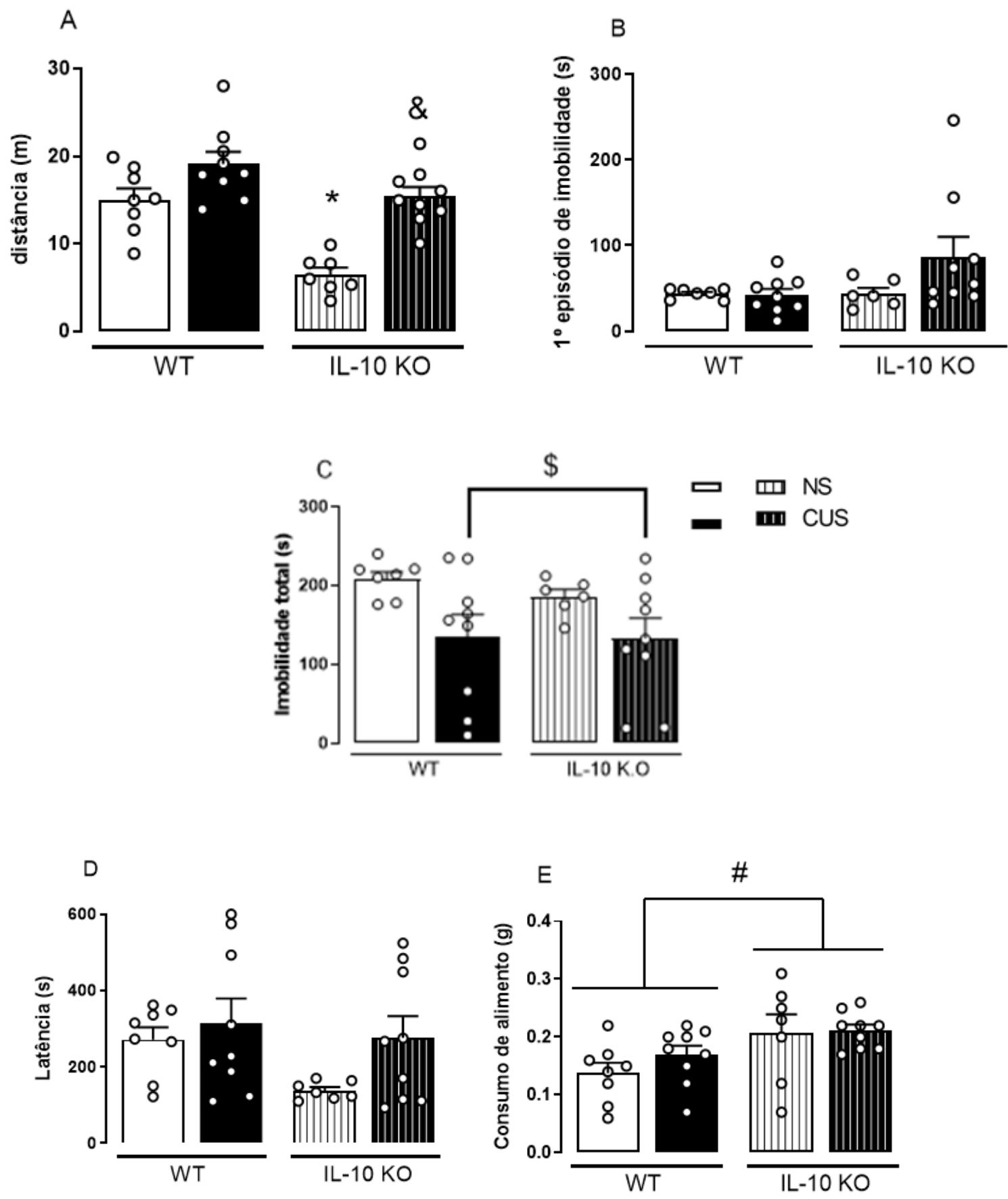

Figura 14: Diferente responsividade ao CUS de animais WT e IL10 KO nãoconsanguíneos. (A) Distância total percorrida no campo aberto $(n=8,9,7,9$ respectivamente); latência para primeiro episódio de imobilidade (B) e imobilidade total (C) no TST ( $n=7,9,6,9$, respectivamente); (D) latência para se alimentar em um ambiente novo e $(E)$ consumo na caixa-residência durante 5 minutos ( $n=8,9,7,9$ respectivamente). Gráficos mostram média \pm EPM. * $p<0,05$ comparado ao WT NS; \# indica $p<0,05$ no fator genótipo; \& indica $p<0,05$ comparado ao IL10 KO NS; \$ indica $p<0,05$ fator estresse. 
Efeito do CUS na densidade de micróglias presente na camada granular de animais IL-10 KO

A exposição ao CUS não foi eficaz em alterar a densidade de células da micróglia presentes na camada granular do giro denteado em nenhum dos grupos analisados (ANOVA de duas-vias $d f=1,17$; genótipo: $F=0.37$; estresse: $F=0.41$; interação: $F=0.01$; Fig 15).
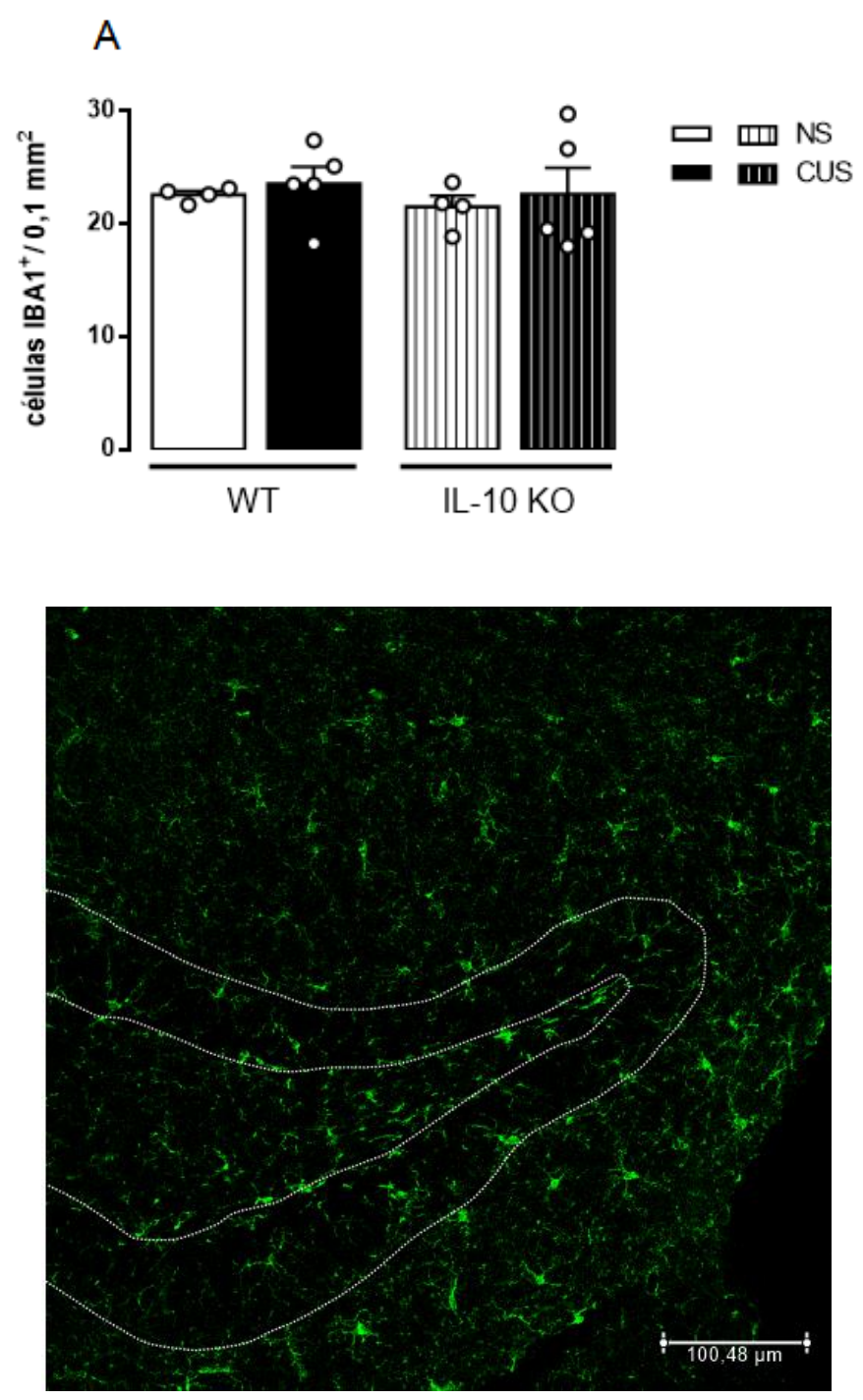

Figura 15: CUS não altera a densidade de micróglias (A) na camada granular de animais WT ou IL-10 KO ( $\mathrm{n}=4,5,4$ e 5 respectivamente). Fotomicrografia representativa do giro denteado de animal WT NS (B). Gráficos expressos em média \pm EPM. 
Efeito do CUS na densidade e na migração de neuroblastos animais IL-10 KO

Foi observado que animais IL-10 KO apresentaram densidade reduzida de neuroblastos em comparação aos animais WT, sendo esse fenômeno não alterado pelo CUS (ANOVA de duas-vias $d f=1,17$; genótipo: $F=11.97, p<0.05$; estresse: $F=0.36$; interação: $F=0.18$; Fig $15 A$ ). No mesmo sentido, o número de neuroblastos migrando para camada granular mostrou-se menor em animais IL$10 \mathrm{KO}$, sendo esse efeito não alterado pela exposição ao CUS (ANOVA de duasvias $d f=1,17$; genótipo: $F=54.67, p<0.05$; estresse: $F=0.07$; interação: $F=0.01$; Fig 15B). 

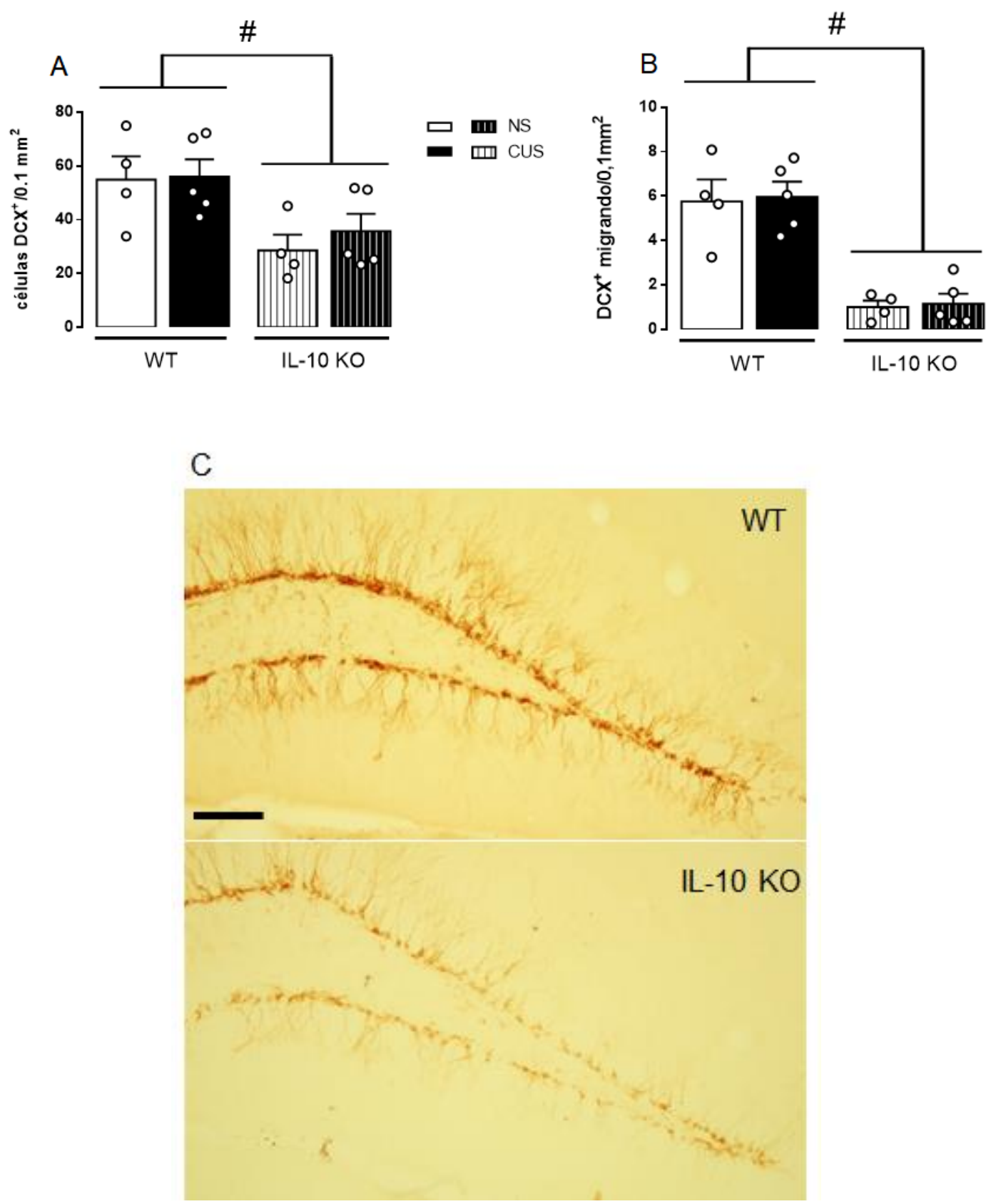

Figura 16: Quantificação do número de neuroblastos ( $D C X+)$ demonstrou redução basal em animais IL-10 KO não afetadas pelo CUS (A). Migração para camada granular também está reduzida em animais IL-10 KO (B). Fotomicrografia representativa de animais WT e IL-10 KO não estressados $(\mathrm{n}=4,5,4$ e 5 respectivamente; escala $=100 \mu \mathrm{m})$. Gráficos expressos em média \pm EPM. \# indica $p<0,05$ no fator genótipo. 


\section{Discussão- Capítulo 2}

Os resultados obtidos nesta etapa do trabalho refutam parcialmente a hipótese de que a ausência de um mediador anti-inflamatório facilitaria respostas associadas à depressão e ansiedade por reduzir a $\mathrm{AHN}$ via aumento na densidade de micróglias no giro denteado.

Já foi descrito que a exposição de animais IL-10 KO a protocolo de 21 de CUS promove redução no consumo da sacarose de maneira semelhante à observada em animais WT (MORMÈDE et al., 2002). Curiosamente, corroborando nossas observações acerca de maior consumo de ração, neste mesmo trabalho os autores também reportaram que animais $\mathrm{IL}-10 \mathrm{KO}$ consumiam mais a solução de sacarose do que animais WT (MORMĖDE et al., 2002). Além disso, Mesquita e colaboradores (2008) demonstraram que animais IL-10 KO não apresentavam resposta de enfrentamento diferentes a animais WT quando submetidos ao FST comparados, mas apresentavam menor tempo de permanência no centro da arena sendo este revertido com a administração de IL-10, sugerindo um fenótipo tipo-ansioso o qual foi revertido quando os autores fizeram a administração de IL-10 por 11 dias consecutivos. É importante ressaltar que os animais IL-10 KO empregados por Mesquista e col. apresentavam como fundo genético ("genetic-background") a linhagem Balb/c, dificultando assim uma melhor comparação entre os resultados, uma vez que estudos demonstram que essas duas linhagens apresentam diferentes padrões comportamentais em testes associados à depressão e ansiedade (MINEUR et al., 2006; O'MAHONY et al., 2010).

Outro estudo recente, demonstrou de forma elegante que a ablação crônica de IL-10 em populações de células que expressam receptor de fractalquina, sendo no SNC as micróglias, induz comportamento tipo-depressivo, avaliado através dos testes de preferência pela sacarose, TST e FST, e tipoansioso, avaliado pelo labirinto em cruz-elevado (YANG et al., 2021). Associado a este fenótipo, os autores também reportaram um aumento na densidade de micróglias no mPFC e na amigdala destes animais. Embora na presente tese não tenhamos observados alterações na densidade de micróglias no giro denteado, é importante ressaltar que uma análise pormenorizada deve ser 
realizada para descartar a hipótese de que a ausência da IL-10 alterações morfológicas nas micróglias associadas a uma maior reatividade.

Nossos resultados acerca da densidade de neuroblastos na SGZ vai ao encontro a dados na literatura que demonstram a importância de IL-10 para o processo de AHN. Mais especificamente, um estudo demonstrou que NSC da ZSV apresentam receptores para IL-10, e sua modulação in vitro é capaz de alterar diferentes fases da neurogênese dessas NSCs (PEREZ-ASENSIO et al., 2013), sendo posteriormente demonstrado pelo mesmo grupo de pesquisa que a IL-10 modula a neurogênese por atuar na via da ERK e da STAT3 (PEREIRA et al., 2015). Além disso, foi demonstrado que a hiperexpressão induzida por vírus da IL-10 em animais APP+PS1, modelo utilizado para o estudo da doença de Alzheimer, foi capaz de reverter o prejuízo na AHN observada nestes animais (KIYOTA et al., 2013).

Além da ausência de interação direta com as NSCs, animais IL-10 KO podem apresentar outros mecanismos compensatórios os quais podem, ao menos em parte, explicar o reduzido número de neuroblastos presente em sua ZSG. Nesse sentido, foi demonstrado que o cólon desses animais apresenta uma hiperativação do sistema de ativação da via da IL-1 $1 \beta$, incluindo a pro-IL-1 $\beta$, caspase-1 (responsável pela clivagem da pro-IL1 $\beta$ ) e da pro-caspase 1 (ZHANG et al., 2014). Além disso, outro estudo demonstrou que animais IL-10 KO apresentam níveis de RNAm para IL-1 $\beta$ maiores quando comparados aos animais WT no córtex, cerebelo, hipotálamo e hipocampo (RICHWINE et al., 2009). Diante disso, é plausível a hipótese de que os níveis elevados de IL-1ß observado nesses animais possa influenciar sua capacidade neurogênica.

Ademais, a colite observada nesses animais, a qual pode promover em última instância prolapso retal, parece estar associada a uma alteração na microbiota intestinal (KEUBLER et al., 2015). Nesse sentido, foi observado que o tratamento de animais IL-10 KO com bactérias do gênero Lactobacillus era capaz de reduzir os níveis de citocinas pro-inflamatórias observadas no cólon destes animais (MCCARTHY et al., 2002). Curiosamente, diversos trabalhos tem demonstrado a relevância da microbiota intestinal nos transtornos psiquiátricos, e como importantes agentes na modulação da AHN (CHEVALIER et al., 2021; SIMPSON et al., 2021; TANG et al., 2021). Corroborando a hipótese do 
desbalanço da microbiota e das observações realizadas por McCarthy e colaboradores (2002), estudos independentes demonstraram que a administração por via oral de Lactobacillus era capaz de promover comportamento tipo-ansiolítico e tipo-antidepressivo em camundongos, bem como reduzir a responsividade do eixo HHA após exposição ao FST (BRAVO et al., 2011; MARIN et al., 2017). Diante do exposto, é plausível a suposição que animais IL-10 KO empregados na presente tese apresentam um desbalanço de sua microbiota intestinal a qual pode estar associada ao reduzido número de neuroblastos observados no giro denteado.

Entretanto é importante salientar que mais estudos devem ser realizados para melhor compreensão do nicho neurogênico de animais IL-10 KO, uma vez que na presente tese não avaliamos a taxa de sobrevivência de novos neurônios no giro denteado de IL-10 KO, nem os níveis de células tipo-I, tipo-II e tipo-III. 


\section{Discussão geral}




\section{Discussão geral}

Embora a literatura apresente trabalhos que propuseram esclarecer a participação de mediadores da resposta imune como modulador da AHN, poucos fizeram uma conexão direta entre esses mediadores no contexto comportamental após exposição ao estresse.

Nesse sentido, estudos independentes realizados com animais deficientes para IL-18, um mediador pró-inflamatório, revelou que estes animais apresentam redução na AHN (YAMANISHI et al., 2019) e apresentam comportamento tipo-ansioso apenas após exposição ao estresse de natação por cinco dias consecutivos (LISBOA et al., 2019). É importante salientar que as respostas comportamentais reportadas nesses trabalhos apresentam algumas diferenças, p.e. Yamanishi e colaboradores (2019) reportaram uma resposta de enfrentamento passiva durante nado em arena aberta, por outro lado, Lisboa e colaboradores (2019) não reportaram alterações durante o período de estresse. Mesmo diante dessa divergência, é concebível a suposição de que a AHN reduzida dos animais IL-18 KO seja um importante mediador de respostas comportamentais associadas a ansiedade após exposição ao estresse.

Além desses, outros estudos demonstraram alterações em parâmetros neurogênicos de animais deficientes para outros mediadores pró-inflamatórios, como IFN-y, IL-2 e IL-6 (BECK et al., 2002; BOWEN et al., 2011; CAMPOS et al., 2013; para revisão de mais trabalhos que investigaram o papel das citocinas no contexto neurogênico ver BORSINI et al., 2014). Desses estudos, apenas o estudo realizado por Campos e colaboradores (2013) se propôs a investigar a relevância comportamental da ausência do IFN-ץ. Os autores observaram que atrelado a esse possível prejuízo neurogênico, demonstrado por uma redução de células DCX positivas, animais IFN-y KO apresentavam comportamentos tipo-depressivos no FST, e de forma similar ao apresentado por animais iNOS KO (capítulo 1) um fenótipo tipo-ansioso.

Acerca de citocinas anti-inflamatórias, um estudo utilizando animais $\mathrm{KO}$ para IL-4 demonstrou que estes animais apresentavam um fenótipo tipo-ansioso (MOON et al., 2014). Entretanto, esse trabalho carece de mecanismos, sendo apenas investigado a concentração de mono-aminas e seu "turn-over" no córtex, 
hipocampo e amígdala. Esses resultados embora encontrem-se em divergência com nossas observações realizadas com a IL-10 realçam a complexidade da interação neuroimume e como essas podem afetar, em última instância, o comportamento e a suscetibilidade ao estresse. Até o presente momento, poucos estudos acerca do papel da IL-13 no SNC foram realizados. Em suma, foi demonstrado que esta citocina parece apresentar um papel neuroprotetor em modelo animal da doença de esclerose múltipla, da doença de ALzheimer e da doença de Parkinson (MORI et al., 2016).

Diante dessa problemática, a presente tese teve como proposta compreender como poderia ocorrer a complexa interação entre mediadores imunes e AHN em contexto de estresse crônico. Coletivamente, nossos dados suportam a relevância desses mediadores em respostas comportamentais, bem como a suscetibilidade ao estresse. Entretanto, os resultados apresentados e os presentes na literatura colocam parcialmente em xeque a premissa inicial e dicotômica dos agentes anti- e pró-inflamatórios, como agentes "neuroprotetores" e "neurodegenerativos", respectivamente.

Nesse sentido, vale destacar que a IL-6, um mediador descrito inicialmente como pró-inflamatório, também é capaz de atuar como uma miocina (moléculas sinalizadoras liberadas pelo músculo esquelética em resposta a atividade física) e parece ser capaz de promover parte dos efeitos benéficos, na periferia e no SNC, associados a prática regular de atividade física (PENDERSEN e FISCHER, 2007; FUSTER e WALSH, 2014; RAISON et al., 2018; STORER et al., 2018). Por exemplo, foi demonstrado que o tecido adiposo de animais IL6 KO não responde de forma similar ao de animais WT após exposição a protocolo de exercício físico (BRANDT et al., 2012).

Ademais, na presente tese nos propusemos a estudar como 0 escitalopram poderia interagir com esses fatores. Recentemente, um estudo se propôs a tentar realizar uma conexão pormenorizada entre esses eventos de forma similar a empregada no presente trabalho. Neste estudo animais KO para o receptor $\mathrm{P} 2 \mathrm{X} 7$, receptor purinérgico envolvido em respostas pró-inflamatórias via estímulo de secreção de IL-1 $\beta$, foram expostos ao protocolo de CUS por um período de 6 semanas e avaliados em testes preditivos para ansiedade e depressão (TROUBAT et al., 2021). Os autores não observaram alterações no 
comportamento basal destes animais, porém observaram que animais $\mathrm{P} 2 \mathrm{X} 7 \mathrm{KO}$ não eram responsivos a alterações comportamentais induzidas pelo estresse no TST, no labirinto em cruz-elevado e no "splash-test" (TROUBAT et al., 2021). Além disso, os autores reportaram que a exposição ao estresse não era capaz de diminuir o número de neuroblastos nesses animais, bem como, o tratamento crônico com fluoxetina por 3 semanas não foi capaz de alterar esses níveis, nem promoveu alterações comportamentais. Novamente é necessário ressaltar que os autores apenas avaliaram a densidade de células que expressam DCX, e como apresentado na discussão do capítulo 1, este marcador pode não ser 0 mais acurado como biomarcador de alterações na AHN ("preprint' MENDEZDAVID et al., 2020). Nesse trabalho, os autores também reportaram que a exposição ao CUS induz alterações na densidade de micróglias no mPFC e no hipocampo, inclusive no giro denteado, apenas de animais WT. Essa divergência entre os nossos resultados do experimento 1 e 3 pode decorrer do protocolo de estresse empregado ou, de como discutido no capitulo 1, a relevância de se destacar qual sub-região do giro denteado foi analisada. Entretanto as observações realizadas por Troubat e col. (2021) encontram-se parcialmente em consonância com o realizado com os animais iNOS KO, uma vez que, aparentemente, ambas manipulações genéticas que prejudicam mediadores pró-inflamatórios parecem comprometer a responsividade ao tratamento com antidepressivos.

Contudo, é importante ressaltar que a análise pormenorizada do efeito do escitalopram em animais IL-10 KO foi prejudica devido a pandemia da COVID19 (do ingês "coronavirus disease-19. Dessa forma, para uma melhor compreensão da relevância da sinalização mediada por IL-10 para os efeitos comportamentais e neurogênicos do escitalopram permanecem por ser investigados. 
Conclusão 


\section{Conclusão}

Coletivamente, nossos resultados sugerem que iNOS parece ter um papel fundamental para a maturação e sobrevivência de novos neurônios no hipocampo sem afetar a integridade do nicho neurogênico. Ademais, a ausência dessa enzima parece promover um aumento na atividade da porção PrL do mPFC. Esses fenômenos paralelos auxiliam na compreensão de possíveis mecanismos neurobiológicos que participam do fenótipo comportamental observado em animais iNOS KO. Por outro lado, nossos resultados obtidos com IL-10 KO sugerem uma possível participação desta interleucina nas etapas de maturação e migração do processo de AHN. Entretanto, a ausência deste mediador parece afetar o comportamento apenas após exposição ao estresse. 


\section{Referências}

ANACKER, Christoph; LUNA, Victor M.; STEVENS, Gregory S.; MILLETTE, Amira; SHORES, Ryan; JIMENEZ, Jessica C.; CHEN, Briana; HEN, René. Hippocampal neurogenesis confers stress resilience by inhibiting the ventral dentate gyrus. Nature, [S. I.], v. 559, n. 7712, p. 98-102, 2018. DOI: 10.1038/s41586-018-0262-4. Disponível em: http://dx.doi.org/10.1038/s41586018-0262-4.

ARNHOLD, S.; FASSBENDER, A.; KLINZ, F. J.; KRUTTWIG, K.; LÖHNIG, B.; ANDRESSEN, C.; ADDICKS, K. NOS-II is involved in early differentiation of murine cortical, retinal and ES cell-derived neurons - An immunocytochemical and functional approach. International Journal of Developmental Neuroscience, [S. I.], v. 20, n. 2, p. 83-92, 2002. DOI: 10.1016/S07365748(02)00020-5.

BALU, Darrick T. et al. Flow cytometric analysis of BrdU incorporation as a highthroughput method for measuring adult neurogenesis in the mouse. Journal of Pharmacological and Toxicological Methods, [S. I.], v. 59, n. 2, p. 100-107, 2009. DOI: 10.1016/j.vascn.2008.12.002. Disponível em: https://linkinghub.elsevier.com/retrieve/pii/S1056871908002372.

BECK, Ray D.; WASSERFALL, Clive; HA, Grace K.; CUSHMAN, Jesse D.; HUANG, Zhi; ATKINSON, Mark A.; PETITTO, John M. Changes in hippocampal IL-15, related cytokines, and neurogenesis in IL-2 deficient mice. Brain Research, [S. I.], v. 1041, n. 2, p. 223-230, 2005. DOI: 10.1016/j.brainres.2005.02.010.

BOLDRINI, Maura; UNDERWOOD, Mark D.; HEN, René; ROSOKLIJA, Gorazd B.; DWORK, Andrew J.; JOHN MANN, J.; ARANGO, Victoria. Antidepressants increase neural progenitor cells in the human hippocampus. Neuropsychopharmacology, [S. I.], v. 34, n. 11, p. 2376-2389, 2009. DOI: 10.1038/npp.2009.75.

BORSINI, Alessandra; ZUNSZAIN, Patricia A.; THURET, Sandrine; PARIANTE, Carmine $M$. The role of inflammatory cytokines as key modulators of neurogenesis. Trends in Neurosciences, [S. I.], v. 38, n. 3, p. 145-157, 2015. DOI: 10.1016/j.tins.2014.12.006.

BOWEN, Kellie K.; DEMPSEY, Robert J.; VEMUGANTI, Raghu. Adult interleukin-6 knockout mice show compromisedneurogenesis. NeuroReport, [S. I.], v. 22, n. 3, p. 126-130, 2011. DOI: 10.1097/WNR.0b013e3283430a44.

BRAVO, Javier A.; FORSYTHE, Paul; CHEW, Marianne V.; ESCARAVAGE, Emily; SAVIGNAC, Hélène M.; DINAN, Timothy G.; BIENENSTOCK, John; CRYAN, John F. Ingestion of Lactobacillus strain regulates emotional behavior and central GABA receptor expression in a mouse via the vagus nerve. Proceedings of the National Academy of Sciences of the United States of America, [S. I.], v. 108, n. 38, p. 16050-16055, 2011. DOI: 10.1073/pnas.1102999108. 
BUSKILA, Yossi; ABU-GHANEM, Yasmin; LEVI, Yifat; MORAN, Arie; GRAUER, Ettie; AMITAI, Yael. Enhanced astrocytic nitric oxide production and neuronal modifications in the Neocortex of a NOS2 mutant mouse. PLoS ONE, [S. I.], v. 2, n. 9, 2007. DOI: 10.1371/journal.pone.0000843.

BUTCHER, R. W. onfutnin pnossbiitrtatio DATP Psee Sizu Rat Brain Binds Adrenal Steroid Hormone: [S. I.], v. 687, n. March, 1972.

CALABRESE, Vittorio; MANCUSO, Cesare; CALVANI, Menotti; RIZZARELLI, Enrico; BUTTERFIELD, D. Allan; GIUFFRIDA STELLA, Anna Maria. Nitric oxide in the central nervous system: Neuroprotection versus neurotoxicity. Nature Reviews Neuroscience, [S. I.], v. 8, n. 10, p. 766-775, 2007. DOI: 10.1038/nrn2214.

CAMERON, H. A.; WOOLLEY, C. S.; MCEWEN, B. S.; GOULD, E. Differentiation of newly born neurons and glia in the dentate gyrus of the adult rat. Neuroscience, [S. I.], v. 56, n. 2, p. 337-344, 1993. DOI: 10.1016/03064522(93)90335-D.

CAMPOS, Alline C. et al. The anxiolytic effect of cannabidiol on chronically stressed mice depends on hippocampal neurogenesis: Involvement of the endocannabinoid system. International Journal of Neuropsychopharmacology, [S. I.], v. 16, n. 6, p. 1407-1419, 2013. DOl: 10.1017/S1461145712001502.

CAMPOS, Alline C.; VAZ, Gabriela N.; SAITO, Viviane M.; TEIXEIRA, Antonio L. Further evidence for the role of interferon-gamma on anxiety- and depressive-like behaviors: Involvement of hippocampal neurogenesis and NGF production. Neuroscience Letters, [S. I.], v. 578, p. 100-105, 2014. DOI: 10.1016/j.neulet.2014.06.039. Disponível em: http://dx.doi.org/10.1016/j.neulet.2014.06.039.

CAN, Adem; DAO, David T.; TERRILLION, Chantelle E.; PIANTADOSI, Sean C.; BHAT, Shambhu; GOULD, Todd D. The Tail Suspension Test. Journal of Visualized Experiments, [S. I.], n. 58, 2011. DOI: 10.3791/3769. Disponível em: http://www.jove.com/details.php?id=3769.

CARREIRA, Bruno P.; MORTE, Maria I.; SANTOS, Ana I.; LOURENÇO, Ana S.; AMBRÓSIO, António F.; CARVALHO, Caetana M.; ARAÚJO, Inês M. Nitric oxide from inflammatory origin impairs neural stem cell proliferation by inhibiting epidermal growth factor receptor signaling. Frontiers in Cellular Neuroscience, [S. I.], v. 8, n. October, p. 1-14, 2014. DOI: 10.3389/fncel.2014.00343.

CARREIRA, Bruno P.; SANTOS, Daniela F.; SANTOS, Ana I.; CARVALHO, Caetana M.; ARAUJO, Inês M. Nitric Oxide Regulates Neurogenesis in the Hippocampus following Seizures. Oxidative Medicine and Cellular Longevity, [S. I.], v. 2015, 2015. DOI: 10.1155/2015/451512.

CARREIRA, Bruno Pereira et al. Nitric oxide stimulates the proliferation of neural stem cells bypassing the epidermal growth factor receptor. Stem Cells, [S. I.], v. 28, n. 7, p. 1219-1230, 2010. DOI: 10.1002/stem.444. 
CHEVALIER, Grégoire et al. Effect of gut microbiota on depressive-like behaviors in mice is mediated by the endocannabinoid system. Nature Communications, [S. I.], v. 11, n. 1, 2020. DOI: 10.1038/s41467-020-19931-2.

CHOURBAJI, Sabine; URANI, Alexandre; INTA, loana; SANCHIS-SEGURA, Carles; BRANDWEIN, Christiane; ZINK, Mathias; SCHWANINGER, Markus; GASS, Peter. IL-6 knockout mice exhibit resistance to stress-induced development of depression-like behaviors. Neurobiology of Disease, [S. I.], v. 23, n. 3, p. 587-594, 2006. DOI: 10.1016/j.nbd.2006.05.001.

COMMONS, Kathryn G.; CHOLANIANS, Aram B.; BABB, Jessica A.; EHLINGER, Daniel G. The Rodent Forced Swim Test Measures Stress-Coping Strategy, Not Depression-like Behavior. ACS Chemical Neuroscience, [S. I.], v. 8, n. 5, p. 955-960, 2017. DOI: 10.1021/acschemneuro.7b00042.

COUCH, Yvonne; ANTHONY, Daniel C.; DOLGOV, Oleg; REVISCHIN, Alexander; FESTOFF, Barry; SANTOS, Ana Isabel; STEINBUSCH, Harry W.; STREKALOVA, Tatyana. Microglial activation, increased TNF and SERT expression in the prefrontal cortex define stress-altered behaviour in mice susceptible to anhedonia. Brain, Behavior, and Immunity, [S. I.], v. 29, p. 136146, 2013. DOI: 10.1016/j.bbi.2012.12.017. Disponível em: http://dx.doi.org/10.1016/i.bbi.2012.12.017.

CRASKE, Michelle G.; STEIN, Murray B.; ELEY, Thalia C.; MILAD, Mohammed R.; HOLMES, Andrew; RAPEE, Ronald M.; WITTCHEN, Hans Ulrich. Anxiety disorders. Nature Reviews Disease Primers, [S. I.], v. 3, n. May, 2017. DOI: 10.1038/nrdp.2017.24.

CULIG, Luka; SURGET, Alexandre; BOURDEY, Marlene; KHEMISSI, Wahid; LE GUISQUET, Anne Marie; VOGEL, Elise; SAHAY, Amar; HEN, René; BELZUNG, Catherine. Increasing adult hippocampal neurogenesis in mice after exposure to unpredictable chronic mild stress may counteract some of the effects of stress. Neuropharmacology, $[S . \quad$ I. $], \quad$ v. 126, p. 179-189, $2017 . \quad$ DOI: 10.1016/j.neuropharm.2017.09.009.

DANTZER, Robert. Neuroimmune interactions: From the brain to the immune system and vice versa. Physiological Reviews, [S. I.], v. 98, n. 1, p. 477-504, 2018. DOI: 10.1152/physrev.00039.2016.

ALTMAN, Joseph; DAS, Gopal D. Autoradiographic and histological evidence of postnatal hippocampal neurogenesis in rats. The Journal of Comparative Neurology, [S. I.], v. 124, n. 3, p. 319-335, 1965. DOI: 10.1002/cne.901240303. Disponível em: https://onlinelibrary.wiley.com/doi/10.1002/cne.901240303.

DAVALOS, Dimitrios; GRUTZENDLER, Jaime; YANG, Guang; KIM, Jiyun V.; ZUO, Yi; JUNG, Steffen; LITTMAN, Dan R.; DUSTIN, Michael L.; GAN, Wen Biao. ATP mediates rapid microglial response to local brain injury in vivo. Nature Neuroscience, [S. I.], v. 8, n. 6, p. 752-758, 2005. DOI: 10.1038/nn1472.

DAVID, Denis J. et al. Neurogenesis-Dependent and -Independent Effects of Fluoxetine in an Animal Model of Anxiety/Depression. Neuron, [S. I.], v. 62, n. 4, 
p. 479-493, 2009. DOI: 10.1016/j.neuron.2009.04.017. Disponível em: http://dx.doi.org/10.1016/j.neuron.2009.04.017.

DENOTH-LIPPUNER, Annina; JESSBERGER, Sebastian. Formation and integration of new neurons in the adult hippocampus. Nature Reviews Neuroscience, [S. I.], v. 22, n. 4, p. 223-236, 2021. DOI: 10.1038/s41583-02100433-z. Disponível em: http://dx.doi.org/10.1038/s41583-021-00433-z.

DOWLATI, Yekta; HERRMANN, Nathan; SWARDFAGER, Walter; LIU, Helena; SHAM, Lauren; REIM, Elyse K.; LANCTÔT, Krista L. A Meta-Analysis of Cytokines in Major Depression. Biological Psychiatry, [S. I.], v. 67, n. 5, p. 446457, 2010. DOI: 10.1016/j.biopsych.2009.09.033. Disponível em: http://dx.doi.org/10.1016/j.biopsych.2009.09.033.

DRUTMAN, Scott B. et al. Fatal Cytomegalovirus Infection in an Adult with Inherited NOS2 Deficiency. New England Journal of Medicine, [S. I.], v. 382, n. 5, p. 437-445, 2020. DOI: 10.1056/nejmoa1910640.

DU, Ren Wei; DU, Ren Hong; BU, Wen Guang. B-Arrestin 2 Mediates the AntiInflammatory Effects of Fluoxetine in Lipopolysaccharide-Stimulated Microglial Cells. Journal of Neuroimmune Pharmacology, [S. I.], v. 9, n. 4, p. 582-590, 2014. DOI: $10.1007 / \mathrm{s} 11481-014-9556-y$.

DUDA, Dan G.; FUKUMURA, Dai; JAIN, Rakesh K. Role of eNOS in neovascularization: NO for endothelial progenitor cells. Trends in Molecular Medicine, $\quad[S . \quad$ I.], v. 10, n. 4, p. 143-145, $2004 . \quad$ DOI: 10.1016/j.molmed.2004.02.001. Disponível em: https://linkinghub.elsevier.com/retrieve/pii/S1471491404000486.

EKDAHL, C. T.; KOKAIA, Z.; LINDVALL, O. Brain inflammation and adult neurogenesis: The dual role of microglia. Neuroscience, [S. I.], v. 158, n. 3, p. 1021-1029, 2009. DOI: 10.1016/j.neuroscience.2008.06.052. Disponível em: http://dx.doi.org/10.1016/j.neuroscience.2008.06.052.

EKDAHL, Christine T.; CLAASEN, Jan Hendrik; BONDE, Sara; KOKAIA, Zaal; LINDVALL, Olle. Inflammation is detrimental for neurogenesis in adult brain. Proceedings of the National Academy of Sciences of the United States of America, [S. I.], v. 100, n. 23, p. 13632-13637, 2003. DOI: 10.1073/pnas.2234031100.

EL-BROLOSY, Mohamed A.; STAINIER, Didier Y. R. Genetic compensation: A phenomenon in search of mechanisms. PLOS Genetics, [S. I.], v. 13, n. 7, p. e1006780, 2017. DOI: 10.1371/journal.pgen.1006780. Disponível em: https://dx.plos.org/10.1371/journal.pgen.1006780.

ELIWA, Hoda; BRIZARD, Bruno; LE GUISQUET, Anne Marie; HEN, René; BELZUNG, Catherine; SURGET, Alexandre. Adult neurogenesis augmentation attenuates anhedonia and HPA axis dysregulation in a mouse model of chronic stress and depression. Psychoneuroendocrinology, [S. I.], v. 124, n. November 2020, 2021. DOI: 10.1016/j.psyneuen.2020.105097.

ERIKSSON, Peter S.; PERRFILIEVA, Ekaterina; BJÖRK-ERIKSSON, Thomas; ALBORN, Ann-Marie; NORDBORG, Claes; PETERSON, Daniel A.; CAGE, Fred 
H. Erikkson Et Al (1998). Nature Medicine, [S. I.], v. 4, n. 11, p. 1313-1317, 1998.

FELGER, Jennifer C. Imaging the role of inflammation in mood and anxietyrelated disorders. Current Neuropharmacology, [S. I.], v. 15, p. 533-558, 2017. DOI: $10.2174 / 1570159 \times 15666171123201142$.

FOGAÇA, Manoela V.; CAMPOS, Alline C.; COELHO, Ludmila D.; DUMAN, Ronald S.; GUIMARÃES, Francisco S. The anxiolytic effects of cannabidiol in chronically stressed mice are mediated by the endocannabinoid system: Role of neurogenesis and dendritic remodeling. Neuropharmacology, [S. I.], v. 135, p. 22-33, 2018. DOI: 10.1016/j.neuropharm.2018.03.001. Disponível em: https://linkinghub.elsevier.com/retrieve/pii/S0028390818301023.

FOGAÇA, Manoela V.; CAMPOS, Alline C.; COELHO, Ludmila D.; DUMAN, Ronald S.; GUIMARÃES, Francisco S. The anxiolytic effects of cannabidiol in chronically stressed mice are mediated by the endocannabinoid system: Role of neurogenesis and dendritic remodeling. Neuropharmacology, [S. I.], v. 135, p. 22-33, 2018. DOI: 10.1016/j.neuropharm.2018.03.001. Disponível em: https://linkinghub.elsevier.com/retrieve/pii/S0028390818301023.

FOGAÇA, Manoela V.; DUMAN, Ronald S. Cortical GABAergic dysfunction in stress and depression: New insights for therapeutic interventions. Frontiers in Cellular Neuroscience, [S. I.], v. 13, n. March 2019, p. 1-20, 2019. DOI: 10.3389/fncel.2019.00087.

FOGAÇA, Manoela V.; WU, Min; LI, Chan; LI, Xiao Yuan; PICCIOTTO, Marina R.; DUMAN, Ronald S. Inhibition of GABA interneurons in the MPFC is sufficient and necessary for rapid antidepressant responses. Molecular Psychiatry, [S. I.], v. 3, 2020. DOI: 10.1038/s41380-020-00916-y. Disponível em: http://dx.doi.org/10.1038/s41380-020-00916-y.

FOSSIER, P.; BLANCHARD, B.; DUCROCQ, C.; LEPRINCE, C.; TAUC, L.; BAUX, G. Nitric oxide transforms serotonin into an inactive form and this affects neuromodulation. Neuroscience, [S. I.], v. 93, n. 2, p. 597-603, 1999. DOI: 10.1016/S0306-4522(99)00165-7.

FRANKLIN, Tina C.; WOHLEB, Eric S.; ZHANG, Yi; FOGAÇA, Manoela; HARE, Brendan; DUMAN, Ronald S. Persistent Increase in Microglial RAGE Contributes to Chronic Stress-Induced Priming of Depressive-like Behavior. Biological Psychiatry, [S. I.], v. 83, n. 1, p. 50-60, 2018. DOI: 10.1016/j.biopsych.2017.06.034.

FUCHIKAMI, Manabu; THOMAS, Alexandra; LIU, Rongjian; WOHLEB, Eric S.; LAND, Benjamin B.; DILEONE, Ralph J.; AGHAJANIAN, George K.; DUMAN, Ronald S. Optogenetic stimulation of infralimbic PFC reproduces ketamine's rapid and sustained antidepressant actions. Proceedings of the National Academy of Sciences of the United States of America, [S. I.], v. 112, n. 26, p. 8106-8111, 2015. DOI: 10.1073/pnas.1414728112.

FUKUMOTO, Kenichi; IIJIMA, Michihiko; CHAKI, Shigeyuki. The Antidepressant Effects of an mGlu2/3 Receptor Antagonist and Ketamine Require AMPA 
Receptor Stimulation in the mPFC and Subsequent Activation of the 5-HT Neurons in the DRN. Neuropsychopharmacology, [S. I.], v. 41, n. 4, p. 10461056, 2016. DOI: 10.1038/npp.2015.233.

GADANI, Sachin P.; CRONK, James C.; NORRIS, Geoffrey T.; KIPNIS, Jonathan. IL-4 in the Brain: A Cytokine To Remember. The Journal of Immunology, [S. I.], v. 189, n. 9, p. 4213-4219, 2012. DOI: 10.4049/jimmunol.1202246.

GAŁECKI, Piotr; GAŁECKA, Elzbieta; MAES, Michael; CHAMIELEC, Marcelina; ORZECHOWSKA, Agata; BOBIŃSKA, Kinga; LEWIŃSKI, Andrzej; SZEMRAJ, Janusz. The expression of genes encoding for COX-2, MPO, iNOS, and SPLA2IIA in patients with recurrent depressive disorder. Journal of Affective Disorders, [S. I.], v. 138, n. 3, p. 360-366, 2012. DOI: 10.1016/j.jad.2012.01.016.

GAŁECKI, Piotr; MAES, Michael; FLORKOWSKI, Antoni; LEWIŃSKI, Andrzej; GAŁECKA, Elz̈bieta; BIEŃKIEWICZ, Małgorzata; SZEMRAJ, Janusz. An inducible nitric oxide synthase polymorphism is associated with the risk of recurrent depressive disorder. Neuroscience Letters, [S. I.], v. 486, n. 3, p. 184187, 2010. DOI: 10.1016/j.neulet.2010.09.048.

GEMMA, Carmelina; BACHSTETTER, Adam D. The role of microglia in adult hippocampal neurogenesis. Frontiers in Cellular Neuroscience, [S. I.], v. 7, n. NOV, p. 1-5, 2013. DOI: 10.3389/fncel.2013.00229.

GERHARD, Danielle M. et al. GABA interneurons are the cellular trigger for ketamine's rapid antidepressant actions. Journal of Clinical Investigation, [S. I.], v. 130, n. 3, p. 1336-1349, 2020. DOI: 10.1172/JCl130808.

GETTING, Stephen J.; SEGIETH, Joanna; AHMAD, Shagufta; BIGGS, Christopher S.; WHITTON, Peter S. Biphasic modulation of GABA release by nitric oxide in the hippocampus of freely moving rats in vivo. Brain Research, [S. I.], v. 717, n. 1-2, p. 196-199, 1996. DOI: 10.1016/0006-8993(96)00127-8.

GOULD, E.; CAMERON, H. A.; DANIELS, D. C.; WOOLLEY, C. S.; MCEWEN, B. S. Adrenal hormones suppress cell division in the adult rat dentate gyrus. Journal of Neuroscience, [S. I.], v. 12, n. 9, p. 3642-3650, 1992. DOI: 10.1523/jneurosci.12-09-03642.1992.

GOULD, Elizabeth; TANAPAT, Patima; MCEWEN, Bruce S.; FLÜGGE, Gabriele; FUCHS, Eberhard. Proliferation of granule cell precursors in the dentate gyrus of adult monkeys is diminished by stress. The Science of Mental Health: Stress and the Brain, [S. I.], v. 9, n. March, p. 106-109, 2013.

SANTARELLI, Luca et al. Requirement of hippocampal neurogenesis for the behavioral effects of antidepressants. Science, [S. I.], v. 301, n. 5634, p. 805809, 2003. DOI: 10.1126/science. 1083328.

GRAEFF, Frederico Guilherme; ZANGROSSI, Hélio. The hypothalamic-pituitaryadrenal axis in anxiety and panic. Psychology \& Neuroscience, [S. I.], v. 3, n. 1, p. 3-8, 2010. DOI: 10.3922/j.psns.2010.1.002. 
HARE, Brendan D.; DUMAN, Ronald S. Prefrontal cortex circuits in depression and anxiety: contribution of discrete neuronal populations and target regions. Molecular Psychiatry, [S. I.], v. 25, n. 11, p. 2742-2758, 2020. DOI: 10.1038/s41380-020-0685-9. Disponível em: http://dx.doi.org/10.1038/s41380020-0685-9.DAS, Gopal D. Altman_et_al-1965The_Journal_of_Comparative_Neurology.[S. I.], 1965.

HELLWIG, Sabine; BRIOSCHI, Simone; DIENI, Sandra; FRINGS, Lars; MASUCH, Annette; BLANK, Thomas; BIBER, Knut. Altered microglia morphology and higher resilience to stress-induced depression-like behavior in CX3CR1-deficient mice. Brain, Behavior, and Immunity, [S. I.], v. 55, p. 126137, 2016. DOI: 10.1016/j.bbi.2015.11.008. Disponível em: http://dx.doi.org/10.1016/j.bbi.2015.11.008.

HELMUT, Kettenmann; HANISCH, Uwe Karsten; NODA, Mami; VERKHRATSKY, Alexei. Physiology of microglia. Physiological Reviews, [S. I.], v. 91, n. 2, p. 461-553, 2011. DOI: 10.1152/physrev.00011.2010.

HIGGINS, Douglas; DWORKIN, Jonathan. Recent progress in Bacillus subtilis sporulation. FEMS Microbiology Reviews, [S. I.], v. 36, n. 1, p. 131-148, 2012. DOI: 10.1111/j.1574-6976.2011.00310.x.

HILL, Alexis S.; SAHAY, Amar; HEN, René. Increasing Adult Hippocampal Neurogenesis is Sufficient to Reduce Anxiety and Depression-Like Behaviors. Neuropsychopharmacology, [S. I.], v. 40, n. 10, p. 2368-2378, 2015. DOI: 10.1038/npp.2015.85.

HODES, Georgia E.; KANA, Veronika; MENARD, Caroline; MERAD, Miriam; RUSSO, Scott J. Neuroimmune mechanisms of depression. Nature Neuroscience, [S. I.], v. 18, n. 10, p. 1386-1393, 2015. DOI: 10.1038/nn.4113.

HOLSBOER, Florian. The Corticosteroid receptor hypothesis of depression. Depression: The Science of Mental Health, [S. I.], v. 6, n. 00, p. 219-244, 2013.

HÖLZEL, Britta K.; CARMODY, James; EVANS, Karleyton C.; HOGE, Elizabeth A.; DUSEK, Jeffery A.; MORGAN, Lucas; PITMAN, Roger K.; LAZAR, Sara W. Stress reduction correlates with structural changes in the amygdala. Social Cognitive and Affective Neuroscience, [S. I.], v. 5, n. 1, p. 11-17, 2009. DOI: 10.1093/scan/nsp034.

HOWREN, M. Bryant; LAMKIN, Donald M.; SULS, Jerry. Associations of depression with c-reactive protein, IL-1, and IL-6: A meta-analysis. Psychosomatic Medicine, [S. I.], v. 71, n. 2, p. 171-186, 2009. DOI: 10.1097/PSY.0b013e3181907c1b.

HU, Dan; WAN, Lei; CHEN, Michael; CAUDLE, Yi; LESAGE, Gene; LI, Qinchuan; YIN, Deling. Essential role of IL-10/STAT3 in chronic stress-induced immune suppression. Brain, Behavior, and Immunity, [S. I.], v. 36, p. 118-127, 2014. DOI: 10.1016/j.bbi.2013.10.016. Disponível em: http://dx.doi.org/10.1016/j.bbi.2013.10.016.

JA, Wook Koo; DUMAN, Ronald S. IL-1 $\beta$ is an essential mediator of the antineurogenic and anhedonic effects of stress. Proceedings of the National 
Academy of Sciences of the United States of America, [S. I.], v. 105, n. 2, p. 751-756, 2008. DOI: 10.1073/pnas.0708092105.

JINKS, Anthony L.; MCGREGOR, lain S. Modulation of anxiety-related behaviours following lesions of the prelimbic or infralimbic cortex in the rat. Brain Research, [S. I.], v. 772, n. 1-2, p. 181-190, 1997. DOI: 10.1016/S00068993(97)00810-X.

JOËLS, Marian. Corticosteroid effects in the brain: U-shape it. Trends in Pharmacological Sciences, [S. I.], v. 27, n. 5, p. 244-250, 2006. DOI: 10.1016/j.tips.2006.03.007.

JUNG, Yang Hee; HONG, Sa Ik; MA, Shi Xun; HWANG, Ji Young; KIM, Jun Sup; LEE, Ju Hyun; SEO, Jee Yeon; LEE, Seok Yong; JANG, Choon Gon. Strain differences in the chronic mild stress animal model of depression and anxiety in mice. Biomolecules and Therapeutics, [S. I.], v. 22, n. 5, p. 453-459, 2014. DOI: 10.4062/biomolther.2014.058.

KAPLAN, Michael S. Environment complexity stimulates visual cortex neurogenesis: Death of a dogma and a research career. Trends in Neurosciences, [S. I.], v. 24, n. 10, p. 617-620, 2001. DOI: 10.1016/S01662236(00)01967-6.

KAPLAN, Michael S.; HINDS, James W. Neurogenesis in the adult rat: Electron microscopic analysis of light radioautographs. Science, [S. I.], v. 197, n. 4308, p. 1092-1094, 1977. DOI: 10.1126/science.887941.

KENNEDY, Rachel H.; SILVER, Rae. Neuroscience in the 21st Century. [s.l: s.n.]. DOI: 10.1007/978-1-4614-6434-1.

KEMPERMANN, Gerd; SONG, Hongjun; GAGE, Fred H. Neurogenesis in the adult hippocampus. Cold Spring Harbor Perspectives in Biology, [S. I.], v. 7, n. 9, 2015. DOI: 10.1101/cshperspect.a018812.

KENNEDY, Rachel H.; SILVER, Rae. Neuroscience in the 21st Century. [s.l: s.n.]. DOI: 10.1007/978-1-4614-6434-1.

KETTENMANN, Helmut; HANISCH, Uwe Karsten; NODA, Mami; VERKHRATSKY, Alexei. Physiology of microglia. Physiological Reviews, [S. I.], v. 91, n. 2, p. 461-553, 2011. DOI: 10.1152/physrev.00011.2010.

KEUBLER, Lydia M.; BUETTNER, Manuela; HÄGER, Christine; BLEICH, André. A multihit model: Colitis lessons from the interleukin-10-deficient mouse. Inflammatory Bowel Diseases, [S. I.], v. 21, n. 8, p. 1967-1975, 2015. DOI: 10.1097/MIB.0000000000000468.

KIYOTA, T.; INGRAHAM, K. L.; SWAN, R. J.; JACOBSEN, M. T.; ANDREWS, S. J.; IKEZU, T. AAV serotype 2/1-mediated gene delivery of anti-inflammatory interleukin-10 enhances neurogenesis and cognitive function in APPPS1 mice. Gene Therapy, [S. I.], v. 19, n. 7, p. 724-733, 2012. DOI: 10.1038/gt.2011.126. Disponível em: http://dx.doi.org/10.1038/gt.2011.126.

KLEMPIN, F.; BEIS, D.; MOSIENKO, V.; KEMPERMANN, G.; BADER, M.; ALENINA, N. Serotonin Is Required for Exercise-Induced Adult Hippocampal 
Neurogenesis. Journal of Neuroscience, [S. I.], v. 33, n. 19, p. 8270-8275, 2013. DOI: 10.1523/JNEUROSCI.5855-12.2013. Disponível em: https://www.jneurosci.org/lookup/doi/10.1523/JNEUROSCI.5855-12.2013.

KONDO, M.; NAKAMURA, Y.; ISHIDA, Y.; SHIMADA, S. The 5-HT3 receptor is essential for exercise-induced hippocampal neurogenesis and antidepressant effects. Molecular Psychiatry, [S. I.], v. 20, n. 11, p. 1428-1437, 2015. DOI: 10.1038/mp.2014.153. Disponível em: http://dx.doi.org/10.1038/mp.2014.153.

KOO, Ja Wook; RUSSO, Scott J.; FERGUSON, Deveroux; NESTLER, Eric J.; DUMAN, Ronald $S$. Nuclear factor-KB is a critical mediator of stress-impaired neurogenesis and depressive behavior. Proceedings of the National Academy of Sciences of the United States of America, [S. I.], v. 107, n. 6, p. 2669-2674, 2010. DOI: 10.1073/pnas.0910658107.

SURGET, A.; BELZUNG, C. Adult hippocampal neurogenesis shapes adaptation and improves stress response: a mechanistic and integrative perspective. Molecular Psychiatry, [S. I.], n. 2, 2021. DOI: 10.1038/s41380-021-01136-8. Disponível em: http://dx.doi.org/10.1038/s41380-021-01136-8.

KOOLHAAS, J. M. et al. Stress revisited: A critical evaluation of the stress concept. Neuroscience and Biobehavioral Reviews, [S. I.], v. 35, n. 5, p. 12911301, 2011. DOI: 10.1016/j.neubiorev.2011.02.003. Disponível em: http://dx.doi.org/10.1016/j.neubiorev.2011.02.003.

KREISEL, T.; FRANK, M. G.; LICHT, T.; RESHEF, R.; BEN-MENACHEMZIDON, O.; BARATTA, M. V.; MAIER, S. F.; YIRMIYA, R. Dynamic microglial alterations underlie stress-induced depressive-like behavior and suppressed neurogenesis. Molecular Psychiatry, [S. I.], v. 19, n. 6, p. 699-709, 2014. DOI: 10.1038/mp.2013.155.

KUBERA, Marta et al. A new animal model of (chronic) depression induced by repeated and intermittent lipopolysaccharide administration for 4months. Brain, Behavior, and Immunity, [S. I.], v. 31, p. 96-104, 2013. DOI: 10.1016/j.bbi.2013.01.001. http://dx.doi.org/10.1016/i.bbi.2013.01.001.

KUDIELKA, B. M.; BUSKE-KIRSCHBAUM, A.; HELLHAMMER, D. H.; KIRSCHBAUM, C. HPA axis responses to laboratory psychosocial stress in healthy elderly adults, younger adults, and children: Impact of age and gender. Psychoneuroendocrinology, [S. I.], v. 29, n. 1, p. 83-98, 2004. DOI: 10.1016/S0306-4530(02)00146-4.

LADURNER, Angela; SCHMITT, Christoph A.; SCHACHNER, Daniel; ATANASOV, Atanas G.; WERNER, Ernst R.; DIRSCH, Verena M.; HEISS, Elke $\mathrm{H}$. Ascorbate stimulates endothelial nitric oxide synthase enzyme activity by rapid modulation of its phosphorylation status. Free Radical Biology and Medicine, [S. I.], v. 52, n. 10, p. 2082-2090, 2012. DOI: 10.1016/j.freeradbiomed.2012.03.022. Disponível em: https://linkinghub.elsevier.com/retrieve/pii/S0891584912001931. 
LI, Jiao et al. Cortical structural differences in major depressive disorder correlate with cell type-specific transcriptional signatures. Nature Communications, [S. I.], v. 12, n. 1, 2021. DOI: 10.1038/s41467-021-21943-5. Disponível em: http://dx.doi.org/10.1038/s41467-021-21943-5.

LISBOA, Sabrina F.; GOMES, Felipe V.; SILVA, Andra L.; ULIANA, Daniela L.; CAMARGO, Laura H. A.; GUIMARS, Francisco S.; CUNHA, Fernando Q.; JOCA, Sia R. L.; RESSTEL, Leonardo B. M. Increased contextual fear conditioning in inos knockout mice: Additional evidence for the involvement of nitric oxide in stress-related disorders and contribution of the endocannabinoid system. International Journal of Neuropsychopharmacology, [S. I.], v. 18, n. 8, p. 112, 2015. DOI: 10.1093/ijnp/pyv005.

LIU, Dexiang; WANG, Zhen; LIU, Shangming; WANG, Fuwu; ZHAO, Shidou; $\mathrm{HAO}$, Aijun. Anti-inflammatory effects of fluoxetine in lipopolysaccharide(LPS)stimulated microglial cells. Neuropharmacology, [S. I.], v. 61, n. 4, p. 592-599, 2011. DOI: 10.1016/j.neuropharm.2011.04.033. Disponível em: http://dx.doi.org/10.1016/j.neuropharm.2011.04.033.

LIU, Qiang; XIN, Wei; HE, Ping; TURNER, Dharshaun; YIN, Junxiang; GAN, Yan; SHI, Fu Dong; WU, Jie. Interleukin-17 inhibits Adult hippocampal neurogenesis. Scientific Reports, [S. I.], v. 4, p. 1-8, 2014. DOI: 10.1038/srep07554.

LOBO-SILVA, Diogo; CARRICHE, Guilhermina M.; CASTRO, A. Gil; ROQUE, Susana; SARAIVA, Margarida. Balancing the immune response in the brain: IL10 and its regulation. Journal of Neuroinflammation, [S. I.], v. 13, n. 1, p. 1-10, 2016. DOI: 10.1186/s12974-016-0763-8. Disponível em: http://dx.doi.org/10.1186/s12974-016-0763-8.

LUO, Chun Xia et al. Reduced neuronal nitric oxide synthase is involved in ischemia-induced hippocampal neurogenesis by up-regulating inducible nitric oxide synthase expression. Journal of Neurochemistry, [S. I.], v. 103, n. 5, p. 1872-1882, 2007. DOI: 10.1111/j.1471-4159.2007.04915.x.

MADONNA, Domenico; DELVECCHIO, Giuseppe; SOARES, Jair C.; BRAMBILLA, Paolo. Structural and functional neuroimaging studies in generalized anxiety disorder: A systematic review. Brazilian Journal of Psychiatry, [S. I.], v. 41, n. 4, p. 336-362, 2019. DOI: 10.1590/1516-4446-20180108.

MAGARIN OS, A. M.; MCEWEN, B. S. Stress-induced atrophy of apical dendrites of hippocampal CA3c neurons: Comparison of stressors. Neuroscience, [S. I.], v. 69, n. 1, p. 83-88, 1995. DOI: 10.1016/0306-4522(95)00256-I.

MALBERG, Jessica E.; EISCH, Amelia J.; NESTLER, Eric J.; DUMAN, Ronald $S$. Chronic antidepressant treatment increases neurogenesis in adult rat hippocampus. Journal of Neuroscience, [S. I.], v. 20, n. 24, p. 9104-9110, 2000. DOI: 10.1523/jneurosci.20-24-09104.2000.

MARIN, loana A. et al. Microbiota alteration is associated with the development of stress-induced despair behavior. Scientific Reports, [S. I.], v. 7, p. 1-10, 2017. DOI: $10.1038 /$ srep43859. 
MCCARTHY, J. et al. Double blind, placebo controlled trial of two probiotic strains in interleukin 10 knockout mice and mechanistic link with cytokine balance. Gut, [S. I.], v. 52, n. 7, p. 975-980, 2003. DOI: 10.1136/gut.52.7.975.

MCEWEN, B. S.; DE KLOET, E. R.; ROSTENE, W. Adrenal steroid receptors and actions in the nervous system. Physiological Reviews, [S. I.], v. 66, n. 4, p. 1121-1188, 1986. DOI: 10.1152/physrev.1986.66.4.1121.

MCEWEN, Bruce S. Glucocorticoids, depression, and mood disorders: Structural remodeling in the brain. Metabolism: Clinical and Experimental, [S. I.], v. 54, n. 5 SUPPL., p. 20-23, 2005. DOI: 10.1016/j.metabol.2005.01.008.

MCEWEN, Bruce S.; WEISS, J. A. Y. M.; SCHWARTZ, Leslie S. U P T A K E OF C O R T I C O S T E R O N E BY RAT BRAIN A N D ITS. [S. I.], v. 16, p. 227241, 1969.

MCEWEN, Bruce S.; WEISS, Jay M.; SCHWARTZ, Leslie S. Selective retention of corticosterone by limbic structures in rat brain [18]. Nature, [S. I.], v. 220, n. 5170, p. 911-912, 1968. DOI: 10.1038/220911a0.

MCKIM, Daniel B.; NIRAULA, Anzela; TARR, Andrew J.; WOHLEB, Eric S.; SHERIDAN, John F.; GODBOUT, Jonathan P. Neuroinflammatory dynamics underlie memory impairments after repeated social defeat. Journal of Neuroscience, [S. I.], v. 36, n. 9, p. 2590-2604, 2016. DOI: 10.1523/JNEUROSCI.2394-15.2016.

MÉNARD, Caroline; PFAU, Madeline L.; HODES, Georgia E.; RUSSO, Scott J. Immune and Neuroendocrine Mechanisms of Stress Vulnerability and Resilience. Neuropsychopharmacology, [S. I.], v. 42, n. 1, p. 62-80, 2017. DOI: 10.1038/npp.2016.90.

Disponível

em:

http://www.nature.com/articles/npp201690.

MENDEZ-DAVID, Indira; DAVID, Denis J.; DELOMÉNIE, Claudine; BEAULIEU, Jean-Martin; GARDIER, Alain M.; HEN, Rene. A Non-Linear Relation between Levels of Adult Hippocampal Neurogenesis and Expression of the Immature Neuron Marker Doublecortin. SSRN Electronic Journal, [S. I.], 2020. DOI: 10.2139/ssrn.3616375.

MESQUITA, Ana Raquel; CORREIA-NEVES, Margarida; ROQUE, Susana; CASTRO, António Gil; VIEIRA, Paulo; PEDROSA, Jorge; PALHA, Joana Almeida; SOUSA, Nuno. IL-10 modulates depressive-like behavior. Journal of Psychiatric Research, [S. I.], v. 43, n. 2, p. 89-97, 2008. DOI: 10.1016/j.jpsychires.2008.02.004.

Microglial-produced nitric oxide and reactive nitrogen oxides mediate neuronal cell death. Brain Research, [S. I.], v. 587, n. 2, p. 250-256, 1992. DOI: 10.1016/0006-8993(92)91004-X.

MINEUR, Yann S.; BELZUNG, Catherine; CRUSIO, Wim E. Effects of unpredictable chronic mild stress on anxiety and depression-like behavior in mice. Behavioural Brain Research, [S. I.], v. 175, n. 1, p. 43-50, 2006. DOI: 10.1016/j.bbr.2006.07.029. 
MONTEZUMA, Karina; BIOJONE, Caroline; LISBOA, Sabrina F.; CUNHA, Fernando Q.; GUIMARÃES, Francisco S.; JOCA, Sâmia R. L. Inhibition of iNOS induces antidepressant-like effects in mice: Pharmacological and genetic evidence. Neuropharmacology, [S. I.], v. 62, n. 1, p. 485-491, 2012. DOI: 10.1016/j.neuropharm.2011.09.004. http://dx.doi.org/10.1016/j.neuropharm.2011.09.004.

MOON, Morgan L.; JOESTING, Jennifer J.; BLEVINS, Neil A.; LAWSON, Marcus A.; GAINEY, Stephen J.; TOWERS, Albert E.; MCNEIL, Leslie K.; FREUND, Gregory G. IL-4 Knock Out Mice Display Anxiety-Like Behavior. Behavior Genetics, [S. I.], v. 45, n. 4, p. 451-460, 2015. DOI: 10.1007/s10519-015-9714x. Disponível em: http://dx.doi.org/10.1007/s10519-015-9714-x.

MOON, Morgan L.; JOESTING, Jennifer J.; BLEVINS, Neil A.; LAWSON, Marcus A.; GAINEY, Stephen J.; TOWERS, Albert E.; MCNEIL, Leslie K.; FREUND, Gregory G. IL-4 Knock Out Mice Display Anxiety-Like Behavior. Behavior Genetics, [S. I.], v. 45, n. 4, p. 451-460, 2015. DOI: 10.1007/s10519-015-9714x. Disponível em: http://dx.doi.org/10.1007/s10519-015-9714-x.

MORI, Simone; MAHER, Pamela; CONTI, Bruno. Neuroimmunology of the interleukins 13 and 4. Brain Sciences, [S. I.], v. 6, n. 2, p. 1-9, 2016. DOI: 10.3390/brainsci6020018.

MORMĖDE, Cécile; CASTANON, Nathalie; MÉDINA, Chantal; MOZE, Elisabeth; LESTAGE, Jacques; NEVEU, Pierre J.; DANTZER, Robert. Chronic mild stress in mice decreases peripheral cytokine and increases central cytokine expression independently of IL-10 regulation of the cytokine network. NeurolmmunoModulation, [S. I.], v. 10, n. 6, p. 359-366, 2002. DOI: 10.1159/000071477.

MOSHE, Hagar; GAL, Ram; BARNEA-YGAEL, Noam; GULEVSKY, Tatiana; ALYAGON, Uri; ZANGEN, Abraham. Prelimbic Stimulation Ameliorates Depressive-Like Behaviors and Increases Regional BDNF Expression in a Novel Drug-Resistant Animal Model of Depression. Brain Stimulation, [S. I.], v. 9, n. 2, p. 243-250, 2016. DOI: 10.1016/j.brs.2015.10.009. Disponível em: http://dx.doi.org/10.1016/j.brs.2015.10.009.

NANDAM, L. Sanjay; BRAZEL, Matthew; ZHOU, Mei; JHAVERI, Dhanisha J. Cortisol and Major Depressive Disorder-Translating Findings From Humans to Animal Models and Back. Frontiers in Psychiatry, [S. I.], v. 10, n. January, p. 1-15, 2020. DOI: 10.3389/fpsyt.2019.00974.

NAWREEN, Nawshaba et al. Chemogenetic inhibition of infralimbic prefrontal cortex gabaergic parvalbumin interneurons attenuates the impact of chronic stress in male mice. eNeuro, $[S$. I. $]$, v. 7, n. 5, 2020. DOI: 10.1523/ENEURO.0423-19.2020.

NESTLER, Eric J.; KELZ, Max B.; CHEN, Jingshan. $\triangle$ FosB: A molecular mediator of long-term neural and behavioral plasticity. Brain Research, [S. I.], v. 835, n. 1, p. 10-17, 1999. DOI: 10.1016/S0006-8993(98)01191-3. 
NGO, Dai Hung; VO, Thanh Sang. An updated review on pharmaceutical properties of gamma-aminobutyric acid. Molecules, [S. I.], v. 24, n. 15, 2019. DOI: 10.3390/molecules24152678.

NIKULINA, Ella M.; ARRILLAGA-ROMANY, Isabel; MICZEK, Klaus A.; HAMMER, Ronald $P$. Long-lasting alteration in mesocorticolimbic structures after repeated social defeat stress in rats: Time course of $\mu$-opioid receptor mRNA and FosB/ $\Delta$ FosB immunoreactivity. European Journal of Neuroscience, [S. I.], v. 27, n. 9, p. 2272-2284, 2008. DOI: 10.1111/j.1460-9568.2008.06176.x.

NIMMERJAHN, Axel; KIRCHHOFF, Frank; HELMCHEN, Fritjof. Neuroscience: Resting microglial cells are highly dynamic surveillants of brain parenchyma in vivo. Science, [S. I.], v. 308, n. 5726, p. 1314-1318, 2005. DOI: 10.1126/science.1110647.

O'BRIEN, Sinead M.; SCULLY, Paul; FITZGERALD, Peter; SCOTT, Lucinda V.; DINAN, Timothy G. Plasma cytokine profiles in depressed patients who fail to respond to selective serotonin reuptake inhibitor therapy. Journal of Psychiatric Research, [S. I.], v. 41, n. 3-4, p. 326-331, 2007. DOI: 10.1016/j.jpsychires.2006.05.013.

ODAKA, Haruki; ADACHI, Naoki; NUMAKAWA, Tadahiro. Impact of glucocorticoid on neurogenesis. Neural Regeneration Research, [S. I.], v. 12, n. 7, p. 1028-1035, 2017. DOI: 10.4103/1673-5374.211174.

OTTE, Christian; GOLD, Stefan M.; PENNINX, Brenda W.; PARIANTE, Carmine M.; ETKIN, Amit; FAVA, Maurizio; MOHR, David C.; SCHATZBERG, Alan F. Major depressive disorder. Nature Reviews Disease Primers, [S. I.], v. 2, n. Mdd, p. 1-21, 2016. DOI: 10.1038/nrdp.2016.65. Disponível em: http://dx.doi.org/10.1038/nrdp.2016.65.

PACKER, Michael A.; STASIV, Yuri; BENRAISS, Abdellatif; CHMIELNICKI, Eva; GRINBERG, Alexander; WESTPHAL, Heiner; GOLDMAN, Steven A.; ENIKOLOPOV, Grigori. Nitric oxide negatively regulates mammalian adult neurogenesis. Proceedings of the National Academy of Sciences of the United States of America, [S. I.], v. 100, n. 16, p. 9566-9571, 2003. DOl: 10.1073/pnas.1633579100.

PAGE, Chloe E.; SHEPARD, Ryan; HESLIN, Kelsey; COUTELLIER, Laurence. Prefrontal parvalbumin cells are sensitive to stress and mediate anxiety-related behaviors in female mice. Scientific Reports, [S. I.], v. 9, n. 1, p. 1-9, 2019. DOI: 10.1038/s41598-019-56424-9. Disponível em: http://dx.doi.org/10.1038/s41598019-56424-9.

PALMER, Theo D.; WILLHOITE, Andrew R.; GAGE, Fred H. Vascular niche for adult hippocampal neurogenesis. Journal of Comparative Neurology, [S. I.], v. 425 , n. 4 , p. 479-494, 2000. DOI: 10.1002/10969861(20001002)425:4<479::AID-CNE2>3.0.CO;2-3.

PATON, John A.; NOTTEBOHM, Fernando N. Neurons generated in the adult brain are recruited into functional circuits. Science, [S. I.], v. 225, n. 4666, p. 1046-1048, 1984. DOI: 10.1126/science.6474166. 
PENG, Yun Li; LIU, Yu Ning; LIU, Lei; WANG, Xia; JIANG, Chun Lei; WANG, Yun Xia. Inducible nitric oxide synthase is involved in the modulation of depressive behaviors induced by unpredictable chronic mild stress. Journal of Neuroinflammation, [S. I.], v. 9, p. 1-12, 2012. DOI: 10.1186/1742-2094-9-75.

PERCIE DU SERT, Nathalie et al. The ARRIVE guidelines 2.0: Updated guidelines for reporting animal research. PLOS Biology, [S. I.], v. 18, n. 7, p. e3000410, 2020. DOI: 10.1371/journal.pbio.3000410. Disponível em: https://dx.plos.org/10.1371/journal.pbio.3000410.

PEREIRA, Leticia; FONT-NIEVES, Miriam; VAN DEN HAUTE, Chris; BAEKELANDT, Veerle; PLANAS, Anna M.; POZAS, Esther. IL-10 regulates adult neurogenesis by modulating ERK and STAT3 activity. Frontiers in Cellular Neuroscience, [S. I.], v. 9, n. FEB, p. 1-9, 2015. DOI: 10.3389/fncel.2015.00057.

PEREZ-ASENSIO, Fernando J.; PERPIÑÁ, Unai; PLANAS, Anna M.; POZAS, Esther. Interleukin-10 regulates progenitor differentiation and modulates neurogenesis in adult brain. Journal of Cell Science, [S. I.], v. 126, n. 18, p. 4208-4219, 2013. DOI: 10.1242/jcs.127803.

PERROT-SINAL, T. S.; OSSENKOPP, K. P.; KAVALIERS, M. Brief predator odour exposure activates the HPA axis independent of locomotor changes. NeuroReport, [S. I.], v. 10, n. 4, p. 775-780, 1999. DOI: 10.1097/00001756199903170-00021.

PERROTTI, Linda I.; HADEISHI, Yuki; ULERY, Paula G.; BARROT, Michel; MONTEGGIA, Lisa; DUMAN, Ronald S.; NESTLER, Eric J. Induction of $\triangle$ FosB in reward-related brain structures after chronic stress. Journal of Neuroscience, [S. I.], v. 24, n. 47, p. 10594-10602, 2004. DOI: 10.1523/JNEUROSCI.254204.2004 .

PRINZ, Marco; PRILLER, Josef. Microglia and brain macrophages in the molecular age: From origin to neuropsychiatric disease. Nature Reviews Neuroscience, [S. I.], v. 15, n. 5, p. 300-312, 2014. DOI: 10.1038/nrn3722.

QIN, Xiaqing; WANG, Wei; WU, Huiran; LIU, Dexiang; WANG, Rui; XU, Jingjing; JIANG, Hong; PAN, Fang. PPARy-mediated microglial activation phenotype is involved in depressive-like behaviors and neuroinflammation in stressed C57BL/6J and ob/ob mice. Psychoneuroendocrinology, [S. I.], v. 117, n. March, p. 104674, 2020. DOI: 10.1016/j.psyneuen.2020.104674. Disponível em: https://doi.org/10.1016/j.psyneuen.2020.104674.

RAMIREZ, Karol; SHEA, Daniel T.; MCKIM, Daniel B.; READER, Brenda F.; SHERIDAN, John F. Imipramine attenuates neuroinflammatory signaling and reverses stress-induced social avoidance. Brain, Behavior, and Immunity, [S. I.], v. 46, p. 212-220, 2015. DOI: 10.1016/j.bbi.2015.01.016. Disponível em: http://dx.doi.org/10.1016/j.bbi.2015.01.016.

RAMIREZ, Karol; SHEA, Daniel T.; MCKIM, Daniel B.; READER, Brenda F.; SHERIDAN, John F. Imipramine attenuates neuroinflammatory signaling and reverses stress-induced social avoidance. Brain, Behavior, and Immunity, [S. 
I.], v. 46, p. 212-220, 2015. DOI: 10.1016/j.bbi.2015.01.016. Disponível em: http://dx.doi.org/10.1016/j.bbi.2015.01.016.

REICHELT, Amy C.; HARE, Dominic J.; BUSSEY, Timothy J.; SAKSIDA, Lisa M. Perineuronal Nets: Plasticity, Protection, and Therapeutic Potential. Trends in Neurosciences, $[S . \quad$ l.], $\quad$ v. $42, \quad$ n. 7 , p. 458-470, 2019. DOI: 10.1016/j.tins.2019.04.003. https://doi.org/10.1016/j.tins.2019.04.003. Disponível em:

RENAULT, Pierre F.; HOOFNAGLE, Jay H.; PARK, Yoon; MULLEN, Kevin D.; PETERS, Marion; JONES, D. Brian; RUSTGI, Vinod; JONES, E. Anthony. Psychiatric Complications of Long-term Interferon Alfa Therapy. Archives of Internal Medicine, [S. I.], v. 147, n. 9, p. 1577-1580, 1987. DOI: 10.1001/archinte.1987.00370090055011.

REUL, J. M. H. M.; DE KLOET, E. R. Two receptor systems for corticosterone in rat brain: Microdistribution and differential occupation. Endocrinology, [S. I.], v. 117, n. 6, p. 2505-2511, 1985. DOI: 10.1210/endo-117-6-2505.

RICHWINE, Amy F.; SPARKMAN, Nathan L.; DILGER, Ryan N.; BUCHANAN, Jessica B.; JOHNSON, Rodney W. Cognitive deficits in interleukin-10-deficient mice after peripheral injection of lipopolysaccharide. Brain, Behavior, and Immunity, [S. I.], v. 23, n. 6, p. 794-802, 2009. DOI: 10.1016/j.bbi.2009.02.020. Disponível em: http://dx.doi.org/10.1016/j.bbi.2009.02.020.

ROM, Oren; REZNICK, Abraham Z. The Stress Reaction: A Historical Perspective. [S. I.], n. February, p. 1-4, 2016. DOI: 10.1007/5584.SARKAR, Susanne; SCHAEFER, Martin. Antidepressant pretreatment for the prevention of interferon alfa-associated depression: A systematic review and meta-analysis. Psychosomatics, [S. I.], v. 55, n. 3, p. 221-234, 2014. DOI: 10.1016/j.psym.2013.06.015. Disponível em: http://dx.doi.org/10.1016/j.psym.2013.06.015.

SAHA, Ramendra N.; PAHAN, Kalipada. Signals for the induction of nitric oxide synthase in astrocytes. Neurochemistry International, [S. I.], v. 49, n. 2, p. 154163, 2006. DOI: 10.1016/j.neuint.2006.04.007.

SAITOH, Akiyoshi; OHASHI, Masanori; SUZUKI, Satoshi; TSUKAGOSHI, Mai; SUGIYAMA, Azusa; YAMADA, Misa; OKA, Jun Ichiro; INAGAKI, Masatoshi; YAMADA, Mitsuhiko. Activation of the prelimbic medial prefrontal cortex induces anxiety-like behaviors via N-Methyl-D-aspartate receptor-mediated glutamatergic neurotransmission in mice. Journal of Neuroscience Research, [S. I.], v. 92, n. 8, p. 1044-1053, 2014. DOI: 10.1002/jnr.23391.

SARKAR, Susanne; SCHAEFER, Martin. Antidepressant pretreatment for the prevention of interferon alfa-associated depression: A systematic review and meta-analysis. Psychosomatics, [S. I.], v. 55, n. 3, p. 221-234, 2014. DOI: 10.1016/j.psym.2013.06.015. http://dx.doi.org/10.1016/j.psym.2013.06.015.

$$
\text { Disponível em: }
$$

SCHAEFER, Martin; SCHWAIGER, Markus; GARKISCH, Andrea S.; PICH, Maurice; HINZPETER, Axel; UEBELHACK, Ralf; HEINZ, Andreas; VAN 
BOEMMEL, Florian; BERG, Thomas. Prevention of interferon-alpha associated depression in psychiatric risk patients with chronic hepatitis $\mathrm{C}$. Journal of Hepatology, [S. I.], v. 42, n. 6, p. 793-798, 2005. DOI: 10.1016/j.jhep.2005.01.020.

SCOPINHO, America Augusto; SCOPINHO, Michele; LISBOA, Sabrina Francesca; CORREA, Fernando Morgan de Aguiar; GUIMARÃES, Francisco Silveira; JOCA, Sâmia Regiane Lourenço. Acute reversible inactivation of the ventral medial prefrontal cortex induces antidepressant-like effects in rats. Behavioural Brain Research, [S. I.], v. 214, n. 2, p. 437-442, 2010. DOI: 10.1016/j.bbr.2010.06.018.

SELYE, H. Forty years of stress research: principal remaining problems and misconceptions. Canadian Medical Association Journal, [S. I.], v. 115, n. 1, p. 53-56, 1976.

SELYE, HANS. A Syndrome produced by Diverse Nocuous Agents. Nature, [S. I.], v. 138, n. 3479, p. 32-32, 1936. DOI: 10.1038/138032a0. Disponível em: http://www.nature.com/articles/138032a0.

SEO, Mi Kyoung et al. Effects of escitalopram and paroxetine on mTORC1 signaling in the rat hippocampus under chronic restraint stress. BMC Neuroscience, [S. I.], v. 18, n. 1, p. 39, 2017. DOI: 10.1186/s12868-017-0357-0. Disponível em: http://bmcneurosci.biomedcentral.com/articles/10.1186/s12868017-0357-0.

SHEN, Jia et al. Neurovascular Coupling in the Dentate Gyrus Regulates Adult Hippocampal Neurogenesis. Neuron, [S. I.], v. 103, n. 5, p. 878- 890.e3, 2019. DOI: $\quad 10.1016 / j$. neuron.2019.05.045.

https://doi.org/10.1016/j.neuron.2019.05.045.

Disponível

em:

SIERRA, Amanda; ENCINAS, Juan M.; DEUDERO, Juan J. P.; CHANCEY, Jessica H.; ENIKOLOPOV, Grigori; OVERSTREET-WADICHE, Linda S.; TSIRKA, Stella E.; MALETIC-SAVATIC, Mirjana. Microglia shape adult hippocampal neurogenesis through apoptosis-coupled phagocytosis. Cell Stem Cell, [S. I.], v. 7, n. 4, p. 483-495, 2010. DOI: 10.1016/j.stem.2010.08.014. Disponível em: http://dx.doi.org/10.1016/j.stem.2010.08.014.

SIERRA, Amanda; PAOLICELLI, Rosa C.; KETTENMANN, Helmut. Cien Años de Microglía: Milestones in a Century of Microglial Research. Trends in Neurosciences, [S. I.], v. 42, n. 11, p. 778-792, 2019. DOI: 10.1016/j.tins.2019.09.004. Disponível em: https://doi.org/10.1016/i.tins.2019.09.004.

SIERRA-MERCADO, Demetrio; PADILLA-COREANO, Nancy; QUIRK, Gregory J. Dissociable roles of prelimbic and infralimbic cortices, ventral hippocampus, and basolateral amygdala in the expression and extinction of conditioned fear. Neuropsychopharmacology, [S. I.], v. 36, n. 2, p. 529-538, 2011. DOI: 10.1038/npp.2010.184. Disponível em: http://dx.doi.org/10.1038/npp.2010.184.

SIMPSON, Carra A.; DIAZ-ARTECHE, Carmela; ELIBY, Djamila; SCHWARTZ, Orli S.; SIMMONS, Julian G.; COWAN, Caitlin S. M. The gut microbiota in anxiety 
and depression - A systematic review. Clinical Psychology Review, [S. I.], v. 83, p. 101943, 2021. DOI: 10.1016/j.cpr.2020.101943. Disponível em: https://linkinghub.elsevier.com/retrieve/pii/S0272735820301318.

SMITH, R. S. The macrophage theory of depression. Medical Hypotheses, [S. I.], v. 36, n. 2, p. 178, 1991. DOI: 10.1016/0306-9877(91)90266-2.BOJE, Kathleen M.; ARORA, Prince K.

SNYDER, Jason S.; SOUMIER, Amélie; BREWER, Michelle; PICKEL, James; CAMERON, Heather A. Adult hippocampal neurogenesis buffers stress responses and depressive behaviour. Nature, [S. I.], v. 476, n. 7361, p. 458-462, 2011. DOI: 10.1038/nature10287.

SONG, Juan et al. Neuronal circuitry mechanism regulating adult quiescent neural stem-cell fate decision. Nature, [S. I.], v. 489, n. 7414, p. 150-154, 2012. DOI: 10.1038/nature11306. Disponível em: http://dx.doi.org/10.1038/nature11306.

STEPHENS, Mary Ann C.; MCCAUL, Mary E.; WAND, Gary S. The Potential Role of Glucocorticoids and the HPA Axis in Alcohol Dependence. Neurobiology of Alcohol Dependence, [S. I.], p. 429-450, 2014. DOI: 10.1016/B978-0-12405941-2.00021-3.

SU, F.; YI, H.; XU, L.; ZHANG, Z. Fluoxetine and S-citalopram inhibit M1 activation and promote M2 activation of microglia in vitro. Neuroscience, [S. I.], v. 294, p. 60-68, 2015. DOI: 10.1016/j.neuroscience.2015.02.028.

SUN, Gerald J. et al. Tangential migration of neuronal precursors of glutamatergic neurons in the adult mammalian brain. Proceedings of the National Academy of Sciences of the United States of America, [S. I.], v. 112, n. 30, p. 94849489, 2015. DOI: 10.1073/pnas.1508545112.

TACIANA, Francisca et al. Major depression model induced by repeated and intermittent lipopolysaccharide administration: Long-lasting behavioral, neuroimmune and neuroprogressive alterations. Journal of Psychiatric Research, [S. I.], v. 107, n. October, p. 57-67, 2018. DOI: 10.1016/j.jpsychires.2018.10.003. Disponível em: https://doi.org/10.1016/j.jpsychires.2018.10.003.

TAN, Yun Long; YUAN, Yi; TIAN, Li. Microglial regional heterogeneity and its role in the brain. Molecular Psychiatry, [S. I.], v. 25, n. 2, p. 351-367, 2020. DOI: 10.1038/s41380-019-0609-8. Disponível em: http://dx.doi.org/10.1038/s41380019-0609-8.

TANAKA, M.; SOTOMATSU, A.; YOSHIDA, T.; HIRAI, S.; NISHIDA, A. Detection of superoxide production by activated microglia using a sensitive and specific chemiluminescence assay and microglia-mediated PC12h cell death. Journal of Neurochemistry, [S. I.], v. 63, n. 1, p. 266-270, 1994. DOI: 10.1046/j.14714159.1994.63010266.x.

TANG, Jie; YU, Wenbo; CHEN, Sheng; GAO, Zidan; XIAO, Baoguo. Microglia Polarization and Endoplasmic Reticulum Stress in Chronic Social Defeat Stress Induced Depression Mouse. Neurochemical Research, [S. I.], v. 43, n. 5, p. 
985-994, 2018. DOI: 10.1007/s11064-018-2504-0. Disponível em: http://dx.doi.org/10.1007/s11064-018-2504-0.

TANG, Wen; MENG, Zhaoyou; LI, Ning; LIU, Yiyan; LI, Li; CHEN, Dongfeng; YANG, Yang. Roles of Gut Microbiota in the Regulation of Hippocampal Plasticity, Inflammation, and Hippocampus-Dependent Behaviors. Frontiers in Cellular and Infection Microbiology, [S. I.], v. 10, n. January, p. 1-15, 2021. DOI: $10.3389 /$ fcimb.2020.611014.

TIMMERMANS, Steven; SOUFFRIAU, Jolien; LIBERT, Claude. A general introduction to glucocorticoid biology. Frontiers in Immunology, [S. I.], v. 10, n. JULY, 2019. DOI: 10.3389/fimmu.2019.01545.

TROUBAT, Romain; LEMAN, Samuel; PINCHAUD, Katleen; SURGET, Alexandre; ROGER, Sébastien; MARIE, Anne; GUISQUET, Le; BRIZARD, Bruno; CAMUS, Vincent. Journal Pre-proofs. [S. I.], 2021. MICHOPOULOS, Vasiliki; POWERS, Abigail; GILLESPIE, Charles F.; RESSLER, Kerry J.; JOVANOVIC, Tanja. Inflammation in Fear-and Anxiety-Based Disorders: PTSD, GAD, and beyond. Neuropsychopharmacology, [S. I.], v. 42, n. 1, p. 254-270, 2017. DOI: 10.1038/npp.2016.146.

TYNAN, Ross J.; NAICKER, Sundresan; HINWOOD, Madeleine; NALIVAIKO, Eugene; BULLER, Kathryn M.; POW, David V.; DAY, Trevor A.; WALKER, Frederick R. Chronic stress alters the density and morphology of microglia in a subset of stress-responsive brain regions. Brain, Behavior, and Immunity, [S. I.], v. 24, n. 7, p. 1058-1068, 2010. DOI: 10.1016/j.bbi.2010.02.001.

TYNAN, Ross J.; WEIDENHOFER, Judith; HINWOOD, Madeleine; CAIRNS, Murray J.; DAY, Trevor A.; WALKER, Frederick R. A comparative examination of the anti-inflammatory effects of SSRI and SNRI antidepressants on LPS stimulated microglia. Brain, Behavior, and Immunity, [S. I.], v. 26, n. 3, p. 469479, 2012. DOI: 10.1016/j.bbi.2011.12.011. Disponível em: http://dx.doi.org/10.1016/i.bbi.2011.12.011.

VAN EEKELEN, J. A. M.; JIANG, W.; DE KLOET, E. R.; BOHN, M. C. Distribution of the mineralocorticoid and the glucocorticoid receptor mRNAs in the rat hippocampus. Journal of Neuroscience Research, [S. I.], v. 21, n. 1, p. 88-94, 1988. DOI: $10.1002 / j n r .490210113$.

VANRYZIN, Jonathan W.; MARQUARDT, Ashley E.; ARGUE, Kathryn J.; VECCHIARELLI, Haley A.; ASHTON, Sydney E.; ARAMBULA, Sheryl E.; HILL, Matthew N.; MCCARTHY, Margaret M. Microglial Phagocytosis of Newborn Cells Is Induced by Endocannabinoids and Sculpts Sex Differences in Juvenile Rat Social Play. Neuron, [S. I.], v. 102, n. 2, p. 435- 449.e6, 2019. DOI: 10.1016/j.neuron.2019.02.006.

https://doi.org/10.1016/j.neuron.2019.02.006.

WALKER, Frederick; NILSSON, Michael; JONES, Kimberley. Acute and Chronic Stress-Induced Disturbances of Microglial Plasticity, Phenotype and Function. Current Drug Targets, [S. I.], v. 14, n. 11, p. 1262-1276, 2013. DOI: 10.2174/13894501113149990208. 
WOHLEB, Eric S.; FRANKLIN, Tina; IWATA, Masaaki; DUMAN, Ronald S. Integrating neuroimmune systems in the neurobiology of depression. Nature Reviews Neuroscience, [S. I.], v. 17, n. 8, p. 497-511, 2016. DOI: 10.1038/nrn.2016.69.

WOHLEB, Eric S.; POWELL, Nicole D.; GODBOUT, Jonathan P.; SHERIDAN, John F. Stress-induced recruitment of bone marrow-derived monocytes to the brain promotes anxiety-like behavior. Journal of Neuroscience, [S. I.], v. 33, n. 34, p. 13820-13833, 2013. DOI: 10.1523/JNEUROSCI.1671-13.2013.

WOHLEB, Eric S.; WU, Min; GERHARD, Danielle M.; TAYLOR, Seth R.; PICCIOTTO, Marina R.; ALREJA, Meenakshi; DUMAN, Ronald S. GABA interneurons mediate the rapid antidepressant-like effects of scopolamine. Journal of Clinical Investigation, [S. I.], v. 126, n. 7, p. 2482-2494, 2016. DOI: $10.1172 / \mathrm{JCl} 85033$.

YAMANISHI, Kyosuke et al. Interleukin-18-deficient mice develop hippocampal abnormalities related to possible depressive-like behaviors. Neuroscience, [S. I.], v. 408, p. 147-160, 2019. DOI: 10.1016/j.neuroscience.2019.04.003. Disponível em: https://doi.org/10.1016/j.neuroscience.2019.04.003.

YANG, Liang et al. Depression-like behavior associated with $E / I$ imbalance of mPFC and amygdala without TRPC channels in mice of knockout IL-10 from microglia. Brain, Behavior, and Immunity, [S. I.], n. March, 2021. DOI: 10.1016/j.bbi.2021.06.015. Disponível em: https://doi.org/10.1016/j.bbi.2021.06.015.

YANG, Ping; GAO, Zhenyong; ZHANG, Handi; FANG, Zeman; WU, Cairu; XU, Haiyun; HUANG, Qing Jun. Changes in proinflammatory cytokines and white matter in chronically stressed rats. Neuropsychiatric Disease and Treatment, [S. I.], v. 11, p. 597-607, 2015. DOI: 10.2147/NDT.S78131.

YOSHIMURA, Reiji; HORI, Hikaru; IKENOUCHI-SUGITA, Atsuko; UMENENAKANO, Wakako; UEDA, Nobuhisa; NAKAMURA, Jun. Higher plasma interleukin-6 (IL-6) level is associated with SSRI- or SNRI-refractory depression. Progress in Neuro-Psychopharmacology and Biological Psychiatry, [S. I.], v. 33, n. 4, p. 722-726, 2009. DOI: 10.1016/j.pnpbp.2009.03.020. Disponível em: http://dx.doi.org/10.1016/j.pnpbp.2009.03.020.

YU, Zhoulong et al. Decreased Density of Perineuronal Net in Prelimbic Cortex Is Linked to Depressive-Like Behavior in Young-Aged Rats. Frontiers in Molecular Neuroscience, [S. I.], v. 13, n. January, p. 1-12, 2020. DOI: 10.3389/fnmol.2020.00004.

ZAKI, Md H.; OKAMOTO, T.; SAWA, T.; FUJII, S.; AKAIKE, T. Nitrative stress in respiratory inflammation caused by influenza virus infection. Clinical and Experimental Allergy Reviews, [S. I.], v. 7, n. 1, p. 19-26, 2007. DOI: 10.1111/j.1365-2222.2007.00120.x. 
ZHANG, J.; FU, S.; SUN, S.; LI, Z.; GUO, B. Inflammasome activation has an important role in the development of spontaneous colitis. Mucosal Immunology, [S. I.], v. 7, n. 5, p. 1139-1150, 2014. DOI: 10.1038/mi.2014.1.

ZHANG, Jinqiang et al. IL4-driven microglia modulate stress resilience through BDNF-dependent neurogenesis. Science Advances, [S. I.], v. 7, n. 12, 2021. DOI: $10.1126 /$ sciadv.abb9888.

ZHENG, Lian Shun et al. Mechanisms for interferon- $\alpha$-induced depression and neural stem cell dysfunction. Stem Cell Reports, [S. I.], v. 3, n. 1, p. 73-84, 2014. DOI: $\quad 10.1016 / j . s t e m c r .2014 .05 .015 . \quad$ Disponível em: http://dx.doi.org/10.1016/j.stemcr.2014.05.015.

ZHU, Dong Ya; LIU, Shu Hong; SUN, Hong Suo; LU, You Ming. Expression of inducible nitric oxide synthase after focal cerebral ischemia stimulates neurogenesis in the adult rodent dentate gyrus. Journal of Neuroscience, [S. I.], v. 23, n. 1, p. 223-229, 2003. DOI: 10.1523/jneurosci.23-01-00223.2003.

ZIV, Yaniv; RON, Noga; BUTOVSKY, Oleg; LANDA, Gennady; SUDAI, Einav; GREENBERG, Nadav; COHEN, Hagit; KIPNIS, Jonathan; SCHWARTZ, Michal. Immune cells contribute to the maintenance of neurogenesis and spatial learning abilities in adulthood. Nature Neuroscience, [S. I.], v. 9, n. 2, p. $268-$ 275, 2006. DOI: 10.1038/nn1629. 


\section{Brain Behavior and Immunity}

\section{Genetic ablation of the inducible form of nitric oxide disrupts immature neuron survival in the adult dentate gyrus.

\author{
--Manuscript Draft--
}

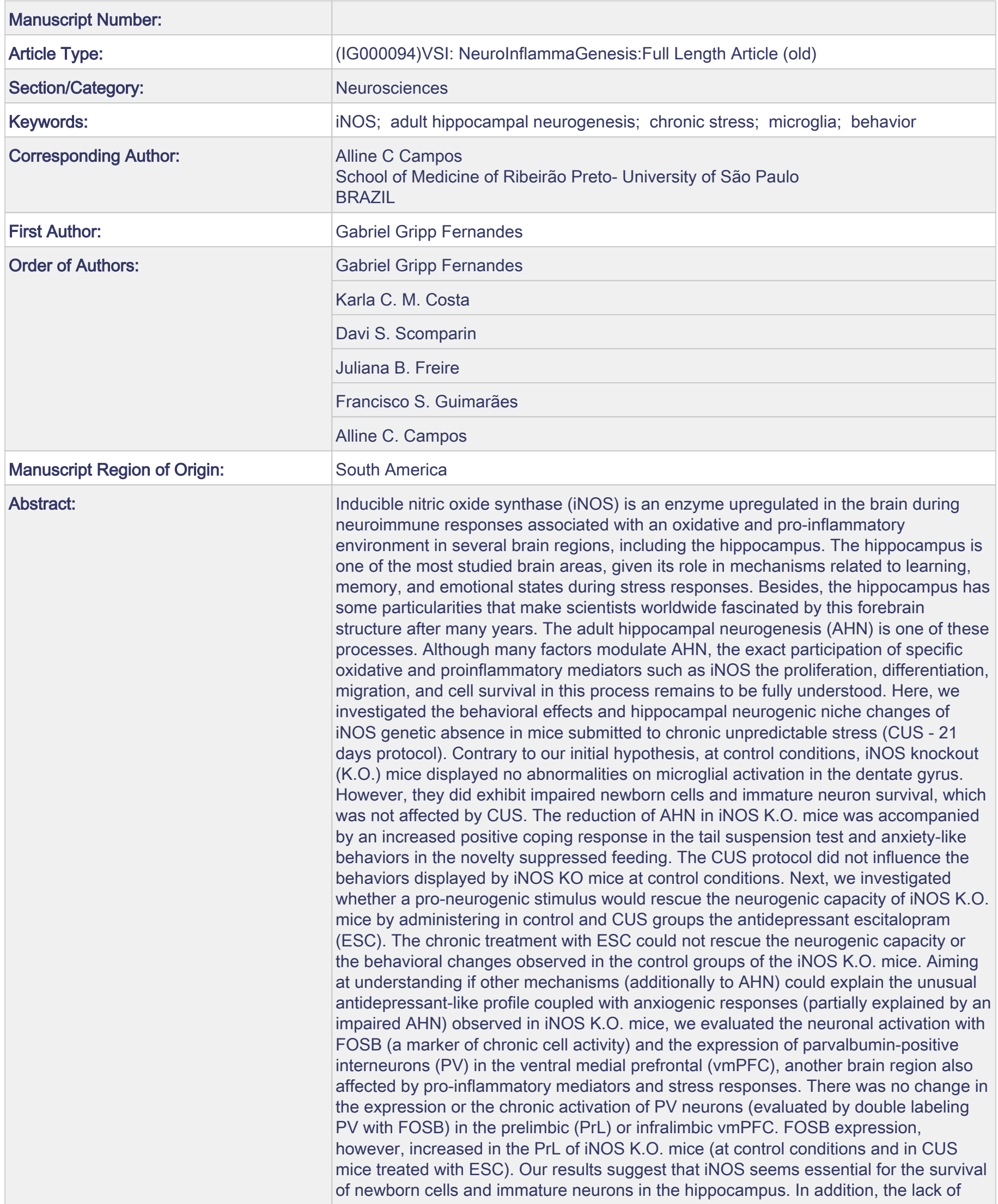


this enzyme appears to result in increased activity of the PrL prefrontal cortex.

Together, these two parallel neurobiological mechanisms could help to explain the opposite effects observed in depressive-like and anxiety-like models. Impaired AHN could result in an anxiogenic-behavioral profile, whereas a higher activity of the PrL cortex could be relevant for the positive copying behaviors observed in the FST.

\begin{tabular}{|l|l|}
\hline Suggested Reviewers: & $\begin{array}{l}\text { Inês Araújo } \\
\text { maraujo@ualg.pt }\end{array}$ \\
\hline $\begin{array}{l}\text { Knut Biber } \\
\text { knut.biber@uniklinik-freiburg.de }\end{array}$ & $\begin{array}{l}\text { Catherine Belzung } \\
\text { catherine.belzung@univ-tours.fr }\end{array}$ \\
\hline
\end{tabular}

Opposed Reviewers: 


\section{UNIVERSIDADE DE SÃO PAULO \\ FACULDADE DE MEDICINA DE RIBEIRÃO PRETO}

Ribeirão Preto, June 30 2021

Maria Antonietta Ajmone Cat

Guest Editor in Brain, Behavior and Immunity

Dear Prof. Ajmone Cat,

Here we present our manuscript, "Genetic ablation of the inducible form of nitric oxide in male mice disrupts immature neuron survival in the adult dentate gyrus" that we want to submit for consideration and possible publication in the Special Issue of Brain, Behavior, and Immunity, "NeuroIflammaGenesis": The interplay between brain inflammation and hippocampal neurogenesis for regulation of cognitive and emotional behavior.

Our study demonstrates that the genetic ablation of the inducible isoform of the enzyme nitric oxide (iNOS) is essential for the survival of adult hippocampal immature newborn neurons in male mice. Furthermore, neither the chronic treatment with antidepressants nor chronic stress changes the hippocampal neurogenic niche of male iNOS K.O.

Besides decreased adult hippocampal neurogenesis, iNOS K.O. mice (males) exhibit increased anxiety-like behaviors (not potentiated by chronic stress nor attenuated by antidepressants), suggesting iNOS can mediate the decreased survival of newborns hippocampal neurons leads to anxious states. However, this assumption seems to not be valid for depressive-like or positive coping behaviors.

We attest that all authors listed in the manuscript contributed substantially to the study design, experiments performed, and the document's final version. All authors approved the current version of the manuscript before its submission.

Our study has not been published elsewhere, nor is it currently under consideration for publication elsewhere.

This manuscript is in accordance with the Authorship statement of ethical standards for manuscripts submitted to Brain, Behavior, and Immunity.

We have no conflicts of interest to disclose.

Thank you for considering our manuscript, and we look forward to receiving the reviewers' comments on our study.

Sincerely,

Alline Cristina de Campos, B.Pharm, Ph.D

Assistant Professor

Departament of Pharmacology

Ribeirão Preto Medical School- USP

Email: allinecampos@usp.br 


\section{Highlights}

- Genetic ablation of iNOS disrupts adult newborn neurons survival on dentate gyrus

- CUS or escitalopram fails to impair or rescue the AHN of iNOS K.O. mice.

- CUS or escitalopram does not modify the iNOS K.O. mice behavior

- CUS does not modify microglia morphology on neurogenic niche. 


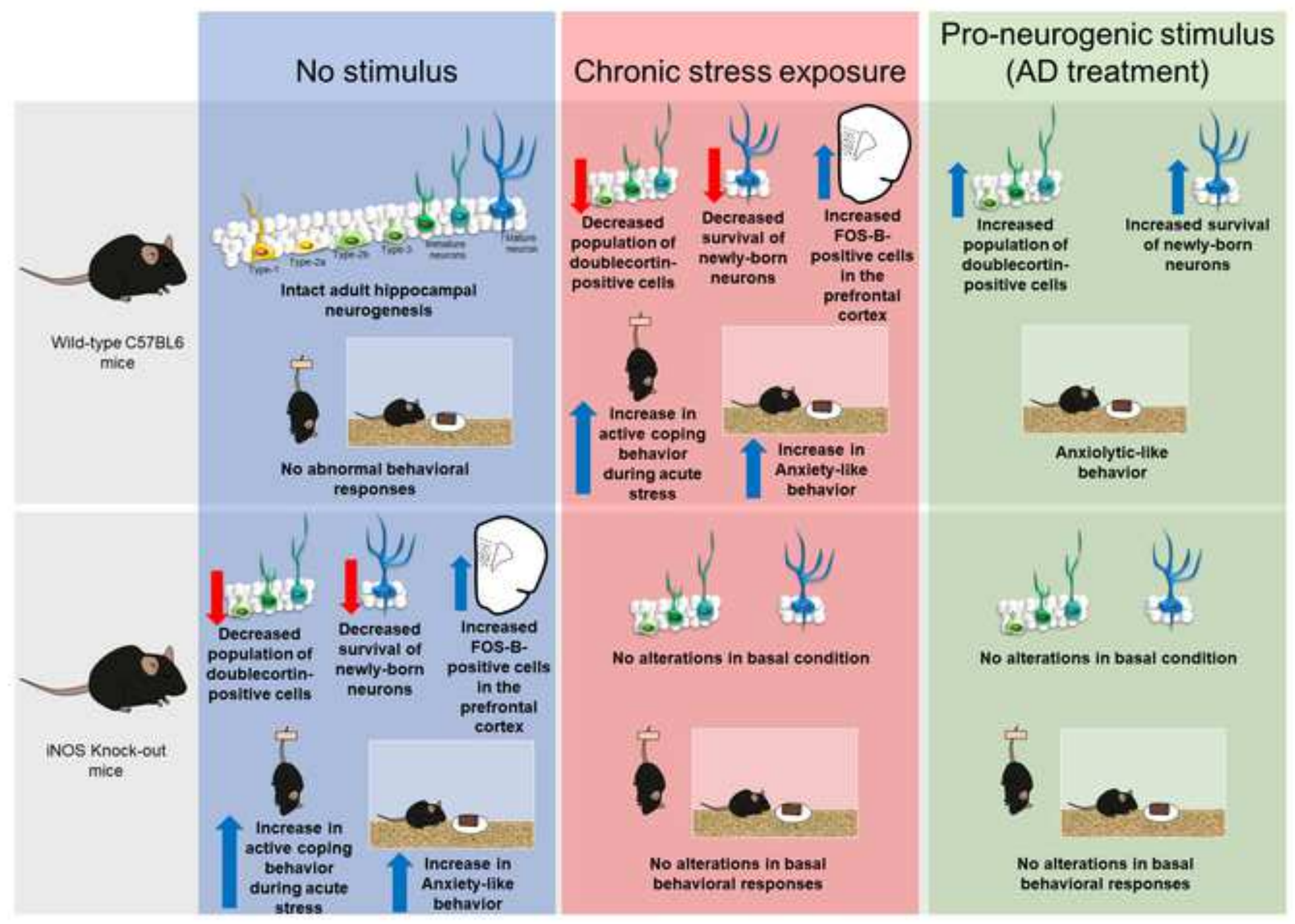

\section{Chronic stress exposure}

mice

normal behavioral

ponses

ring acute

Anxiety-jike
behavior behavioral responses

behavioral responses

\section{Pro-neurogenic stimulus (AD treatment)}

No alterations in basal condition 


\section{Title page}

Genetic ablation of the inducible form of nitric oxide disrupts immature neuron survival in the adult dentate gyrus.

Gabriel G. Fernandes ${ }^{a}$, Karla C. M. Costa ${ }^{a}$, Davi S. Scomparin ${ }^{a}$, Juliana B. Freire ${ }^{a}$, Francisco S. Guimarães ${ }^{\mathrm{a}}$, Alline C. Campos ${ }^{\mathrm{a} *}$.

${ }^{\text {a }}$ Department of Pharmacology, Ribeirão Preto Medical School, University of São Paulo Brazil.

\section{*Corresponding author:}

\section{Alline C Campos}

Assistant Professor

Laboratory of Pharmacology of Neuroplasticity

Department of Pharmacology

Ribeirão Preto Medical School

3900 Bandeirantes avenue-Monte Alegre-Ribeirão Preto-São Paulo-Brazil- 14049-900

Phone: +551633150217

Email: allinecampos@usp.br

Keywords: iNOS; adult hippocampal neurogenesis; chronic stress; microglia; behavior.

Running title: iNOS and adult hippocampal neurogenesis 


\section{Abstract}

Inducible nitric oxide synthase (iNOS) is an enzyme upregulated in the brain during neuroimmune responses associated with an oxidative and pro-inflammatory environment in several brain regions, including the hippocampus. The hippocampus is one of the most studied brain areas, given its role in mechanisms related to learning, memory, and emotional states during stress responses. Besides, the hippocampus has some particularities that make scientists worldwide fascinated by this forebrain structure after many years. The adult hippocampal neurogenesis (AHN) is one of these processes. Although many factors modulate AHN, the exact participation of specific oxidative and proinflammatory mediators such as iNOS the proliferation, differentiation, migration, and cell survival in this process remains to be fully understood. Here, we investigated the behavioral effects and hippocampal neurogenic niche changes of iNOS genetic absence in mice submitted to chronic unpredictable stress (CUS - 21 days protocol). Contrary to our initial hypothesis, at control conditions, iNOS knockout (K.O.) mice displayed no abnormalities on microglial activation in the dentate gyrus. However, they did exhibit impaired newborn cells and immature neuron survival, which was not affected by CUS. The reduction of AHN in iNOS K.O. mice was accompanied by an increased positive coping response in the tail suspension test and anxiety-like behaviors in the novelty suppressed feeding. The CUS protocol did not influence the behaviors displayed by iNOS KO mice at control conditions. Next, we investigated whether a pro-neurogenic stimulus would rescue the neurogenic capacity of iNOS K.O. mice by administering in control and CUS groups the antidepressant escitalopram (ESC). The chronic treatment with ESC could not rescue the neurogenic capacity or the behavioral changes observed in the control groups of the iNOS K.O. mice. Aiming at understanding if other mechanisms (additionally to AHN) could explain the unusual antidepressant-like profile coupled with 
anxiogenic responses (partially explained by an impaired AHN) observed in iNOS K.O. mice, we evaluated the neuronal activation with FOSB (a marker of chronic cell activity) and the expression of parvalbumin-positive interneurons (PV) in the ventral medial prefrontal (vmPFC), another brain region also affected by pro-inflammatory mediators and stress responses. There was no change in the expression or the chronic activation of PV neurons (evaluated by double labeling PV with FOSB) in the prelimbic (PrL) or infralimbic vmPFC. FOSB expression, however, increased in the PrL of iNOS K.O. mice (at control conditions and in CUS mice treated with ESC). Our results suggest that iNOS seems essential for the survival of newborn cells and immature neurons in the hippocampus. In addition, the lack of this enzyme appears to result in increased activity of the PrL prefrontal cortex. Together, these two parallel neurobiological mechanisms could help to explain the opposite effects observed in depressive-like and anxiety-like models. Impaired AHN could result in an anxiogenic-behavioral profile, whereas a higher activity of the PrL cortex could be relevant for the positive copying behaviors observed in the FST. 


\section{Introduction}

Adult hippocampal neurogenesis (AHN) consists of a well-orchestrated form of neuroplasticity present amongst several mammals, including humans, that involves symmetrical and asymmetrical division of neural stem cells (NSCs) present in the subgranular zone of the dentate gyrus, their migration towards the granular layer and their maturation and integration onto the local neurocircuitry (Altman and Das, 1965; Eriksson et al., 1998; Kempermann et al., 2015).

Although their exact function remains obscure, several lines of evidence suggest that $\mathrm{AHN}$ is an important mediator needed for a proper behavioral and physiological response to acute and chronic stress (Anacker et al., 2018; Eliwa et al., 2021; Snyder et al., 2011). Impairment of AHN has been associated with the development of depressive and anxiety disorders (Surget and Belzung, 2021). Stress hormones and stress exposure are important negative modulators of AHN (Gould et al., 1992; Gould and Cameron, 1996). Preclinical studies suggest that inflammatory mediators may underlie the antineurogenic effects of stress (Ja and Duman, 2008; Koo et al., 2010). Corroborating this hypothesis, patients suffering from depressive or anxiety disorders have altered levels of circulating cytokines (Dowlati et al., 2010; Howren et al., 2009; Michopoulos et al., 2017; O’Brien et al., 2007; Yoshimura et al., 2009).

Several proinflammatory cytokines upregulate the expression of inducible nitric oxide synthase (iNOS) (Saha and Pahan, 2006; Zaki et al., 2007), raising the possibility that this enzyme could be an effector of the neurogenic suppressive effects of stress. Furthermore, in contrast to the other isoforms of NOS, upon activation, this enzyme produces high NO levels from L-arginine, which creates a toxic environment due to its oxidative properties (Calabrese et al., 2007). 
In preclinical studies, pharmacological or genetic manipulation of iNOS in rodents reveal antidepressant-like behaviors in the forced swim test (FST) (Montezuma et al., 2012) anti-anhedonic-like behavior in chronic stress models (Peng et al., 2012). Noteworthy, iNOS is elevated in the peripheral blood of depressed patients (Gałecki et al., 2012), and polymorphism in this enzyme is associated as an increased risk -factor for recurrent depressive disorder (Gałecki et al., 2010).

Only a few studies have investigated the role of iNOS in adult neurogenesis. Carreira and colleagues (2014) showed that, after a proinflammatory stimulus, the proliferation of neural precursor cells decreased in another neurogenic nice, the subventricular zone (SVZ). In addition, the antiproliferative effects of a proinflammatory stimulus were mediated by iNOS present in microglia cells (Carreira et al., 2014).

Microglia is recognized as the immunocompetent glia cell present throughout the central nervous system (Helmut et al., 2011). Besides, microglia cells have been identified as an important player in the neurogenic process, eliminating apoptotic new-born cells (Sierra et al., 2010), releasing factors that may enhance (Zhang et al., 2021) or diminish (Ekdahl et al., 2003) new-born cells proliferation and/or survival (Ekdahl et al., 2009; Gemma and Bachstetter, 2013). Chronic stress exposure recruits these cells (Hellwig et al., 2016; Kreisel et al., 2014; Walker et al., 2013) and promotes phenotypic changes associated with an inflammatory profile, such as increased expression of inflammatory mediators and iNOS (Ramirez et al., 2015; Tang et al., 2018; Zhang et al., 2021).

Therefore, our initial hypothesis was that genetic ablation of iNOS would prevent the neurogenic and behavioral effects of chronic stress by precluding microglia from assuming a proinflammatory phenotype. Surprisingly, here we report that iNOS knockout (K.O.) mice had an impaired AHN that was not altered by CUS exposure nor accompanied by microglia morphological changes. Also, iNOS K.O. mice displayed an 
active coping response and an anxiogenic-like phenotype that was not affected by CUS. Chronic treatment with escitalopram did not modify the neurogenic and behavioral changes observed in these animals. Considering that parvalbumin (PV) interneurons in the prefrontal cortex are also capable of modulating depressive- and anxiety-like behaviors (Fogaça et al., 2020; Nawreen et al., 2020; Page et al., 2019), we decided to investigate the impact of iNOS deletion in another region and cell population associated with these changes. We observed that neither PV density nor their recruitment was affected by our manipulation. iNOS K.O. mice, however, showed increased levels of FOSB, a transcription factor associated with neuronal recruitment and activation, in the prelimbic (Nestler et al., 1999). Therefore, the anxiogenic profile related to the facilitation of acute stress coping strategies observed in iNOS K.O. mice may reflect distinct cellular modifications (impaired AHN coupled with increased prelimbic acidity).

\section{Material and Methods}

\subsection{Animals}

All experiments involving animals were conducted following the ARRIVE guidelines (Percie du Sert et al., 2020). Animal procedures were previously approved by the Experimental Committee of the University of São Paulo (protocol number 182/2017), which conforms to the Brazilian College of Animal Experimentation (COBEA). Male iNOS knockout (iNOS K.O.) and WT C57BL6 mice were acquired from the Special Mice Breeding Center and Central Animal House Facility of the University of São Paulo, Ribeirão Preto, respectively. For outbred experiments, 28 iNOS K.O. and 26 WT mice were obtained with matching ages and left undisturbed until 8-10 weeks old when they were used for experimental protocols. For the inbred experiment, female iNOS K.O. was bred with male WT C57BL6 on their matching ages. Their progeny, iNOS heterozygote 
(iNOS Het), were bred and all males (20 iNOS K.O., 14 iNOS Het, and 15 WT littermates) were separated and genotyped for subsequent experiments. Mice were housed in groups of 4-5 per cage. Until the stress protocol started, all mice were kept in a quiet room with controlled temperature $\left(24 \pm 1^{\circ} \mathrm{C}\right)$, humidity, a dark-light cycle of $12 \mathrm{~h}$ (lights on at 6:30 a.m.) with water and food ad libitum. To avoid acute stress due to the new environment, animals were allowed to acclimate for at least $1 \mathrm{~h}$ to the experimental room throughout all the behavioral procedures.

\subsection{Drugs}

The following drugs were used: 5-Bromo-2'-deoxyuridine (BrdU; Sigma-Aldrich, MO, USA; 200 mg/Kg) (Balu et al., 2009) and escitalopram (Esc; Pratti-Donaduzzi, PR, Brazil; $10 \mathrm{mg} / \mathrm{Kg}$ ) (preprint study from our lab Scarante, 2021; Seo et al., 2017). Ketamine and xylazine (both from Syntec, SP, Brazil; $150 \mathrm{mg} / \mathrm{Kg}$ and $8 \mathrm{mg} / \mathrm{Kg}$, respectively) were used diluted in saline $0.9 \%$ as an anesthetic for tissue collection protocol.

\subsection{Stress protocol and behavioral tests}

\subsubsection{Chronic Unpredictable Stress}

WT and iNOS KO mice (outbred and inbred) were submitted to a randomized protocol of chronic unpredictable stress (CUS) for 21 consecutive days (Campos et al., 2013; Santarelli et al., 2003). The CUS protocol consists of submitting the animals to one of the following daily stressors chosen randomly between the weeks to avoid habituation: forced swimming (15 minutes), restraint stress (2 hours), intermittent dark/light cycle (24h), inverted dark/light cycle (24h), wet bedding (24h), tilted cage (overnight) and food deprivation (24h) (adapted from Willner et al., 1992). 


\subsubsection{Novelty-suppressed feeding test (NSFT)}

The animals were placed in a square acrylic box $(50 \times 50 \times 40 \mathrm{~cm})$ with the floor covered with sawdust. In the middle of the arena, a single pellet of food was placed on the top of a platform. Each animal was placed in one of the apparatus corners, and the latency to start feeding was measured with a cutoff period of 10 minutes. After the test, all animals returned to their home cages, and the amount of food consumed in a total period of 5 minutes was measured (Campos et al., 2013; Fogaça et al., 2018).

\subsubsection{Tail suspension test (TST)}

Animals were suspended by their tail at the height of $60 \mathrm{~cm}$ and fixed by adhesive tape on a wooden surface. The experiment was recorded and the latency for the first immobile episode and time spent immobile during the 6 minutes was analyzed by an experimenter blinded to the animal experimental group. Animals that climbed or fell during the experimental session were excluded from the analysis (Can et al., 2011).

\subsubsection{Open field test (OFT)}

The OFT was performed as a movement control to exclude any possible bias in NSFT and TST. The apparatus consisted of a circular arena with a diameter of $30 \mathrm{~cm}$. The test duration was 5 minutes and was performed in a sound-attenuated and temperaturecontrolled room. To analyze the total distance traveled, the ANYMAZE software (Stoelting Co, IL, USA) was used (Montezuma et al., 2012).

\subsection{Behavioral experiments design}

2.4.1 Experiment 1: effects of chronic unpredictable stress (CUS) on iNOS KO mice 
All animals received $1 \mathrm{~h}$ before the first stressor $200 \mathrm{mg} / \mathrm{Kg}$ of BrdU, as illustrated in Figure 1A. Mice of all genotype groups were submitted to the CUS protocol or remained undisturbed on their home cage to serve as non-stressed controls. On the $20^{\text {th }}$ day of the experimental protocol, the animals were submitted to the OFT at 8 a.m., and subsequently to the TST at 1 p.m. On the $21^{\text {st }}$ day, all animals had their food removed, and after $24 \mathrm{~h}$ were submitted to the NSFT. Twenty-four hours after the test, the animals were perfused and their brains removed for immunohistochemical assay (Fig 1A).

\subsubsection{Experiment 2: effect of escitalopram on iNOS KO mice submitted to CUS}

As illustrated in Figure 1B, all animals receive $1 \mathrm{~h}$ before the first stressor 200 $\mathrm{mg} / \mathrm{kg}$ of BrdU. A randomized group of animals was submitted to the CUS protocol or remained undisturbed in their home cage. During CUS protocol, animals were treated with escitalopram $(10 \mathrm{mg} / \mathrm{Kg})$ or vehicle from 4 p.m to 5 p.m. On the $20^{\text {th }}$ day of the experimental protocol, the animals were submitted to the OFT (experiments starting at 8 a.m) and the TST (experiments beginning at 1 p.m). On the $21^{\text {st }}$ day, all groups of animals had their food removed and after 20-24h were submitted to the NSFT. Twenty-four hours after the test, the animals were perfused and their brains removed for immunohistochemical assay (Fig 1B). 

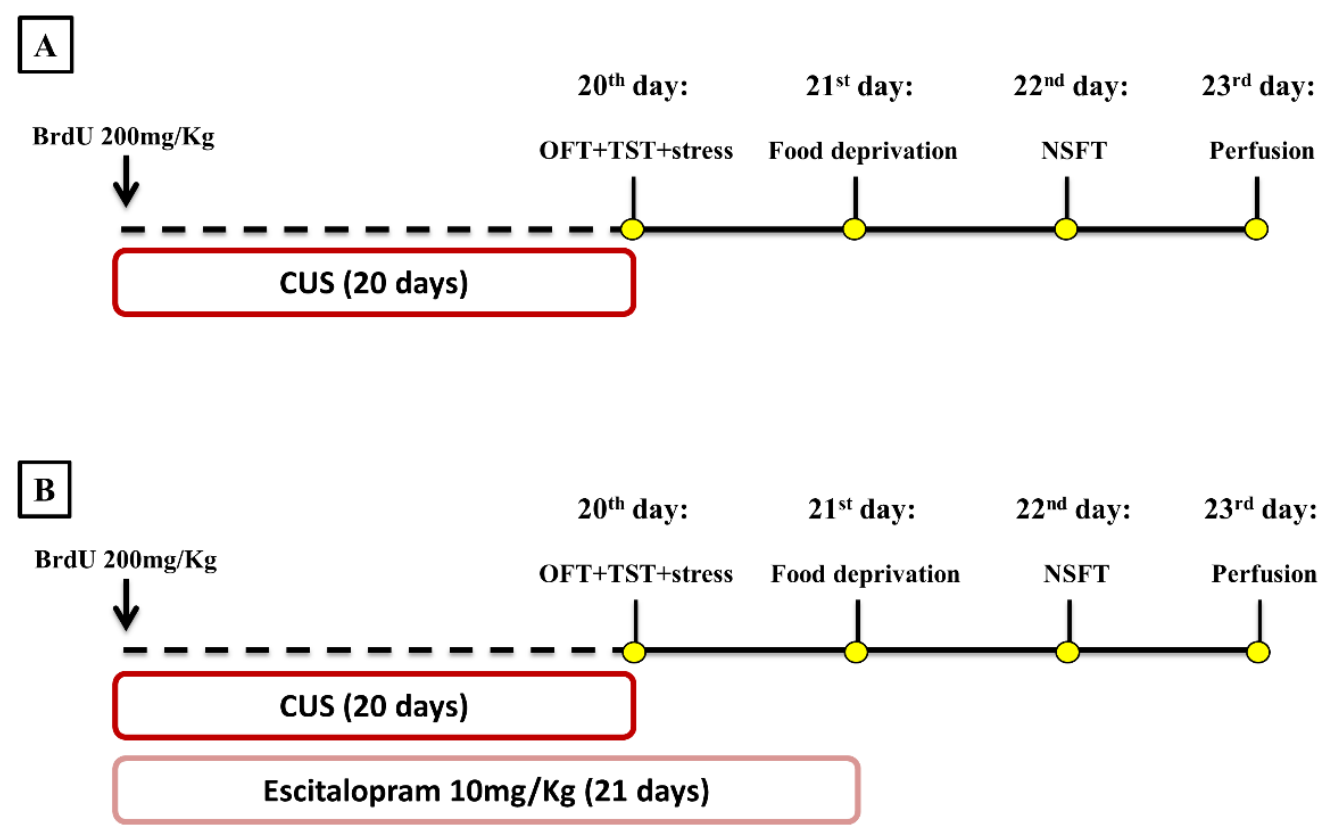

Figure 1: Schematic representation of the treatments, stress protocols, and behavioral assessment time course. Animals received a single dose of BrdU $200 \mathrm{mg} / \mathrm{Kg} 1 \mathrm{~h}$ before the CUS protocol start. Independent experimental groups were treated with ESC 10 $\mathrm{mg} / \mathrm{Kg}$ by 21 days (B), while controls remained without pharmacological manipulation (A). CUS protocol lasted for 20 days and was followed by OFT and TST tests on the $20^{\text {th }}$ day, food deprivation on the $21^{\text {st }}$ day, and NSFT on the $22^{\text {nd }}$ day. All animals had their brain collected for posterior analysis.

\subsection{Immunoassays}

\subsubsection{Tissue preparation}

The animals were anesthetized with xylazine/ketamine and transcardially perfused with $0.01 \mathrm{M}$ PBS followed by $4 \%$ PFA in $0.2 \mathrm{M}$ PB for the immunoassays. The brains were removed and post-fixed for $24 \mathrm{~h}$ in $4 \%$ PFA. The brains were transferred to a $30 \%$ sucrose solution for a week and then frozen on $-30^{\circ} \mathrm{C}$ isopentane for cryoprotection. Eight to ten coronal slices with $30 \mu \mathrm{m}$ thick were obtained from the prefrontal cortex (Bregma -2.1 to $-1.5 \mathrm{~mm}$ ) and hippocampus (Bregma 1.46 to $3.08 \mathrm{~mm}$ ) using a cryostat at $-20^{\circ} \mathrm{C}$. 
The sections were kept in an anti-freezing solution (30\% ethylene glycol/20\% glycerol); until the assays were performed.

\subsubsection{Immunohistochemistry for detection of DCX}

Briefly, free-floating sections were washed three times with TBS (Tris Buffered saline, $50 \mathrm{mM}$ - 15 minutes each) followed by $30 \mathrm{~min}$ incubation with citrate buffer 10 $\mathrm{mM}(\mathrm{pH}=6.0)$ at $70^{\circ} \mathrm{C}$ for antigen retrieval. After three washes with TBS (15 min/wash), the sections were incubated with a blocking solution (TBS + Triton X $0.025 \%+$ BSA $0.1 \%$ ) for 4 hours followed by overnight incubation under agitation $\left(18^{\circ} \mathrm{C}\right)$ with antiDCX primary antibody (Santa Cruz Biotechnology, TX, USA; goat; 1:200). After three times washes with TBS, the sections were incubated for $1.5 \mathrm{~h}$ with a secondary antibody (Vectastain anti-goat biotinylated; 1:1000). Next, the complex $\mathrm{A}+\mathrm{B}$ reaction was performed for 1h (1:500, ABC Elite-Vectastain kit, Vector Labs, Burlingame, CA, USA) followed by incubation with 3,3'-Diaminobenzidine $(0.2 \mathrm{mg} / \mathrm{ml}, 10 \mathrm{~min}$, Sigma-Aldrich; MO, USA).

\subsubsection{Immunofluorescence for detection of BrdU, DCX, and NeuN}

After three washes with TBS, free-floating sections were incubated for $30 \mathrm{~min}$ with $\mathrm{HCl} 2 \mathrm{~N}$ at $37^{\circ} \mathrm{C}$, followed by two washes with boric acid $(0.1 \mathrm{M} ; \mathrm{pH}=8.9 ; 10$ $\min$ /wash) for antigen retrieval. The sections were incubated with the blocking solution (TBS + Triton $\mathrm{X} 0,025 \%+$ BSA $0.1 \%$ ) for 4 hours, and then incubated with anti-BrdU (Abcam; Cambridge, England, UK; rabbit; 1:100), anti-DCX (Cell-Signaling; rat; 1:500) and anti-NeuN (Millipore; MA, USA; mouse; 1:500) primary antibodies overnight at $18^{\circ} \mathrm{C}$ under agitation. On the next day, the sections were washed three times with TBS-T (Tris-buffered saline with $10 \%$ Triton) and incubated for $1.5 \mathrm{~h}$ with the secondary 
antibodies (anti-rabbit AlexaFluor 488, anti-rat Alexa-Fluor 594, and anti-mouse AlexaFluor 647; Invitrogen, Massachusetts, USA)

\subsubsection{Immunofluorescence for detection of IBA-1, GFAP, SOX2, PV, and FOSB}

As described in item 2.5.2, after the blocking section, slices were incubated with antiIBA1 (Wako; VA; USA; rabbit; 1:1000) or with anti-GFAP (Cell-Signaling; MA; USA; mouse; 1:500) plus SOX2 (Millipore; MA, USA; rabbit; 1:500) or with anti-Parvalbumin (Sigma-Aldrich; MO, USA; mouse; 1:500) plus FOSB (Cell-Signaling; MA; USA; rabbit; 1:500). Then, sections were incubated for $1.5 \mathrm{~h}$ with secondary antibodies (antirabbit AlexaFluor 488, anti-mouse AlexaFluor 594; Invitrogen, Massachusetts, USA) Hoechst staining (1:10,000 from $2 \mu \mathrm{g} / \mathrm{mL}$ stock solution) was used to visualize the cortex and hippocampus.

\subsubsection{Image acquisition and quantification}

\subsubsection{Confocal quantification of BrdU/DCX/NeuN, GFAP/SOX2, and PV/FosB}

BrdU positive cells located at the granular layer of the dentate gyrus were visualized and manually quantified at 40X objective using Leica TSE-SPE microscope (Leica, Wetzlar, Germany). Confocal microscopy (Leica TSE-SPE) was performed for double and triple staining in the following sets: BrdU/DCX/NeuN, smart-gain:840V; GFAP/SOX2, smart-gain: 890V; PV/FOS, smart-gain: 950V. In all analyses, the smart offset was set as $-100 \%$, cells were tracked using z-stacks ( 6 steps) and visualized by 3D projections using the Leica X Software (Leica Microsystem, Wetzlar, Germany). For hippocampal staining, at least 6 slices containing both dentate gyri were analyzed. The absolute number of positive cells was calculated by the sum of the areas analyzed multiplied by the distance between them (Campos et al., 2013). For cortical staining, at 
least eight slices were analyzed, and the density of cells was calculated by dividing the number of positive cells and the area analyzed.

\subsubsection{IBA-1 quantification and Sholl analysis}

IBA-1 positive cells were quantified on the granular layer of dentate gyrus using the epifluorescence microscope (Olympus, Shinjuku, Tokyo, Japan; 40X objective). The cell density was calculated by normalizing the number of cells counted by the area analyzed (measured using 10x objective). For Sholl analysis, IBA-1 positive cells located at the granular layer of the dentate gyrus were reconstructed using confocal microscopy (Leica TSE-SPE, objective 63X, smart-gain: 940V), and data were analyzed using Imaris Filament Tracer (v 9.3.1). Only cells presenting a whole labeling and visible process on 3D reconstruction were analyzed for their total process length and Sholl analysis parameter using concentric spheres of 5um radii. A total of 15 cells per animal were analyzed, totalizing 75 cells per group (Hellwig et al., 2016).

\subsubsection{Quantification of FOSB+ and PV+ cells}

For FOSB and PV cell quantification, images were acquired using the Leica TSESPE 20X objective. Positive cells were visualized and manually counted using Leica X Software (Leica Microsystem, Wetzlar, Germany). Values were normalized by the area analyzed using the same software.

\subsection{Statistical analysis}

All data were analyzed for normal distribution using the Kolmogorov-Smirnov test and for homoscedasticity using Levene's test before analysis. Data from inbred NSFT (Suppl Fig 1D) and SOX2/GFAP analysis (Fig 5G) did not follow these prerequisites. 
They were analyzed using the nonparametric Kruskal-Wallis and Mann-Whitney tests, with data represented as median and interquartile range. Otherwise, data collected from experiment 1 were analyzed using two-way ANOVA (factor 1: stress; factor 2: genotype), and data gathered from experiment 2 were analyzed using three-way ANOVA (factor 1: stress; factor 2: genotype; factor 3: treatment). When appropriated, Duncan's post hoc test was performed. $\mathrm{P}$ values equal to or lower than 0.05 were considered significant. Data are represented as mean \pm standard error of the mean (SEM).

\section{Results}

3.1 The iNOS K.O. mice exhibited decreased survival rates of newborn cells in the DG without changes in the pattern of microglial activation

Initially, we investigated neurogenic parameters in iNOS $\mathrm{KO}$ under control or submitted to CUS. Surprisingly, iNOS K.O. mice present a lower number of neuroblasts expressing doublecortin (DCX - classified as Type IIb and III). Different from WT animals, CUS did not affect the number of DCX+ cells ( 2 way-ANOVA $d f=1,19$; genotype: $\mathrm{F}=35.94, \mathrm{p}<0.05$; stress: $\mathrm{F}=5.87, \mathrm{p}<0.05$; interaction: $\mathrm{F}=3.20$; Fig $2 \mathrm{~A}$ ). As these cells migrate towards the granular layer to maturate and integrate the regional circuitry, we assessed the number of DCX+ present on the granular layer. Corroborating our previous observation, iNOS mice had a reduced number of DCX + on the granular layer that was not affected by CUS (Two way-ANOVA df=1,19; genotype: $F=36.84$, $\mathrm{p}<0.05$; stress: $\mathrm{F}=1.36$; interaction: $\mathrm{F}=3.06$; Fig 2B-C).

Next, we addressed the question of whether our results with DCX cells would reflect a reduced survival rate of adult newborn neurons. First, we evaluated the total number of BrdU+ cells 23 days after BrdU administration. Our results showed that iNOS K.O. mice had a reduced number of BrdU+ cells on the dentate gyrus, that was unaffected 
by CUS (Two way-ANOVA $\mathrm{df}=1,17$; genotype: $\mathrm{F}=21.97, \mathrm{p}<0.05$; stress: $\mathrm{F}=2.61$; interaction: $F=3.15$; Fig 2D). We also analyzed the phenotype of BrdU+ cells by performing a triple-staining analysis $(\mathrm{BrdU}+\mathrm{DCX}+\mathrm{NeuN})$. Cells classified as type IIb/III $(\mathrm{BrdU}+\mathrm{DCX}+\mathrm{NeuN}+)$ were reduced in iNOS K.O. mice (Two way-ANOVA $\mathrm{df}=1,17$; genotype: $\mathrm{F}=21.99, \mathrm{p}<0.05$; stress: $\mathrm{F}=2.65$; interaction: $\mathrm{F}=3.16$; Fig $2 \mathrm{E}$ ). In the same direction, we observed that mature neurons $(\mathrm{BrdU}+\mathrm{NeuN}+)$ were reduced on iNOS K.O. mice and unaffected by CUS. Interestingly, CUS reduced the survival of adult newborn neurons on WT mice (Two way-ANOVA df=1,17; genotype: $\mathrm{F}=20.87, \mathrm{p}<0.05$; stress: $\mathrm{F}=4.40, \mathrm{p}=0.054$; interaction: $\mathrm{F}=4.63, \mathrm{p}<0.05$; Fig $2 \mathrm{~F}$ ). Representative images of each marker are found in Fig 2G. 

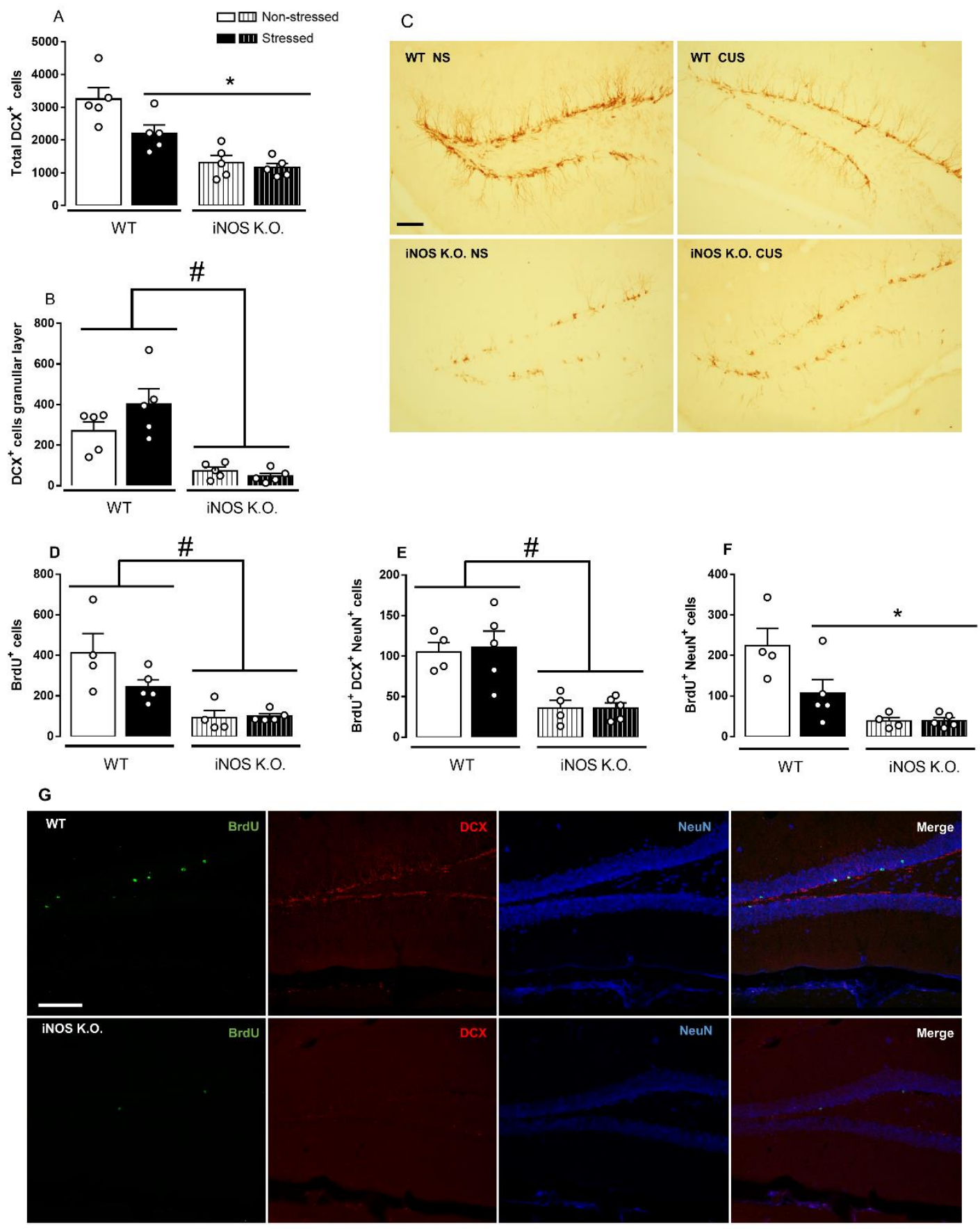

Figure 2: Adult-hippocampal neurogenesis is impaired on iNOS K.O.mice and does not exacerbate after CUS exposure. Quantification of neuroblast revealed a reduced number and migration towards the granular layer on iNOS K.O.mice that did not alter after CUS (A and B, respectively). Representative image of neuroblast (DCX+ cells) on the dentate gyrus of all groups analyzed $(\mathrm{n}=5 /$ group, scale bar $=100 \mu \mathrm{m})(\mathrm{C})$. BrdU incorporation analysis revealed a reduced survival of adult-born new neurons on iNOS K.O.mice that 
was not affected by CUS (D, E, and F; n=4,5,4 and 5 respectively). Representative images of immunofluorescence technique showing BrdU, DCX NeuN, and the merge of these markers in WT non-stress and iNOS K.O. non-stressed group (scale bar $=100 \mu \mathrm{m})(\mathrm{G})$. Data present as mean $\pm \mathrm{SEM} *$ indicates $\mathrm{p}<0.05$ compared to WT NS mice. \# indicates $\mathrm{p}<0.05$ on genotype factor.

As microglia cells are a major player during all phases of AHN (Sierra et al., 2010, Sato, 2015), we investigated their density in the granular layer of the dentate gyrus of mice submitted to CUS. We also evaluated their morphology, which has been associated with their phenotype and properties (Lopez-Rodrigues et al., 2015, Hellwig et al., 2016). CUS had no effect on microglia density in the dentate gyrus (Two way-ANOVA $\mathrm{df}=1,19$; genotype: $\mathrm{F}=0.32$; stress: $\mathrm{F}=2.16$; interaction: $\mathrm{F}=1.80$; Fig $3 \mathrm{~A})$. Regarding their morphological features (Fig 3C), none of our manipulations modified their process length (Two way-ANOVA df=1,19; genotype: $F=3.66$; stress: $F=0.03$; interaction: $F=0.47$; Fig 3B). Sholl's analysis revealed that there were no differences regarding their interaction with $5 \mu \mathrm{m}$ radii spheres (Fig 3D) and total intersections (Two way-ANOVA $\mathrm{df}=1,19$; genotype: $\mathrm{F}=3.45$; stress: $\mathrm{F}=0.25$; interaction: $\mathrm{F}=0.01$; Fig 3E). 

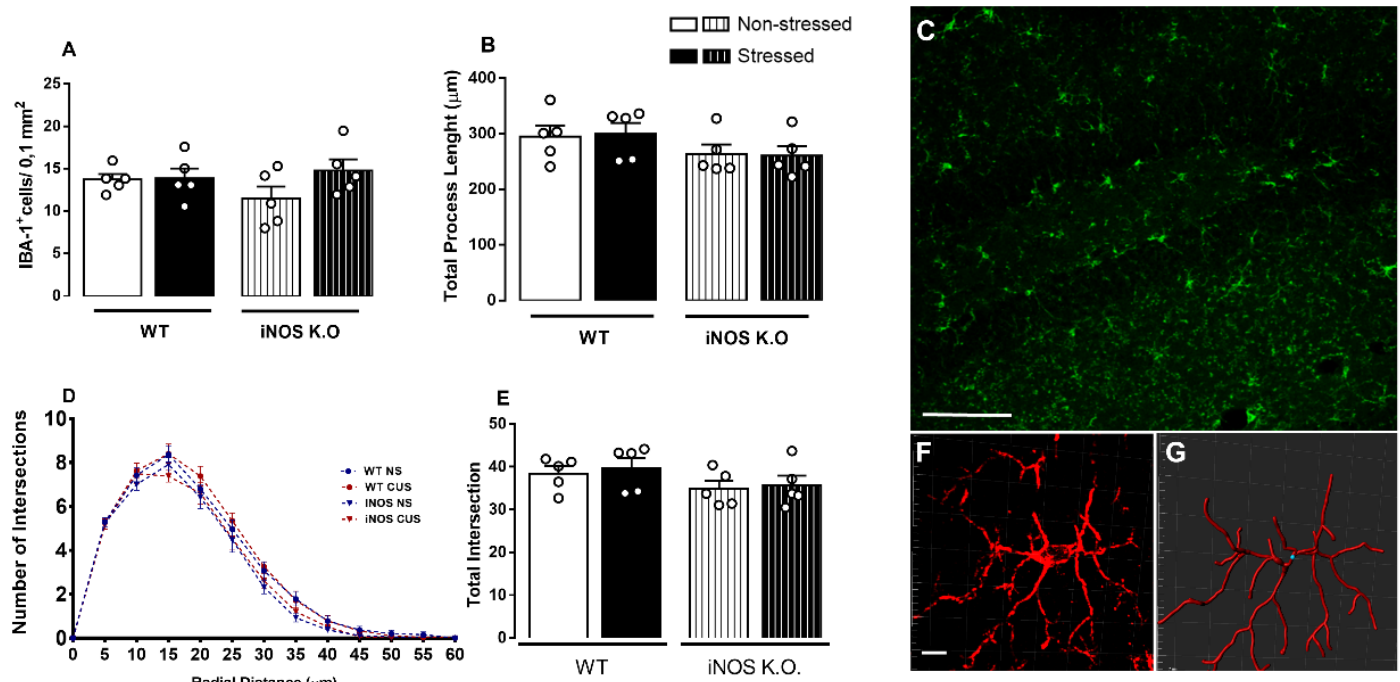

Figure 3: Chronic unpredictable stress does not alter microglia density (A) or complexity $(\mathrm{C}, \mathrm{D}, \mathrm{E})$ on the granular zone of the dentate gyrus neither of WT or iNOS K.O. mice (B). Representative photomicrography of dentate gyrus of WT non-stressed animals (scale bar $=99,98 \mu \mathrm{m})$ and filament 3D reconstruction on IMARIS (scale bar $=7 \mu \mathrm{m})(\mathrm{F}$ and $\mathrm{G})$. Data presented as mean \pm SEM ( $n=5 /$ group)

3.2 CUS does not modify the behavioral phenotype of iNOS K.O. observed in control/basal conditions.

We also evaluated whether CUS would affect the behavior of iNOS KO mice on tests related to depressive-like and anxiety-like behaviors. Using different breeding strategies, we observed that outbred iNOS K.O. mice had an increased latency for the first immobility episode that was unaffected by CUS (Two way-ANOVA $\mathrm{df}=1,16$; genotype: $F=6.52, p<0.05$; stress: $F=0.64$; interaction: $F=0.95$; Fig 4B). Also, outbred iNOS K.O. mice presented an active coping response in the TST that, different from WT mice, was not affected by CUS (Two way-ANOVA df=1,16; genotype: $F=14.07, p<0.05$; stress: $\mathrm{F}=4.27$; interaction: $\mathrm{F}=8.58, \mathrm{p}<0.05$; Fig 4C). Regarding anxiety-related behaviors, iNOS 
K.O. mice presented an anxiogenic-like phenotype which, different from the WT animals, was not affected by CUS exposure (Two way-ANOVA $\mathrm{df}=1,19$; genotype: $\mathrm{F}=7.81$, $\mathrm{p}<0.05$; stress: $\mathrm{F}=1.45$; interaction: $\mathrm{F}=4.52, \mathrm{p}<0.05$; Fig 4D). None of the interventions changed the food intake in the home cage (Two way-ANOVA df=1,19; genotype: $\mathrm{F}=2.57$; stress: $F=0.38$; interaction: $F=0.23$; Fig $4 \mathrm{E}$ ). To access their locomotor activity, which may affect the TST response, we performed the OFT test. iNOS K.O. mice presented an increased locomotor activity compared to WT mice (Two way-ANOVA $\mathrm{df}=1,19$; genotype: $\mathrm{F}=9.71, \mathrm{p}<0.05$; stress: $\mathrm{F}=0.49$; interaction: $\mathrm{F}=1.29$; Fig 4A).

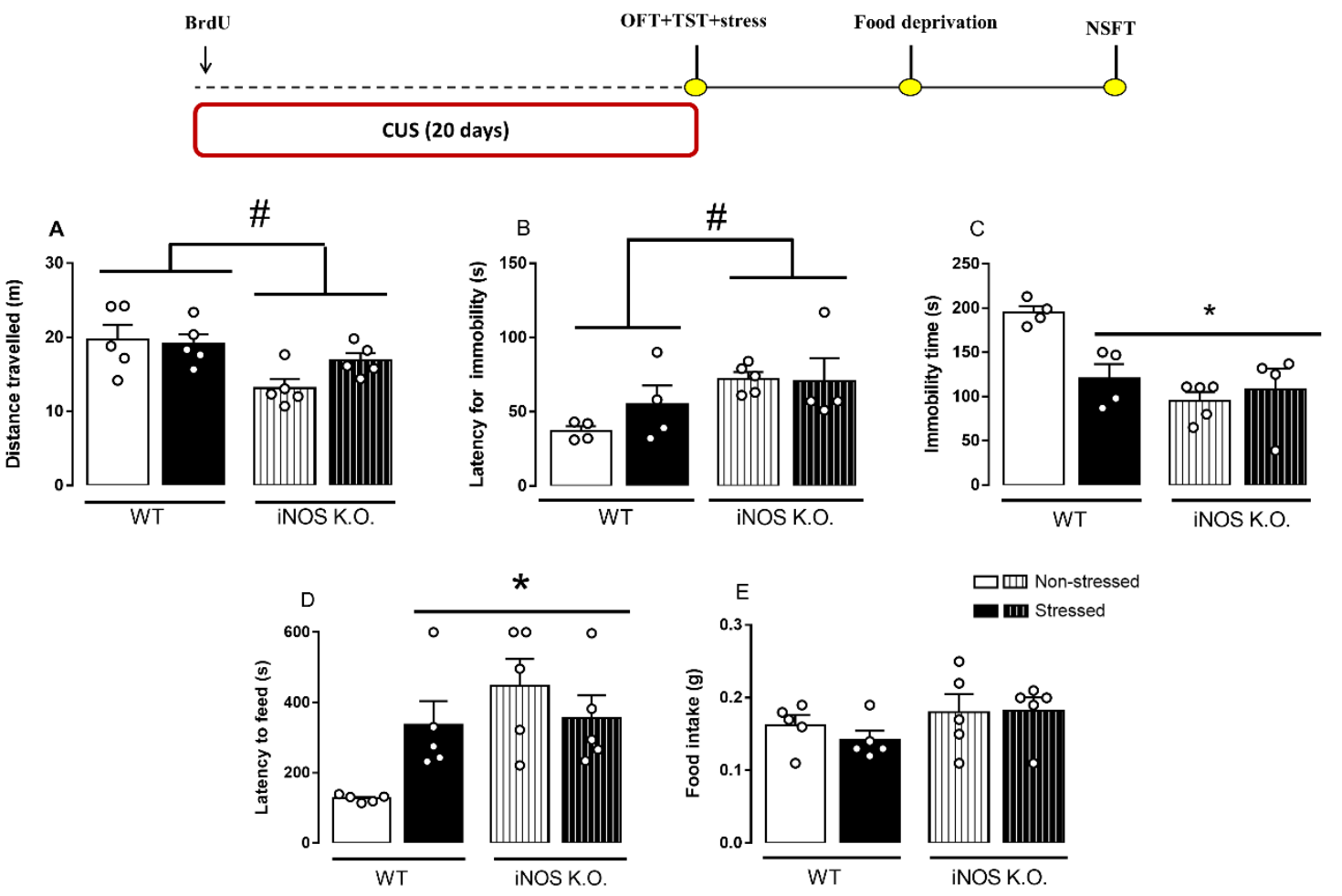

Figure 4: Distinct behavioral response to CUS of outbred WT and iNOS K.O. mice. (A): total distance traveled on the open field test ( $\mathrm{n}=5 /$ group); latency for the first immobility episode (B) and total immobility time on the tail suspension test $(n=4,4,5$ and 4 , respectively) (C); (D): latency to feed in a novel environment (E): total feeding consumption during five minutes in the home-cage ( $n=5 /$ group). Data presented as mean \pm S.E.M. ${ }^{*} \mathrm{p}<0,05$ from WT non-stressed; \# indicates $\mathrm{p}<0.05$ on genotype factor. 


\subsection{Escitalopram did not rescue AHN parameters in iNOS K.O. mice.}

Next, we investigated whether chronic escitalopram treatment, a pro-neurogenic stimulus, would promote changes in the neurogenic niche of iNOS K.O. mice. We started our investigation by measuring the density of DCX+cells in the dentate gyrus and their migratory number toward the granular layer. None of our interventions induced any significant changes in iNOS K.O. mice. In the WT animals, escitalopram and, surprisingly, CUS augmented the number o DCX+ cells in the dentate gyrus. This effect was not observed when these two conditions were combined (Three way-ANOVA

$\mathrm{df}=1,33$; genotype: $\mathrm{F}=128.56, \mathrm{p}<0.05$; stress: $\mathrm{F}=1.98$; treatment: $\mathrm{F}=0.05$; genotype $\mathrm{x}$ stress: $F=2.18$; genotype $x$ treatment: $F=0.70$; stress $x$ treatment: $F=20.93$, $p<0,05$; stress $\mathrm{x}$ treatment $\mathrm{x}$ genotype: $\mathrm{F}=16.87, \mathrm{p}<0,05$ Fig $5 \mathrm{~A}$ ). iNOS K.O. mice presented a lower number of migrating cells manipulations compared with WT mice that was independent of stress and drug treatment (Three way-ANOVA df=1,33; genotype: $\mathrm{F}=108.78, \mathrm{p}<0.05$; stress: $\mathrm{F}=0.45$; treatment: $\mathrm{F}=2.34$; genotype $\mathrm{x}$ stress: $\mathrm{F}=0.68$; genotype $\mathrm{x}$ treatment: $\mathrm{F}=$ 2.15; stress $x$ treatment: $F=1.89$; stress $x$ treatment $x$ genotype: $F=1.05$, Fig 5B).

We also addressed the question whether the BrdU+ incorporation and retention in adult newborn neurons would be affected by escitalopram (Fig 5I). Similar to our DCX observations, none of our interventions induced any significant change in iNOS K.O. mice. In WT animals, escitalopram and CUS increased the survival of cells that incorporated BrdU in the dentate gyrus. Again, this effect was independent of stress and drug treatment (Three way-ANOVA df=1,33; genotype: $\mathrm{F}=18.15, \mathrm{p}<0.05$; stress: $\mathrm{F}=0.40$; treatment: $\mathrm{F}=0.14$; genotype $\mathrm{x}$ stress: $\mathrm{F}=0.48$; genotype $\mathrm{x}$ treatment: $\mathrm{F}=0.02$; stress $\mathrm{x}$ treatment: $F=5.17, p<0.05$; stress $x$ treatment $x$ genotype: $F=5.58, p<0.05$ Fig 5D). To characterize the fate of BrdU cells, we investigated the number of type IIb/III cells 
colocalized with BrdU. None of our interventions promoted any significant changes in either iNOS K.O. or WT mice (Three way-ANOVA df=1,33; genotype: $F=15.85$, $p<0.05$; stress: $\mathrm{F}=0.27$; treatment: $\mathrm{F}=0.44$; genotype $\mathrm{x}$ stress: $\mathrm{F}=0.12$; genotype $\mathrm{x}$ treatment: $\mathrm{F}=$ 0.01; stress $x$ treatment: $F=3.41$; stress $x$ treatment $x$ genotype: $F=3.58$ Fig 5E). In the same direction, none of our interventions changed the number of mature adult-born neurons in WT or iNOS K.O. mice (Three way-ANOVA df=1,33; genotype: $\mathrm{F}=8.64$, $\mathrm{p}<0.05$; stress: $\mathrm{F}=0.01$; treatment: $\mathrm{F}=0.35$; genotype $\mathrm{x}$ stress: $\mathrm{F}=0.22$; genotype $\mathrm{x}$ treatment: $F=0.06$; stress $\mathrm{x}$ treatment: $\mathrm{F}=0.55$; stress $\mathrm{x}$ treatment $\mathrm{x}$ genotype: $\mathrm{F}=1.11$, Fig 5F).

Lastly, we questioned whether our results would reflect an impaired neurogenic niche capacity, reflected by reduced numbers of neural stem cells or type I cells $(\mathrm{GFAP}+\mathrm{SOX} 2+$ cells $)$ located at the subgranular zone. To answer this question, we measured the number of GFAP+SOX2+ cells in all our interventions (Fig 5J). Surprisingly, none of our interventions modified the number of type I cells in the dentate gyrus of our animals $\left(\chi^{2}=4,59\right)$. The Type IIa cells $(\mathrm{SOX} 2+)$, also denominated intermediate progenitors' cells or transient amplifying progenitors cells, possess a high mitotic activity (Kempermann et al., 2015). Their number increased in iNOS KO mice. None of our interventions modified this number (Three way-ANOVA df=1,33; genotype: $\mathrm{F}=6.44, \mathrm{p}<0.05$; stress: $\mathrm{F}=0.52$; treatment: $\mathrm{F}=0.02$; genotype $\mathrm{x}$ stress: $\mathrm{F}=0.62$; genotype $\mathrm{x}$ treatment: $\mathrm{F}=0.46$; stress $\mathrm{x}$ treatment: $\mathrm{F}=0.83$; stress $\mathrm{x}$ treatment $\mathrm{x}$ genotype: $\mathrm{F}=$ 0.75, Fig 5H). 

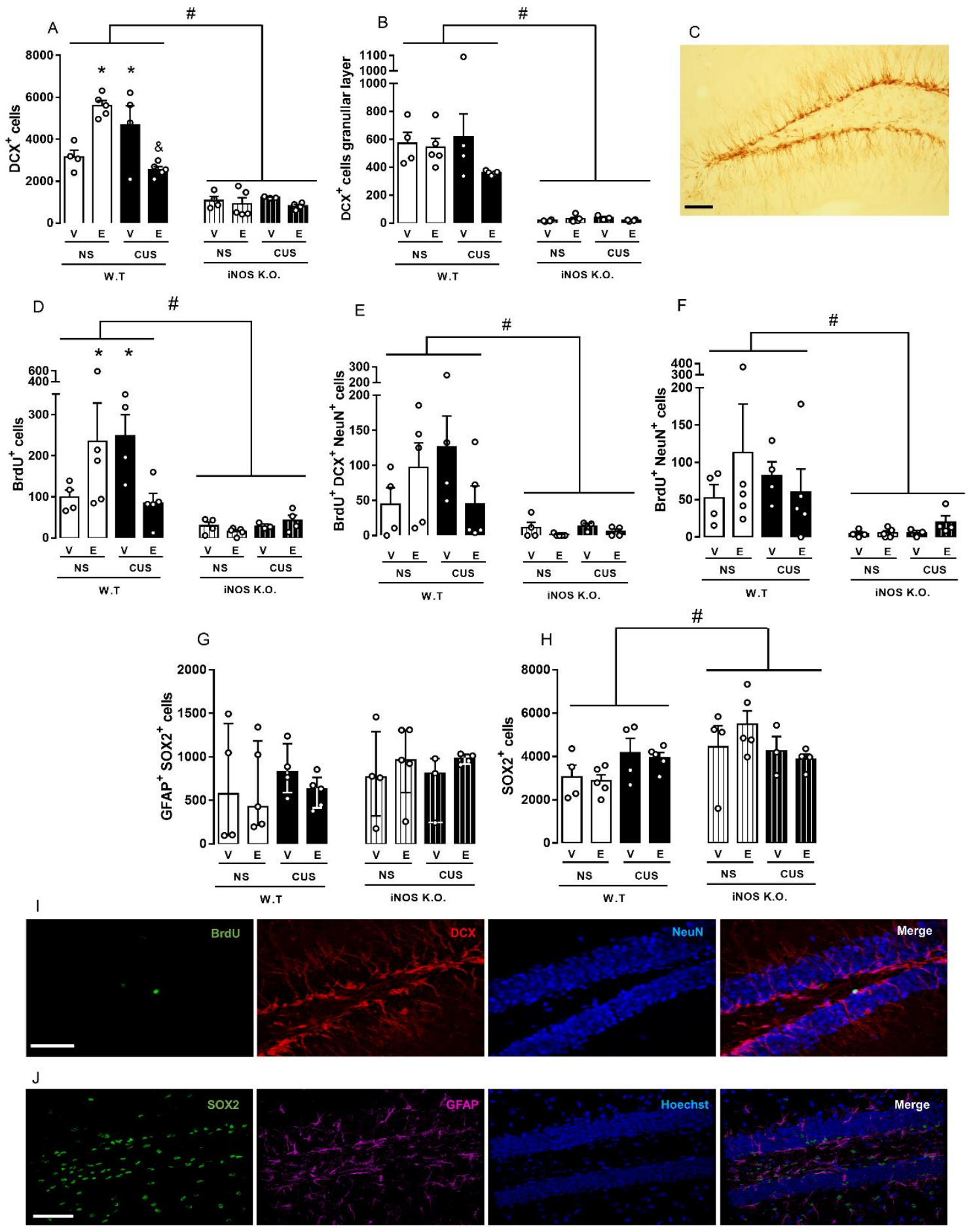

Figure 5: Escitalopram does not modify the AHN impairment observed on iNOS KO mice. Quantification of neuroblast total number and migration towards the granular layer (A and B, respectively). BrdU incorporation analysis revealed a reduced survival of adultborn new neurons in iNOS K.O. mice that were not affected by escitalopram or CUS interventions (D, E, and F; $\mathrm{n}=4,5,4,5,4,5,3$ and 4, respectively). Type I cells analysis 
showed that these cells are not altered in iNOS K.O. mice nor affected by any employed manipulations $(\mathrm{G})$. Quantification of SOX2 positive cells $(\mathrm{H} ; \mathrm{n}=4,5,4,5,4,5,3$ and 4, respectively). Representative image showing DCX, BrdU/DCX/NeuN, and GFAP/SOX2 positive cells in the dentate gyrus of a WT non-stressed animal (C, I, and J, respectively; scale bar $=50 \mu \mathrm{m})$. Data present as mean $\pm \operatorname{SEM}(\mathrm{A}, \mathrm{B}, \mathrm{D}, \mathrm{E}, \mathrm{F}, \mathrm{H})$ or median and interquartile range $(\mathrm{G}) *$ indicates $\mathrm{p}<0.05$ compared to WT NS mice. \# indicates $\mathrm{p}<0.05$ on genotype factor, \& p<0.05 compared with WT CUS vehicle mice.

3.4 The chronic treatment with escitalopram failed to change iNOS K.O. mice behaviors.

We were also interested to evaluate whether the behavioral effects of escitalopram would parallel our observation on AHN on iNOS K.O. mice. Regarding the latency to the first immobility episode in the TST, none of our interventions changed the behavior compared to their respective controls ( 3 way-ANOVA df=1,32; genotype: $\mathrm{F}=13.01$, $\mathrm{p}<0.05$; stress: $\mathrm{F}=1.87$; treatment: $\mathrm{F}=0.54$; genotype $\mathrm{x}$ stress: $\mathrm{F}=2.87$; genotype $\mathrm{x}$ treatment: $F=0.18$; stress $x$ treatment: $F=0.30$; stress $x$ treatment $x$ genotype: $F=0.25 .11$, Fig 6B). On the same direction, none of our interventions modified the total immobility time in the TST (Three way-ANOVA $\mathrm{df}=1,32$; genotype: $\mathrm{F}=20.83, \mathrm{p}<0.05$; stress: $\mathrm{F}=0.54$; treatment: $\mathrm{F}=0.08$; genotype $\mathrm{x}$ stress: $\mathrm{F}=0.62$; genotype $\mathrm{x}$ treatment: $\mathrm{F}=0.88$; stress $x$ treatment: $F=2.46$; stress $x$ treatment $x$ genotype: $F=1.48$, Fig $6 C$ ). In the NSFT, none of our interventions changed the anxiogenic-like response presented by iNOS K.O. mice, even tough, in WT mice, CUS augmented the latency to feed on the novel environment. Escitalopram treatment prevented this behavior (Three way-ANOVA $\mathrm{df}=1,33$; genotype: $\mathrm{F}=42.97, \mathrm{p}<0.05$; stress: $\mathrm{F}=0.99$; treatment: $\mathrm{F}=3.68$; genotype $\mathrm{x}$ stress: $F=0.12$; genotype $X$ treatment: $F=0.47$; stress $X$ treatment: $F=2.08$; stress $\mathrm{X}$ treatment $\mathrm{x}$ genotype: $\mathrm{F}=4.40, \mathrm{p}<0.05$, Fig 6D). There was no food intake difference in 
the home-cage consumption test (Three way-ANOVA df=1,33; genotype: $F=1.08$; stress: $\mathrm{F}=0.94$; treatment: $\mathrm{F}=0.71$; genotype $\mathrm{x}$ stress: $\mathrm{F}=0.17$; genotype $\mathrm{x}$ treatment: $\mathrm{F}=0.35$; stress $X$ treatment: $F=1.08$; stress $X$ treatment $X$ genotype: $F=0.03$, Fig 6E). The OFT showed that iNOS K.O. mice keep presenting an hypolocomotion compared to WT mice and neither CUS protocol nor ESC treatment could change this behavior (Three wayANOVA $\mathrm{df}=1,33$; genotype: $\mathrm{F}=42.97, \mathrm{p}<0.05$; stress: $\mathrm{F}=0.99$; treatment: $\mathrm{F}=3.61$; genotype $\mathrm{x}$ stress: $\mathrm{F}=0.12$; genotype $\mathrm{X}$ treatment: $\mathrm{F}=0.47$; stress $\mathrm{x}$ treatment: $\mathrm{F}=2.08$; stress $\mathrm{x}$ treatment $\mathrm{x}$ genotype: $\mathrm{F}=3.48$, Fig $6 \mathrm{~A}$ ).
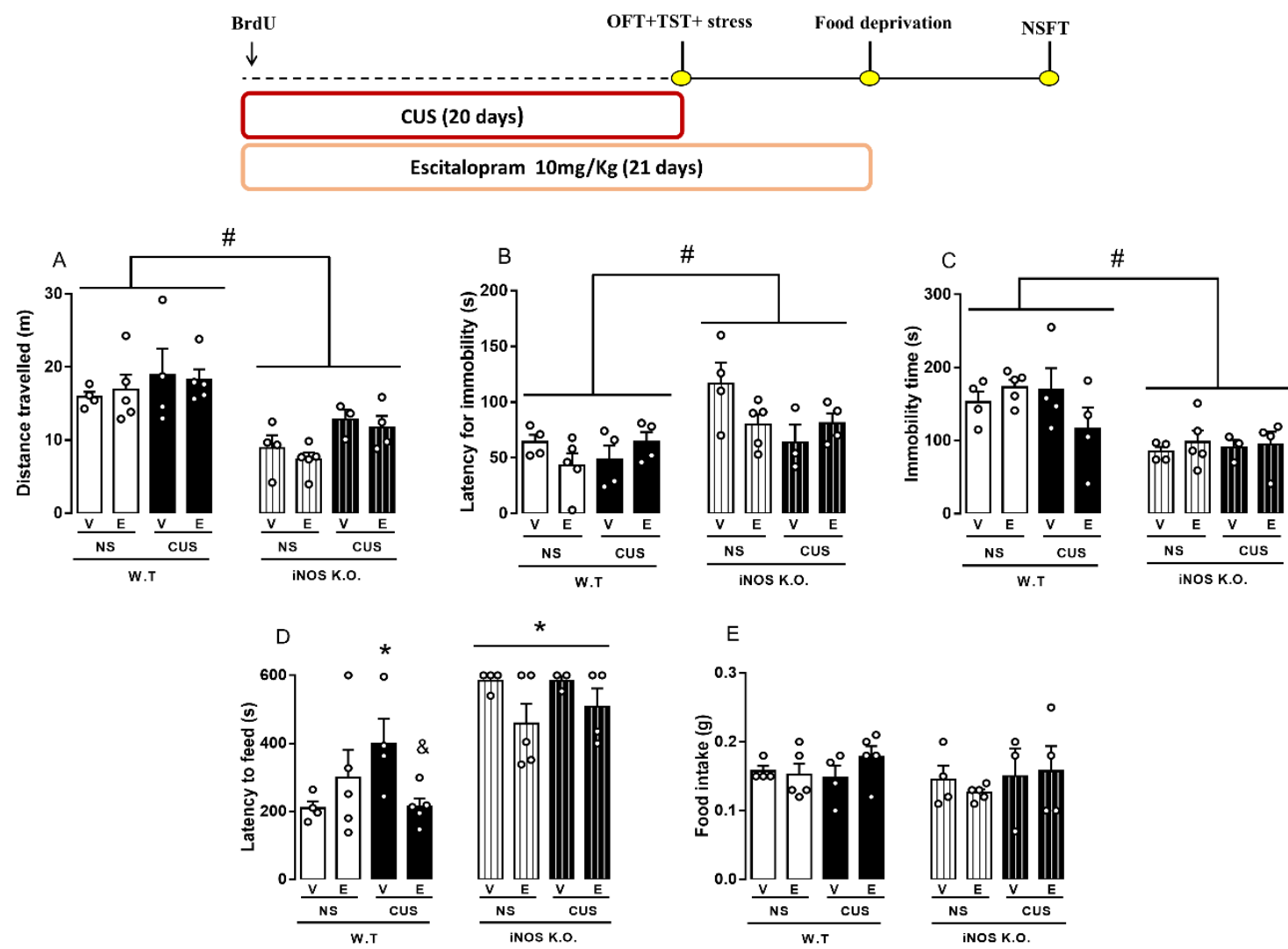

Figure 6: Escitalopram is devoid of behavioral effects in iNOS K.O. mice. (A): total distance travelled in the open field test ( $n=4,5,4,5,4,5,3$ and 4 respectively); (B) first immobility episode and (C) total immobility time in the tail suspension test $(n=4,5,4,4,4,4,3$ and 4 respectively); (D): latency to feed in a novel environment (E): total 
feeding consumption during five minutes in home-cage $(n=4,5,4,5,4,5,3$ and 4 respectively). Data presented as mean $\pm \mathrm{SEM} * \mathrm{p}<0,05$ from WT non-stressed vehicle; \# indicates $\mathrm{p}<0.05$ on genotype factor; $\& \mathrm{p}<0.05$ compared with WT CUS vehicle mice.

\subsection{The CUS decreased, but ESC restored, the chronic activation of prelimbic portions} of the vmPFC observed in iNOS K.O. mice

Lastly, we investigated if the cellular activation and the number of parvalbumin $(\mathrm{PV}+)$ interneurons in the subregions of the ventromedial prefrontal cortex (vmPFC).

CUS increased cellular activation in the prelimbic (PrL) area in WT animals that was not modified by escitalopram. iNOS KO mice also presented and increased number of FOSB+ cells in the prelimbic (PrL). In this case, this difference was attenuated by CUS exposure. In these animals (iNOS K.O. exposed to CUS), escitalopram increased the number of FOSB+ cells. (Three way-ANOVA $\mathrm{df}=1,31$; genotype: $\mathrm{F}=5.55, \mathrm{p}<0,05$; stress: $F=0.57$; treatment: $F=6.43, p<0.05$; genotype $x$ stress: $F=6.07, p<0.05$; genotype $x$ treatment: $F=3.95$; stress $x$ treatment: $F=0.01$; stress $x$ treatment $x$ genotype: $F=2.99$, Fig 7A). No significant effect was observed in the infralimbic (IL) cortex (Three wayANOVA $\mathrm{df}=1,31$; genotype: $\mathrm{F}=0.26$; stress: $\mathrm{F}=0.07$; treatment: $\mathrm{F}=2.71$; genotype $\mathrm{x}$ stress: $F=1,65$; genotype $x$ treatment: $F=1.31$; stress $x$ treatment: $F=2.87$; stress $x$ treatment $x$ genotype: $F=0.15$, Fig 7D). The density of PV+ cells was not different among the groups (Three way-ANOVA $\mathrm{df}=1,31$; genotype: $\mathrm{F}=0.38$; stress: $\mathrm{F}=3.81$; treatment: $F=0.01$; genotype $x$ stress: $F=0,23$; genotype $x$ treatment: $F=1,71$; stress $x$ treatment: $F=$ 0.45; stress $\mathrm{x}$ treatment $\mathrm{x}$ genotype: $\mathrm{F}=0.02$, Fig $7 \mathrm{~B}$ ) nor on IL (Three way-ANOVA $\mathrm{df}=1,31$; genotype: $\mathrm{F}=0.14$; stress: $\mathrm{F}=2,90$; treatment: $\mathrm{F}=0.35$; genotype $\mathrm{x}$ stress: $\mathrm{F}=0.10$; genotype $\mathrm{x}$ treatment: $\mathrm{F}=3.29$; stress $\mathrm{x}$ treatment: $\mathrm{F}=0.37$; stress $\mathrm{x}$ treatment $\mathrm{x}$ genotype: $\mathrm{F}=0.06$, Fig 7E).We also did not observed any increase of the activation of PV+ cells by 
co-labeling with FOSB in the PrL (Three way-ANOVA df=1,31; genotype: $\mathrm{F}=0.02$; stress: $\mathrm{F}=0.32$; treatment: $\mathrm{F}=0.31$; genotype $\mathrm{x}$ stress: $\mathrm{F}=4.03$; genotype $\mathrm{x}$ treatment: $\mathrm{F}=$ 3.53; stress $x$ treatment: $F=2.06$; stress $x$ treatment $x$ genotype: $F=0.79$, Fig $7 \mathrm{C}$ ) nor on IL (Three way-ANOVA df=1,31; genotype: $F=1.55$; stress: $F=1.16$; treatment: $F=0.14$; genotype $\mathrm{x}$ stress: $\mathrm{F}=0.04$; genotype $\mathrm{x}$ treatment: $\mathrm{F}=1.11$; stress $\mathrm{x}$ treatment: $\mathrm{F}=0.11$; stress $\mathrm{x}$ treatment $\mathrm{x}$ genotype: $\mathrm{F}=0.01$, Fig $7 \mathrm{~F})$.

\section{Prelimbic cortex}
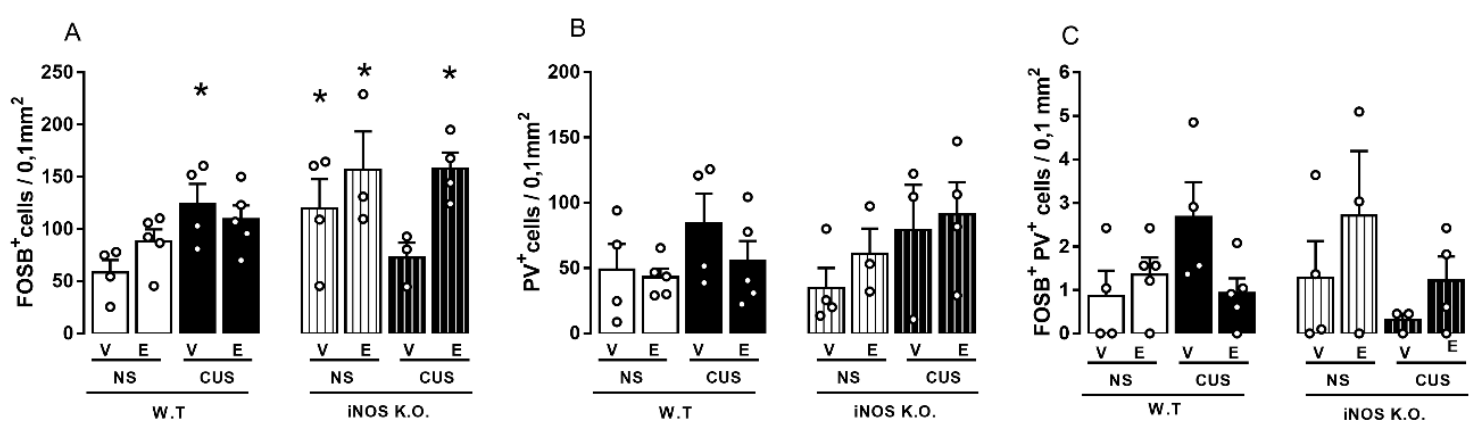

Infralimbic cortex
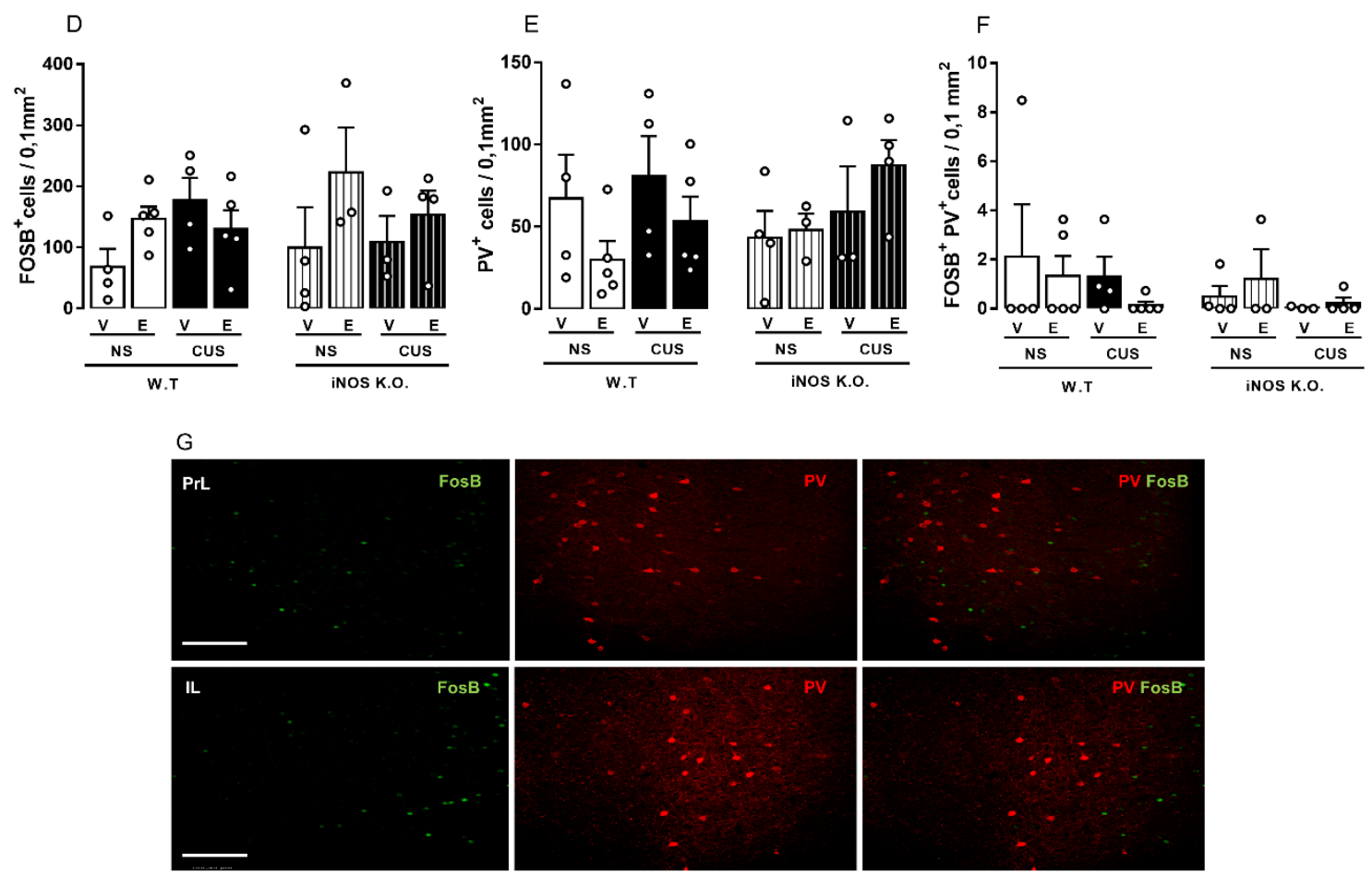

Figure 7: Escitalopram does not modify the activation of parvalbumin-positive cells in the prelimbic and infralimbic cortices of iNOS K.O. mice. $\mathrm{FOSB}^{+}$cells quantification on PrL and IL (A and D, respectively), PV+ cells density (B and E, respectively), and 
$\mathrm{FOSB}^{+} \mathrm{PV}^{+}$colocalization density in the $\operatorname{PrL}$ and $\mathrm{IL}$ (C and $\mathrm{F}$, respectively). $\mathrm{N}=4,5,4,5,4,3,3,4$, respectively. ${ }^{*} \mathrm{p}<0.05$ from WT non-stressed vehicle.

\section{4) Discussion}

The present study tested the hypothesis that the genetic absence of iNOS K.O. mice would prevent the behavioral and anti-neurogenic consequences of CUS exposure by modulating the microglial phenotype. Surprisingly, we found that iNOS K.O. mice exhibit impaired survival of newly generated neurons in the adult DG (Fig 2). Moreover, manipulation to either reduce (CUS) or augment AHN (chronic escitalopram treatment) failed to produce their common described effects (Gould et al., 1992; Malberg et al., 2000 - Fig 2 and 4). The behavioral phenotypes of these animals are also not modified by these manipulations (Fig 3 and 5). Together, these findings suggest that iNOS may be an essential factor for the survival of adult newborn neurons and behavioral adaptability. Interestingly, none of our interventions induce any behavioral changes in heterozygous mice (Supplement Fig 1). To better understand this phenotype, however, further investigation is needed. Even though homozygosis related to a genetic absence of iNOS has been described in humans, this condition seems to be fatal when individuals are exposed to pathogens. This observation indicates that heterozygosis in this condition may exist among the human population (Drutman et al., 2020).

In agreement with some of our findings, Carreira and colleagues (2015) showed that administration of kainic acid, an epileptic drug with pro neurogenic properties, promoted seizures in iNOS K.O. mice. However, unlike the WT mice, these animals did not respond with an increased density of DCX-positive cells in the dentate gyrus (Carreira et al., 2015, 2010). Genetic ablation of iNOS also prevents ischemia-induced neurogenesis (Zhu et al., 2003). 
Several lines of evidence support the hypothesis that the microglia cell phenotype differently modulates the AHN (Ekdahl et al., 2009). For instance, systemic administration of lipopolysaccharide induces recruitment and activation towards an inflammatory phenotype of microglial cells, leading to reduced survival of adult newborn-neuron (Ekdahl et al., 2003). On the other hand, Ziv and colleagues (2006) showed that the pro neurogenic effects induced by environment enrichment depend on Tcells and, ultimately, the recruitment of microglia present in the neurogenic niche. (Ziv et al., 2006). Mechanistically, it has been proposed that NO and reactive oxidative species (ROS) produced by the microglia cells are the mediators of their detrimental effects on AHN neurogenesis (Boje and Arora, 1992; Tanaka et al., 2002). Supporting this assumption, Carreira and colleagues (2014) showed that inflammatory stimulus reduced the proliferation of neural stem cells derived from the subventricular zone only when these cells were cocultured with microglia that expressed iNOS (Carreira et al., 2014). Also, Tang and colleagues (2018) showed that chronic social defeat stress (SDS), a wellknown model that diminishes AHN (McKim et al., 2016), induces the microglia cells to express iNOS in the dentate gyrus. In this study, however, the authors did not explore whether this effect is related to the SDS behavioral outcome (Tang et al., 2018).

Despite the evidence mentioned above, we observed that iNOS K.O. mice had an impaired AHN (Fig 2). Moreover, no changes in microglial cells were observed in the dentate gyrus (Fig 3). This latter result contrasts with several reports showing that chronic stress, either homotypic or heterotypic, affect microglia cells in limbic structures resulting in changes in their density, morphology, and priming (Franklin et al., 2018; Hellwig et al., 2016; Kreisel et al., 2014; Ramirez et al., 2015; Tynan et al., 2010; Walker et al., 2013; Wohleb et al., 2013). One factor that could help to explain this discrepancy is that some studies did not restrict their observation to one subregion of the dentate gyrus. For 
instance, Kreisel and colleagues (2014) analyzed the entire dentate gyrus (Kreisel et al., 2014). On the other hand, Hellwig and colleagues (2016) restricted their morphological analysis to the inferior molecular layer of the dentate gyrus (Hellwig et al., 2016). Even if our results suggest that our CUS protocol did not modify microglial cells in the dentate gyrus, they need to be confirmed by other molecular markers such as the expression of MHC-II, CD-68 (associated with pro-inflammatory microglia response), and the presence of phagocytic calyxes (morphological feature related to phagocytosis of apoptotic newborn cells) (Sierra et al., 2010; VanRyzin et al., 2019).

In parallel to our AHN and microglial observations, we also report that iNOS K.O. mice present an antidepressant- and anxiogenic-like phenotype not altered by CUS exposure or chronic escitalopram treatment. Previous studies from the literature had already shown that pharmacological or genetic iNOS modulation facilitates an active coping strategy on the forced swim test (Montezuma et al., 2012). Also, the administration of a selective iNOS inhibitor, 1400W, prevented anhedonic-like behavior induced by CUS (Peng et al., 2012). Concerning anxiety-like behaviors, iNOS K.O. mice presented an anxious-like phenotype and enhanced freezing in the fear conditioning paradigm (Buskila et al., 2007, Lisboa et al., 2015).

In addition to confirming these results, the present data also suggests a possible mechanist explanation for this behavioral profile. Several studies indicate that AHN could fine-tune the hippocampal function, facilitating spatial navigation and stress adaptability (for a recent review, see Surget and Belzung, 2021). Corroborating this proposal, impaired AHN in our study was associated with an anxiogenic response in the NSFT (Fig 3) and a lack of response to escitalopram treatment (Fig 5). These observations are in line with those made by Santarelli and co-workers (2003). They suggest that the behavioral effects of antidepressants depend on an intact AHN (Santarelli et al., 2003). In agreement 
with this suggestion, genetic augmentation of AHN produces an antidepressant- and anxiolytic-like effect on animals chronically exposed to corticosterone (Hill et al., 2015). However, other studies using a similar genetic approach to enhance neurogenesis failed to reproduce the previous results on a CUS paradigm, suggesting that the behavioral properties of AHN may be related to the challenge used (Culig et al., 2017; Eliwa et al., 2021). Also, the survival of adult newborn neurons on iNOS K.O. mice was not related to an impaired neurogenic niche in our study. Corroborating these results, Arnhold and colleagues (2002) showed that pharmacological inhibition of iNOS impairs the proper neuronal development and differentiation of embryonic neural stem cells (Arnhold et al., 2002).

Escitalopram treatment prevented the anxiogenic-like behavior induced by CUS without changing neurogenesis markers in the dentate gyrus, such as DCX cell number. However, a recent paper suggests that DCX expression may not always reflect changes in the survival of adult newborn neurons nor their proliferation rate (Mendez-David et al., 2020). Other mechanisms, therefore, could also be involved in the behavioral effects of escitalopram repeated treatment.

Besides AHN, several lines of evidence show that the vmPFC modulates behaviors associated with depression and anxiety (Jinks and McGregor, 1997; Saitoh et al., 2014; Scopinho et al., 2010). It was recently proposed that fast act-antidepressants could act by interfering with a distinct population of interneurons present in the vmPFC, including PV+ cells (Fogaça et al., 2020; review Fogaça and Duman, 2019; Gerhard et al., 2020; Wohleb et al., 2016). Specific manipulations of PV interneurons in the vmPFC recapitulate the behavioral response observed after a single dose of ketamine, a fast-acting antidepressant/anxiolytic drug (Fogaça et al., 2020). Corroborating these observations, Page and colleagues (2019) showed that after 4 weeks of CUS exposure, stressed-mice 
presented augmented cFos reactivity (a marker of neuronal activation) in PV+ cells in the vmPFC (Page et al., 2019).

FOSB expression has been associated with cellular activation after repeated stimuli (Nestler et al., 1999). In agreement with our results, different chronic stress protocols increase the expression and accumulation of FOSB in the vmPFC (Nikulina et al., 2008; Perrotti, 2004). Even if our results indicate that this effect does not depend on a specific increase in PV+ cells, additional studies are needed to investigate: i) whether the augmentation reported here occurs on GAD67+ cells or excitatory neurons; and ii) whether other interneurons populations, such as neurons expressing somatostatin (Fogaça et al., 2020), are recruited on iNOS KO mice.

Taken together, our observations suggest that in iNOS K.O. mice that AHN modulates anxiety-related behaviors after stress, while the PrL cortex could be involved in depressive-like behaviors (Hare and Duman, 2020; Moshe et al., 2016).

\section{Conclusion}

iNOS seems to play an essential role in the survival of newborn cells and immature neurons in the hippocampus. In addition, the lack of this enzyme appears to result in increased activity of the PrL prefrontal cortex. These two parallel neurobiological mechanisms could help to explain the antidepressant and anxiogenic behavioral profile observed in the iNOS KO mice. Whereas impaired AHN would increase anxiety, a higher PrL activity would be involved with positive copying behavior strategies. Further studies with site-directed conditional knockouts and direct pharmacological interventions are needed to address these possibilities.

\section{Declarations of interest:}


The authors declare no conflict of interest.

\section{Acknowledgments:}

We want to thank Eleni Tamburus, Tadeu Vieira (in memoriam), and Giuliana Bertozi for their excellent technical support. We thank the Ph.D. student, Franciele Franco Scarante for her incredible design on the graphical abstract used in this study. We also thank our lab colleagues for keeping such an amazing and supportive environment in our young research group. This study was supported by FAPESP Young research grant (2015/05551-0), thematic grant (2017/24304-0), the L'Oreal-Unesco-Brazilian Academy of Science for Women in Science Fellowship, and CNPq Universal Grant line A (400033/2016-0). ACC and FSG are recipients of CNPq research fellowships. GGF and JBF received scholarships from CNPq. DSS and KCMC are CAPES fellowships.

\section{Authors Contributions:}

GGF conceptualized the project, performed the behavioral and immunohistochemical procedures, analyzed the data, and wrote the draft of the manuscript. KCMC performed behavioral and immunohistochemical procedures, reviewed the figures, and helped to write the first draft of the manuscript. DSS performed genotype experiments, performed behavioral procedures, and reviewed the first draft of the manuscript. JBF participated in the immunohistochemical experiments and their analysis. FSG revised the manuscript. ACC was the project principal investigator, conceptualized the project, provided the resources, reviewed, and edited the draft versions of the manuscript. All authors approved the final version of the manuscript before its initial submission.

\section{References:}


Altman, J., Das, G.D., 1965. Autoradiographic and histological evidence of postnatal hippocampal neurogenesis in rats. J. Comp. Neurol. 124, 319-335. https://doi.org/10.1002/cne.901240303

Anacker, C., Luna, V.M., Stevens, G.S., Millette, A., Shores, R., Jimenez, J.C., Chen, B., Hen, R., 2018. Hippocampal neurogenesis confers stress resilience by inhibiting the ventral dentate gyrus. Nature 559, 98-102. https://doi.org/10.1038/s41586-018-0262-4

Arnhold, S., Faßbender, A., Klinz, F. - J., Kruttwig, K., Löhnig, B., Andressen, C., Addicks, K., 2002. NOS- II is involved in early differentiation of murine cortical, retinal and ES cell- derived neurons - an immunocytochemical and functional approach. Int. J. Dev. Neurosci. 20, 83-92. https://doi.org/10.1016/S07365748(02)00020-5

Balu, D.T., Hodes, G.E., Hill, T.E., Ho, N., Rahman, Z., Bender, C.N., Ring, R.H., Dwyer, J.M., Rosenzweig-Lipson, S., Hughes, Z.A., Schechter, L.E., Lucki, I., 2009. Flow cytometric analysis of BrdU incorporation as a high-throughput method for measuring adult neurogenesis in the mouse. J. Pharmacol. Toxicol. Methods 59, 100-107. https://doi.org/10.1016/j.vascn.2008.12.002

Boje, K.M., Arora, P.K., 1992. Microglial-produced nitric oxide and reactive nitrogen oxides mediate neuronal cell death. Brain Res. 587, 250-256. https://doi.org/10.1016/0006-8993(92)91004-X

Buskila, Y., Abu-Ghanem, Y., Levi, Y., Moran, A., Grauer, E., Amitai, Y., 2007. Enhanced astrocytic nitric oxide production and neuronal modifications in the Neocortex of a NOS2 mutant mouse. PLoS One 2. https://doi.org/10.1371/journal.pone.0000843

Calabrese, V., Mancuso, C., Calvani, M., Rizzarelli, E., Butterfield, D.A., Giuffrida 
Stella, A.M., 2007. Nitric oxide in the central nervous system: Neuroprotection versus neurotoxicity. Nat. Rev. Neurosci. 8, 766-775.

https://doi.org/10.1038/nrn2214

Campos, A.C., Ortega, Z., Palazuelos, J., Fogaça, M. V, Aguiar, D.C., Díaz-Alonso, J., Ortega-Gutiérrez, S., Vázquez-Villa, H., Moreira, F.A., Guzmán, M., GalveRoperh, I., Guimarães, F.S., 2013. The anxiolytic effect of cannabidiol on chronically stressed mice depends on hippocampal neurogenesis: Involvement of the endocannabinoid system. Int. J. Neuropsychopharmacol. 16, 1407-1419. https://doi.org/10.1017/S1461145712001502

Can, A., Dao, D.T., Terrillion, C.E., Piantadosi, S.C., Bhat, S., Gould, T.D., 2011. The Tail Suspension Test. J. Vis. Exp. 3769. https://doi.org/10.3791/3769

Carreira, B.P., Morte, M.I., Inácio, Â., Costa, G., Rosmaninho-Salgado, J., Agasse, F., Carmo, A., Couceiro, P., Brundin, P., Ambrósio, A.F., Carvalho, C.M., Araújo, I.M., 2010. Nitric Oxide Stimulates the Proliferation of Neural Stem Cells Bypassing the Epidermal Growth Factor Receptor. Stem Cells 28, N/A-N/A. https://doi.org/10.1002/stem.444

Carreira, B.P., Morte, M.I., Santos, A.I., Lourenço, A.S., Ambrósio, A.F., Carvalho, C.M., Araújo, I.M., 2014. Nitric oxide from inflammatory origin impairs neural stem cell proliferation by inhibiting epidermal growth factor receptor signaling. Front. Cell. Neurosci. 8, 1-14. https://doi.org/10.3389/fncel.2014.00343

Carreira, B.P., Santos, D.F., Santos, A.I., Carvalho, C.M., Araújo, I.M., 2015. Nitric Oxide Regulates Neurogenesis in the Hippocampus following Seizures. Oxid. Med. Cell. Longev. 2015, 1-14. https://doi.org/10.1155/2015/451512

Culig, L., Surget, A., Bourdey, M., Khemissi, W., Le Guisquet, A.M., Vogel, E., Sahay, A., Hen, R., Belzung, C., 2017. Increasing adult hippocampal neurogenesis in mice 
after exposure to unpredictable chronic mild stress may counteract some of the effects of stress. Neuropharmacology 126, 179-189. https://doi.org/10.1016/j.neuropharm.2017.09.009

Dowlati, Y., Herrmann, N., Swardfager, W., Liu, H., Sham, L., Reim, E.K., Lanctôt, K.L., 2010. A Meta-Analysis of Cytokines in Major Depression. Biol. Psychiatry 67, 446-457. https://doi.org/10.1016/j.biopsych.2009.09.033

Drutman, S.B., Mansouri, D., Mahdaviani, S.A., Neehus, A.-L., Hum, D., Bryk, R., Hernandez, N., Belkaya, S., Rapaport, F., Bigio, B., Fisch, R., Rahman, M., Khan, T., Al Ali, F., Marjani, M., Mansouri, N., Lorenzo-Diaz, L., Emile, J.-F., Marr, N., Jouanguy, E., Bustamante, J., Abel, L., Boisson-Dupuis, S., Béziat, V., Nathan, C., Casanova, J.-L., 2020. Fatal Cytomegalovirus Infection in an Adult with Inherited NOS2 Deficiency. N. Engl. J. Med. 382, 437-445. https://doi.org/10.1056/nejmoa1910640

Ekdahl, C.T., Claasen, J.H., Bonde, S., Kokaia, Z., Lindvall, O., 2003. Inflammation is detrimental for neurogenesis in adult brain. Proc. Natl. Acad. Sci. U. S. A. 100, 13632-13637. https://doi.org/10.1073/pnas.2234031100

Ekdahl, C.T., Kokaia, Z., Lindvall, O., 2009. Brain inflammation and adult neurogenesis: The dual role of microglia. Neuroscience 158, 1021-1029. https://doi.org/10.1016/j.neuroscience.2008.06.052

Eliwa, H., Brizard, B., Le Guisquet, A.M., Hen, R., Belzung, C., Surget, A., 2021. Adult neurogenesis augmentation attenuates anhedonia and HPA axis dysregulation in a mouse model of chronic stress and depression. Psychoneuroendocrinology 124. https://doi.org/10.1016/j.psyneuen.2020.105097 Eriksson, P.S., Perfilieva, E., Björk-Eriksson, T., Alborn, A.-M., Nordborg, C., Peterson, D.A., Gage, F.H., 1998. Neurogenesis in the adult human hippocampus. 
Nat. Med. 4, 1313-1317. https://doi.org/10.1038/3305

Fogaça, M. V, Campos, A.C., Coelho, L.D., Duman, R.S., Guimarães, F.S., 2018. The anxiolytic effects of cannabidiol in chronically stressed mice are mediated by the endocannabinoid system: Role of neurogenesis and dendritic remodeling. Neuropharmacology 135, 22-33. https://doi.org/10.1016/j.neuropharm.2018.03.001

Fogaça, M. V, Duman, R.S., 2019. Cortical GABAergic dysfunction in stress and depression: New insights for therapeutic interventions. Front. Cell. Neurosci. 13, 1-20. https://doi.org/10.3389/fncel.2019.00087

Fogaça, M. V, Wu, M., Li, C., Li, X.Y., Picciotto, M.R., Duman, R.S., 2020. Inhibition of GABA interneurons in the mPFC is sufficient and necessary for rapid antidepressant responses. Mol. Psychiatry 3. https://doi.org/10.1038/s41380-02000916-y

Franklin, T.C., Wohleb, E.S., Zhang, Y., Fogaça, M., Hare, B., Duman, R.S., 2018. Persistent Increase in Microglial RAGE Contributes to Chronic Stress-Induced Priming of Depressive-like Behavior. Biol. Psychiatry 83, 50-60. https://doi.org/10.1016/j.biopsych.2017.06.034

Gałecki, P., Gałecka, E., Maes, M., Chamielec, M., Orzechowska, A., Bobińska, K., Lewiński, A., Szemraj, J., 2012. The expression of genes encoding for COX-2, MPO, iNOS, and sPLA2-IIA in patients with recurrent depressive disorder. J. Affect. Disord. 138, 360-366. https://doi.org/10.1016/j.jad.2012.01.016

Gałecki, P., Maes, M., Florkowski, A., Lewiński, A., Gałecka, E., Bieńkiewicz, M., Szemraj, J., 2010. An inducible nitric oxide synthase polymorphism is associated with the risk of recurrent depressive disorder. Neurosci. Lett. 486, 184-187. https://doi.org/10.1016/j.neulet.2010.09.048 
Gemma, C., Bachstetter, A.D., 2013. The role of microglia in adult hippocampal neurogenesis. Front. Cell. Neurosci. 7, 1-5. https://doi.org/10.3389/fncel.2013.00229

Gerhard, D.M., Pothula, S., Liu, R.J., Wu, M., Li, X.Y., Girgenti, M.J., Taylor, S.R., Duman, C.H., Delpire, E., Picciotto, M., Wohleb, E.S., Duman, R.S., 2020. GABA interneurons are the cellular trigger for ketamine's rapid antidepressant actions. J. Clin. Invest. 130, 1336-1349. https://doi.org/10.1172/JCI130808

Gould, E., Cameron, H.A., 1996. Regulation of Neuronal Birth, Migration and Death in the Rat Dentate Gyrus. Dev. Neurosci. 18, 22-35. https://doi.org/10.1159/000111392

Gould, E., Cameron, H.A., Daniels, D.C., Woolley, C.S., McEwen, B.S., 1992. Adrenal hormones suppress cell division in the adult rat dentate gyrus. J. Neurosci. 12, 3642-3650. https://doi.org/10.1523/jneurosci.12-09-03642.1992

Hare, B.D., Duman, R.S., 2020. Prefrontal cortex circuits in depression and anxiety: contribution of discrete neuronal populations and target regions. Mol. Psychiatry 25, 2742-2758. https://doi.org/10.1038/s41380-020-0685-9

Hellwig, S., Brioschi, S., Dieni, S., Frings, L., Masuch, A., Blank, T., Biber, K., 2016. Altered microglia morphology and higher resilience to stress-induced depressionlike behavior in CX3CR1-deficient mice. Brain. Behav. Immun. 55, 126-137. https://doi.org/10.1016/j.bbi.2015.11.008

Helmut, K., Hanisch, U.K., Noda, M., Verkhratsky, A., 2011. Physiology of microglia. Physiol. Rev. 91, 461-553. https://doi.org/10.1152/physrev.00011.2010

Hill, A.S., Sahay, A., Hen, R., 2015. Increasing Adult Hippocampal Neurogenesis is Sufficient to Reduce Anxiety and Depression-Like Behaviors. Neuropsychopharmacology 40, 2368-2378. https://doi.org/10.1038/npp.2015.85 
Howren, M.B., Lamkin, D.M., Suls, J., 2009. Associations of depression with c-reactive protein, IL-1, and IL-6: A meta-analysis. Psychosom. Med. 71, 171-186. https://doi.org/10.1097/PSY.0b013e3181907c1b

Ja, W.K., Duman, R.S., 2008. IL-1 $\beta$ is an essential mediator of the antineurogenic and anhedonic effects of stress. Proc. Natl. Acad. Sci. U. S. A. 105, 751-756. https://doi.org/10.1073/pnas.0708092105

Jinks, A.L., McGregor, I.S., 1997. Modulation of anxiety-related behaviours following lesions of the prelimbic or infralimbic cortex in the rat. Brain Res. 772, 181-190. https://doi.org/10.1016/S0006-8993(97)00810-X

Kempermann, G., Song, H., Gage, F.H., 2015. Neurogenesis in the adult hippocampus. Cold Spring Harb. Perspect. Biol. 7. https://doi.org/10.1101/cshperspect.a018812 Koo, J.W., Russo, S.J., Ferguson, D., Nestler, E.J., Duman, R.S., 2010. Nuclear factor$\mathrm{B}$ is a critical mediator of stress-impaired neurogenesis and depressive behavior. Proc. Natl. Acad. Sci. 107, 2669-2674. https://doi.org/10.1073/pnas.0910658107

Kreisel, T., Frank, M.G., Licht, T., Reshef, R., Ben-Menachem-Zidon, O., Baratta, M. V, Maier, S.F., Yirmiya, R., 2014. Dynamic microglial alterations underlie stressinduced depressive-like behavior and suppressed neurogenesis. Mol. Psychiatry 19, 699-709. https://doi.org/10.1038/mp.2013.155

Lisboa, S.F., Gomes, F. V, Silva, A.L., Uliana, D.L., Camargo, L.H.A., Guimars, F.S., Cunha, F.Q., Joca, S.R.L., Resstel, L.B.M., 2015. Increased contextual fear conditioning in inos knockout mice: Additional evidence for the involvement of nitric oxide in stress-related disorders and contribution of the endocannabinoid system. Int. J. Neuropsychopharmacol. 18, 1-12. https://doi.org/10.1093/ijnp/pyv005

Malberg, J.E., Eisch, A.J., Nestler, E.J., Duman, R.S., 2000. Chronic antidepressant 
treatment increases neurogenesis in adult rat hippocampus. J. Neurosci. 20, 91049110. https://doi.org/10.1523/jneurosci.20-24-09104.2000

McKim, D.B., Niraula, A., Tarr, A.J., Wohleb, E.S., Sheridan, J.F., Godbout, J.P., 2016. Neuroinflammatory dynamics underlie memory impairments after repeated social defeat. J. Neurosci. 36, 2590-2604. https://doi.org/10.1523/JNEUROSCI.239415.2016

Mendez-David, I., David, D.J., Deloménie, C., Beaulieu, J.-M., Gardier, A.M., Hen, R., 2020. A Non-Linear Relation between Levels of Adult Hippocampal Neurogenesis and Expression of the Immature Neuron Marker Doublecortin. SSRN Electron. J. https://doi.org/10.2139/ssrn.3616375

Michopoulos, V., Powers, A., Gillespie, C.F., Ressler, K.J., Jovanovic, T., 2017. Inflammation in Fear-and Anxiety-Based Disorders: PTSD, GAD, and beyond. Neuropsychopharmacology 42, 254-270. https://doi.org/10.1038/npp.2016.146

Montezuma, K., Biojone, C., Lisboa, S.F., Cunha, F.Q., Guimarães, F.S., Joca, S.R.L., 2012. Inhibition of iNOS induces antidepressant-like effects in mice: Pharmacological and genetic evidence. Neuropharmacology 62, 485-491. https://doi.org/10.1016/j.neuropharm.2011.09.004

Moshe, H., Gal, R., Barnea-Ygael, N., Gulevsky, T., Alyagon, U., Zangen, A., 2016. Prelimbic Stimulation Ameliorates Depressive-Like Behaviors and Increases Regional BDNF Expression in a Novel Drug-Resistant Animal Model of Depression. Brain Stimul. 9, 243-250. https://doi.org/10.1016/j.brs.2015.10.009 Nawreen, N., Cotella, E.M., Morano, R., Mahbod, P., Dalal, K.S., Fitzgerald, M., Martelle, S., Packard, B.A., Franco-Villanueva, A., Moloney, R.D., Herman, J.P., 2020. Chemogenetic inhibition of infralimbic prefrontal cortex gabaergic parvalbumin interneurons attenuates the impact of chronic stress in male mice. 
eNeuro 7. https://doi.org/10.1523/ENEURO.0423-19.2020

Nestler, E.J., Kelz, M.B., Chen, J., 1999. $\Delta$ FosB: a molecular mediator of long-term neural and behavioral plasticity. Brain Res. 835, 10-17.

https://doi.org/10.1016/S0006-8993(98)01191-3

Nikulina, E.M., Arrillaga-Romany, I., Miczek, K.A., Hammer, R.P., 2008. Long-lasting alteration in mesocorticolimbic structures after repeated social defeat stress in rats: Time course of $\$ \mu \$$-opioid receptor mRNA and FosB $/ \$ \Delta \$ F$ osB immunoreactivity. Eur. J. Neurosci. 27, 2272-2284. https://doi.org/10.1111/j.14609568.2008.06176.x

O’Brien, S.M., Scully, P., Fitzgerald, P., Scott, L. V, Dinan, T.G., 2007. Plasma cytokine profiles in depressed patients who fail to respond to selective serotonin reuptake inhibitor therapy. J. Psychiatr. Res. 41, 326-331. https://doi.org/10.1016/j.jpsychires.2006.05.013

Page, C.E., Shepard, R., Heslin, K., Coutellier, L., 2019. Prefrontal parvalbumin cells are sensitive to stress and mediate anxiety-related behaviors in female mice. Sci. Rep. 9, 1-9. https://doi.org/10.1038/s41598-019-56424-9

Peng, Y.L., Liu, Y.N., Liu, L., Wang, X., Jiang, C.L., Wang, Y.X., 2012. Inducible nitric oxide synthase is involved in the modulation of depressive behaviors induced by unpredictable chronic mild stress. J. Neuroinflammation 9, 1-12. https://doi.org/10.1186/1742-2094-9-75

Percie du Sert, N., Ahluwalia, A., Alam, S., Avey, M.T., Baker, M., Browne, W.J., Clark, A., Cuthill, I.C., Dirnagl, U., Emerson, M., Garner, P., Holgate, S.T., Howells, D.W., Hurst, V., Karp, N.A., Lazic, S.E., Lidster, K., MacCallum, C.J., Macleod, M., Pearl, E.J., Petersen, O.H., Rawle, F., Reynolds, P., Rooney, K., Sena, E.S., Silberberg, S.D., Steckler, T., Würbel, H., 2020. Reporting animal 
research: Explanation and elaboration for the ARRIVE guidelines 2.0. PLOS Biol. 18, e3000411. https://doi.org/10.1371/journal.pbio.3000411

Perrotti, L.I., 2004. Induction of FosB in Reward-Related Brain Structures after Chronic Stress. J. Neurosci. 24, 10594-10602. https://doi.org/10.1523/JNEUROSCI.254204.2004

Ramirez, K., Shea, D.T., McKim, D.B., Reader, B.F., Sheridan, J.F., 2015. Imipramine attenuates neuroinflammatory signaling and reverses stress-induced social avoidance. Brain. Behav. Immun. 46, 212-220.

https://doi.org/10.1016/j.bbi.2015.01.016

Saha, R.N., Pahan, K., 2006. Signals for the induction of nitric oxide synthase in astrocytes. Neurochem. Int. 49, 154-163. https://doi.org/10.1016/j.neuint.2006.04.007

Saitoh, A., Ohashi, M., Suzuki, S., Tsukagoshi, M., Sugiyama, A., Yamada, Misa, Oka, J.I., Inagaki, M., Yamada, Mitsuhiko, 2014. Activation of the prelimbic medial prefrontal cortex induces anxiety-like behaviors via N-Methyl-D-aspartate receptor-mediated glutamatergic neurotransmission in mice. J. Neurosci. Res. 92, 1044-1053. https://doi.org/10.1002/jnr.23391

Santarelli, L., Saxe, M., Gross, C., Surget, A., Battaglia, F., Dulawa, S., Weisstaub, N., Lee, J., Duman, R., Arancio, O., Belzung, C., Hen, R., 2003. Requirement of hippocampal neurogenesis for the behavioral effects of antidepressants. Science (80-. ). 301, 805-809. https://doi.org/10.1126/science.1083328

Scarante, F.F., Lopes, V.D., Fusse, E.J., Vicente, M.A., Araújo, M.R., Scomparin, D.S., Aguiar, R.P., Guimarães, F.S., Nardini, V., Sorgi, C.A., Faccioli, L.H., Hallak, J.E.C., Joca, S., Mackie, K., Zuardi, A.W., Crippa, J.A.S., Campos, A.C., 2021. Cannabidiol as an add-on therapy to overcome the slow-onset and, possibly, 
resistance to antidepressant treatment: involvement of NAPE-PLD in the medial prefrontal cortex. bioRxiv. https://doi.org/10.1101/2021.04.23.441143

Scopinho, A.A., Scopinho, M., Lisboa, S.F., Correa, F.M. de A., Guimarães, F.S., Joca, S.R.L., 2010. Acute reversible inactivation of the ventral medial prefrontal cortex induces antidepressant-like effects in rats. Behav. Brain Res. 214, 437-442. https://doi.org/10.1016/j.bbr.2010.06.018

Seo, M.K., Choi, C.M., McIntyre, R.S., Cho, H.Y., Lee, C.H., Mansur, R.B., Lee, Y., Lee, J.-H., Kim, Y.H., Park, S.W., Lee, J.G., 2017. Effects of escitalopram and paroxetine on mTORC1 signaling in the rat hippocampus under chronic restraint stress. BMC Neurosci. 18, 39. https://doi.org/10.1186/s12868-017-0357-0

Sierra, A., Encinas, J.M., Deudero, J.J.P., Chancey, J.H., Enikolopov, G., OverstreetWadiche, L.S., Tsirka, S.E., Maletic-Savatic, M., 2010. Microglia shape adult hippocampal neurogenesis through apoptosis-coupled phagocytosis. Cell Stem Cell 7, 483-495. https://doi.org/10.1016/j.stem.2010.08.014

Snyder, J.S., Soumier, A., Brewer, M., Pickel, J., Cameron, H.A., 2011. Adult hippocampal neurogenesis buffers stress responses and depressive behaviour. Nature 476, 458-462. https://doi.org/10.1038/nature10287

Surget, A., Belzung, C., 2021. Adult hippocampal neurogenesis shapes adaptation and improves stress response: a mechanistic and integrative perspective. Mol. Psychiatry. https://doi.org/10.1038/s41380-021-01136-8

Tanaka, M., Sotomatsu, A., Yoshida, T., Hirai, S., Nishida, A., 2002. Detection of Superoxide Production by Activated Microglia Using a Sensitive and Specific Chemiluminescence Assay and Microglia-Mediated PC12h Cell Death. J. Neurochem. 63, 266-270. https://doi.org/10.1046/j.1471-4159.1994.63010266.x Tang, J., Yu, W., Chen, S., Gao, Z., Xiao, B., 2018. Microglia Polarization and 
Endoplasmic Reticulum Stress in Chronic Social Defeat Stress Induced Depression Mouse. Neurochem. Res. 43, 985-994. https://doi.org/10.1007/s11064-018-2504-0 Tynan, R.J., Naicker, S., Hinwood, M., Nalivaiko, E., Buller, K.M., Pow, D. V, Day, T.A., Walker, F.R., 2010. Chronic stress alters the density and morphology of microglia in a subset of stress-responsive brain regions. Brain. Behav. Immun. 24, 1058-1068. https://doi.org/10.1016/j.bbi.2010.02.001

VanRyzin, J.W., Marquardt, A.E., Argue, K.J., Vecchiarelli, H.A., Ashton, S.E., Arambula, S.E., Hill, M.N., McCarthy, M.M., 2019. Microglial Phagocytosis of Newborn Cells Is Induced by Endocannabinoids and Sculpts Sex Differences in Juvenile Rat Social Play. Neuron 102, 435--449.e6. https://doi.org/10.1016/j.neuron.2019.02.006

Walker, F., Nilsson, M., Jones, K., 2013. Acute and Chronic Stress-Induced Disturbances of Microglial Plasticity, Phenotype and Function. Curr. Drug Targets 14, 1262-1276. https://doi.org/10.2174/13894501113149990208

Willner, P., Muscat, R., Papp, M., 1992. Chronic mild stress-induced anhedonia: A realistic animal model of depression. Neurosci. Biobehav. Rev. 16, 525-534. https://doi.org/10.1016/S0149-7634(05)80194-0

Wohleb, E.S., Franklin, T., Iwata, M., Duman, R.S., 2016. Integrating neuroimmune systems in the neurobiology of depression. Nat. Rev. Neurosci. 17, 497-511. https://doi.org/10.1038/nrn.2016.69

Wohleb, E.S., Powell, N.D., Godbout, J.P., Sheridan, J.F., 2013. Stress-induced recruitment of bone marrow-derived monocytes to the brain promotes anxiety-like behavior. J. Neurosci. 33, 13820-13833. https://doi.org/10.1523/JNEUROSCI.1671-13.2013

Yoshimura, R., Hori, H., Ikenouchi-Sugita, A., Umene-Nakano, W., Ueda, N., 
Nakamura, J., 2009. Higher plasma interleukin-6 (IL-6) level is associated with SSRI- or SNRI-refractory depression. Prog. Neuro-Psychopharmacology Biol. Psychiatry 33, 722-726. https://doi.org/10.1016/j.pnpbp.2009.03.020

Zaki, M.H., Okamoto, T., Sawa, T., Fujii, S., Akaike, T., 2007. Nitrative stress in respiratory inflammation caused by influenza virus infection. Clin. Exp. Allergy Rev. 7, 19-26. https://doi.org/10.1111/j.1365-2222.2007.00120.x

Zhang, J., Rong, P., Zhang, L., He, H., Zhou, T., Fan, Y., Mo, L., Zhao, Q., Han, Y., Li, S., Wang, Y., Yan, W., Chen, H., You, Z., 2021. IL4-driven microglia modulate stress resilience through BDNF-dependent neurogenesis. Sci. Adv. 7. https://doi.org/10.1126/sciadv.abb9888

Zhu, D.Y., Liu, S.H., Sun, H.S., Lu, Y.M., 2003. Expression of inducible nitric oxide synthase after focal cerebral ischemia stimulates neurogenesis in the adult rodent dentate gyrus. J. Neurosci. 23, 223-229. https://doi.org/10.1523/jneurosci.23-0100223.2003

Ziv, Y., Ron, N., Butovsky, O., Landa, G., Sudai, E., Greenberg, N., Cohen, H., Kipnis, J., Schwartz, M., 2006. Immune cells contribute to the maintenance of neurogenesis and spatial learning abilities in adulthood. Nat. Neurosci. 9, 268-275. https://doi.org/10.1038/nn1629 


\section{Click here to access/download \\ Supplementary Material Supplement.docx}




\title{
Zebrafish as a Translational Model: An Experimental Alternative to Study the Mechanisms Involved in Anosmia and Possible Neurodegenerative Aspects of COVID-19?
}

\author{
- Karla C. M. Costa, ${ }^{1}$ Tamires A. V. Brigante, ${ }^{1}$ Gabriel G. Fernandes, ${ }^{1}$ Davi S. Scomparin, ${ }^{1}$ \\ Franciele F. Scarante, ${ }^{1}$ Danielle P. de Oliveira, ${ }^{2}$ and Alline C. Campos ${ }^{1}$
}

https://doi.org/10.1523/ENEURO.0027-21.2021

${ }^{1}$ Pharmacology of Neuroplasticity Laboratory, Department of Pharmacology, Ribeirão Preto Medical School, University of São Paulo, São Paulo, Brazil, 14049-900, and ${ }^{2}$ EcoHumanTox Laboratory, Department of Clinical, Toxicological and Bromatological Analysis, School of Pharmaceutical Science of Ribeirão Preto, University of São Paulo, São Paulo, Brazil 14049-900

\section{Visual Abstract}

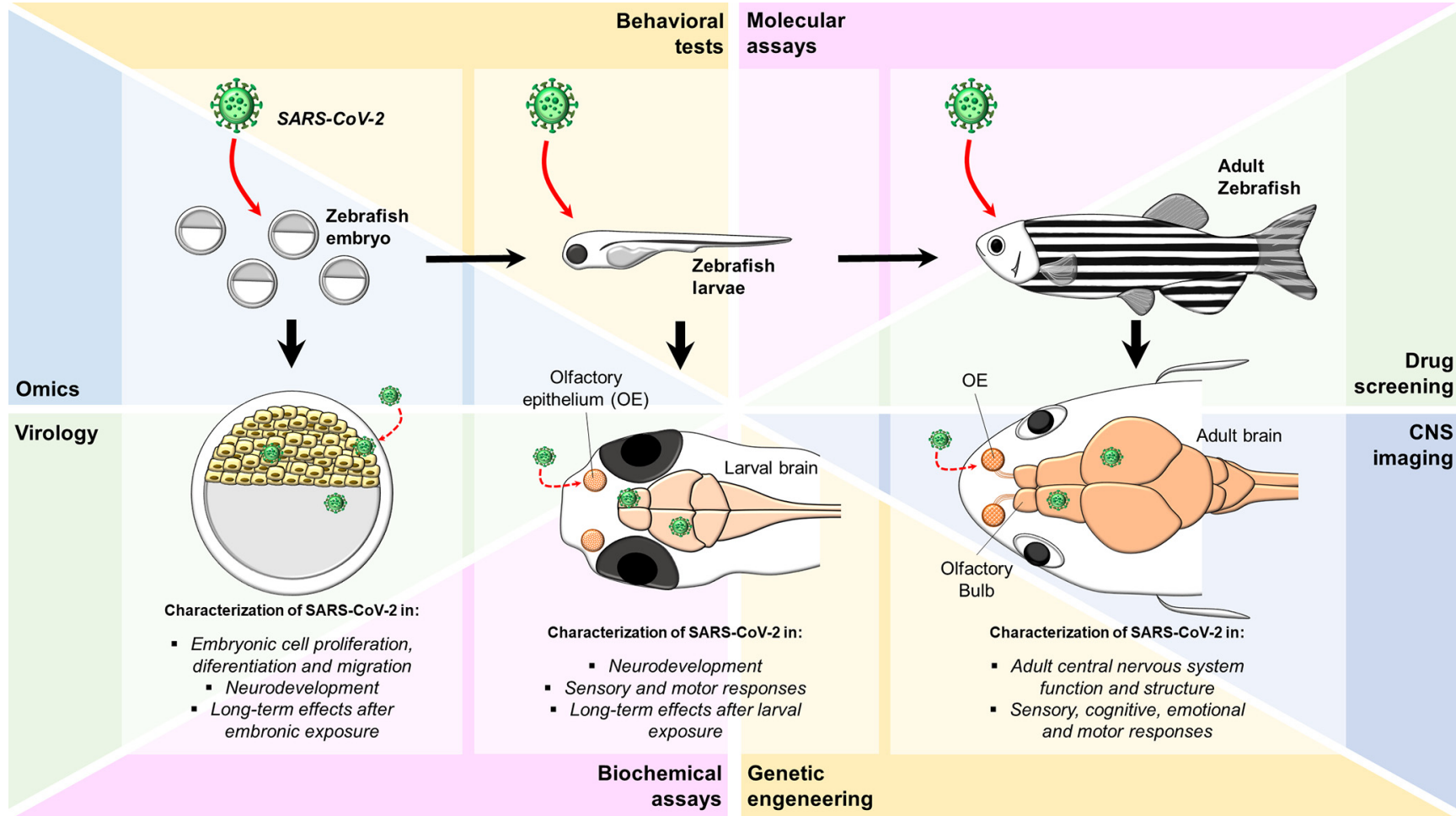

The Coronavirus disease-2019 (COVID-19) presents a variability of clinical symptoms, ranging from asymptomatic to severe respiratory and systemic conditions. In a cohort of patients, the Severe Acute Respiratory Syndrome Coronavirus (SARS-CoV-2), beyond the classical respiratory manifestations, induces anosmia. Evidence has suggested SARS-CoV-2-induced anosmia can be the result of neurodegeneration of the olfactory pathway. Neurologic symptoms associated with COVID-19 have been reported; however, the precise mechanism and possible long-lasting effects remain poorly investigated. Preclinical models are valuable tools 


\section{Significance Statement}

The Coronavirus disease-2019 (COVID-19) is characterized not only by respiratory, but also neurologic symptoms that may persevere even longer than the respiratory condition. However, some questions remain unanswered. How does the Severe Acute Respiratory Syndrome Coronavirus 2 (SARS-CoV-2) enter the brain? Which brain regions are infected? How does the virus affect our behavioral and sensorial responses? Can the brain infection induce alterations that last longer? We propose that the zebrafish is a suitable model to study the effects of SARS-CoV-2 in the brain, especially because of the similarities between the fish' and the human brain. Zebrafish is a cheap animal model and several reproducible and fast animal tests can be used to investigate its behavioral and sensory functions.

for describing and testing new possible treatments for neurologic disorders. In this way, the zebrafish (Danio rerio) organism model represents an attractive tool in the field of neuroscience, showing economic and logistic advantages besides genetic and physiologic similarities with mammalian, including the brain structure and functions. Besides, its external embryonic development, high availability of eggs, and fast development allows easy genetic manipulation and fast replications. In the present review, we suggest that the zebrafish model can be advantageous to investigate the neurologic features of COVID-19.

Key words: anosmia; encephalitis; olfactory system; pandemic; SARS-CoV-2; zebrafish

\section{COVID-19 and Society: The Urgent Need of a Rapid and Fast Animal Model}

The novel strain of coronavirus responsible for the Coronavirus disease-2019 (COVID-19) emerged in December 2019 in Wuhan, a province in China (Rothan and Byrareddy, 2020). In a short period, COVID-19 cases have rapidly spread worldwide causing frightful rates of morbidity and mortality (Jain et al., 2020) and declared as a global public health threat by the World Health Organization in March 2020 (World Health Organization, 2020).

Because of efforts made by different groups of scientists, the etiologic agent of this new pandemic was characterized as a $\beta$ coronavirus named Severe Acute Respiratory Syndrome-Coronavirus 2 (SARS-CoV-2), which is closely related to its previous relative SARSCoV, responsible for the SARS outbreak in China during the early 2000s (Ksiazek et al., 2003). Similar to its "older cousin," spike proteins S1 and S2 of the SARS-CoV-2

Received January 21, 2021; accepted April 12, 2021; First published May 5, 2021.

The authors declare no competing financial interests.

Author contributions: K.C.M.C., D.P.d.O., and A.C.C. designed research; K.C.M.C., T.A.V.B., G.G.F., D.S.S., F.F.S., D.P.d.O., and A.C.C. performed research; K.C.M.C., T.A.V.B., G.G.F., D.S.S., F.F.S., D.P.d.O., and A.C.C. analyzed data; K.C.M.C., T.A.V.B., G.G.F., D.S.S., F.F.S., D.P.d.O., and A.C.C. wrote the paper.

This work was supported by Fundação de Amparo à Pesquisa do Estado de São Paulo (FAPESP) Grants 2020/05416-4 and 2018/24298-2.

Acknowledgements: We thank our laboratory colleagues for their support and for building an amazing teamwork environment.

Correspondence should be addressed to Karla C. M. Costa at karlacmc@usp.br

https://doi.org/10.1523/ENEURO.0027-21.2021

Copyright @ 2021 Costa et al.

This is an open-access article distributed under the terms of the Creative Commons Attribution 4.0 International license, which permits unrestricted use, distribution and reproduction in any medium provided that the original work is properly attributed. use the host angiotensin-converting enzyme 2 (ACE2) as a receptor (Walls et al., 2020) to initiate its entrance into the cell. This interaction with ACE2 seems to be primed by a proteolytic cleavage of the spike (S) protein by the transmembrane protease serine (TMPRSS2), responsible for the virus interaction with its target receptor (Hoffmann et al., 2020; Ou et al., 2020). Moreover, unlike SARS-CoV, the invasive mechanism of SARS-CoV-2 seems to involve preactivation by furin, a proprotein convertase that reduces the dependence of the novel coronavirus on recruiting proteases of the target cells for its successful entry (Shang et al., 2020).

Early epidemiological studies suggested that most patients infected with SARS-CoV-2 developed none or mild symptoms, similar to common flu, caused by influenza viruses, such as fever, cough, fatigue, rhinorrhea, sneezing, and sore throat. However, recent evidences showed that beyond the respiratory system infection, SARS-CoV-2 could also produce a severe syndrome with its collection of symptoms: severe pneumonia, important damage in the cardiovascular system, including thrombosis, persistent anosmia, and in some quite often neurologic symptoms (encephalitis, disturbed consciousness, and cerebrovascular accident; Duong et al., 2020; Ellul et al., 2020; Mao et al., 2020; Rothan and Byrareddy, 2020; Wu and McGoogan, 2020; Xu et al., 2020).

A great number of patients with COVID-19 have described neurologic complications associated with the viral infection (Helms et al., 2020; Mao et al., 2020). These case reports raise questions regarding the SARS-CoV-2 neurotropism, and how it contributes to the postinfection complications in the CNS (Netland et al., 2008; Huang et al., 2020; Zhang, 2020). A recent study (Chen et al., 2021) showed that ACE2, the target for SARS-CoV-2 entrance, could be identified in different components of CNS such as neurons, astrocytes, and oligodendrocytes. Many brain structures exhibited a high expression of ACE2 including the olfactory bulb, a region that has 
been associated with anosmia (loss of smell sense), a recurrent symptom also reported by patients with COVID-19 (Chen et al., 2021). Besides, other neurologic manifestations have already been identified in patients diagnosed with COVID-19, such as headache, confusion, and disabling strokes (ladecola et al., 2020). However, it is not well characterized how the SARS-CoV-2 affects directly the CNS or to what extent the neurologic disorders are consequences to secondary mechanisms.

The ACE2 is an enzyme expressed in many tissues, including the brain cells (Gheblawi et al., 2020), which can infer that once in the brain parenchyma, SARS-CoV-2 could be neuroinvasive. Additionally, SARS-CoV-2 is mainly transmitted through expelled virus-laden droplets, which can be inhaled by another person, leaving the virus exposed mainly to epithelium-like tissues throughout the respiratory tract. In this way, recent evidence suggests that the virus may enter the brain via the olfactory system through the nasal cavity, affecting breath control (Li et al., 2020a). Although other species of virus are capable of penetrating the CNS (for detailed review, see Koyuncu et al., 2013) the precise mechanism involved in SARS-CoV2 neurologic manifestation remains poorly understood.

Other viruses from the coronavirus family have been shown to use the olfactory pathway to enter the brain following intranasal inoculation. Perlman et al. (1990) showed that the Mouse hepatitis virus (MHV), a neurotropic coronavirus, is detected in brain areas neuroanatomically connected to the olfactory nerve after intranasal exposure to the virus. Furthermore, surgical bulbectomy prevented the entry of MHV into the brain via the olfactory pathway (Perlman et al., 1990). Moreover, in transgenic mice that express the human ACE2 receptor under the control of the human cytokeratin 18 (K18) promoter, SARS-CoV, after intranasal inoculation, was rapidly found in the olfactory bulb and in brain regions that have first or second-order connections with the olfactory bulb, indicating that the virus enters the brain through the olfactory tract and reaches connected brain areas through transneuronal spreading (Netland et al., 2008). A similar mechanism of neuro-propagation from the olfactory bulb to neuroanatomically associated areas was described for the human coronavirus strain OC43 (Dubé et al., 2018).

If SARS-CoV-2 uses the olfactory route to enter the brain and migrates through transsynaptic spreading to brain regions directly or indirectly connected to the olfactory bulb, the virus can potentially invade the thalamus, the hypothalamus, cortical regions, the midbrain, and even the brainstem. This could be related not only to the neurologic manifestations described in several COVID-19 patients but could also contribute to the respiratory symptoms since the neuro-invasiveness of SARS-CoV-2 could compromise the respiratory center of the brainstem (Gandhi et al., 2020; Li et al., 2020b; Manganelli et al., 2020; Dey et al., 2021).

The assumption of the olfactory pathway as the route of entry for SARS-CoV-2 into the brain is supported by the expression of ACE2 in the olfactory bulb and in brain regions that are directly connected to the olfactory tract (Chen et al., 2021). The ACE2 receptor is expressed in numerous cell types, including excitatory and inhibitory neurons, as well as microglia, oligodendrocytes, oligodendrocyte-precursor cells, and astrocytes (Chen et al., 2021). Moreover, TMPRSS2, a protease that participates in the cellular transfection of the virion, and neuropilin-1, a signaling molecule shown to increase SARS-CoV-2 infectivity, are also expressed in the olfactory neuroepithelium (Butowt and Bilinska, 2020; Matschke et al., 2020; Karuppan et al., 2021).

Histopathological evidence also supports that SARSCoV-2 could directly infect cells from the olfactory tract. Meinhardt et al. (2021) reported the presence of the SARS-CoV-2 spike (S) protein within neuronal cells in the olfactory mucosa from patients with COVID-19. They also found SARS-CoV-2 RNA in the olfactory bulb and in brain regions that receive projections from the olfactory tract (Meinhardt et al., 2021). In K18-hACE2 mice, after intranasal inoculation of SARS-CoV-2, the virus was detected in the brain tissue on day 3 after infection. By day 6 after the inoculation, SARS-CoV-2 was detectable in the olfactory bulb, cortex, cerebellum, and hippocampus of K18hACE2 mice (Kumari et al., 2021).

The SARS-CoV-2 infection has been associated with brain damage in the olfactory bulb and its neuroanatomically connected areas. Stoyanov et al. (2020) described severe neurodegeneration and inflammatory cell infiltration in the olfactory bulb of two COVID-19 patients. In a postmortem case series conducted in Germany, neuropathological analysis of glial activation patterns revealed a high degree of astrogliosis and microgliosis in the olfactory bulb, with low levels of cytotoxic-T cell infiltration (Matschke et al., 2020). The study also reported activation of microglial cells and infiltration of CD8-positive lymphocytes in the brainstem and a level of astrogliosis in the frontal cortex of COVID-19 patients (Matschke et al., 2020). In K18-hACE mice, SARS-CoV-2 intranasal inoculation triggered an increase in proinflammatory cytokines and chemokines in the brain and induced neuronal cell death in the hippocampus, cortex, and cerebellum (Kumari et al., 2021).

Animal models are the founding steps toward a better understanding of biological processes. Rodents-based models, such as mice and rats are widely used in biomedical research, but because of their intrinsic phenotype, their use in COVID-19 is limited. This restriction is associated with crucial amino acid variations in the primary structure of the ACE2 receptor (Chan et al., 2020). To circumvent this limitation, transgenic mice models expressing human ACE2 (hACE2) are available, but there are some limitations regarding their use: (1) there are reports that SARS-CoV-2 induces mortality on $7 \mathrm{~d}$ postinfection (dpi) limiting their use on long-term experiments; (2) because of the high demand of research labs, their breeding and distribution are limited. Other animal models are being studied, such as ferrets (Kim et al., 2020), golden hamster (Chan et al., 2020; Sia et al., 2020), and nonhuman primates (Bao et al., 2020; Rockx et al., 2020), but to perform experiments using these animals, several laboratories must adapt their animal housing facilities, and some of them take several weeks to produce offspring 
(for detailed review of animal models available, see Johansen et al., 2020).

Since there is an urgency to establish new and effective experimental models to understand the neurologic components associated with COVID-19, our goal with this review is to present evidences supporting the use of Danio rerio, commonly known as zebrafish, as a powerful tool to comprehend to which extent the SARS-CoV-2 may affect and alter the CNS homeostasis.

\section{Zebrafish as a rapid and replicable experimental model}

Zebrafish (D. rerio) is a small teleost that originated from the South of Asia and is characterized by the blue-black longitudinal stripes alternating with silver-white stripes that extend across its body (Lawrence, 2007). After fertilization, a large number of eggs ( $~ 100$ per day) is generated. The eggs are transparent, making it possible to observe the structures of the zebrafish's organs during development. They achieve the larval stage from 2 to $3 \mathrm{~d}$ after the fertilization period in which the organogenesis of many structures is still not complete (Kimmel et al., 1995; Spence et al., 2007). Its small size, easy maintenance in the laboratory, external fertilization, transparency of the embryos, and well-defined stages of development make the zebrafish an attractive model for research in many fields (Kimmel et al., 1995; Howe et al., 2013; Diniz et al., 2015; Kundap et al., 2017; Saad et al., 2017; Ayala-Nunez et al., 2019). Besides, zebrafish have genetics and physiologic similarities with mammals, increasing their value as a powerful tool on the bench side of the scientific methods (MacRae and Peterson, 2015).

Genetic sequences in zebrafish have been studied since the 1980s. Njølstad et al. (1988) characterized a zebrafish homeobox and found that this sequence shares similarities that lead to the same encoded proteins as the murine domain hox-2.1. In the following years, other zebrafish genes were sequenced and compared with mammalian. Several genes showed similarities in the sequence, expression, and encoded proteins (Njølstad et al., 1988; Krauss et al., 1991). Postlethwait et al. (1998) mapped 144 zebrafish genes and described large conservation of chromosome segments between zebrafish and mammalian, including some human genes. Sahly et al. (1999) described the expression of eya1 that is involved in embryogenesis, and their results predicted a protein with $84.7 \%$ similarities with its human orthologue. Blaker-Lee et al. (2012) described zebrafish genes orthologues with human genes involved in brain disorders.

Howe et al. (2013) accomplished the significant step to evaluate the homology between human and zebrafish genomes in 2013. The zebrafish genome comprises around 26 thousand protein-coding genes in 26 pairs of chromosomes, while the human genome is composed of between 20-25 thousand genes in 23 pairs of chromosomes (Howe et al., 2013; International Human Genome Sequencing Consortium, 2001). The researchers observed that $>70 \%$ of human genes have an orthologue in zebrafish. The authors also found that some human genes have no orthologue in zebrafish, even presenting related receptors. These facts indicate that zebrafish have proteins with similar functions to human proteins; however, they encoded for different genes in humans and zebrafish. They also compared the zebrafish genes with the human genes described in the Online Mendelian Inheritance in Man (OMIM) database, which catalog genes involved in morbidity development. More than $80 \%$ of the 3176 genes described have an orthologue in zebrafish, allowing the use of zebrafish to investigate numerous human morbidities (Howe et al., 2013).

Over the years, many authors described genes associated with CNS development (Mack-Bucher et al., 2007; Xu et al., 2011; Blaker-Lee et al., 2012; Umans et al., 2017; Wu et al., 2019), CNS functions (Cocco et al., 2017; Laboissonniere et al., 2018), neurogenesis (Krauss et al., 1991; Byrd and Brunjes, 2001; GermanÀ et al., 2011), suggesting that zebrafish is a suitable model to evaluate neural disturbance mechanisms, efficacy, and toxicology of potential treatments. Besides, it is extremely important to highlight that although both species, human and zebrafish, possess a distinct systemic respiratory mechanism, studies have shown that the zebrafish swimming bladder (a specialized organ responsible for a proper buoyancy of teleosts) possesses anatomic, embryological, and transcriptome resemblances with human (and other mammals) lungs (Zheng et al., 2011). Moreover, Jonz and Nurse (2003) showed that the neuroepithelial cells (NECs) which are involved in respiratory control in mammals, are also present in larval and adult zebrafish. As indicated by immunolabeling, the NECs have vesicles containing the neurotransmitter serotonin, which seems to play a role in the respiratory system (Jonz and Nurse, 2003). These aspects suggest that not only the neuroinvasion could be studied (as discussed below) but also other systemic COVID-19s manifestation and complication.

Moreover, using zebrafish is a tremendous advantage because it has been accepted as an alternative model since it fulfills the 3R's principles: reduction, refinement, and replacement. The current European Union legislation (European Parliament, 2010) on the protection of animals used for scientific purposes considers that the early stages of the development of zebrafish [until $5 \mathrm{~d}$ postfertilization (dpf)] do not need protection since the procedures conducted will not provide suffering. The period before embryos and larvae reach exogenous feeding is used as criteria by EU Directive 2010/63/EU to define the period that fish do not require regulation (Scholz et al., 2008; Beekhuijzen et al., 2015; Bhusnure et al., 2015). Using zebrafish for research purposes also contributes to reduction because it allows the economy of animals of higher orders in many research steps, such as screening of substances in drug discovery. Also, because it undergoes the processes of absorption, distribution, metabolism, and excretion, zebrafish's use reduces the difference in results obtained between in vitro and in vivo tests (Bhusnure et al., 2015).

\section{Zebrafish's susceptibility to SARS-CoV-2 infection}

In addition to the receptor ACE2, the TMPRSS2, the proteases cathepsin L, trypsin, and furin were referred 
to mediate the virus' entry into the cells. Between the countless human-related proteins that zebrafish presents, there is also evidence of these enzymes involved in SARS-CoV-2 infection. This information can be used to design experiments that could help understand the virus infection's whole process or even study potential drugs, which target these enzymes.

Cathepsin $L$ is present in zebrafish since the early stage of development. Expression of the gene catL can be detected even around $7 \mathrm{~h}$ postfertilization (hpf), and the expression is higher at the hatching time. Cathepsin $L$ is involved in the development and hatching processes (Vogel and Gerster, 1997). Dana et al. (2019) used zebrafish as the in vivo model to ensure the efficacy of a selective probe synthesized to study human cathepsin L. Therefore, cathepsin $L$ was proposed as a biomarker for chemical exposure by evaluating its enzymatic activity in zebrafish embryos (Küster, 2005).

Trypsin and its receptor Par2 are present in zebrafish. The receptor Par2 is ubiquitously distributed while the trypsin was found in higher concentrations in the gill, nasal cavity, and mouth of embryo-larvae stages of zebrafish. It seems to play a role in response to injury, protecting the fish from bleeding (Kim et al., 2009; Xu et al., 2011).

Expression of furin genes was also described in zebrafish even in early stages and seemed to be relevant in the development and immunologic system (Walker et al., 2006; Ojanen et al., 2015).

The protease TMPRSS2 has only been studied in zebrafish in its rearranged form TMPRSS2-ERG, a biomarker of prostate cancer. However, there is still evidence that zebrafish have an orthologue to the TMPRSS2 protease (Bansal et al., 2014; Butler et al., 2017). Ohler and BeckerPauly (2011) observed high evolutionary conservation between the genes encoding TMPRSS4 in zebrafish and humans. They also demonstrated that the early development of zebrafish was affected by the TMPRSS4 gene silencing (Ohler and Becker-Pauly, 2011).

The zebrafish ACE2 receptor region that interacts with the protein S seems to share 50-64\% similarities with the same human region (Kraus et al., 2020). This characteristic was explored in a recent preprint paper, in which the authors showed that an exposure of zebrafish larvae to SARS-CoV-2 protein S receptor-binding domain (RBD) induced augmentation on heart rate at 5 and $7 \mathrm{dpf}$. This parameter was normalized after larvae exposure to captopril, suggesting the participation of the ACE2 receptor on this cardiovascular parameter (Kraus et al., 2020). Intriguingly, the authors also observed that intranasal delivery to $R B D$ resulted in disrupted integrity of the olfactory system, such as edema, hemorrhage, and apical loss of olfactory sensory neurons, accompanied by reduced electro-olfactogram signal (Kraus et al., 2020).

\section{Modeling zebrafish's viral infection: a powerful tool to understand SARS-CoV-2}

The zebrafish organism is gaining considerable visibility as an animal model to study pathogenesis and to screen new potential compounds for the treatment of different bacterial (Takaki et al., 2013) and viral infections (Gabor et al., 2014) that also affects the respiratory system in humans. Zebrafish has several components of human immunity. The innate immunity is present since the larvae hatched from the egg, whereas adaptive immunity takes weeks to fully develop (Lam et al., 2004; Novoa and Figueras, 2012). Despite the evolutionary distance, there are several similarities between the human and zebrafish immune systems; those include cellular components, i.e., macrophages, neutrophils, eosinophils, dendritic cells, and signal transduction pathways to eliminate the intruders (Goody et al., 2014).

The innate immune system first recognizes viral infections through mechanisms that may rely on toll-like receptors (TLRs), among them 3, 7, 8, and 9, retinoic acidinducible gene l-like receptors, nucleotide oligomerization domain-like receptors, and receptors that detect DNA in the cytoplasm (for more details, see Thompson and Iwasaki, 2008). Although the exact mechanism responsible for an immune response toward SARS-CoV-2 is still under loose, it is conceivable to assume that it interacts with one or more of these receptors. Elucidating this piece of the puzzle may help comprehend one of the significant complications concerning the COVID-19's evolution and mortality.

It is assumed that the exacerbated immune response toward SARS-CoV-2 elicits a colossal increase in peripheral proinflammatory cytokine and chemokine that ultimately can promote organ failure and death, an effect known as a "cytokine storm" (Mehta et al., 2020; Qin et al., 2020). In this way and assuming the importance of generating new rapid models to study this phenomenon in the laboratory, Kraus et al. (2020) have established zebrafish, in different stages of life, as useful models to investigate the pathophysiological effects of SARS-CoV-2 infection on both olfactory and cardiovascular system. The study revealed that the immune response of zebrafish to recombinant protein $\mathrm{S}$ parallel those observed in humans that present a mild-form of COVID-19. More specifically, the authors observed an increase in mRNA of antiviral response and proinflammatory cytokines, such as interleukin-1 $\beta$ (IL-1 $\beta$ ), tumor necrosis- $\alpha$ (TNF $\alpha$ ), interleukin-17 (IL-17), and chemokine ligand 20 (CCL20; Kraus et al., 2020).

Highlighting the converge immune response of zebrafish and humans, Progatzky et al. (2019) elegantly showed that mimicking viral infection on the upper respiratory tract through intranasal administration of resiquimod (TLR $7 / 8$ agonist) promoted an increase in proinflammatory cytokines expressions, such as IL-1 $\beta$, type-I interferons (IFN- a crucial antiviral signaling molecule) and TNF- $\alpha$. The study provided insights that zebrafish responses to resiquimod stimuli were similar to those observed in humans, both presented an augmentation of TNF- $\alpha$ and IFN- $\gamma$ in a time-dependent manner, while in mice the levels of TNF- $\alpha$ drastically reduced below basal levels after 1 h. Moreover, the authors also observed that the exposure to polyinosinic:polycytidylic acid (poly (l:C), a viral doublestrand RNA mimetic) produced an upregulation of genes 
responsible for TNF- $\alpha$, IL-6, and IFN- $\gamma$ only in mice, while there was no observable changes neither on humans or zebrafish after 1 or $8 \mathrm{~h}$ exposure (Progatzky et al., 2019). More intriguing, Gabor et al. (2014) described zebrafish as a valuable animal model to investigate the infection of different strains of human Influenza A virus (IAV), which similarly to SARS-CoV-2, is characterized as a causative agent of respiratory disease. The infected animals presented an increase in viral burden, recapitulating the immune and clinical symptoms of influenza infections in humans, showing an increased and sustained IFN expression, edema, and tissue destruction with multiple organ involvement. Besides, the treatment of infected zebrafish with Zanamivir, an anti-influenza compound, was able to reduced mortality and the expression of viral gene product, demonstrating the validity of zebrafish as a model to screen new antiviral compounds for IAV treatment (Gabor et al., 2014).

Besides its use on cytokine profile to immune challenges, zebrafish can be genetically manipulated to gain or loss-of-function of a myriad of proteins and may help to characterize the SARS-CoV-2 kinetic and dynamic. These have been applied to understand in vivo viral infection kinetic, cell tropism, phagocytic behavior, spatiotemporal activation of antiviral pathways (Ding et al., 2011; Palha et al., 2013; Passoni et al., 2017). In this direction, Ding et al. (2011) investigated whether zebrafish could be a potential model for Hepatitis $C$ virus (HCV) replication research. The animals microinjected with NS5B-plasmids demonstrated viral particles amplified in the liver. Even without any abnormalities in the development of zebrafish larvae, the viral amplification induced a similar gene expression pattern as those observed in human hepatocytes (increased expression of Argsyn, Hsp70, Leugpcr, ScarF2, Rasgbd, and chemokine-1 genes). Beyond the immune similarities, the administration of anti-HCV drugs, ribavirin and oxymatrine, was able to reduce the amplification rate in infected larvae, demonstrating again the great potential of this model as a tool for HCV drug screening (Ding et al., 2011). Another suitable example of zebrafish versatility to study viral infections was demonstrated by Passoni et al. (2017) using a transgenic zebrafish and genetically modified Chikungunya virus (CHIKV) and Sinbdis virus (SINV), both pathogens that sometimes are associated with neuropathies. The study showed that microinjection of green fluorescent protein (GFP)-expressing CHIKV and SINV on zebrafish larvae promoted an increase in GFP intensity in different organs. The authors also observed that SINV possesses a broad organ tropism as showed by GFP expression on central and peripheral organs after $1 \mathrm{~d}$ postinjection. Moreover, this study has demonstrated, by using a transgenic zebrafish expressing the red fluorescent protein (RFP) on endothelial cells, that only GFP-CHIKV colocalized with RFP-endothelium after 1 and $2 \mathrm{~d}$ postinfection, revealing that CHIKV, but not SINV, infects endothelial cells of the blood-brain barrier (BBB). Besides, they also studied the "Trojan-horse" neuroinvasion hypothesis, a secondary mechanism for CNS entry. By using a transgenic zebrafish line in which macrophages (including the microglia) express $m C h e r r y$, a red cytosolic fluorescent protein, the authors showed that neither CHIKV nor SINV use this alternative route for CNS infection. Altogether, these results aid by unveiling possible tools to understand viruses neuroinvasion mechanism on humans (Passoni et al., 2017).

\section{The Zebrafish CNS, Olfactory Pathway, and Its Possible Relevance in the Context of COVID-19}

Among the preclinical models applied o to study the physiological and abnormal brain functions, rodents still are the most employed animals in the neuroscience field. However, other animal models, like zebrafish, are emerging as promisor candidates (Keifer and Summers, 2016).

As exemplified in Figure 1, the zebrafish's brains share many neuroarchitecture and cellular morphology with mammals, including humans, characteristics that configure it as a valuable tool to model a wide range of human brain disorders (Kalueff et al., 2014; Stewart et al., 2014). Moreover, zebrafish have a very similar neurotransmitter system when compared with humans. Among the already neurotransmitters and neuromodulators characterized in this teleost are the GABA, glutamate, dopamine, noradrenaline, serotonin, acetylcholine, and histamine systems, which can already be observed at the early stages of zebrafish embryo and seems to play similar roles to those observed on mammals (for detailed review, see Horzmann and Freeman, 2016).

Regarding anatomy and physiology, despite its smaller cerebral hemispheres, the zebrafish brain presents a highly conserved organization, keeping important similarities when compared with the human brain. For instance, zebrafish have all typical sensory functions (vision, olfaction, taste, hearing, and tactile), and of note, all the sensory pathways share significant homology with humans (Byrd et al., 1996; Wullimann and Puelles, 1999). Highlighting similarities with humans' brain organization, the BBB is present on zebrafish, which develops on $3 \mathrm{dpf}$, and controls small molecules' permeability (Fleming et al., 2013).

Like mammals, the adult zebrafish brain is divided into the forebrain, midbrain, and hindbrain. The forebrain is the anterior part and includes the telencephalon and diencephalon. The midbrain is the portion between the forebrain and hindbrain, divided into optic tectum, torus semicircularis, torus longitudinalis, and midbrain tegmentum. Besides, the posterior portion of the brain is the hindbrain, which is composed of the cerebellum and medulla oblongata (Wullimann et al., 1996; Mueller et al., 2011; Folgueira et al., 2012). Functional similarities are also observed, for instance, the lateral pallium of zebrafish contains homologous structures to the hippocampus (Fig. 1), a structure that is derived from the medial pallium and is closely related to spatial memory (Eichenbaum et al., 1999; Rodríguez et al., 2002). Besides, the medial pallium of zebrafish presents an amygdaloid-like function (Fig. 1), a brain structure involved in the aversive learning in humans (Martín et al., 2011; Mueller et al., 2011; von Trotha et al., 2014). Similar to the olfactory system of mammals, neurons in the olfactory bulb of zebrafish project toward 


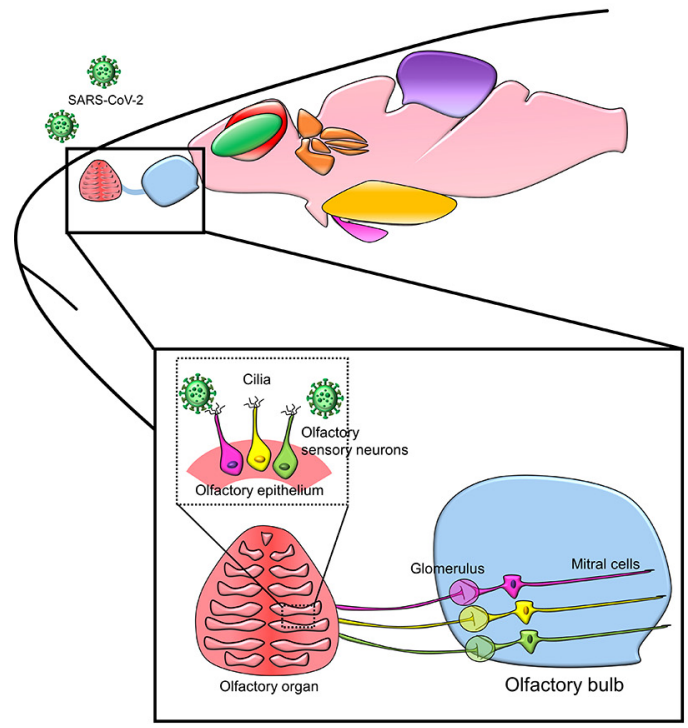

ZEBRAFISH BRAIN AREAS

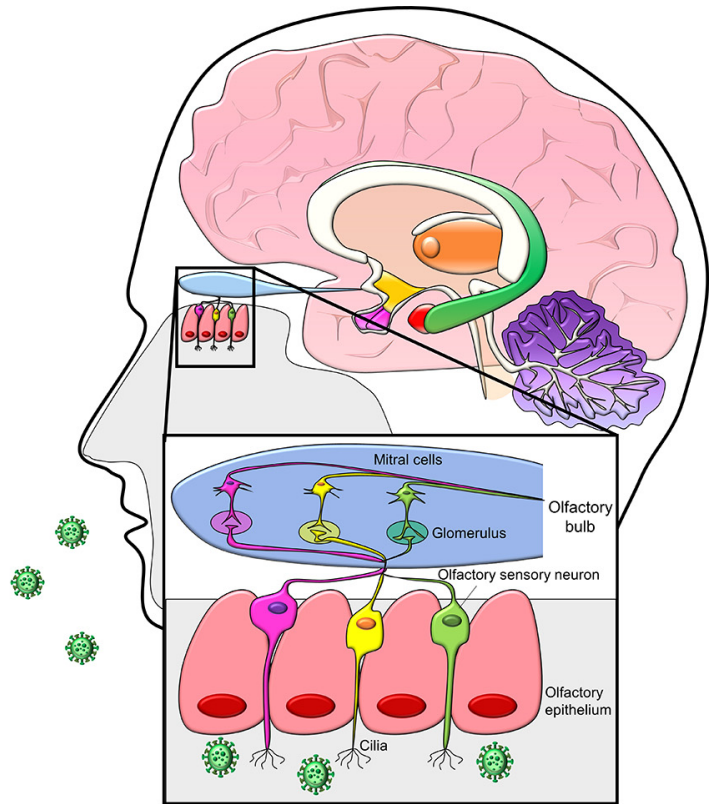

HUMAN BRAIN AREAS

$\begin{array}{ll}\text { Olfactory bulb } & \text { Olfactory bulb } \\ \text { Lateral Pallium } & \text { Hippocampus } \\ \text { Medial Pallium } & \text { Amygdala } \\ \text { Thalamus } & \text { Thalamus } \\ \text { Hypothalamus } & \text { Hypothalamus } \\ \text { Pituitary gland } & \text { Pituitary gland } \\ \text { Cerebellum } & \text { Cerebellum }\end{array}$

Figure 1. Zebrafish versus human olfactory system as one of the possible routes for the entrance of SARS-CoV-2 into the central nervous system. The human olfactory neuroepithelium comprehends ACE2-expressing olfactory sensory neurons that communicate with mitral cells in the olfactory bulb. The structure and cytoarchitecture of zebrafish's olfactory neuroepithelia and olfactory bulb are similar to that found in humans. Moreover, human brain areas present functional and structural correlates in the zebrafish brain.

the telencephalon and diencephalon (Wullimann and Puelles, 1999), suggesting that the zebrafish present an anatomic and functional organization that parallel those observed on humans (Fig. 1). In this sense, Miyasaka et al. (2014) used single-neuron labeling analysis in larvae zebrafish to reveal that axons at glomerular clusters in the olfactory bulb target the regions of the forebrain such as the posterior telencephalon, ventral telencephalon, the right habenula, the posterior tuberculum and the olfactory bulb itself in ipsilateral and contralateral regions. Noteworthy in the context of COVID-19, the olfactory system of zebrafish also shares many similarities with those observed in terrestrial mammals, including humans (Hildebrand and Shepherd, 1997; Howe et al., 2013; Saraiva et al., 2015; Fig. 1).

In zebrafish, the olfactory system can be divided into two main structures: the peripheral organ that organizes itself in a pair of rosettes on the nasal cavity, and the superior structure that is represented by the olfactory bulb and attached structures, responsible for diverse behavioral responses (Baier and Korsching, 1994; Korsching et al., 1997; Friedrich et al., 2013). The odorant receptors, responsible for the primary signal transduction in the periphery organ, follow the one neuron - one receptor rule, by which the sensory neurons can express only one receptor of many existing types. These neurons expressing the same receptors converge their axons onto a specific location in the olfactory bulb, and different odors can activate different types of compromised neurons, encoding a specific pattern of activation responsible for singular odors sensations (Barth et al., 1996; Friedrich and Korsching, 1997).

Another advantage is that zebrafish's olfactory system has a quick development detecting and discriminating odors between 2 and 4 dpf (Lindsay, 2004; Vitebsky et al., 2005). Moreover, this teleost also presents anatomically olfactory components more accessible than other vertebrates, allowing invasive manipulations with an increased rate of survival (Baier and Korsching, 1994; lqbal and Byrd-Jacobs, 2010; Paskin and Byrd-Jacobs, 2012; 
White et al., 2015). Altogether, these characteristics allow a quick and effective investigation of SARS-CoV-2 infection both on embryonic and adult olfactory systems.

\section{Zebrafish as a model of neurologic disorders}

How SARS-CoV-2 encroaches on the CNS is a question that remains unexplained. As mentioned, the primary hypothesis is that the virus can reach the neuronal cells through the olfactory nerves, promoting complications related to the olfactory perception, such as anosmia (for detailed review, see Lao et al., 2020). Corroborating this premise, functional analysis using magnetic resonance imaging of a patient who suffered from COVID-19 anosmia and dysgeusia suggested an altered cortical activity that normalized after resolving these symptoms (Politi et al., 2020).

Another hypothesis suggests that SARS-CoV-2 can promote an entry by a hematogenous route, either infecting the BBB cells or camouflaging itself in immune cells to enter the central nervous system as Trojan horses, both leading to possible neuroinflammatory boards. This hypothesis is based on the neurovascular symptoms, such as stroke, that affect many contaminated patients (Kumar et al., 2020). These possible pathways to SARS-CoV-2 entry in the CNS agree with the secondary neurologic symptoms presented by the patients, which can range from simple headaches to hemorrhagic strokes (Berger, 2020; Orrù et al., 2020), a serious condition that can increase the risk of death (for more detailed review of SARS-CoV-2 neuroinvasion, see ladecola et al., 2020).

The zebrafish model shows up great features once it is already used as a neurologic model for the disorders studies because of its similarities with the human CNS and the easy access to the communications routes among the brain areas, mainly in the embryonic phase (MacRae and Peterson, 2003). The neurovascular system can be evaluated in zebrafish and robust protocols and neuroimages assays that can easily show the dimension of the stroke-induced (Crilly et al., 2019) and can lead to a neuroinflammatory correlation process, as happens in parallel in SARS-CoV-2 infection. Furthermore, transsynaptic tracing using viruses to enable gene transfer has been used in zebrafish to study neuronal connection (Mundell et al., 2015). In this sense, similar techniques in addition to fluorescent labeling could be used to evaluate the spreading of SARS-CoV-2 in the CNS. Beyond that, the virus' pathways to entry in the CNS can be easily verified in the zebrafish model, as already happened with Chikungunya virus and Sindbis virus through fluorescent techniques (Passoni et al., 2017), a protocol that may be applied in COVID-19 research.

More than evaluating the acute consequences of the infection and its correlation with the CNS, zebrafish can provide long-term results about these consequences. It is unknown whether and how the interaction with SARSCoV-2 and the brain can lead to the worsening of other preexistent neurologic conditions or precipitate the appearance of symptoms in people susceptible to neurologic diseases in a long-term manner, either by the possible capacity of the virus to cause brain injury directly or through affecting the people by promoting a stressful overload because of pandemic era events, like social distancing.

Anosmia and ageusia, symptoms experience for most patients infected with SARS-CoV-2, are also reported in the initial stages of neurodegenerative diseases such as Alzheimer's and Parkinson's disease (Tarakad and Jankovic, 2017; Marin et al., 2018). Therefore, the concern that the new coronavirus can promote a certain degree of neurodegeneration, or even modulate the CNS homeostasis to lead to a new pathologic state, as happened with one patient that presents a quick development of Parkinson's disease starting after SARS-CoV-2 diagnosis (Cohen et al., 2020). To evaluate whether these factors can induce long-term changes, the zebrafish is a valuable tool since it is an established model to study neurodegeneration even in the context of neurodegenerative disorders (Tierney, 2011; Martín-Jiménez et al., 2015), and can be used to assess infection course and neurodegeneration relationship in a longitudinal way, because of quick and easy mode to obtain young to aged zebrafish (Kao et al., 2014). Teleosts also present an interesting great feature that can serve as an advantage against the rodent models: the possibility to regenerate the brain tissue (Kizil et al., 2012; Gemberling et al., 2013).

People who do not suffer from SARS-CoV-2 infection can experiment with its effect on their brains, even if not directly. Many studies reveal that pandemic issues tend to increase mood disorders (such as depression and anxiety) diagnosis worldwide (Tang et al., 2021), a problem that may have worse consequences in the future. One manner of studying these consequences is through behavioral analysis, an area where zebrafish can get great importance once it demonstrates a wide range of complex behaviors that can be evaluated and recently gained notoriety (Jesuthasan, 2012). Moreover, software that analyzes many behavioral types (such as ANY-maze software for rodents) can be found for zebrafish (Khan et al., 2017), which adds to its short development and great reproducibility and can save even more time and make searching even easier.

\section{Evaluation of SARS-CoV-2 Neurologic Alterations through Zebrafish's Behavior}

Behavioral tests have been used in neuroscience, neuropharmacology, and neurotoxicity fields to access numerous CNS disorders. This tool can help to elucidate the mechanisms involved in pathologies or injuries caused by chemical exposure and may be conducted with adults (Abreu et al., 2017; Kundap et al., 2017; Genario et al., 2020; Müller et al., 2020) or larvae zebrafish (Vitebsky et al., 2005; Krishnan et al., 2014; Ko et al., 2019), and may use the exploratory pattern to stimuli, such as light vibration and odorants exposure (Kalueff et al., 2013). In this context, many protocols have been developed and cataloged over the past decade; for instance, Kalueff et al. (2013) clustered 190 distinct behavioral phenotypes that include anxiety-like, freeze, spasm behaviors, and seizures. 
In the light of COVID-19 CNS alterations, anosmia may be evaluated in zebrafish at the behavioral level. In this direction, assessing locomotor activity with adults or larvae can be used to evaluate the olfactory system function (Krishnan et al., 2014; Abreu et al., 2017). It has been described that anosmia induced by lidocaine and $\mathrm{ZnSO} 4$ promoted anxiety-like behaviors in zebrafish (Abreu et al., $2016,2017)$. Also, protocols aiming at evaluating the olfaction capacity can include predator responses. These stimuli can be produced by using the skin of the predator as stimuli (Volz et al., 2020), skin injury mixture to evoke stress-related behavior (Diaz-Verdugo et al., 2019), or water-soluble chemicals such as food preparation, for the search for food behavior (Braubach et al., 2009; Chen et al., 2019), amino acids (Krishnan et al., 2014; Wakisaka et al., 2017), or bile acids (Koide et al., 2009; Wakisaka et al., 2017). Interestingly, even in the first stages of development, it is possible to evaluate zebrafish's motor activity. At almost $24 \mathrm{hpf}$ (19-27 hpf), zebrafish have spontaneously tail coiling measured by frequency and duration of occurrence. These assays enable the evaluation of SARSCoV-2 infection during development and may shed light on possible future alterations (Menelaou et al., 2008; Selderslaghs et al., 2013).

Regarding long-term behavioral alterations promoted by SARS-CoV-2 that may suggest neurodegeneration, several reports are evaluating the zebrafish memory performance in a distinct context such as spatial memory function (Williams et al., 2002), stress-induced memory impairment (Gaikwad et al., 2011), and scopolamine-induced memory impairment (Richetti et al., 2011).

\section{To model zebrafish into a preclinical and efficient model of COVID-19 model: exploring the strategies and tools}

The generation of the first transgenic mammal in the 1980s opened a wide venue for this field (Gordon and Ruddle, 1981). Nowadays, genetic manipulation of animals is an invaluable tool for understanding human disease. Although almost 40 years have passed since Palmiter et al. (1992) successfully generated "gigantic" mice, the steps used to generate transgenic mice are almost the same, which involve: (1) constructing a transgene; (2) obtaining fertilized eggs from female mice donors; (3) microinjections of the transgene material into the pronuclei/zygote; (4) implanting the modified zygote into pseudo-pregnant female mice; (5) genotype the transgene offspring. These several steps and the limitation of offspring generated by each pregnancy lead to several months of work until a viable transgenic mouse is established. These limitations and the urgency of viable tools to understand the behavior of SARS-CoV-2 during this pandemic raise the undeniable necessity of a rapid and reliable animal model.

Zebrafish's genetic manipulation offers an undeniable resource. The first transgenic zebrafish were obtained in the 1980s (Stuart et al., 1988) that showed that DNA transplantation into the zebrafish's embryo could be integrated and inherited by their germline. Almost a decade later, two distinct groups successfully created a transgenic zebrafish that expressed green fluorescent protein (GFP) under promoter-control that conveyed a tissue-dependent expression pattern (Long et al., 1997; Higashijima, 2008). These rudimentary protocols highlight the advantages of zebrafish over rodents. The former produces hundreds of eggs that can be fertilized and generated offspring's in a shorter period; their eggs are translucent, allowing in vivo imaging studies during the development of the CNS (Long et al., 1997).

Nowadays, several techniques have been described to generate transgenic zebrafish, such as knock-down with morpholinos, insertion of exogenous DNA with Tol2 transposons, knock-in for fate-mapping studies (Kizil et al., 2013; Kesavan et al., 2017; Rafferty and Quinn, 2018). To provide organized information regarding the strains of zebrafish, plasmids, and antibodies accessible, online database centers were created, such as the Zebrafish Information Network (Varshney et al., 2016; Gut et al., 2017).

\section{Real-time visualization of the zebrafish's CNS and SARS-CoV-2}

Imaging tools can be very useful for understanding the possible alterations triggered in the CNS, facilitating, and improving clinical prognosis. Beyond the conventional immunohistochemistry protocols, new strategies allowed in vivo screening and whole-brain assays in the zebrafish. These tools can be very important in the characterization of the neuroinvasion promoted by SARS-CoV-2 (Solomon et al., 2020).

Some fluorescent markers, like the GFP and the yellow fluorescent protein (YFP), can be used to label neuronal projections during zebrafish neurodevelopment. Indeed, the combined expression of different fluorescent markers refers to the transgenic technology known as Brainbow, in which several neurons can be individually labeled through genetic recombination (Cai et al., 2013). This technology was recently applied to the zebrafish model (Pan et al., 2011), giving rise to the successful transgenic tool named Zebrabow (Pan et al., 2013), enabling the broad study of the zebrafish's CNS.

Moreover, the functional analyses and activity of neurons can be achieved through genomic tools like the genetically-encoded calcium indicators (Ahrens et al., 2013) and the optogenetic neuromodulation (Knafo and Wyart, 2015). Both strategies can be easily inserted in the zebrafish genome by driving the expression of many proteinbased systems for genome engineering (Kawakami et al., 2004; Scott et al., 2007), targeting a specific neuronal population of interest. Unlike other vertebrate models, using light-sheet microscopy, the whole-brain activity of larval zebrafish can be rapidly obtained without attaching any fiber optic cables (Ahrens et al., 2013).

In addition to the techniques for functional analyses in the brain of zebrafish larvae, there are the fluorescent false neurotransmitters that are capable of measuring the in vivo uptake and release of a specific neurotransmitter. These synapse-markers are based on a fluorescent label of the synaptic vesicle or the extracellular neurotransmitters (Gubernator et al., 2009). 
Because of the lack of transparency and a larger brain, imaging the CNS of adult zebrafish is a challenge. However, methods like the use of different solvents to remove the excess of lipids and reduce light scattering (Ertürk et al., 2012), allow transforming a fixed and opaque organ into a transparent one, enabling an in situ analysis of the whole adult brain (Susaki et al., 2014). Another recent protocol applied for imaging the brain of adult zebrafish is the contrast-enhanced X-ray micro-computed tomography, which provides a 3D brain visualization (Babaei et al., 2016). Furthermore, the optical coherence tomography enables an in vivo and non-invasive real-time $3 \mathrm{D}$ imaging of the adult zebrafish brain anatomy (Rao et al., 2009).

\section{Molecular and biochemical analysis in the zebrafish model}

As in whole science, molecular biology techniques are essential in virology research, even more, if we consider that viruses do not have macro features to be analyzed, which gives great importance to genomic and proteomic analysis. Despite being a relatively new model, zebrafish can supply the molecular research with optimized protocols that ensure not only technical quality but also relative simplicity, presenting several examples of its use in viral infection research in zebrafish (Goody et al., 2014).

The Western blotting (WB) technique is one of the most used techniques to evaluate protein content and can be performed to verify proteins involved with viral infection as well as the proteins that lead the immune response to the viral infection. Furthermore, zebrafish provide a broad spectrum of possibilities once the protein content can be measured and compared in different developmental phases with relative speed. Newly published protocols also guarantee sample economy and optimized protein extraction of a single zebrafish larvae or embryo for WB, which added to the high fertility of zebrafish culminates in a large amount of sample in short periods (Schnabel et al., 2019). Besides that, the availability of antibodies specific to zebrafish samples is increasing.

Despite the utility of WB to provide previously known protein quantity information, much more unknown proteins can be related to viral infections and disease progression, further in novel viral infections such as COVID-19. In this case, zebrafish can be a useful tool in the research as well, which can involve specifically protocols for proteomics assays that can lead to a protein screening in diverse scenarios, from electrophoresis to the mass spectrometry techniques, both in adults and embryos (Link et al., 2006; Singh et al., 2013).

If the aim of the work concentrates on the genomic profile, zebrafish can help mainly in the evaluation of viral infection kinetics studies and genome expression measurements, not only for viral particles or whole-genome but also for the genes of target-proteins for viruses (Goody et al., 2014). The evaluation of the RNA content can be a powerful tool against SARS-CoV-2, once this virus has a single-stranded RNA, enabling the investigation of a plausible connection between the viral proteins and the ACE2 target-protein in humans. Furthermore, using the reverse
transcription-PCR quantitative real-time (RT-qPCR) technique, ACE2 domains in different neurons and regions in zebrafish were already identified (Chou et al., 2006).

Besides the aforementioned, biochemical assays comprehend the understanding of the chemical reactions that occur inside the organism. This type of essay allows us to elucidate the mechanism of action of many substances. Many procedures to perform the biochemical assays developed for other species (Ellman et al., 1961; Misra and Fridovich, 1972; Bradford, 1976; Aebi, 1984; Draper and Hadley, 1990; LeBel et al., 1992; Frasco and Guilhermino, 2002) has been adapted and used in zebrafish with great results (Jin et al., 2015; Abe et al., 2018; Agostini et al., 2018; Maharajan et al., 2018; Sarasamma et al., 2018, 2019; Bernardo et al., 2019; Mocelin et al., 2019; Schmitt et al., 2019; Ûnal et al., 2019; Walpitagama et al., 2019).

Different enzymes or processes can be studied by biochemical assays in zebrafish and may be used to understand the possible alterations promoted by SARS-CoV-2 at the cellular and tissue level. For instance, some tests allow the determination of the reactive oxygen species, the lipid peroxidation, and the activity of the enzymes involved in antioxidant mechanisms, such as superoxide dismutase, catalase, and glutathione-S-transferase (Diniz et al., 2015; Jin et al., 2015; Sarasamma et al., 2018). Besides, some assays enable the measurement of distinct neurotransmitters activity, such as the choline, GABA, glutamate, glycine, dopamine, and 5-hydroxytryptamine (Abe et al., 2018; Agostini et al., 2018; Sarasamma et al., 2018, 2019; Schmitt et al., 2019; Walpitagama et al., 2019).

As was previously discussed, some enzymes are involved in SARS-CoV-2 entrance into the cells, such as the proteases cathepsin L, TMRPSS, trypsin, and furin. These enzymes could be used as a target for new drug development. A methodology to evaluate cathepsin $L$ activity was already developed and tested in zebrafish (Dana et al., 2019). It was developed for different purposes, happened before SARS-CoV-2 was brought to light, but it could be helpful to assess the efficacy of drugs that target cathep$\sin \mathrm{L}$.

\section{The "omics-era" and zebrafish}

Much of our knowledge about single cells evolved drastically within the past decades with advanced molecular biology techniques. Nowadays, it is possible to comprehend the system-behavior in a single-cell resolution (Wagner and Klein, 2020).

The advent of omics analysis, which refers to an integrative discipline with the objective of mapping genes and proteins and comprehends the interactions and relationship among them and the environment surrounding the cell, has enabled the in-depth knowledge of the different systems and how diseases may disturb the homeostasis of these systems (Jehan, 2019; Unterman et al., 2020).

Regarding COVID-19, the omics approach has already been used to clarify some of the molecular alterations promoted by SARS-CoV-2 infection in humans (Song et al., 2020; Unterman et al., 2020). For 
instance, lipidomes analysis revealed that some plasma metabolites differed from COVID-19 patients compared with healthy controls (Song et al., 2020), and a multiomics single-cells analysis revealed that worse response to SARS-CoV-2 infection was associated with predominant interferon type-1 response across different immune cells accompanied with an imbalance between innate and adaptive immunity (Unterman et al., 2020). However, preclinical studies using the omics approach and SARS-CoV-2 dynamics still need to be explored.

In this direction, some shreds of evidence strongly suggest that zebrafish omics may be used to screen the biological activity of distinct chemical compounds, testing its teratogenicity and toxicity (Sukardi et al., 2010; Hung et al., 2012). Also, the proteomics approach has already been used to understand age-related neurodegenerative diseases, such as Alzheimer's and Parkinson's (Abramsson et al., 2010; Mushtaq et al., 2013), alterations on the Rett syndrome model (Cortelazzo et al., 2017), to demonstrate the similarities between humans and zebrafish plasma composition (Li et al., 2016) and neutrophils (Singh et al., 2013), to explore different biomarkers for liver dysfunction (Ayobahan et al., 2020), to explore the dynamics of extracellular matrix composition during heart regeneration (Garcia-Puig et al., 2019), and to investigate the alterations promoted by spring viremia of Carp virus in the zebrafish (Liu et al., 2020). These pieces of evidence highlight that omics tools may be used for different purposes on the zebrafish model and are a powerful tool for a better understanding of human diseases with distinct etiology, including COVID-19.

\section{Conclusion}

Among all the animal models, zebrafish has proven to be an essential and powerful tool for human disease analysis. General attributes, like the low-cost maintenance, external fertilization, a large number of eggs, rapid life cycle, transparency of the embryos, and the several available techniques make this vertebrate an attractive model for research. Zebrafish also display genetics and physiologic similarities with mammalian, including the brain structure and functions, which highlights its great potential as an animal model for studying the neurologic components associated with SARSCoV-2 infection. Several of the genetic, behavioral, cellular, molecular, and biochemical approaches already standardized in other animal models are also applicable in this teleost. Altogether, those advantages ensure reliable, fast, and reproducible results for COVID-19 analysis when compared with other animal models. The goal of proposing an innovative animal model like zebrafish to study neurologic components related to SARS-CoV2 infection is ambitious but will be of great value for more robust and effective analysis.

\section{Search strategy}

All the relevant articles were identified and collected from the PubMed database from April 1, 2020, up to
November 30, 2020. The following search terms were used (alone or in combination): zebrafish, SARS-CoV-2, COVID-19, CNS, encephalitis, neurologic disorders, anosmia, ciliopathy, olfactory system, olfactory bulb, olfactory neurons, ACE2, TMPRSS2, immunity, behavior, genetic manipulation, imaging tools, molecular analysis, biochemical analysis, omics. The reference list was generated based on papers relevant to the topics discussed in this review.

\section{References}

Abe FR, Soares AMVM, de Oliveira DP, Gravato C (2018) Toxicity of dyes to zebrafish at the biochemical level: cellular energy allocation and neurotoxicity. Environ Pollut 235:255-262.

Abramsson A, Westman-Brinkmalm A, Pannee J, Gustavsson M, von Otter M, Blennow K, Brinkmalm G, Kettunen P, Zetterberg H (2010) Proteomics profiling of single organs from individual adult zebrafish. Zebrafish 7:161-168.

Abreu MS, Giacomini ACVV, Kalueff AV, Barcellos LJG (2016) The smell of "anxiety": behavioral modulation by experimental anosmia in zebrafish. Physiol Behav 157:67-71.

Abreu MS, Giacomini ACVV, Rodriguez R, Kalueff AV, Barcellos LJG (2017) Effects of ZnSO 4 -induced peripheral anosmia on zebrafish behavior and physiology. Behav Brain Res 320:275-281.

Aebi H (1984) Catalase in vitro. Methods Enzymol 105:121-126.

Agostini JF, Toé HCZD, Vieira KM, Baldin SL, Costa NLF, Cruz CU, Longo L, Machado MM, da Silveira TR, Schuck PF, Rico EP (2018) Cholinergic system and oxidative stress changes in the brain of a zebrafish model chronically exposed to ethanol. Neurotox Res 33:749-758.

Ahrens MB, Orger MB, Robson DN, Li JM, Keller PJ (2013) Wholebrain functional imaging at cellular resolution using light-sheet microscopy. Nat Methods 10:413-420.

Ayala-Nunez NV, Follain G, Delalande F, Hirschler A, Partiot E, Hale GL, Bollweg BC, Roels J, Chazal M, Bakoa F, Carocci M, Bourdoulous S, Faklaris O, Zaki SR, Eckly A, Uring-Lambert B, Doussau F, Cianferani S, Carapito C, Jacobs FMJ, et al. (2019) Zika virus enhances monocyte adhesion and transmigration favoring viral dissemination to neural cells. Nat Commun 10:4430.

Ayobahan SU, Eilebrecht S, Baumann L, Teigeler M, Hollert H, Kalkhof S, Eilebrecht E, Schäfers C (2020) Detection of biomarkers to differentiate endocrine disruption from hepatotoxicity in zebrafish (Danio rerio) using proteomics. Chemosphere 240:124970.

Babaei F, Hong TLC, Yeung K, Cheng SH, Lam YW (2016) Contrastenhanced $\mathrm{x}$-ray micro-computed tomography as a versatile method for anatomical studies of adult zebrafish. Zebrafish 13:310-316.

Baier H, Korsching S (1994) Olfactory glomeruli in the zebrafish form an invariant pattern and are identifiable across animals. J Neurosci 14:219-230.

Bansal N, Davis S, Tereshchenko I, Budak-Alpdogan T, Zhong H, Stein MN, Kim IY, DiPaola RS, Bertino JR, Sabaawy HE (2014) Enrichment of human prostate cancer cells with tumor initiating properties in mouse and zebrafish xenografts by differential adhesion. Prostate 74:187-200.

Bao L, Deng W, Gao H, Xiao C, Liu J, Xue J, Lv Q, Liu J, Yu P, Xu Y, Qi F, Qu Y, Li F, Xiang Z, Yu H, Gong S, Liu M, Wang G, Wang S, Song Z, et al. (2020) Reinfection could not occur in SARS-CoV-2 infected rhesus macaques. bioRxiv 2020.03.13.990226.

Barth AL, Justice NJ, Ngai J (1996) Asynchronous onset of odorant receptor expression in the developing zebrafish olfactory system. Neuron 16:23-34.

Beekhuijzen M, de Koning C, Flores-Guillén M-E, de VriesBuitenweg S, Tobor-Kaplon M, van de Waart B, Emmen H (2015) From cutting edge to guideline: a first step in harmonization of the zebrafish embryotoxicity test (ZET) by describing the most optimal 
test conditions and morphology scoring system. Reprod Toxicol 56:64-76.

Berger JR (2020) COVID-19 and the nervous system. J Neurovirol 26:143-148.

Bernardo HT, Agostini JF, Toé HCZD, Vieira KM, Baldin SL, Schuck PF, Uribe-Cruz C, Longo L, da Silveira TR, Rosemberg DB, Rico EP (2019) Cholinergic system and exploratory behavior are changed after weekly-binge ethanol exposure in zebrafish. Pharmacol Biochem Behav 186:172790.

Bhusnure OG, Mane JM, Gholve SB (2015) Drug target screening and its validation by zebrafish as a novel tool. Pharm Anal Acta 6:10.

Blaker-Lee A, Gupta S, McCammon JM, De Rienzo G, Sive H (2012) Zebrafish homologs of genes within $16 \mathrm{p} 11.2$, a genomic region associated with brain disorders, are active during brain development, and include two deletion dosage sensor genes. Dis Model Mech 5:834-851.

Bradford MM (1976) A rapid and sensitive method for the quantitation of microgram quantities of protein utilizing the principle of protein-dye binding. Anal Biochem 72:248-254.

Braubach OR, Wood H-D, Gadbois S, Fine A, Croll RP (2009) Olfactory conditioning in the zebrafish (Danio rerio). Behav Brain Res 198:190-198.

Butler MS, Roshan-Moniri M, Hsing M, Lau D, Kim A, Yen P, Mroczek M, Nouri M, Lien S, Axerio-Cilies P, Dalal K, Yau C, Ghaidi F, Guo Y, Yamazaki T, Lawn S, Gleave ME, Gregory-Evans CY, Mclntosh LP, Cox ME, et al. (2017) Discovery and characterization of small molecules targeting the DNA-binding ETS domain of ERG in prostate cancer. Oncotarget 8:42438-42454.

Butowt R, Bilinska K (2020) SARS-CoV-2: olfaction, brain infection, and the urgent need for clinical samples allowing earlier virus detection. ACS Chem Neurosci 11:1200-1203.

Byrd C, Brunjes P (2001) Neurogenesis in the olfactory bulb of adult zebrafish. Neuroscience 105:793-801.

Byrd CA, Jones JT, Quattro JM, Rogers ME, Brunjes PC, Vogt RG (1996) Ontogeny of odorant receptor gene expression in zebrafish, Danio rerio. J Neurobiol 29:445-458.

Cai D, Cohen KB, Luo T, Lichtman JW, Sanes JR (2013) Improved tools for the Brainbow toolbox. Nat Methods 10:540-547.

Chan JF, Zhang AJ, Yuan S, Poon VK, Chan CC, Lee AC, Chan WM, Fan Z, Tsoi HW, Wen L, Liang R, Cao J, Chen Y, Tang K, Luo C, Cai JP, Kok KH, Chu H, Chan KH, Sridhar S, et al. (2020) Simulation of the clinical and pathological manifestations of coronavirus disease 2019 (COVID-19) in a golden Syrian hamster model: implications for disease pathogenesis and transmissibility. Clin Infect Dis 71:2428.

Chen R, Wang K, Yu J, Howard D, French L, Chen Z, Wen C, Xu Z (2021) The spatial and cell-type distribution of SARS-CoV-2 receptor ACE2 in the human and mouse brains. Front Neurol 11:573095.

Chen W, Peng X, Deng Q, Chen M, Du J, Zhang B (2019) Role of olfactorily responsive neurons in the right dorsal habenula-ventral interpeduncular nucleus pathway in food-seeking behaviors of larval zebrafish. Neuroscience 404:259-267.

Chou CF, Loh CB, Foo YK, Shen S, Fielding BC, Tan THP, Khan S, Wang Y, Lim SG, Hong W, Tan YJ, Fu J (2006) ACE2 orthologues in non-mammalian vertebrates (Danio, Gallus, Fugu, Tetraodon and Xenopus). Gene 377:46-55.

Cocco A, Rönnberg AMC, Jin Z, André GI, Vossen LE, Bhandage AK, Thörnqvist P-O, Birnir B, Winberg S (2017) Characterization of the $\gamma$-aminobutyric acid signaling system in the zebrafish (Danio rerio Hamilton) central nervous system by reverse transcription-quantitative polymerase chain reaction. Neuroscience 343:300-321.

Cohen ME, Eichel R, Steiner-Birmanns B, Janah A, loshpa M, BarShalom R, Paul JJ, Gaber H, Skrahina V, Bornstein NM, Yahalom G (2020) A case of probable Parkinson's disease after SARS-CoV2 infection. Lancet Neurol 19:804-805.

Cortelazzo A, Pietri T, De Felice C, Leoncini S, Guerranti R, Signorini C, Timperio AM, Zolla L, Ciccoli L, Hayek J (2017) Proteomic analysis of the Rett syndrome experimental model mecp2Q63X mutant zebrafish. J Proteomics 154:128-133.
Crilly S, Njegic A, Parry-Jones AR, Allan SM, Kasher PR (2019) Using zebrafish larvae to study the pathological consequences of hemorrhagic stroke. J Vis Exp 59716.

Dana D, Garcia J, Bhuiyan Al, Rathod P, Joo L, Novoa DA, Paroly S, Fath KR, Chang EJ, Pathak SK (2019) Cell penetrable, clickable and tagless activity-based probe of human cathepsin L. Bioorg Chem 85:505-514.

Dey J, Alam MT, Chandra S, Gupta J, Ray U, Srivastava AK, Tripathi PP (2021) Neuroinvasion of SARS-CoV-2 may play a role in the breakdown of the respiratory center of the brain. $J$ Med Virol 93:1296-1303.

Diaz-Verdugo C, Sun GJ, Fawcett CH, Zhu P, Fishman MC (2019) Mating suppresses alarm response in zebrafish. Curr Biol 29:2541-2546.e3.

Ding CB, Zhang JP, Zhao Y, Peng ZG, Song DQ, Jiang JD (2011) Zebrafish as a potential model organism for drug test against Hepatitis C virus. PLoS One 6:e22921.

Diniz MS, Salgado R, Pereira VJ, Carvalho G, Oehmen A, Reis MAM, Noronha JP (2015) Ecotoxicity of ketoprofen, diclofenac, atenolol and their photolysis byproducts in zebrafish (Danio rerio). Sci Total Environ 505:282-289.

Draper HH, Hadley M (1990) Malondialdehyde determination as index of lipid peroxidation. Methods Enzymol 186:421-431.

Dubé M, Le Coupanec A, Wong AHM, Rini JM, Desforges M, Talbot PJ (2018) Axonal transport enables neuron-to-neuron propagation of human coronavirus OC43. J Virol 92:e00404-18.

Duong L, Xu P, Liu A (2020) Meningoencephalitis without respiratory failure in a young female patient with COVID-19 infection in Downtown Los Angeles, early April 2020. Brain Behav Immun 87:33.

Eichenbaum H, Dudchenko P, Wood E, Shapiro M, Tanila H (1999) The hippocampus, memory, and place cells. Neuron 23:209-226.

Ellman GL, Courtney KD, Andres V, Featherstone RM (1961) A new and rapid colorimetric determination of acetylcholinesterase activity. Biochem Pharmacol 7:88-95.

Ellul MA, Benjamin L, Singh B, Lant S, Michael BD, Easton A, Kneen $R$, Defres S, Sejvar J, Solomon T (2020) Neurological associations of COVID-19. Lancet Neurol 19:767-783.

Ertürk A, Becker K, Jährling N, Mauch CP, Hojer CD, Egen JG, Hellal F, Bradke F, Sheng M, Dodt H-U (2012) Three-dimensional imaging of solvent-cleared organs using 3DISCO. Nat Protoc 7:19831995.

European Parliament (2010) Directive 2010/63/EU of the European Parliament and of the Council of 22 September 2010 on the protection of animals used for scientific purposes. EUR-Lex. Available from https://eur-lex.europa.eu/eli/dir/2010/63/oj. Accessed January 6, 2021.

Fleming A, Diekmann H, Goldsmith P (2013) Functional characterisation of the maturation of the blood-brain barrier in larval zebrafish. PLoS One 8:e77548.

Folgueira M, Bayley P, Navratilova P, Becker TS, Wilson SW, Clarke JD (2012) Morphogenesis underlying the development of the everted teleost telencephalon. Neural Dev 7:32.

Frasco MF, Guilhermino L (2002) Effects of dimethoate and betanaphthoflavone on selected biomarkers of Poecilia reticulata. Fish Physiol Biochem 26:149-156.

Friedrich RW, Korsching SI (1997) Combinatorial and chemotopic odorant coding in the zebrafish olfactory bulb visualized by optical imaging. Neuron 18:737-752.

Friedrich RW, Genoud C, Wanner AA (2013) Analyzing the structure and function of neuronal circuits in zebrafish. Front Neural Circuits 7:71.

Gabor KA, Goody MF, Mowel WK, Breitbach ME, Gratacap RL, Witten PE, Kim CH (2014) Influenza A virus infection in zebrafish recapitulates mammalian infection and sensitivity to anti-influenza drug treatment. Dis Model Mech 7:1227-1237.

Gaikwad S, Stewart A, Hart P, Wong K, Piet V, Cachat J, Kalueff AV (2011) Acute stress disrupts performance of zebrafish in the cued and spatial memory tests: the utility of fish models to study stressmemory interplay. Behav Processes 87:224-230. 
Gandhi S, Srivastava AK, Ray U, Tripathi PP (2020) Is the collapse of the respiratory center in the brain responsible for respiratory breakdown in COVID-19 patients? ACS Chem Neurosci 11:13791381.

Garcia-Puig A, Mosquera JL, Jiménez-Delgado S, García-Pastor C, Jorba I, Navajas D, Canals F, Raya A (2019) Proteomics analysis of extracellular matrix remodeling during zebrafish heart regeneration. Mol Cell Proteomics 18:1745-1755.

Gemberling M, Bailey TJ, Hyde DR, Poss KD (2013) The zebrafish as a model for complex tissue regeneration. Trends Genet 29:611620.

Genario R, Giacomini ACVV, de Abreu MS, Marcon L, Demin KA, Kalueff AV (2020) Sex differences in adult zebrafish anxiolytic-like responses to diazepam and melatonin. Neurosci Lett 714:134548.

GermanÀ A, Montalbano G, Guerrera MC, Amato V, LaurÀ R, Magnoli D, Campo S, Suarez-Fernandez E, Ciriaco E, Vega JA (2011) Developmental changes in the expression of sox2 in the zebrafish brain. Microsc Res Tech 74:347-354.

Gheblawi M, Wang K, Viveiros A, Nguyen Q, Zhong J-C, Turner AJ, Raizada MK, Grant MB, Oudit GY (2020) Angiotensin-converting enzyme 2: SARS-CoV-2 receptor and regulator of the renin-angiotensin system. Circ Res 126:1456-1474.

Goody MF, Sullivan C, Kim CH (2014) Studying the immune response to human viral infections using zebrafish. Dev Comp Immunol 46:84-95.

Gordon J, Ruddle F (1981) Integration and stable germ line transmission of genes injected into mouse pronuclei. Science 214:12441246.

Gubernator NG, Zhang H, Staal RGW, Mosharov EV, Pereira DB, Yue M, Balsanek V, Vadola PA, Mukherjee B, Edwards RH, Sulzer D, Sames D (2009) Fluorescent false neurotransmitters visualize dopamine release from individual presynaptic terminals. Science 324:1441-1444.

Gut P, Reischauer S, Stainier DYR, Arnaout R (2017) Little fish, big data: zebrafish as a model for cardiovascular and metabolic disease. Physiol Rev 97:889-938.

Helms J, Kremer S, Merdji H, Clere-Jehl R, Schenck M, Kummerlen C, Collange O, Boulay C, Fafi-Kremer S, Ohana M, Anheim M, Meziani F (2020) Neurologic features in severe SARS-CoV-2 infection. N Engl J Med 382:2268-2270.

Higashijima S (2008) Transgenic zebrafish expressing fluorescent proteins in central nervous system neurons. Dev Growth Differ 50:407-413.

Hildebrand JG, Shepherd GM (1997) Mechanisms of olfactory discrimination: converging evidence for common principles across phyla. Annu Rev Neurosci 20:595-631.

Hoffmann M, Kleine-Weber $\mathrm{H}$, Schroeder S, Krüger N, Herrler T, Erichsen S, Schiergens TS, Herrler G, Wu N-H, Nitsche A, Müller MA, Drosten C, Pöhlmann S (2020) SARS-CoV-2 cell entry depends on ACE2 and TMPRSS2 and is blocked by a clinically proven protease inhibitor. Cell 181:271-280.e8.

Horzmann K, Freeman J (2016) Zebrafish get connected: investigating neurotransmission targets and alterations in chemical toxicity. Toxics 4:19.

Howe K, Clark MD, Torroja CF, Torrance J, Berthelot C, Muffato M, Collins JE, Humphray S, McLaren K, Matthews L, McLaren S, Sealy I, Caccamo M, Churcher C, Scott C, Barrett JC, Koch R, Rauch GJ, White S, Chow W, et al. (2013) The zebrafish reference genome sequence and its relationship to the human genome. Nature 496:498-503.

Huang C, Wang Y, Li X, Ren L, Zhao J, Hu Y, Zhang L, Fan G, Xu J, Gu X, Cheng Z, Yu T, Xia J, Wei Y, Wu W, Xie X, Yin W, Li H, Liu M, Xiao Y, et al. (2020) Clinical features of patients infected with 2019 novel coronavirus in Wuhan, China. Lancet 395:497-506.

Hung MW, Zhang ZJ, Li S, Lei B, Yuan S, Cui GZ, Man Hoi P, Chan K, Lee SMY (2012) From omics to drug metabolism and high content screen of natural product in zebrafish: a new model for discovery of neuroactive compound. Evid Based Complement Alternat Med 2012:1-20. ladecola C, Anrather J, Kamel H (2020) Effects of COVID-19 on the nervous system. Cell 183:16-27.e1.

International Human Genome Sequencing Consortium (2001) Correction: initial sequencing and analysis of the human genome. Nature 412:565-566.

lqbal T, Byrd-Jacobs C (2010) Rapid degeneration and regeneration of the zebrafish olfactory epithelium after Triton X-100 application. Chem Senses 35:351-361.

Jain J, Gaur S, Chaudhary Y, Kaul R (2020) The molecular biology of intracellular events during Coronavirus infection cycle. Virusdisease 31:75-79.

Jehan Z (2019) Single-cell omics: an overview. In: Single-cell omics, pp 3-19. San Diego: Elsevier.

Jesuthasan S (2012) Fear, anxiety, and control in the zebrafish. Dev Neurobiol 72:395-403.

Jin Y, Liu Z, Liu F, Ye Y, Peng T, Fu Z (2015) Embryonic exposure to cadmium (II) and chromium (VI) induce behavioral alterations, oxidative stress and immunotoxicity in zebrafish (Danio rerio). Neurotoxicol Teratol 48:9-17.

Johansen MD, Irving A, Montagutelli X, Tate MD, Rudloff I, Nold MF, Hansbro NG, Kim RY, Donovan C, Liu G, Faiz A, Short KR, Lyons JG, McCaughan GW, Gorrell MD, Cole A, Moreno C, Couteur D, Hesselson D, Triccas J, et al. (2020) Animal and translational models of SARS-CoV-2 infection and COVID-19. Mucosal Immunol 13:877-891.

Jonz MG, Nurse CA (2003) Neuroepithelial cells and associated innervation of the zebrafish gill: a confocal immunofluorescence study. J Comp Neurol 461:1-17.

Kalueff AV, Gebhardt M, Stewart AM, Cachat JM, Brimmer M, Chawla JS, Craddock C, Kyzar EJ, Roth A, Landsman S, Gaikwad S, Robinson K, Baatrup E, Tierney K, Shamchuk A, Norton W, Miller N, Nicolson T, Braubach O, Gilman CP, et al. (2013) Towards a comprehensive catalog of zebrafish behavior 1.0 and beyond. Zebrafish 10:70-86.

Kalueff AV, Stewart AM, Gerlai R (2014) Zebrafish as an emerging model for studying complex brain disorders. Trends Pharmacol Sci 35:63-75.

Kao TT, Chu CY, Lee GH, Hsiao TH, Cheng NW, Chang NS, Chen BH, Fu TF (2014) Folate deficiency-induced oxidative stress contributes to neuropathy in young and aged zebrafish - implication in neural tube defects and Alzheimer's diseases. Neurobiol Dis 71:234-244.

Karuppan MKM, Devadoss D, Nair M, Chand HS, Lakshmana MK (2021) SARS-CoV-2 infection in the central and peripheral nervous system-associated morbidities and their potential mechanism. Mol Neurobiol 1-16.

Kawakami K, Takeda H, Kawakami N, Kobayashi M, Matsuda N, Mishina M (2004) A transposon-mediated gene trap approach identifies developmentally regulated genes in zebrafish. Dev Cell $7: 133-144$.

Keifer J, Summers CH (2016) Putting the "biology" back into "neurobiology": the strength of diversity in animal model systems for neuroscience research. Front Syst Neurosci 10:69.

Kesavan G, Chekuru A, Machate A, Brand M (2017) CRISPR/Cas9mediated zebrafish knock-in as a novel strategy to study midbrain-hindbrain boundary development. Front Neuroanat 11:1-14.

Khan KM, Collier AD, Meshalkina DA, Kysil EV, Khatsko SL, Kolesnikova T, Morzherin YY, Warnick JE, Kalueff AV, Echevarria DJ (2017) Zebrafish models in neuropsychopharmacology and CNS drug discovery. Br J Pharmacol 174:1925-1944.

Kim S, Carrillo M, Kulkarni V, Jagadeeswaran P (2009) Evolution of primary hemostasis in early vertebrates. PLoS One 4:e8403.

Kim YI, Kim SG, Kim SM, Kim EH, Park SJ, Yu KM, Chang JH, Kim EJ, Lee S, Casel MAB, Um J, Song MS, Jeong HW, Lai VD, Kim Y, Chin BS, Park JS, Chung KH, Foo SS, Poo H, et al. (2020) Infection and rapid transmission of SARS-CoV-2 in ferrets. Cell Host Microbe 27:704-709.e2.

Kimmel CB, Ballard WW, Kimmel SR, Ullmann B, Schilling TF (1995) Stages of embryonic development of the zebrafish. Dev Dyn 203:253-310. 
Kizil C, Kaslin J, Kroehne V, Brand M (2012) Adult neurogenesis and brain regeneration in zebrafish. Devel Neurobio 72:429-461.

Kizil C, Iltzsche A, Kaslin J, Brand M (2013) Micromanipulation of gene expression in the adult zebrafish brain using cerebroventricular microinjection of morpholino oligonucleotides. J Vis Exp 1-6.

Knafo S, Wyart C (2015) Optogenetic neuromodulation: new tools for monitoring and breaking neural circuits. Ann Phys Rehabil Med 58:259-264.

Ko MJ, Ganzen LC, Coskun E, Mukadam AA, Leung YF, van Rijn RM (2019) A critical evaluation of TRPA1-mediated locomotor behavior in zebrafish as a screening tool for novel anti-nociceptive drug discovery. Sci Rep 9:2430.

Koide T, Miyasaka N, Morimoto K, Asakawa K, Urasaki A, Kawakami $\mathrm{K}$, Yoshihara $Y$ (2009) Olfactory neural circuitry for attraction to amino acids revealed by transposon-mediated gene trap approach in zebrafish. Proc Natl Acad Sci USA 106:9884-9889.

Korsching SI, Argo S, Campenhausen H, Friedrich RW, Rummrich A, Weth F (1997) Olfaction in zebrafish: what does a tiny teleost tell us? Semin Cell Dev Biol 8:181-187.

Koyuncu OO, Hogue IB, Enquist LW (2013) Virus infections in the nervous system. Cell Host Microbe 13:379-393.

Kraus A, Casadei E, Huertas M, Ye C, Bradfute S, Boudinot P, Levraud J-P, Salinas I (2020) A zebrafish model for COVID-19 recapitulates olfactory and cardiovascular pathophysiologies caused by SARS-CoV-2. bioRxiv 2020.11.06.368191.

Krauss S, Johansen T, Korzh V, Fjose A (1991) Expression of the zebrafish paired box gene pax[zf-b] during early neurogenesis. Development 113:1193-1206.

Krishnan S, Mathuru AS, Kibat C, Rahman M, Lupton CE, Stewart J, Claridge-Chang A, Yen S-C, Jesuthasan S (2014) The right dorsal habenula limits attraction to an odor in zebrafish. Curr Biol 24:1167-1175.

Ksiazek TG, Erdman D, Goldsmith CS, Zaki SR, Peret T, Emery S, Tong S, Urbani C, Comer JA, Lim W, Rollin PE, Dowell SF, Ling AE, Humphrey CD, Shieh WJ, Guarner J, Paddock CD, Rota P, Fields B, DeRisi J, et al. (2003) A novel coronavirus associated with severe acute respiratory syndrome. N Engl J Med 348:19531966.

Kumar A, Pareek V, Prasoon P, Faiq MA, Kumar P, Kumari C, Narayan RK (2020) Possible routes of SARS-CoV-2 invasion in brain: in context of neurological symptoms in COVID-19 patients. J Neurosci Res 98:2376-2383.

Kumari P, Rothan HA, Natekar JP, Stone S, Pathak H, Strate PG, Arora K, Brinton MA, Kumar M (2021) Neuroinvasion and encephalitis following intranasal inoculation of SARS-CoV-2 in K18-hACE2 mice. Viruses 13:132.

Kundap UP, Kumari Y, Othman I, Shaikh MF (2017) Zebrafish as a model for epilepsy-induced cognitive dysfunction: a pharmacological, biochemical and behavioral approach. Front Pharmacol 8:515.

Küster E (2005) Cholin- and carboxylesterase activities in developing zebrafish embryos (Danio rerio) and their potential use for insecticide hazard assessment. Aquat Toxicol 75:76-85.

Laboissonniere LA, Smith CL, Mesenbrink J, Chowdhury R, Burney A, Lang M, Sierra M, Stark A, Maldonado-Casalduc G, Muller M, Trimarchi JM (2018) ALS-associated genes display CNS expression in the developing zebrafish. Gene Expr Patterns 30:14-31.

Lam S, Chua H, Gong Z, Lam T, Sin Y (2004) Development and maturation of the immune system in zebrafish, Danio rerio: a gene expression profiling, in situ hybridization and immunological study. Dev Comp Immunol 28:9-28.

Lao WP, Imam SA, Nguyen SA (2020) Anosmia, hyposmia, and dysgeusia as indicators for positive SARS-CoV-2 infection. World $\mathrm{J}$ Otorhinolaryngol Head Neck Surg 6:S22-S25.

Lawrence C (2007) The husbandry of zebrafish (Danio rerio): a review. Aquaculture 269:1-20.

LeBel CP, Ischiropoulos H, Bondy SC (1992) Evaluation of the probe 2', 7'-dichlorofluorescin as an indicator of reactive oxygen species formation and oxidative stress. Chem Res Toxicol 5:227-231.
Li C, Tan XF, Lim TK, Lin Q, Gong Z (2016) Comprehensive and quantitative proteomic analyses of zebrafish plasma reveals conserved protein profiles between genders and between zebrafish and human. Sci Rep 6:24329.

Li Y, Bai W, Hashikawa T (2020a) Response to Commentary on "The neuroinvasive potential of SARS-CoV-2 may play a role in the respiratory failure of COVID-19 patients." J Med Virol 92:707-709.

Li Y, Bai W, Hashikawa T (2020b) The neuroinvasive potential of SARS-CoV2 may play a role in the respiratory failure of COVID-19 patients. J Med Virol 92:552-555.

Lindsay SM (2004) Behavioral responses of newly hatched zebrafish (Danio rerio) to amino acid chemostimulants. Chem Senses 29:93100.

Link V, Shevchenko A, Heisenberg C-P (2006) Proteomics of early zebrafish embryos. BMC Dev Biol 6:1.

Liu R, Hu X, Lü A, Song Y, Lian Z, Sun J, Sung YY (2020) Proteomic profiling of zebrafish challenged by spring viremia of carp virus provides insight into skin antiviral response. Zebrafish 17:91-103.

Long Q, Meng A, Wang M, Jessen JR, Farrell MJ, Lin S (1997) GATA1 expression pattern can be recapitulated in living transgenic zebrafish using GFP reporter gene. Development 124:4105-4111.

Mack-Bucher JA, Li J, Friedrich RW (2007) Early functional development of interneurons in the zebrafish olfactory bulb. Eur $J$ Neurosci 25:460-470.

MacRae CA, Peterson RT (2003) Zebrafish-based small molecule discovery. Chem Biol 10:901-908.

MacRae CA, Peterson RT (2015) Zebrafish as tools for drug discovery. Nat Rev Drug Discov 14:721-731.

Maharajan K, Muthulakshmi S, Nataraj B, Ramesh M, Kadirvelu K (2018) Toxicity assessment of pyriproxyfen in vertebrate model zebrafish embryos (Danio rerio): a multi biomarker study. Aquat Toxicol 196:132-145.

Manganelli F, Vargas M, lovino A, lacovazzo C, Santoro L, Servillo G (2020) Brainstem involvement and respiratory failure in COVID-19. Neurol Sci 41:1663-1665.

Mao L, Jin H, Wang M, Hu Y, Chen S, He Q, Chang J, Hong C, Zhou Y, Wang D, Miao X, Li Y, Hu B (2020) Neurologic manifestations of hospitalized patients with coronavirus disease 2019 in Wuhan, China. JAMA Neurol 77:683.

Marin C, Vilas D, Langdon C, Alobid I, López-Chacón M, Haehner A, Hummel T, Mullol J (2018) Olfactory dysfunction in neurodegenerative diseases. Curr Allergy Asthma Rep 18:42.

Martín-Jiménez R, Campanella M, Russell C (2015) New zebrafish models of neurodegeneration. Curr Neurol Neurosci Rep 15:33.

Martín I, Gómez A, Salas C, Puerto A, Rodríguez F (2011) Dorsomedial pallium lesions impair taste aversion learning in goldfish. Neurobiol Learn Mem 96:297-305.

Matschke J, Lütgehetmann M, Hagel C, Sperhake JP, Schröder AS, Edler C, Mushumba $H$, Fitzek A, Allweiss L, Dandri M, Dottermusch M, Heinemann A, Pfefferle S, Schwabenland M, Sumner Magruder D, Bonn S, Prinz M, Gerloff C, Püschel K, Krasemann S, et al. (2020) Neuropathology of patients with COVID-19 in Germany: a post-mortem case series. Lancet Neurol 19:919-929.

Mehta P, McAuley DF, Brown M, Sanchez E, Tattersall RS, Manson JJ (2020) COVID-19: consider cytokine storm syndromes and immunosuppression. Lancet 395:1033-1034.

Meinhardt J, Radke J, Dittmayer C, Franz J, Thomas C, Mothes R, Laue M, Schneider J, Brünink S, Greuel S, Lehmann M, Hassan O, Aschman T, Schumann E, Chua RL, Conrad C, Eils R, Stenzel W, Windgassen M, Rößler L, et al. (2021) Olfactory transmucosal SARS-CoV-2 invasion as a port of central nervous system entry in individuals with COVID-19. Nat Neurosci 24:168-175.

Menelaou E, Husbands EE, Pollet RG, Coutts CA, Ali DW, Svoboda KR (2008) Embryonic motor activity and implications for regulating motoneuron axonal pathfinding in zebrafish. Eur $\mathrm{J}$ Neurosci 28:1080-1096.

Misra HP, Fridovich I (1972) The role of superoxide anion in the autoxidation of epinephrine and a simple assay for superoxide dismutase. J Biol Chem 247:3170-3175. 
Miyasaka N, Arganda-Carreras I, Wakisaka N, Masuda M, Sümbül U, Seung HS, Yoshihara Y (2014) Olfactory projectome in the zebrafish forebrain revealed by genetic single-neuron labelling. Nat Commun 5:3639.

Mocelin R, Marcon M, da Rosa Araujo AS, Herrmann AP, Piato A (2019) Withdrawal effects following repeated ethanol exposure are prevented by $\mathrm{N}$-acetylcysteine in zebrafish. Prog Neuropsychopharmacol Biol Psychiatry 93:161-170.

Mueller T, Dong Z, Berberoglu MA, Guo S (2011) The dorsal pallium in zebrafish, Danio rerio (Cyprinidae, Teleostei). Brain Res 1381:95-105.

Müller TE, Ziani PR, Fontana BD, Duarte T, Stefanello FV, Canzian J, Santos ARS, Rosemberg DB (2020) Role of the serotonergic system in ethanol-induced aggression and anxiety: a pharmacological approach using the zebrafish model. Eur Neuropsychopharmacol 32:66-76

Mundell NA, Beier KT, Pan YA, Lapan SW, Göz Aytürk D, Berezovskii VK, Wark AR, Drokhlyansky E, Bielecki J, Born RT, Schier AF, Cepko CL (2015) Vesicular stomatitis virus enables gene transfer and transsynaptic tracing in a wide range of organisms. J Comp Neurol 523:1639-1663.

Mushtaq MY, Verpoorte R, Kim HK (2013) Zebrafish as a model for systems biology. Biotechnol Genet Eng Rev 29:187-205.

Netland J, Meyerholz DK, Moore S, Cassell M, Perlman S (2008) Severe acute respiratory syndrome coronavirus infection causes neuronal death in the absence of encephalitis in mice transgenic for human ACE2. J Virol 82:7264-7275.

Njølstad PR, Molven A, Fjose A (1988) A zebrafish homologue of the murine Hox-2.1 gene. FEBS Lett 230:25-30.

Novoa B, Figueras A (2012) Zebrafish: model for the study of inflammation and the innate immune response to infectious diseases. In: Current topics in innate immunity II. New York: Springer New York.

Ohler A, Becker-Pauly C (2011) Morpholino knockdown of the ubiquitously expressed transmembrane serine protease TMPRSS4a in zebrafish embryos exhibits severe defects in organogenesis and cell adhesion. Biol Chem 392:653-664.

Ojanen MJT, Turpeinen H, Cordova ZM, Hammarén MM, Harjula SKE, Parikka M, Rämet M, Pesu M (2015) The proprotein convertase subtilisin/kexin furinA regulates zebrafish host response against Mycobacterium marinum. Infect Immun 83:1431-1442.

Orrù G, Conversano C, Malloggi E, Francesconi F, Ciacchini R, Gemignani A (2020) Neurological complications of COVID-19 and possible neuroinvasion pathways: a systematic review. Int $\mathrm{J}$ Environ Res Public Health 17:6688.

Ou X, Liu Y, Lei X, Li P, Mi D, Ren L, Guo L, Guo R, Chen T, Hu J, Xiang Z, Mu Z, Chen X, Chen J, Hu K, Jin Q, Wang J, Qian Z (2020) Characterization of spike glycoprotein of SARS-CoV-2 on virus entry and its immune cross-reactivity with SARS-CoV. Nat Commun 11:1620.

Palha N, Guivel-Benhassine F, Briolat V, Lutfalla G, Sourisseau M, Ellett F, Wang C-H, Lieschke GJ, Herbomel P, Schwartz O, Levraud J-P (2013) Real-time whole-body visualization of Chikungunya virus infection and host interferon response in zebrafish. PLoS Pathog 9:e1003619.

Palmiter RD, Brinster RL, Hammer RE, Trumbauer ME, Rosenfeld MG, Birnberg NC, Evans RM (1992) Dramatic growth of mice that develop from eggs microinjected with metallothionein-growth hormone fusion genes. 1982. Biotechnology 24:429-433.

Pan YA, Livet J, Sanes JR, Lichtman JW, Schier AF (2011) Multicolor brainbow imaging in zebrafish. Cold Spring Harb Protoc 2011: pdb.prot5546.

Pan YA, Freundlich T, Weissman TA, Schoppik D, Wang XC, Zimmerman S, Ciruna B, Sanes JR, Lichtman JW, Schier AF (2013) Zebrabow: multispectral cell labeling for cell tracing and lineage analysis in zebrafish. Development 140:2835-2846.

Paskin TR, Byrd-Jacobs CA (2012) Reversible deafferentation of the adult zebrafish olfactory bulb affects glomerular distribution and olfactory-mediated behavior. Behav Brain Res 235:293-301.

Passoni G, Langevin C, Palha N, Mounce BC, Briolat V, Affaticati P, De Job E, Joly JS, Vignuzzi M, Saleh MC, Herbomel P, Boudinot P,
Levraud JP (2017) Imaging of viral neuroinvasion in the zebrafish reveals that sindbis and chikungunya viruses favour different entry routes. Dis Model Mech 10:847-857.

Perlman S, Evans G, Afifi A (1990) Effect of olfactory bulb ablation on spread of a neurotropic coronavirus into the mouse brain. J Exp Med 172:1127-1132.

Politi LS, Salsano E, Grimaldi M (2020) Magnetic resonance imaging alteration of the brain in a patient with coronavirus disease 2019 (COVID-19) and anosmia. JAMA Neurol 77:1028.

Postlethwait JH, Yan YL, Gates MA, Horne S, Amores A, Brownlie A, Donovan A, Egan ES, Force A, Gong Z, Goutel C, Fritz A, Kelsh R, Knapik E, Liao E, Paw B, Ransom D, Singer A, Thomson M, Abduljabbar TS, et al. (1998) Vertebrate genome evolution and the zebrafish gene map. Nat Genet 18:345-349.

Progatzky F, Jha A, Wane M, Thwaites RS, Makris S, Shattock RJ, Johansson C, Openshaw PJ, Bugeon L, Hansel TT, Dallman MJ (2019) Induction of innate cytokine responses by respiratory mucosal challenge with $\mathrm{R} 848$ in zebrafish, mice, and humans. J Allergy Clin Immunol 144:342-345.e7.

Qin C, Zhou L, Hu Z, Zhang S, Yang S, Tao Y, Xie C, Ma K, Shang K, Wang W, Tian D-S (2020) Dysregulation of immune response in patients with coronavirus 2019 (COVID-19) in Wuhan, China. Clin Infect Dis 71:762-768.

Rafferty SA, Quinn TA (2018) A beginner's guide to understanding and implementing the genetic modification of zebrafish. Prog Biophys Mol Biol 138:3-19.

Rao KD, Alex A, Verma Y, Thampi S, Gupta PK (2009) Real-time in vivo imaging of adult Zebrafish brain using optical coherence tomography. J Biophoton 2:288-291.

Richetti SK, Blank M, Capiotti KM, Piato AL, Bogo MR, Vianna MR, Bonan CD (2011) Quercetin and rutin prevent scopolamine-induced memory impairment in zebrafish. Behav Brain Res 217:1015.

Rockx B, Kuiken T, Herfst S, Bestebroer T, Lamers MM, Oude Munnink BB, de Meulder D, van Amerongen G, van den Brand J, Okba NMA, Schipper D, van Run P, Leijten L, Sikkema R, Verschoor E, Verstrepen B, Bogers W, Langermans J, Drosten C, et al. (2020) Comparative pathogenesis of COVID-19, MERS, and SARS in a nonhuman primate model. Science 368:1012-1015.

Rodríguez F, López JC, Vargas JP, Broglio C, Gómez Y, Salas C (2002) Spatial memory and hippocampal pallium through vertebrate evolution: insights from reptiles and teleost fish. Brain Res Bull 57:499-503.

Rothan HA, Byrareddy SN (2020) The epidemiology and pathogenesis of coronavirus disease (COVID-19) outbreak. J Autoimmun 109:102433.

Saad M, Matheeussen A, Bijttebier S, Verbueken E, Pype C, Casteleyn C, Van Ginneken C, Apers S, Maes L, Cos P, Van Cruchten S (2017) In vitro CYP-mediated drug metabolism in the zebrafish (embryo) using human reference compounds. Toxicol Vitr 42:329-336.

Sahly I, Andermann P, Petit C (1999) The zebrafish eya1 gene and its expression pattern during embryogenesis. Dev Genes Evol 209:399-410.

Saraiva LR, Ahuja G, Ivandic I, Syed AS, Marioni JC, Korsching SI, Logan DW (2015) Molecular and neuronal homology between the olfactory systems of zebrafish and mouse. Sci Rep 5:11487.

Sarasamma S, Audira G, Juniardi S, Sampurna B, Liang ST, Hao E, Lai YH, Hsiao CD (2018) Zinc chloride exposure inhibits brain acetylcholine levels, produces neurotoxic signatures, and diminishes memory and motor activities in adult zebrafish. Int $\mathrm{J}$ Mol Sci 19:3195.

Sarasamma S, Audira G, Samikannu P, Juniardi S, Siregar P, Hao E, Chen JR, Hsiao CD (2019) Behavioral impairments and oxidative stress in the brain, muscle, and gill caused by chronic exposure of C70 nanoparticles on adult zebrafish. Int J Mol Sci 20:5795.

Schmitt C, McManus M, Kumar N, Awoyemi O, Crago J (2019) Comparative analyses of the neurobehavioral, molecular, and enzymatic effects of organophosphates on embryo-larval zebrafish (Danio rerio). Neurotoxicol Teratol 73:67-75. 
Schnabel D, Castillo-Robles J, Lomeli H (2019) Protein purification and Western blot detection from single zebrafish embryo. Zebrafish 16:505-507.

Scholz S, Fischer S, Gündel U, Küster E, Luckenbach T, Voelker D (2008) The zebrafish embryo model in environmental risk assessment-applications beyond acute toxicity testing. Environ Sci Pollut Res 15:394-404.

Scott EK, Mason L, Arrenberg AB, Ziv L, Gosse NJ, Xiao T, Chi NC, Asakawa K, Kawakami K, Baier H (2007) Targeting neural circuitry in zebrafish using GAL4 enhancer trapping. Nat Methods 4:323326.

Selderslaghs IWT, Hooyberghs J, Blust R, Witters HE (2013) Assessment of the developmental neurotoxicity of compounds by measuring locomotor activity in zebrafish embryos and larvae. Neurotoxicol Teratol 37:44-56.

Shang J, Wan Y, Luo C, Ye G, Geng Q, Auerbach A, Li F (2020) Cell entry mechanisms of SARS-CoV-2. Proc Natl Acad Sci USA 117:11727-11734.

Sia SF, Yan LM, Chin AWH, Fung K, Choy KT, Wong AYL, Kaewpreedee P, Perera RAPM, Poon LLM, Nicholls JM, Peiris M, Yen HL (2020) Pathogenesis and transmission of SARS-CoV-2 in golden hamsters. Nature 583:834-838.

Singh SK, Sethi S, Aravamudhan S, Krüger M, Grabher C (2013) Proteome mapping of adult zebrafish marrow neutrophils reveals partial cross species conservation to human peripheral neutrophils. PLoS One 8:e73998.

Solomon IH, Normandin E, Bhattacharyya S, Mukerji SS, Keller K, Ali AS, Adams G, Hornick JL, Padera RF, Sabeti P (2020) Neuropathological features of Covid-19. N Engl J Med 383:989992.

Song JW, Lam SM, Fan X, Cao WJ, Wang SY, Tian H, Chua GH, Zhang C, Meng FP, Xu Z, Fu JL, Huang L, Xia P, Yang T, Zhang S, Li B, Jiang TJ, Wang R, Wang Z, Shi M, et al. (2020) Omics-driven systems interrogation of metabolic dysregulation in COVID-19 pathogenesis. Cell Metab 32:188-202.e5.

Spence R, Gerlach G, Lawrence C, Smith C (2007) The behaviour and ecology of the zebrafish, Danio rerio. Biol Rev 83:13-34.

Stewart AM, Braubach O, Spitsbergen J, Gerlai R, Kalueff AV (2014) Zebrafish models for translational neuroscience research: from tank to bedside. Trends Neurosci 37:264-278.

Stoyanov GS, Petkova L, Dzhenkov DL, Sapundzhiev NR, Todorov I (2020) Gross and histopathology of COVID-19 with first histology report of olfactory bulb changes. Cureus 12:e11912.

Stuart GW, McMurray JV, Westerfield M (1988) Replication, integration and stable germ-line transmission of foreign sequences injected into early zebrafish embryos. Development 103:403412.

Sukardi H, Ung CY, Gong Z, Lam SH (2010) Incorporating zebrafish omics into chemical biology and toxicology. Zebrafish 7 : 41-52.

Susaki EA, Tainaka K, Perrin D, Kishino F, Tawara T, Watanabe TM, Yokoyama C, Onoe H, Eguchi M, Yamaguchi S, Abe T, Kiyonari H, Shimizu Y, Miyawaki A, Yokota H, Ueda HR (2014) Whole-brain imaging with single-cell resolution using chemical cocktails and computational analysis. Cell 157:726-739.

Takaki K, Davis JM, Winglee K, Ramakrishnan L (2013) Evaluation of the pathogenesis and treatment of Mycobacterium marinum infection in zebrafish. Nat Protoc 8:1114-1124.

Tang F, Liang J, Zhang H, Kelifa MM, He Q, Wang P (2021) COVID19 related depression and anxiety among quarantined respondents. Psychol Health 36:164-178.

Tarakad A, Jankovic J (2017) Anosmia and ageusia in Parkinson's disease. Int Rev Neurobiol 133:541-556.

Thompson J, Iwasaki A (2008) Toll-like receptors regulation of viral infection and disease. Adv Drug Deliv Rev 60:786-794.

Tierney KB (2011) Behavioural assessments of neurotoxic effects and neurodegeneration in zebrafish. Biochim Biophys Acta 1812: 381-389.
Umans RA, Henson HE, Mu F, Parupalli C, Ju B, Peters JL, Lanham KA, Plavicki JS, Taylor MR (2017) CNS angiogenesis and barriergenesis occur simultaneously. Dev Biol 425:101-108.

Ûnal i, Ûstündağ ÛV, Ateş PS, Eğilmezer G, Alturfan AA, Yiğitbaşı T, Emekli-Alturfan E (2019) Rotenone impairs oxidant/antioxidant balance both in brain and intestines in zebrafish. Int $\mathrm{J}$ Neurosci 129:363-368.

Unterman A, Sumida TS, Nouri N, Yan X, Zhao AY, Gasque V, Schupp JC, Asashima H, Liu Y, Cosme C Jr, Deng W, Chen M, Brickman Raredon MS, Hoehn K, Wang G, Wang Z, Deluliis G, Ravindra NG, Li N, Castaldi N, et al. (2020) Single-cell omics reveals dyssynchrony of the innate and adaptive immune system in progressive COVID-19. medRxiv 2020.07.16.20153437.

Varshney GK, Zhang S, Pei W, Adomako-Ankomah A, Fohtung J, Schaffer K, Carrington B, Maskeri A, Slevin C, Wolfsberg T, Ledin J, Sood R, Burgess SM (2016) CRISPRz: a database of zebrafish validated sgRNAs. Nucleic Acids Res 44:D822-D826.

Vitebsky A, Reyes R, Sanderson MJ, Michel WC, Whitlock KE (2005) Isolation and characterization of thelaure olfactory behavioral mutant in the zebrafish, Danio rerio. Dev Dyn 234:229242.

Vogel AM, Gerster T (1997) Expression of a zebrafish Cathepsin L gene in anterior mesendoderm and hatching gland. Dev Genes Evol 206:477-479.

Volz SN, Hausen J, Smith K, Ottermanns R, Schaeffer A, Schiwy S, Hollert H (2020) Do you smell the danger? Effects of three commonly used pesticides on the olfactory-mediated antipredator response of zebrafish (Danio rerio). Chemosphere 241: 124963

Trotha JW, Vernier P, Bally-Cuif L (2014) Emotions and motivated behavior converge on an amygdala-like structure in the zebrafish. Eur J Neurosci 40:3302-3315.

Wagner DE, Klein AM (2020) Lineage tracing meets single-cell omics: opportunities and challenges. Nat Rev Genet 21:410-427.

Wakisaka N, Miyasaka N, Koide T, Masuda M, Hiraki-Kajiyama T, Yoshihara Y (2017) An adenosine receptor for olfaction in fish. Curr Biol 27:1437-1447.e4.

Walker MB, Miller CT, Coffin Talbot J, Stock DW, Kimmel CB (2006) Zebrafish furin mutants reveal intricacies in regulating Endothelin1 signaling in craniofacial patterning. Dev Biol 295:194-205.

Walls AC, Park YJ, Tortorici MA, Wall A, McGuire AT, Veesler D (2020) Structure, function, and antigenicity of the SARS-CoV-2 spike glycoprotein. Cell 181:281-292.e6.

Walpitagama M, Carve M, Douek AM, Trestrail C, Bai Y, Kaslin J, Wlodkowic D (2019) Additives migrating from 3D-printed plastic induce developmental toxicity and neuro-behavioural alterations in early life zebrafish (Danio rerio). Aquat Toxicol 213:105227.

White EJ, Kounelis SK, Byrd-Jacobs CA (2015) Plasticity of glomeruli and olfactory-mediated behavior in zebrafish following detergent lesioning of the olfactory epithelium. Neuroscience 284:622-631.

Williams FE, White D, Messer WS (2002) A simple spatial alternation task for assessing memory function in zebrafish. Behav Processes 58:125-132.

World Health Organization (2020) WHO timeline - COVID-19. World Heal Organ. https://www.who.int/emergencies/diseases/novelcoronavirus-2019. (Accessed April 4, 2021).

Wu M, Zhang S, Chen X, Xu H, Li X (2019) Expression and function of IncRNA MALAT-1 in the embryonic development of zebrafish. Gene 680:65-71.

Wu Z, McGoogan JM (2020) Characteristics of and important lessons from the coronavirus disease 2019 (COVID-19) outbreak in China: summary of a report of 72314 cases from the Chinese center for disease control and prevention. JAMA 323:1239.

Wullimann MF, Puelles L (1999) Postembryonic neural proliferation in the zebrafish forebrain and its relationship to prosomeric domains. Anat Embryol (Berl) 199:329-348. 
Wullimann MF, Rupp B, Reichert H (1996) Neuroanatomy of the zebrafish brain. Basel: Birkhäuser Basel.

Xu H, Echemendia N, Chen S, Lin F (2011) Identification and expression patterns of members of the protease-activated receptor (par) gene family during zebrafish development. Dev Dyn 240:278-287.

Xu XW, Wu XX, Jiang XG, Xu KJ, Ying LJ, Ma CL, Li SB, Wang HY, Zhang S, Gao HN, Sheng JF, Cai HL, Qiu YQ, Li LJ (2020) Clinical findings in a group of patients infected with the 2019 novel coronavirus (SARS-Cov-2) outside of Wuhan, China: retrospective case series. BMJ 368:m606.

Zhang $H$ (2020) Early lessons from the frontline of the 2019-nCoV outbreak. Lancet 395:687.

Zheng W, Wang Z, Collins JE, Andrews RM, Stemple D, Gong Z (2011) Comparative transcriptome analyses indicate molecular homology of zebrafish swimbladder and mammalian lung. PLoS One 6:e24019. 